Portland State University

PDXScholar

Dissertations and Theses

Dissertations and Theses

$1-1-1977$

\title{
The statistical manipulation of Delphi statements
}

Bradley William Nelson

Portland State University

Follow this and additional works at: https://pdxscholar.library.pdx.edu/open_access_etds Let us know how access to this document benefits you.

\section{Recommended Citation}

Nelson, Bradley William, "The statistical manipulation of Delphi statements" (1977). Dissertations and Theses. Paper 835.

https://doi.org/10.15760/etd.835

This Dissertation is brought to you for free and open access. It has been accepted for inclusion in Dissertations and Theses by an authorized administrator of PDXScholar. Please contact us if we can make this document more accessible: pdxscholar@pdx.edu. 


\title{
The Statistical Manipulation of Delphi Statements
}

\author{
by
}

Bradley William Nelson

A thesis submitted in partial fullfillment of the requirements for the degree of

\author{
Doctor of Philosophy \\ in \\ Systems Science
}

Portland State University June $1977^{\circ}$

(C) 1977 Bradley William Nelson 
PLEASE NOTE:

Dissertation contains pages with small and indistinct print. Filmed as received. UNIVERSITY MICROFILMS 
TO THE OFFICE OF GRADUATE STUDIES AND RESEARCH

The members of the Committee approve the thesis of

Bradley William Nelson presented June, 1977.
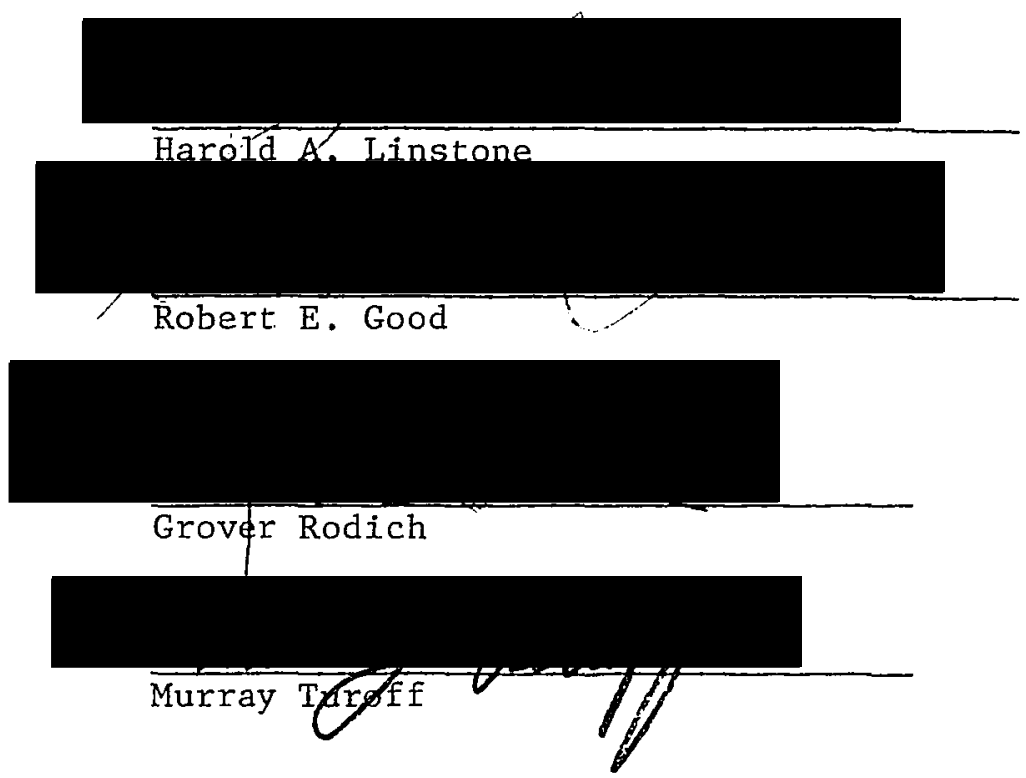

APPROVED :

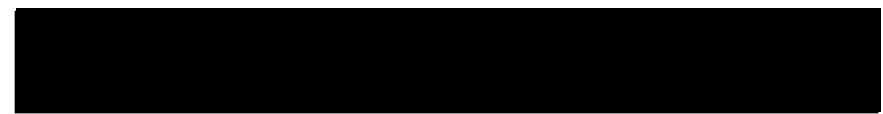

Harold A. Linstone, Director, Systems Science Doctoral Program

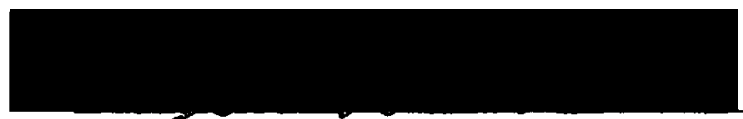

Stanley Rauch, Dean of Graduate Studies and Research 
AN ABSTRACT OF THE THESIS OF Bradley W. Nelson for the Doctor of Philosophy in Systems Science presented June, 1977.

Title: The Statistical Manipulation of Delphi Statements.

APPROVED BY MEMBERS OF THE THESIS COMMITTEE:

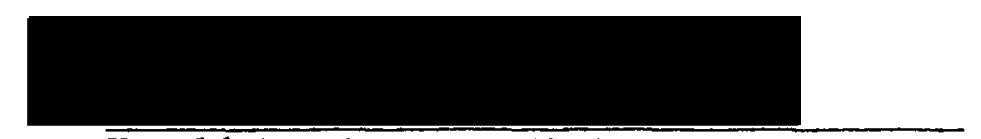

Harold A. Linstone, Chairman

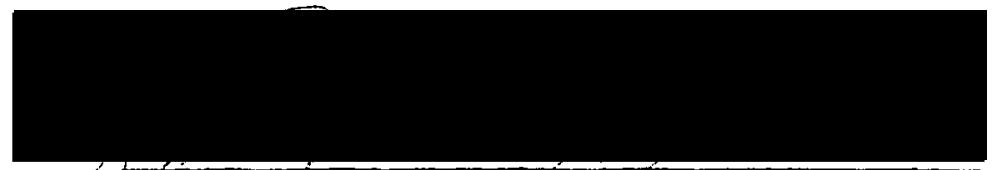

Robert E. Good
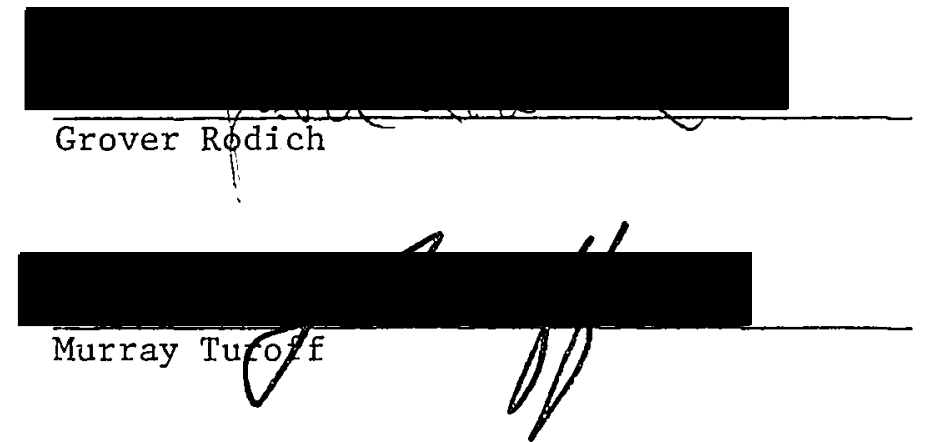

Since i.ts invention twenty years ago, the Delphi technique has been gaining wider and wider acceptance as a tool for forecasting technology; gathering expert opinion from a local to world wide "advice community" upon which government, industry, and other policy making bodies must so frequently rely; and providing judgmental input for studies (e.g., social sciences) where hard data are unavailable or too difficult to obtain. Accompanying this increased acceptance is an increased danger of manipulation of a Delphi to 
produce the resulta deslred by one certain Individual or group of individuals. Manfpulation is increasingly being mentloned in the literature as a danger but little has been done to study the problem. Two groups of thirty United States Air Force Officers enrolled in a Masters of Business Administration program participated in a fact probing Delphi containing thirty statements. The participants of one group were given falsified statistical feedback on fifteen of the statements, while the participants of the other group were given falsified statistical feedback on the other fifteen statements. A similar study was done with another group of officers using a value probing Delphi.

The results of these studies showed a high degree of success in obtalning a desired value through the use of manipulated statistical feedback. This success was enhanced by running additional rounds. It was also found that the statistical manipulation had a significant effect on the convergence and stability of the Delphi statements.

The effects of statistical manipulation on confldence as measured by self-rating was also studied. It was found that there was a significant tendency for Delphi participants to shift their selfrating during later rounds toward the middle. The effect of the distance between a participant's original estimate and the median reported back to him on the amount the participant changed his self-rating was investigated. The results were inconsistent. Statistically manipulated particlpants showed an overall decrease in confidence, regardless of their original self-rating. 
Suggestions for extending the research in the area of manipulation of Delphi statements plus a taxonomy of the variables that comprise the problem of mantpulation are discussed. 
The author first wishes to thank the members of his immediate family for tolerating an absentee husband and father who, when they did see him, was generally Mr. Grump. Special thanks must also be given to Dr. Harold Linstone and the other members of my committee for their prompt response to my requests and for the encouragement and suggestions they supplied at the needed times.

One must also not forget the poor secretaries who must transform a barely decipherable draft into an aesthetic finished product in half the time necessary to do it. Thank you Debbie Fugleberg and Marie Baumgartner for tolerating me.

Finally, the author wishes to thank the United States Air Force Officers whose participation made this research possible. 
TABLE OF CONTENTS

PAGE

ACKNOWLEDGMENTS. . . . . . . . . . . . . . . . $i i i$

LIST OF TABLES . . . . . . . . . . . . . . . . . vii vi vi

LIST OF FIGURES. . . . . . . . . . . . . . . . . . . ix

CHAPTER

I INTRODUCTION . . . . . . . . . . . . . . . 1

Background ............... . . 3

Purpose. . . . . . . . . . . . . 6

Research Hypotheses. ........... . 6

Assumptions and Constraints. . . . . . . 7

Significance of the Study. . . . . . . . 10

Organization of the Dissertation ....... . 14

II REVIEW OF LITERATURE . . . . . . . . . . . . 15

Literature Direct1y Related to Manipulation. . . 15

Literature Indirectly Related to Manipulation. . 23

III DESIGN OF THE STUDY. . . . . . . . . . . 36

Characteristics of Participants. . . . . . 36

Subject Matter of the Delphis. . . . . . . 49

General Procedure for Administering the Delphis. $\quad 50$

General Design Considerations. . . . . . . 54

Statistical Procedures . . . . . . . . 57

Measurements Used in Statistical Tests

Statistical Methodology

Summary. . . . . . . . . . . . . 92 
Success and Statistical Manipulation......

Factually-based Delphi Results

Value-laden Delphi Results

Additional Results Using the Success Data

Comparison of Factually-based and valueladen Delphis

Summary of Success Results

Statistical Manipulation and Convergence of

Delphi Statements. . . . . . . . . .

Factually-based Delphi Results

Value-laden Delphi Results

Comparison of Factually-based and

Value-laden Delphis

Summary of Convergence Results

Statistical Manipulation and Stability of

Delphi Statements. . . . . . . . . .

Factually-based Delphi Results

Value-laden Delphi Results

Additional Results Using the Stability Data

Comparison of Factually-based and Valueladen Delphis

Sumary of Stability Results

Statistical Manipulation and Confidence of

Delphi Participants. . . . . . . . . .

Factually-based Delphi Results

Summary of Confidence Results

Sumnary of Results . . . . . . . . . 142

V CONCLUSIONS AND EXTENSIONS . . . . . . . . . . 146

Conclusions. . . . . . . . . . . 146

Recommendations for Avoiding Statistical

Manipulation ............ . 148

Extensions . . . . . . . . . . . 152

GLOSSARY . . . . . . . . . . . . . . . . . 161

REFERENCES . . . . . . . . . . . . . . . . 163 
APPENDIX A Factually-based Delphi Used in This Experiment. . 173

APPENDIX B Value-1aden Delphi Used in This Experiment. . . . 182

APPENDIX C Berger's Revision of Rokeach's Dogmatism Scale. . 192

APPENDIX D Computer Program to Calculate Intermediate

Statistics............. 201

APPENDIX E Computer Program to Analyze Final Results . . . 218 


\section{LIST OF TABLES}

TABLE

PAGE

I Background of Factually-based Delphi Participants. . .

II Background of Value-Iaden Delphi Participants. . . . .

III Results of Berger's Revision of Rokeach's Dogmatism Scale (the FCD scale)............. 47

IV Success of Manipulation. . . . . . . . . . . 95

V Success of Manipulation-Detail . . . . . . . . 100

VI Results of Correlation on Round 4 Degree of Success and Amount of Movement. . . . . . . . . . . 101

VII Results of Analysis of Variances on the Change of Each Manipulated Participant by the Change of Each NonManipulated Participant. . . . . . . . . . 102

VIII Results of Comparing the Success of the Factually-based Delphi with the Success of the Value-laden Delphi. . . 104

IX Results of Statistical Tests on Convergence - Factuallybased Delphi................. 107

$\mathrm{X} \quad$ Results of $\mathrm{F}_{\max }$ Test for Equal Variances . . . . . . 109

XI Results of Statistical Tests on Convergence - Valueladen Delphi ................ 111

XII Stability of Manipulation - Factually-based Delphi . . . 115

XIII Stability of Manipulation - Value-laden Delphi . . . . 117

XIV Results of Statistical Tests on Stability. . . . . . 119

XV Number of Factualiy-based Delphi Statements that Changed Between Rounds.............. 122

XVI Analysis of Variance on Summarized 20\% Stability Data. . 124

XVII Analysis of Variance on Summarized 15\% Stability Data. . $\quad 125$

XVIII t-test on Summarized Stability Data. . . . . . . . 127 
viii

TABLE

PAGE

XIX Results of Statistical Tests on the Average Differences Between Round 1 and Round 4 Self-Rating By Manipulated and Non-manipulated Participants . . .

$\mathrm{XX}$ Analysis of Variance to Test the Significance of the Shift of Self-rating Towards the Middle in Later

Rounds......................

XXI Significance of Differences Between Means of Self-rating Between Round 1 and Round 4 for Manipulated and Non-manipulated Participants . . . . . . . . . .

XXII Significance of Differences Between Means of Self-rating Change for Those in Lower Range 1 and Those Not in Lower Range 1. . . . . . . . . . . . . 136

XXIII Significance of Differences Between Means of Self-rating Change for Those in Upper Range 2 and Those Not in Upper Range 2. • . • . . . . . . . . . . . . . . 138

XXIV Analysis of Variance to Test the Significance of the Mean Change in Answers . . . . . . . . . . . . .

XXV Significance of Differences Between Means of Change in Answers for Manipulated and Non-manipulated Participants Depending on Their Round 1 Self-rating. . 
1 Goals Delphi algorithm. . . . . . . . . . . .

2 Flowchart of design considerations. . . . . . . .

3 Flowchart of the results of the statistical tests...

4 Factors that may determine the degree of manipulability of Delphi statements. . . . . . ..... 159

5 Factors that may determine the susceptibility of participants to be manipulated. . . . . . . . . 160

6 Factors that may determine the effectiveness of statistical feedback in manipulation. . . . . . . . 


\section{CHAPTER I}

\section{INTRODUCTION}

Important policy decisions are being made every day in government, business, education, and other organizations. These decisions are heavily impacted by information obtained by the use of the Delphi technique. Our national drug abuse policy has received valuable input from a Delphi study run in 1975 [46]. The School of Education at the Universtty of Virginia used a Delphi to establish the prime targets on which it should concentrate its energies and resources in the next decade [17]. DuPont has used the results of a Delphi study involving the entire adhesives industry to determine the future trends in adhesives in order to build up the technology and productive facllities to support the evolution of the adhesives industry [31].

Delphi's popularity and use is increasing to the point that the number of studies that have been run are counted in the thousands. The topics of such studies range from predicting functional capabil1ties of future technology to providing important sought-after input for policy making bodies. People are contlnuing to find new ways of using Delphis to suit their needs; thus, many new versions of the Delphi technique are appearing in 11terature. In addition, research is also being done to expand the concepts of Delphi into a general theory of group estimation [22].

However, in all the frenzied development of Delph1, no one has serfously addressed the problem of misuse of the Delphi technique. 
This is especially surprising in light of the recent years during which there has been so much corruption in government and business (e.g. Watergate, the probes into the FBI and the CIA, the resignation of the President and Vice President of the United States, and Lockheed's foreign payoff scandal, to mention a few). Is it possible that an individual or a group of individuals could use the Delphi technique to achieve certain vested interests? Is it possible that organized crime could have influenced the drug abuse Delphi mentioned earlier in an effort to encourage policy that would have been favorable to their position? Is it possible that DuPont could have influenced the adhesives Delphi in an effort to convince the adhesives industry to develop along the lines that would have been best for DuPont?

This research is the first known serious attempt to examine the posstbility of manipulating the results of a Delphi to produce results an individual or group of individuals desire. This study is not the Einal word on the topic but is instead a beginning point. The research has found that manfpulation of factually-based and value-laden Delphi statements $^{1}$ via falsified statistical feedback was successful in achieving a desired value. Further, the results indicated this form of manipulation has an effect on the convergence and stability of the responses to Delphi statements and on the confidence participants have in their ability to respond to the Delphi statements.

While the reader is assumed th have some precursory knowledge of the Delphi technique, a brief sketch of the technique will be presented to assure a comon starting ground.

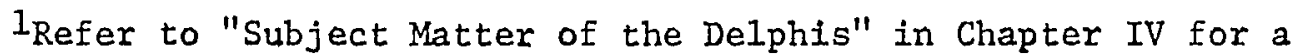
definition of factually-based and value-laden Delphi statements.
} 
BACKGROUND

Murray Turoff defines the Delphi technique as a "method for the systematic solicitation and collation of informed judgments on a particular topic," [94:149] and describes the procedure as a "set of carefully designed sequential questionnaires interspersed with summarized information and opinions feedback derived from earlier responses." [94:149] Norman Dalkey defines it as ". . . a method of ellciting and refining group judgements." [18:408] Harold Linstone and Murray Turoff in their book on the Delphi method state that "Delphi may be characterIzed as a method for structuring a group communication process so that the process is effective in allowing a group of individuals, as a whole, to deal with a complex problem." [56:3] All of these definitions tend to be a bit general and lack the nice closed picture that most of us would like to see in a definition. The reason for this is that the Delphi method is an evolving technique, and its definition is still developing. It started in the early 1950's (although it was not communicated widely until the middle $1960^{\prime} \mathrm{s}$ ) as a forecasting procedure. Since then, the Delphi method has been adapted and modified in many ways. It has found application in many diverse areas, some of which are:

- Gathering current and historical data not accurately known or available

. Examining the significance of historical events

- Evaluating possible budget allocations

- Exploring urban and regional planning options

- Planning university campus and curriculum development

- Putting together the structure of a model

- Delineating the pros and cons associated with potential

policy options 
- Developing causal relationships in complex economic or social phenomena

-Distinguishing and clarifying real and perceived human motivations

. Exposing priorities of personal values, social goals [56:4]

While the Delphi method has been adapted and modifled in many ways, there tend to be three features that are common to the procedure: anonymous response, iterative and controlled feedback, and statistical group response. While each of these has been subjected to numerous studies and there have been many variations of each of them, they sti11 tend to appear in the design procedures of most Delphis. The object of anonymous response is to eliminate many of the disadvantages of face-to-face communication. For example, committees often face the disadvantages of a dominant or charismatic individual, vested interest, reluctance to lose face by changing one's position, and group pressure to conform to a minority viewpoint. The use of anonymity can help circumvent these problems. Quantity versus quality of arguments often is the deciding factor in many committee meetings. To avoid this problem, but at the same time allow a free flow of arguments for and against or statements concerning a particular Delphi statement, controlled narrative feedback is often encouraged. Th1s is done during several iterations of the Delphi process to encourage full exchange of ideas and comments. While being one of the most important features of Delphi, narrative feedback is also the feature that often receives the least attention because of the additional work it creates for the administrator. Statistical group response is the feature that probably has the most varlations and has been investigated the most. The intent of this feature is to give the participants some concept of the group response. As discussed later, there has been a fair amount of 
discussion concerning the effect this has on the degree of convergence, but without some statistical group response there tends to be 11ttle or no change in the responses over several rounds. Therefore, some statistical group response seems to be necessary.

The evolution and use of the Delphi procedure has been rapid and impressive. The first Delphi was run in the early 1950's by Dalkey and Helmer of the Rand Corporation to study ". . the selection, from the point of view of a Soviet strategic planner, of an optimal U.S. industrial target system and to the estimation of the number of A-bombs required to reduce the munitions output by a prescribed amount." (19: 458] This work, however, was not pubilshed until 1963 due to 1ts secret nature. A later paper by Gordon and Helmer in 1964 was the first published paper that brought the Delphi method to the attention of those outside the defense community. Since then, Delphi has behaved as a grass fire. It has been estimated there have been over ten thousand Delphis run. The results of some have been published, but many have merely served the purpose for which they were intended. Some of the articles have been orlented towards improving and evaluating the methodology while others have been concerned with applications of the Delphi method. (For the most complete bibllography of Delph1 and Delphi related publications refer to [56]).

As with all useful methodologies, there exist some pitfalls.

Linstone [55] has registered the following list:

1. discounting the future

2. the prediction urge

3. the simplification urge

4. 11lusory expertise

5. sloppy execution

6. optimism-pessimism bias

7. overselling

8. deception 
The last pitfall (deception) is the subject with which this report is concerned.

PURPOSE

The purpose of this research is to investigate empirically the statistical manipulation of factually-based and value-laden Delphi statements to see if a particular desired value could be achieved and to explore the effects such manipulation has upon the convergence and stability of the responses to Delphi statements. The effects of statistical manipulation upon the confidence of the Delphi participant (as measured by self-rating) is also explored.

\section{RESEARCH HYPOTHESES}

The above purpose of this research is more explicitly communicated in the research hypotheses:

Rl - factually-based Delphi statements can not be successfully manipulated by the means of manipulated statistical feedback;

R2 - value-laden Delphi statements can not be successfully manipulated by the means of manipulated statistical feedback;

R3 - there is no difference between the manipulability of factually-based Delphi statements and the manipulability of value-laden Delphi statements, with respect to manipulation via statistical feedback;

R4 - manipulation of statistical feedback will not result in a lesser degree of convergence for factually-based Delphi statements;

R5 - manipulation of statistical feedback will not result in a lesser degree of convergence for value-laden Delph1 statements; 


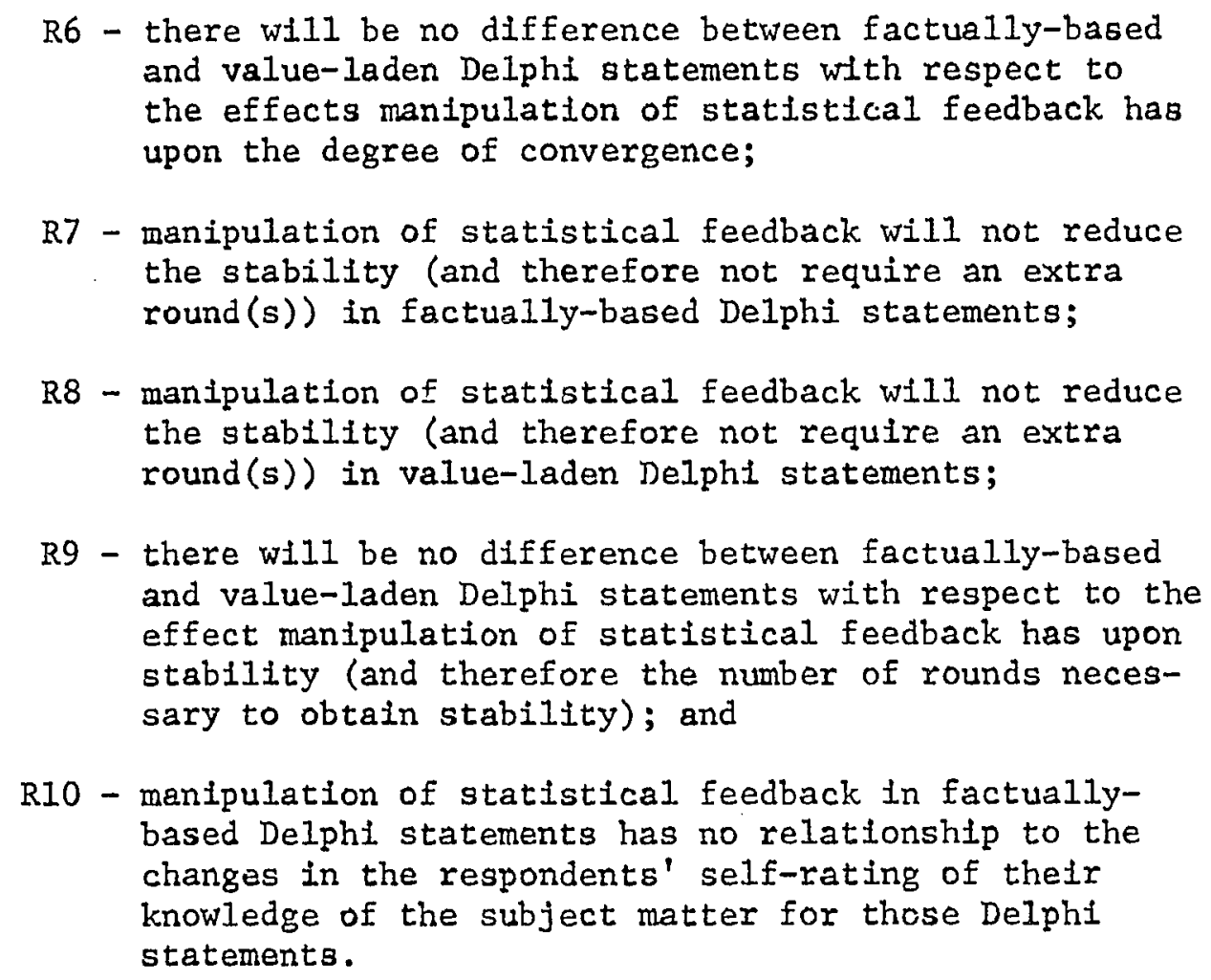

R6 - there will be no difference between factually-based and value-laden Delphi statements with respect to the effects manipulation of statistical feedback has upon the degree of convergence;

R7 - manipulation of statistical feedback will not reduce the stability (and therefore not require an extra round(s)) in factually-based Delphi statements;

R8 - manipulation of statistical feedback will not reduce the stability (and therefore not require an extra round(s)) in value-laden Delphi statements;

R9 - there will be no difference between factually-based and value-laden Delphi statements with respect to the effect manipulation of statistical feedback has upon stability (and therefore the number of rounds necessary to obtain stability); and

RIO - manipulation of statistical feedback in factuallybased Delphi statements has no relationship to the changes in the respondents' self-rating of their knowledge of the subject matter for those Delphi statements.

Note that this research attempts to reject research hypotheses $R 1$ and R2 and that research hypothesis R3 is conditional upon the successful rejection of $R 1$ and $R 2$. Similar statements can be made for the triads $R 4, R 5, R 6$ and $R 7, R 8, R 9$. An attempt is also made to refect research hypothesis $\mathrm{R} 10$.

\section{ASSUMPTIONS AND CONSTRAINTS}

An ideal design for this research would have resulted in a full description of the impact and characteristics of manipulation. This would have involved testing all possible forms of manipulation for all possible types of Delphis for all possible populations of participants. The above combinations also would have been replicated several times with different Delphi statements and participants. Obviously, due to resource constraints, this was not possible. Even if one had unlimited 
resources, it would not have been posstble since the Delphi technique is st111 an evolving technique. Therefore, it was not the goal of this study to investigate the entire question of manipulation of Delphi statements but instead to make an initial probe into the subject and to determine whether further studies in this area need to be made.

Since this research was not funded and had to be completed within six to ten months, it was necessary to use participants who were readily avallable, who could complete the Delphi within a short period of time, and who would not require remuneration to partlcipate. It was thus declded to use United States Air Force officers who were enrolled in a Master of Business Administration program at Grand Forks Air Force Base, ${ }^{2}$ North Dakota (the author was teaching in this program at the time of the study).

The only manpower available for this study was the author. This in combination with the time and money constraint limited the study to two Delphis. Since there are two broad classifications of Delphi (factually-based and value-laden), a Delphi representative of each of these classiflcations was run. An almanac Delphi was used for the factually-based Delphi and was assumed to be representative of factuallybased Delphis. A policy Delph1 was used for the value-laden Delpht and was assumed to be representative of value-laden Delphis.

The usual procedure in running a Delphi is first to design the Delpht and then select the panel members who would be appropriate for the Delphi. Since in this study it was desired to use the participants

2 This program is funded by the Air Force Institute of Technology and is administered by the University of North Dakota. 
fust described the process was reversed. The Delphis were designed so the particlpants would be considered experts in the almanac Delphi and representatives of a point of view on the Policy Delphi. 3 Therefore, while the participants were perhaps not truly representative of the population of all panel members, it is assumed they were representative of the panel members one might choose for the Delphis that were run.

The form of manipulation chosen for this study was the manipulatIon of statistical feedback. There are many ways one can mantpulate Delphi statements through statistical feedback. To explore all of these also would have required an enormous amount of time, effort, and cost. Therefore, a decision was made to explore the general success of statistical manipulation by choosing one combination that would have been most representative of how one might have gone about manipulating via statistical feedback and that intuitively would have had a high degree of success associated with it. Statistical manipulation was done by a relatively large amount. This assured that the movement was not just accidental. A strategy of manipulation by the full desired amount during the first round and then maintaining it around that point for each of the remaining rounds (thus manipulation occurs during all rounds) was used. Ranges were chosen that heuristically appeared to help accomplish the desired point. Manipulation was towards the true answer but beyond it or towards the true answer if the original response was too far from the true. 4

${ }^{3} \mathrm{~A}$ further discussion of this is given in Chapter III under the heading "Subject Matter of the Delphis."

${ }^{4} \mathrm{~A}$ more complete discussion of the concept of the pull of the median and the pull of the true will be given in the latter portion of Chapter II. 
This combined both the pull of the median as well as the pull of the true. The standard form of statistical feedback was used.

A further assumption must be made that the author was successful in eliminating bias and ambiguity In the wording of the Delphi statements. The statements were all pretested to eliminate these problems. There was no feedback during the study that indicated such problems existed.

An assumption was also made that the measures were valid measures of the variables being tested (success, convergence, stability, and confidence).

Since this was an empirical attempt to determine the ability to manipulate Delphi statements, no attempt was made to explain the psychological and sociological reasons why people respond in the manner they do.

SIGNIFICANCE OF THE STUDY

The problem of manipulation of Delphi statements has been mentioned in several places. Linstone states "Today the least acknow1edged hazard in connection with Delphi is its potential use for deceptIve, manipulative purposes. . . The anonymity in such a situatton may even facilitate the deception process: how can the participants in a Policy Delphi possibly detect distortion of the feedback they receive?" [55:585-6] Before this question can be asked, it is precursory to first understand something about the degree to which De1phis can be manipulated and the characteristics of this manipulability. Once these fundamental questions have been explored, then one can develop procedures to help circumvent this problem. 
Iinstone and Turoff also discuss the problem of manipulation as a "virtual" problem, a problem that does not in itself affect the ut11ity of the technique. They indicate

A third virtual problem is the honesty of the monitor team, and it is of the same concern as the honesty of any study or analysis group. In fact, there is probably more likelihood in most Instances of exposure of misrepresentation in a Delphi sumary than in a typical group study report. $[56: 6-7]$

What they are saying is that Delphis are as subject to manipulation by the administrators as any other form of group analysis; however, the risk of exposure may be higher. In personal correspondence, Dr. Turoff has indicated:

I do believe it is possible to manipulate numeric estimates except where the majority of the group has conviction about their estimates. I do think this becomes significantly more difficult where respondents are allowed to provide associated pleces of knowledge to support their estimate, and these are fed back. . . [The primary reason for this 1s] that it is going to be obvious to someone if you left his argument out or poorly worded it.

While the above may be true, one must realize there tends to be a lack of a unffled group of people who are cognizant of what exactly has evolved during the Delphi and who have access to the final results. This, in turn, does allow the administrators a greater opportunity to misrepresent the results of the Delphi.

Whatever the situation, the results of a Delphi must ultimately rest on the integrity and honesty of the administrators. If they lack this Integrity and honesty and are willing to take the rlsk of exposure, they could attempt to twist the results via two methods. They could try to shape the consensus through manipulation of feedback such that the 
final round results are what they desire, or they could merely misrepresent the final results (1.e. report something other than what occurred). The fundamental difference is, in the former case, the administrator molds the respondents to answer in the manner he desires. In the latter case, the administrator merely lies about the results. Both are guilty of fraudulent misrepresentation of the results; but if the former is less subject to manipulation than one might assume, new credibility and assurance can be added to the Delphi procedure. There also has been some concern about manipulation of Delphi statements by people who are using the Delphi in practice. One such example is John Ludlow's Delphi study on the Grand Traverse Bay watershed region, part of the Michigan Sea Grant Program. This concern was shown when he indicated several significant modifications and refinements were made to the basic Delphi methodology because of ". . . the perceived threat of a manipulated consensus. . " [57:103] and severa1 other reasons that are not pertinent to this report. He falled to mention, however, what changes were made relative to the question of manlpulability.

Ludlow made one other mention of the power of the Delphi technique to manipulate opinion and policy.

The suggestion that the method "can result in a manipulated and arbitrary consensus" received a neutral judgment from all three groups, perhaps indicating that the respondents felt this danger to be no greater than it would be in alternative techniques for securing group judgments. However, it is this administrator's opinion that the Delphi techniques could be a powerful tool for mantpulating opinion and policy. [57:119]

This point is somewhat exemplified by the effects polls can have on election trends and by the fact that media (e.g. radio and television) 
cannot begin reporting the tallies of how people voted until after the polls have closed.

As w11l be shown in the review of the 11terature, I1ttle has been done to investigate this area and many questions remain unresolved. With increased use of the Delphi technique, especially in areas of policy and goal formulation, it is becoming even more critical to consider this point. The government has already used the Delphi technique to provide input into policy decisions in areas such as drug abuse [46], social policy planning and research [58, 91], and many others. Businesses have used Delphis to help establish policy decisions in areas such as marketing [47], manpower forecasting [64], and many unpublished areas. Universities have used it to establish objectives for programs and Institutions $[2,16,17,43,49,50,96]$. The list of uses continues to grow and the Delphi technique shows promise in replacing instruments such as polls, questionnaires, and committees in important govexnment, educational, and business organizations. To continue the use and expanded use of Delphi and not understand some of the underlying characteristics of manipulation is courting folly.

Murray Turoff in discussing Policy Delphi makes the following comment:

As with any policy process, there are many ways to abuse the use of the Policy Delphi: the manner in which comments are edited, the neglect of items, the organization of the results. However, such a process is a rather dangerous game and not likely to go unnoticed by some segment of the respondents. There are very few greater wraths than that of a respondent who discovers himself to be engaged in a biased exercise. [95:101]

While this author agrees with Turoff, one must realize we are dealing with people, one of the most open systems known, and thus we 
can not dismiss the posstble misuse of the Delpht technique. Oar better understanding of how this misuse might behave may help us in discovering or avoiding its abuse; or if we find that the Delphi procedure is indeed more robust than we think, in trusting its results.

\section{ORGANIZATION OF THE DISSERTATION}

This study is presented in five chapters entitled: (1) Introduction, (2) Review of Related Literature, (3) Design of the Study, (4) Results, and (5) Conclusions and Extensions.

Chapter I has presented a brief background of Delphi, the purpose of this research, the research hypotheses to be investigated, the assumptions and constraints under which this research will be made, the significance of the problem, and the organtzation of this study. Chapter II is a review of the Iiterature related directly and Indrectly to manipulation of Delphi statements.

Chapter III is devoted to the methods and procedures utilized by the investigator to secure, compile, and analyze the data.

Chapter IV contains the results of the analysis of the data concerning the success of statlstical manipulation and the effects statistical manipulation has on the convergence and stability of the responses to Delphi statements and on the confidence of Delphi participants.

Chapter V presents a summary of the findings, some recommendattons for avolding statistical manipulation, and a discussion of some possible extensions of this work. 


\section{CHAPTER II}

\section{REVIEW OF RELATED LITERATURE}

This chapter is composed of two sections. The first is concerned with the literature that directly discusses the topic of manipulation and applies it to at least one Delphi statement in a study. The second section discusses articles that do not mention the topic of manipulation but do implicitly generate pertinent questions worthy of consideration.

\section{LITERATURE DIRECTLY RELATED TO MANIPULATION}

There have been three attempts at exploring the effects of manipulation on Delphi statements. Two of these attempts $[16,85]$ have only involved the manipulation of one Delphi statement in the entire Delphi. These were obviously not serious attempts at trying to look critically at the question of manipulation but were merely probes to see if the ability to manipulate did in fact exist. Both attempts were successful. The third attempt [98] was a conscious effort to test the manipulability of Delphi statements by the administrator. The conclusion was that the Delphi procedure was in fact more robust than one might expect and that it was not susceptible to manipulation. This was contradictory to the other two studies. As we shall see when we discuss these articles, the latter study was, however, poorly reported and only looked at part of the overall problem. It is interesting to note that the author Ignored his findings when discussing the problem in a later paper [99] where he 
mentioned the opposite of his findings as being true. Thus the three attempts to look at the problem of manipulability have not resolved the question but have merely added more uncertainty. A review of each of the articles and some of the questions generated by them will now fol1ow. It should be noted that it is not the fintent of this research to answer all the questions generated in the review of the following art1cles but merely to bring them to light.

Cyphert and Gant [16,17] were the first to test the question of manipulability of Delphi statements. The primary object of their policy Delphi exerclse was to establish ". . prime targets on which the School of Education [at the University of Virginia] should concentrate its energies and resources in the next decade." [16:273] During the Delph1 process they attempted to test "the hypothesis that the technique can be used to mold oplnion as well as collect it. . ." [16: 273] They did this by taking an item that was ranked relatively low and fed back distorted statistical feedback indicating it had a high ranking. The result of this manipulation was that it was in the end ranked above average, although not in the top ten. These results Indicate at least partial success in manipulating the results. The authors however did not indicate exactly where the item was ranked originally and where it was ranked at the end; thus the absolute movement cannot be determined. They also failed to indicate how the manipulation was done. Was it manipulated only in the statistical feedback returned in round three and then left to fend for itself or was it manipulated in both rounds three and four? It also was not mentioned whether there was a target for the manipulation. Were they trying to achieve a particular ranking for this item; and if so, how successful 
were they in achieving thelr target? Would the use or lack of use of narrative feedback have helped achleve the target, 1.e. what effect does narrative feedback have on achieving a manipulated target? Cyphert and Gant also did not indicate the degree of consensus the bogus item had. Is it easier to manipulate a Delphi statement whose inftial consensus is in low agreement or in high agreement or does it matter how much agreement there 1s? Do manipulated Delphi statements tend to have less consensus at the end than non-manipulated statements? While it was not the intent of Cyphert and Gant to answer these questions, they are questions that need to be answered before one can understand the characteristics of manipulability of Delphi statements.

Cyphert and Gant also mentioned that virtually all (99\%) of the consensus occurred by the end of round three and thus questioned the need for a fourth round. One may ask the question here if the number of rounds affect the ability to manipulate Delphi statements? Since the feedback is contrary to what was reported and thus expected, might it take an extra round to establish stability and/or consensus? Could this be a means to help limit the degree of manipulability of a statement?

Schelbe, Skutsch, and Schofer also conducted a Delphi where they manipulated one Delphi statement. The subject matter of the Delphi was to develop and weigh ". . . a hierarchy of goals and objectives for use in evaluating a number of hypothetical transportation facility alternatives." [85:263] The objective, however, was not to come up with a viable set of goals and objectives but to test certain aspects of the Delphi methodology. Among these were: 
1. the effect of using different scaling techniques to rank Delph1 statements,

2. the measurement of feedback effectiveness,

3. the use of stability rather than consensus to determine the end point of a Delphi statement, and

4. the use of high/low self-confidence ratings and other personal descriptive variables to improve the results of Delphi.

The second of these aspects of Delphi methodology was of particular interest with respect to this paper in as much as it concerned the use of manipulated statistlcal feedback. In an effort to examine ". . . the round-by round effect of feedback. . . [and to investigate] the manner in which the feedback affects the distribution of scores in a particular round," [85:270] the participants were provided with false feedback on one question during the first round and the effect on the distribution of priority-weighted scores was observed. A question

which appeared to have a good consensus after the first round was chosen. A falsified distribution in the opposite direction was returned to the participants during the second round. There was no further manipulation. It was determined that the respondents would respond to this falsification in one of three ways. Since the falsified feedback was given in the opposite direction as the original consensus, the respondents could

- . ignore the feedback and keep their votes constant; they could rebel against the feedback and move their votes to the rlght in the interest of moving the group mean closer to their true desire; or they could acknowledge the feedback and move their votes nearer the false mean. If they had followed efther of the first two options, it would indicate that the feedback was not effective in changing individuals attitudes. [85:270]

The result was the respondents shifted their positions away from the true mean and toward the falsified mean. However, since there was no more manipulation (the respondents were fed back the actual 
distributions that resulted during round 2 and 3 ), the respondents

slowly reverted back toward their orfglnal consensus, although there

was some residual effect remaining (the distribution was shifted

slightly toward the manipulated direction). This, the authors felt,

- . suggests that the respondents are, in fact, sensitive to the feedback of distributions of scores from the group as a whole. These results seem to indicate that most respondents are both Interested in the opinions of the other members of the group and desirous of moving closer to the percelved consensus. [85:272]

While the intent of the above was not to measure the ab1lity of one to manipulate Delphi statements, it does lead us to a serles of questions which are relevant to the topic of manipulability of Delphi statements.

1. What would be the effect of falsified feedback being given during the entire Delphi process (rather than just the first round)? Would the respondents tend to go back to the original consensus if falsifled feedback were given during round 1 only, rounds 1 and 2 only, or during all rounds?

2. Would the respondents have a higher propensity to be manipulated on questions that have low consensus or does the degree of consensus have little effect on the propensity to be manipulated? The question chosen by Scheibe, Skutsch, and Schafer to manipulate was one that had a high degree of consensus. The results of round 2 showed a shift in the manipulated direction; however, the resulting distribution was rather flat, Indicating a lack of consensus. Had they chosen a statement whose first round distribution was flat (lack of consensus) would the results of round 2 have shown a higher consensus in the falsifled direction?

3. Would the use of mantpulated narrative feedback have achleved even greater success in establishing a desired degree of manipulation? Could a higher degree of consensus around a desired manipulated point be achievable through the use of manipulated narrative feedback in combination with manipulated statistical feedback than manlpulated statistical feedback alone?

4. What levels of success can one achieve for different levels of manipulation? Can one actually try to achieve manipulated consensus for a particular point? Does the success 
of achieving this point depend on the direction from the true answer one is manlpulating toward (1.e. would one be more successful in manipulating toward the true answer, toward the true answer but beyond it, or away from the true answer) and/or the distance from the original consensus (i.e. would one be more successful in moving the answer a little bit or a larger amount)?

5. Would manipulation be more successful if one manipulated the statistical feedback by small increments each round toward the desired manipulated point or by an initial large manipulation which is maintained or adjusted to accomplish the desired manipulated point? If one wishes to acquire a particular point, would it be easier to manipulate the respondents by a series of gentle manipulations until that point is reached or would it be easier to adjust manipulated results around that point in the beginning and merely adjust the manipulation to fit the respondents consensus but at all times maintaining the mantpulation to encourage the desired point?

6. What level of success can one attain at achieving a desired distribution? Can one, through the use of manipulation, achieve a uniform distribution (lack of consensus), a normal distribution (consensus), and/or a bimodal distribution (conflicting consensus)?

Another area of interest in this study is the relationship between the degree of confidence (as measured by self-rating) and the degree of manipulability. Norman Dalkey [21] In his original study of the use of self-ratings to improve group estimates (and also in later works [ 8 and 23] concluded that one can substantially improve the performance of Delphi through the use of self-rating subgroups. Others such as Gordon Welty [97-101] repudiate the use of experts altogether. Schelbe, Skutsch, and Schofer add to this topic by saying:

Studies in the psychology of small groups, however, indicate that highly confident persons should be less influenced by group pressure than those with less confidence, and therefore $1 t$ would be expected that highly confident individuals move less toward consensus than do others in the Delph1 context. [85:275]

If the above Is true, one would expect those who rate themselves as more confident would be less subject to manipulation. If this is 
true, it would lend more credibility to the argument that the Delphi panelists should be experts and/or that some self-ratings procedure be used and that consensus of the high self-rated group be used over the consensus of the entire group.

While Cyphert and Gant and Scheibe, Skutsch, and Schofer both use manipulation in one of their Delphi statements, Gordon Welty [97101] is the only person who has directly attacked ". . . the robustness of the Delphi exercise in withstanding deliberate manipulation of judgemental and deceitful opinion formulation." [98:377] He did this by running a Delphi on a portion of Nicholas Rescher's questionnaire study of Atnerican values by 2000 A.D. [76] The portion of Rescher's study he chose was Question 2, a list of 37 values. The participants were to indicate whether in their judgement each value would change in the direction of greatly increased emphasis, slightly increased emphasis, Ifttle or no change, slightly decreased emphasis, or greatly decreased emphasis. The respondents were also to indicate the desirability/undesirability of such a change using a similar five point scale.

It is rather interesting to follow the sequence of articles Welty published on his study. He set out to develop two hypotheses. The first dealt with whether there is a significant difference between the conclusions of a non-expert Delphi panel and an expert one. The tiea was to shed some light on whether a Delphi panel should be composed of experts or not. His first article [97] stated his results and concluded that there was no significant difference. His following four articles merely restated the same results in a different manner. His second hypothesis, however, is of more interest in this study and 
certainly has a more interesting (1f not conflicting) development in his succession of articles. His second hypothesis deals with ". . deliberate distortion of experts opinion by the managers of the Delphi exerc1se." [97:403] In article [97] he makes a case that the Delph1 exerclse is subject to "deliberate distortion" and that it appears impossible to control. He indicates that they have attempted to test this hypothesis and will report on it later. He concludes his article stating that for these two reasons the Delphi process is ". . the antithesis of scientific forecasting." [97:407]

Three articles later [98], Welty reports on his efforts to test the second hypothesis. The results of his experiment show that ". . the participants were not susceptible to influence and opinion formation..." [98:380] that "the Delphi technique appears, on the basis of our research, to be more powerful an institution in reststing willful and arbitrary manipulation than we might have been led to believe on the basis of Cyphert and Gant's work." [98:381] This is certalnly a change of position from his previous comments.

Welty's most recent article [99] (published two years after the above study) is an impressive and flamboyant article drawing heavily from Greek mythology and philosophy. It is interesting to read his conclusions in light of the results of his above study. While he mentions Cyphert and Gant's work again, he falls to mention the results he published two years earlier. Either he must not believe, or lacks confidence in, his own results or he must have forgotten them. of course, since the article was so heavily oriented to the concept of deception, to say the Delphi technique is otherwise would have been contrary to his laboriously developed theme. 
Rather than belaboring this let us instead review the article [98] where he reported the results of his study. Welty's presentation of his study was at best inadequate. He spent two short paragraphs (nine sentences to be exact) explaining his methodology and analysis procedures. During these two paragraphs he failed to explain adequately both the dependent and independent variables (percent labelled deviant and average distance moved per item) of his regression analysis. By looking at Table 1 in his paper and referring to Rescher's paper [76], one can determine what he meant by distance moved, but confusion returns when it is obvious he only counts deviations in the percent labelled deviant responses but discusses it in terms of causing ". . . substantial shifts in group opinion. . ." (underline added) [98:380] Percent labelled deviant is subject to several interpretations, all of which are confusing. Without a full comprehension of the dependent and independent variables, it is imposstble to draw any conclusions relative to its validity. To add to the inadequacies of his paper, Welty also neglects to Indicate how he manipulated the respondents Delphi statements and how much he manipulated them. Without this, one certainly cannot draw any conclusions relative to the effect of manipulability of Delphi statements. The most that can be said for Welty's work is that it generated more questions than it answered and left the initial question he set out to answer even more puzzling. Perhaps this Is why he ignored his results in his later publication.

\section{IITERATURE INDIRECTLY RELATED TO MANIPULATION}

The following articles while not directly attuning themselves to the problem of manipulation of Delphi statements do implicitly generate 
pertinent questions worthy of consideration.

Skutsch and Schofer [91] dlscuss planning as a process involving two psrts, (1) setting the goals and (2) reaching the goals. In recent years, many tools have been developed to attain the latter; however, little has been done relative to the former. Not only has this area lacked adequate development, but the methods and techniques developed for obtaining goals requlre even more explicitly and meticulously defined goals.

They suggest use of a "goals hierarchy" such that unwritten community "values and norms" may form the peak of the pyramid. Horizontal aspirations may be included as "goals" while at a lower level "objectives" are identified as specific intents and directions for action. For each value there may be many goals, and for each goal, many objectives .. [91:305]

By accepting this "goals hierarchy" one thus enhances the specificity, directionality, measurability, and ability to weight goals or objectives according to their relative priority.

They suggest a Goals Delphi to develop a community consensus as to the goals hierarchy and to derive the weighting of the goals and objectives. Figure I gives a diagram of the procedure.

In addition they mentioned three princlpals upon which Delphi is based:

1. . . group judgements are superior to individual ones;

2. anonymity allows greater rationality;

3. group pressure acts to consolidate group opinion. $[91: 306-8]$

They agreed with the reasoning of the first two principles; however they felt not enough has been done by Delphi theorists on the last principle. They indicate that ". . . Delphi was developed, in part, as a means for identifying divergence of opinions as well as areas of consensus . . ." 


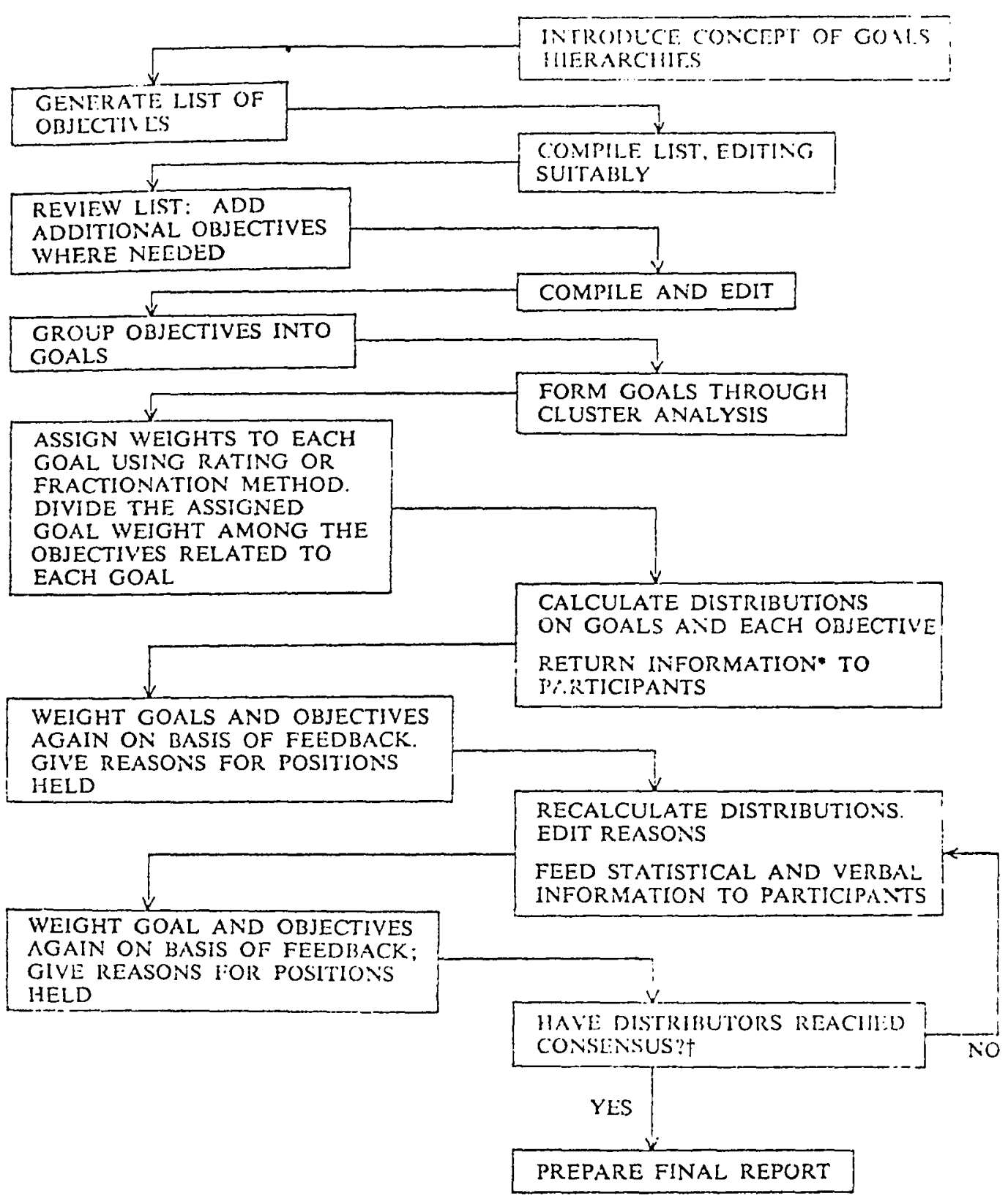

* Statistical feedback chosen will depend on. desiga necds; could be a histogram, mode, mean and interquartile range, etc.

tConernciss mav he defined in tarme of stahility

\section{Figure I. Goals Delphi algorithm [91:307]}


[91:308] Thus before one applies Delphi to the formulation of goals, one must understand the Internal process of feedback and consensus to assure oneself that he is not developing $a$ ". . . forced, and hence short-11ved, consensus." [91:308]

Even though Delphi was initially designed to overcome conformity to the dominant opinion (Dalkey indicates the "use of a statistical definition of the group response is a way of reducing group pressures for conformity ..." [21:16]), there exists a strong tendency to conform to the group opinion. The more clearly visible the majority opinIon the greater the movement towards the center of opinion and the more likely the Iess confldent members of the group will conform.

This implies that the development of a consensus need not necessarily be the result of logical coalescence of opinion through a learning process based on controlled group interaction, and, therefore that the consensus may not necessarily represent a judgment superior to the judgments of individuals. The effect of this phenomenon essentially militates against Principle 1 underlying the value of Delphi itself. [91:309]

To combat this problem, Skutsch and Schofer suggest the following three considerations:

1. reduce the visibility of group pressure to the participants,

2. use stability of opinion distributions as a stopping criteria rather than degree of consensus, and

3. use ". . . the entire distribution of opinion to describe the goal weights, rather than a single value of group opinion, such as the median. . . It provides considerably more information on the opinion of the group." [91:310]

One can reduce the visibility of group pressure by reducing the amount of statistical feedback one gives the participants. Skutsch and Schafer show this by the following: 


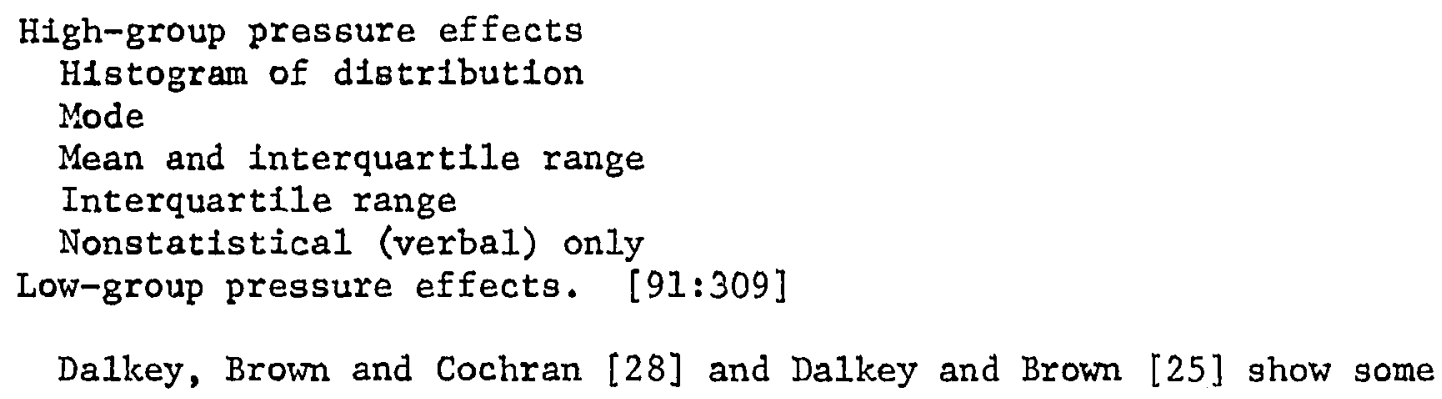
evidence contrary to this. Without getting into a prolonged discussion on the subject let us consider what one would have to do to test the possible effects of these different types of feedback on the manipulability of Delphi statements. If one accepted the hypothesis that the degree of manipulability of Delphi statements is affected by type of stat1stical feedback used, it seems clear that the form of statistical feedback which affects a high-group pressure will result in a better ability to manipulate. To test this, one would have to run the test Delphi using each of the statistical feedback methods suggested. Since this would enlarge the study considerably and produce an overburdening pressure on the resources available, a test of this hypothesis was not attempted.

Determining when to stop a Delphi has traditionally been centered around the number of rounds necessary to develop consensus. Skutsch and Schofer suggest that stability of a distribution might be a better measure for determining when to stop. While it was felt that the latter may be a better measure, four rounds were used in this study so that other hypotheses could be tested. There was an attempt, however, to review the degree of movement found between each round. It was viewed both in terms of movement towards consensus as well as stability of distributions. 
Skutsch and Schofer also discuss the use of Delph1 to develop fudgments of values rather than facts. They distinguish between valueestimation (where the Delphi participants are called upon ". . . to 'estimate' the desires and needs of the community in weighting the goals" [91:311]) and value-election (where the ". . participants are asked to express their own opinions on goal weights and to state their own reasons for these weights" [91:310]). While there exist possibilities for both, the value-estimation version holds the predominant position. "This must, in part, be due to the fact that decision makIng authority is generally concentrated in the hands of a few, while the Delphi usually is applied on a wider basis." [91:311] Another area one might consider with respect to manipulability of Delphi statements is the interjection of bias by respondents to sway the statistical feedback in a manner that is favorable to their own bias. Chester Jones makes the following comment with respect to a group of Delphis he ran in the United States Air Force in an attempt to establish priorities for the System Concept Options.

One concern that is often raised about the credibility of Delphi results is that individual experts may bias their responses so that they are overly favorable towards areas of personal interest. This is of particular concern when experts are asked to evaluate areas in which they are presently working and when the final Delphi results could impact the importance attached to these areas. In this paper results will be presented that indicate that no such blas occurred in the Delphis reported on. It appears that the group of experts used were able to rise above the desire to protect personal interests. [48:160]

While this report is not conclusive for all situations, it supports the idea that a panel of experts would tend to hold the value of the results above their personal bias or interests. Since the nature 
of this form of manipulation (i.e. voting overly favorable towards areas of personal interest) is different from the form of manipulation that was originally Intended to be tested, it will not be considered in this paper.

In an article published long before Delphi was even conceived, Thomas Coffin [15] concluded:

1. ". . . there is a tendency for suggestibility on problems to increase with the difficulty of the problems" [15:16] and

2. those with more training (more expert) were less prone to suggestibility but were still subject to some suggestibility.

He used 16 mathematical problems of increasing difficulty (complexity) In his non-Delphi study. Included with each problem was a suggestion towards its solution (four of which were correct, twelve incorrect). Suggestibility was indicated when one accepted the suggestion in trying to solve the problem; non-suggestibility was indicated when one rejected the suggestion and did it his own way. Correctness of answer was not considered.

The above has several implications relative to self-rating and the degree of manipulability of Delphi statements. If one can accept the direct relationship between suggestibility (and thus manipulability) and the knowledge and training of the respondent, one could anticipate that an expert (one who has more knowledge and training relative to a Delphi statement) would be less susceptible to manipulation than a non-expert. This would add credence to the concept of having one's panel made up of experts.

One can also develop another implication from the above. Since people either know something about a factually oriented Delphi statement 
or have little or no knowledge concerning 1t, one would expect factually orlented Delphi statements to be elther less or more manipulative, respectively, than value orlented Delphi statements (usually everyone has at least some opinion or famlliarity with a value statement). However, Coffin's first point indicates a direct relationship exists between the suggestibility and the difficulty (complexity) of a problem. Often times, value oriented Delphi statements tend to be more complex due to their openness ("depends on how you look at it"). Self-rating by experts may again help alleviate or recognize when this problem exists.

In an effort to explain some of the forces that influence the Improvement experfenced between rounds by Delphi statements, Dalkey [19] discusses the "pull of the median" and the "pull of the true." He shows that the further an answer is from the median answer, the greater will be the likelihood of change. While those who are further from the median are more likely to change their answer, there also tends to be a magnetic effect towards the true answer; however, the pull of the true answer is considerably weaker than the pull of the median. Thus Dalkey attributes convergence to a combination of the pull of the median and the pull of the true answer with the former playing the predominant role. The result of this disequilibrium is that overconvergence occurs; ". . the increase in accuracy is not commensurate with the reduction in spread. . ." [19:425]

of special interest to this paper is whether these pulls can be manipulated in such a manner that one can arrive at a predesigned value. The pull of the true answer is present and can only be affected by falsifying the true answer itself (which obviously cannot be done). 
Since the pull of the median is greater, by feeding back a falsified median, one should be able to achleve a greater movement in the direction desired. This leads us to two questions. The first question asks If there is a point where the pull of the true answer outweighs the pull of the median? That is, is there a point some distance from the true answer where the pull of the true answer equals or outweighs the pull of the median as the median travels further away from the true answer? This would indicate there is a point where people would not believe the median and would weight their answer more towards the true answer. This can be expressed by the following diagram:

$$
\text { unbelievable median true answer }
$$

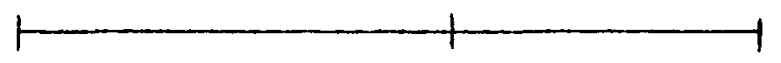

As the median moves towards the unbellevable, the pull of the true answer becomes stronger and the pull of the medlan weaker, thus causing respondents to weight their answers toward the true answer. If this holds true, the question becomes, will this be a gradual movement or will people stick with the pull of the median until some threshold is reached and then abandon it radically for the pull of the true answer?

The second question generated is whether the pull of the median versus the pull of the true answer would be the same or different for a value Delphi versus an almanac Delphi. Since the value Delpht has no true answer per se, this is difficult to measure. If the value Delphi tends to be less manipulable than the almanac Delphi, one could, however Infer that the pull of the median is less predominant in the value Delphi than In the almanac Delphi. 
Dalkey also suggests another question, ". . can the pull of the true be amplified and the pull of the median be dampened?" [19:425] He suggests that this might be done by ". . . feeding back something weaker than the three quartiles." [19:425] In a later work Dalkey, Brown, and Cochran [28] tried this by feeding back the percentile location of an individual's response rather than the median and quartiles. It was hypothesized that this would be a less specific "target" for changes In the Individuals response, thus increasing the relative weight of the pull of the true answer.

The results of the experiment with percentile feedback would appear to indicate that the Delphi process is not very sensitive to the form of feedback as long as it involves some relatively preclse summary of the group response on the previous round. The percentile feedback appears to be slightly less effective than medians and quartiles with respert to numerical improvement (average error), but nelther form of feedback is very effective on this measure. [28:28]

Dalkey, Brown, and Cochran a1so considered a second varlation in the form of feedback which dealt with ". . presenting the respondent with a single additional relevant fact." [28:V] It was hypothesized that the respondents accuracy would improve if they were given an additional relevant fact for each question. The result of this "feed-in" was that 1t greatly increased the accuracy of the respondents. "The abllity of the subjects to use essentially any fact, whatever the nature of its relevance to the question Involved, is suggestive of the great flexibility of the human mind in dealing with fragmentary information." [28:28] They then went on and discussed the selection of relevant information, saturation of relevant facts, and the extension of the Delphi procedure to include "Interaction of the panel with large exogenous sources of information..." [28:29] 
The above presents a question that is relevant to this study. If feed-In can Increase the overall accuracy of the DelphI responses, can false feed-In decrease the overall accuracy of the Delphi response. To go one step further, by controlling the degree of the falsity of the feed-in (i.e. by supplying statistical numbers or facts in the iterative feedback that express the range deslred or by supplying only one side of a story) can one actually control and/or predict the response to a Delphi statement?

Jolson and Rossow lend some support to ". . . the assumption that the correct answer will continue to be an underlying force, even under the obvious attraction of the group median..." [47:446] They Included two control questions in their attempt to test the Delphi process in assigning prior probabilities in a marketing decision under uncertainty. Both questions were the type where one group would have expert (large) knowledge and the other group would have little knowledge of the subject.

Half the responses to the second and third-round questionnaires for the validation study were closer to the true answer than to the median returned from the previous round. Also, the attraction of the true answer seemed to vary directly with the distance between the group median and true value. [47:446]

In both cases, the expert group was able to produce a much better estimate than the non-expert group. It was also noted that the know1edgeable, confident panel member was less likely to revise his prediction over 1terations.

Dalkey indicates

- - the average error on round one is a linear function of the dispersion of the answers. The average amount of change of op inion between round one and round two is a well-behaved function of two parametera - the distance of the first-round answer from the group median, and the distance from the true answer. [21:vi] 
This statement attunes 1tself to the question of the strength of the pull of the median versus the pull of the true answer. Later in his paper, Dalkey demonstrates this relationship. Of concern to this paper is whether the above will hold true for both the control and the experimental groups or whether the effects of the manipulation will change the pattern of the relationshtps.

Dalkey's results show that iteration results in an improvement In accuracy; however, this is less dramatic than the amount of convergence. While iteration results in improvements in accuracy, its main effect lies in the Increased convergence. One might next ask: w111 manipulated results show similar results? If manlpulation was successful, movement towards the desired answer should occur and should be accompanied by an increase in convergence around the desired answer.

Does this really occur, or is the movement toward the menipulated answer less pronounced and the convergence less successful (perhaps even divergent)?

An additional implication that results from the increased convergence is that people desire to be within the range of the upper and lower quartile. If, for whatever reason, this is true, could the size of the range determine or affect the amount of manipulation that can be achieved? If people desire to be within the range, might one achleve better results if he used a small range versus a large range? The idea here is that people may tend to give an answer that is close to the end of a range because it satisfies their desire to be within the range but is closex to the yalue of their original 
estimate (it is more believable). If this is true, smaller ranges would move the participants closer to the deslred answer. However, if the endpoint of the range is too distant from their original estimate, the particlpants may question the validity of the feedback and stay closer to their original answer. 
CHAPTER III

DESIGN OF THE STUDY

This chapter is concerned with the design considerations of this study. They can perhaps best be summarized by the flowchart found in Figure 2.5 The structure of this chapter follows the general breakdown of the flowchart. The characteristics of the two populations (participants and Delphi statements, respectively) will first be discussed. A discussion of the general procedure for administering the Delphis will follow. Preceding the specific statistical procedures for each dependent variable (success, convergence, stability, and confidence) will be a discussion of the general design considerations.

\section{CHARACTERISTICS OF THE PARTICIPANTS}

The participants who participated in the Delphis were all United States Air Force officers who were enrolled in a Master of Business Administration program at Grand Forks Air Force Base, North Dakota. The program is funded by the Air Force Institute of Technology and administered by the University of North Dakota. There were two groups of thirty volunteers for both Delphis administered. Thirty students volunteered for both Delphis. Thus out of a possible 151 students, 90 students participated in the Delphis. The two groups of students met for class on separate days and were therefore generally assigned different duty

5 Figure 3, at the end of Chapter IV, gives a brief synopsis of the findings of the statistical tests indicated in Figure 2. 


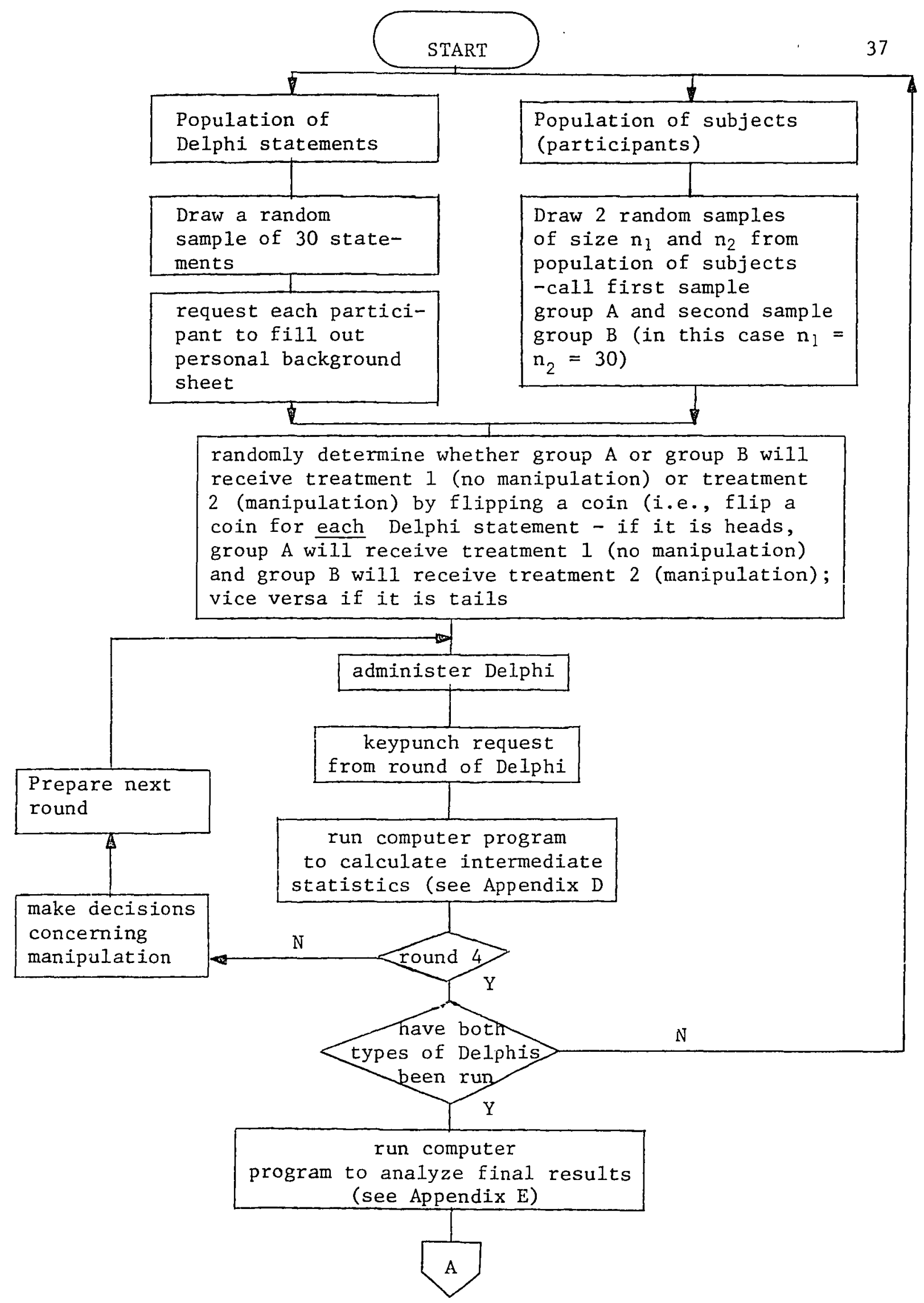

Figure 2. Flowchart of design considerations. 


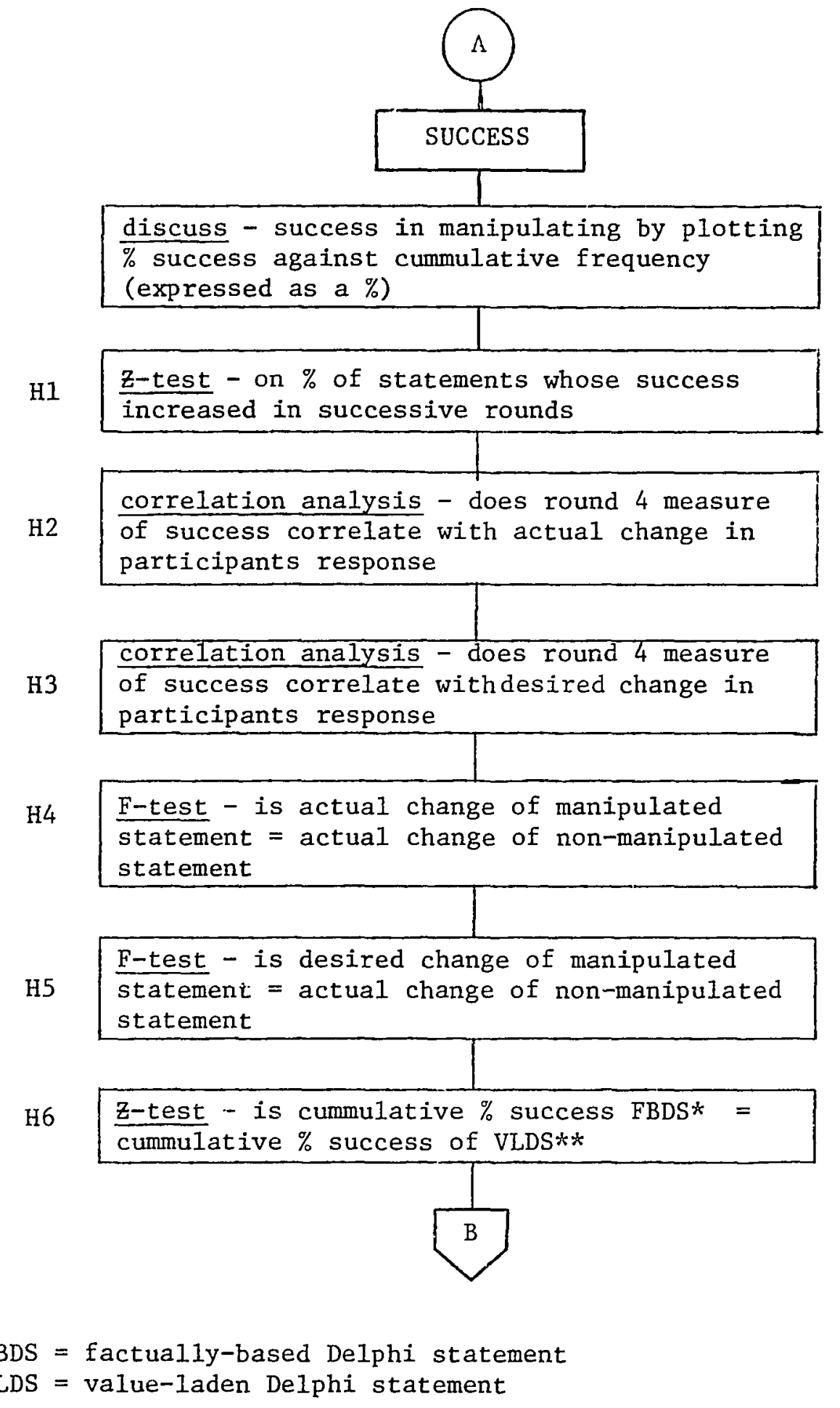


H7a

$t$-test and anal. of var. - is standardized $\sigma$

CONVERGENCE of manipulated FBDS = standardized $\sigma$ of nonmanipulated FBDS

$\mathrm{H} 7 \mathrm{~b}$

$t$-test and anal. of var. - is quartile range of manipulated FBDS = quartile range of nonmanipulated FBDS

\section{H7d}

F-max - is variance of manipulated $\mathrm{FBDS}=$ variance of non-manipulated FBDS (for each statement individua11y)

H7c

t-tes and anal. of var. - is $\sigma$ of manipulated

VLDS $=\sigma$ of non-manipulated VLDS

H8

\section{STABILITY}

t-test and anal. of var. - is \% of manipulated FBDS that change between 2 consecutive rounds $=\%$ of non-manipulated FBDS that change

H9

$t$-test and anal. of var. - is round where $20 \%(15 \%)$ stability manipulated FBDS(VLDS) = the same for non-manipulated FBDS(VLDS)

$\mathrm{H} 10-\mathrm{H} 13$

t-test and ana1. of var. - test the relationships among the combinations of manipulated/non-manipulated and FBDS/VLDS on the average number of rounds necessary to reach $20 \%(15 \%)$ stability 
$\mathrm{H} 14$

t-test - is the change in the participants' self-rating between rounds 1 and $4=0$ or $=$ mean change of all the non-manipulated Delphi statements

H15

$t$-test and anal. of var. - is there a tendency for the change in the participants' self-rating between rounds 1 and 4 to shift towards the middle (i.e., those who rate themselves low increase their self-rating and those who rate themselves high decrease their self-rating)

H16

t-test - do those who originally self-rate themselves low but whose answers are closely supported by the reported median have a propensity to increase their self-ratings more than those whose answers are not closely supported by the median; and do those who originally self-rate themselves high but whose answers are distant from the reported median have a propensity to decrease their self-rating more than those whose answers are not as distant from the median

t-test and anal. of var. - test the relationship among the combinations of manipulated/non-manipulated and how a participant self-rates himself during round 1 , on the actual change between rounds 1 and 4

DONE 
schedules. This limited the contact between the two groups. The participants were also instructed not to discuss the Delphis with anyone nor to research any of the Delphi statements.

Both groups were given the same Delphis under the same conditions for the same number of rounds. The only differences were 1) the statistical feedback given was for their group only and 2) if the first group was manipulated on a statement, the second group was not manipulated and vice versa (the assignment of which statements were manipulated for which group was random - a more complete discussion of this procedure will be given 1ater).

Each participant was requested to fill out a personal background sheet. Table I gives the results of this backgroud sketch for both groups for the factually-based Delphi. Table II does the same for the value-laden Delphi. Since they were participating in a MBA program, all of the participants had bachelor degrees. Their degrees ranged from the hard sciences (mathematics, chemistry, physics, etc.) to the soft sciences (philosphy, social science, political science, etc.) to the arts (music) to degrees in the business area from universities throughout the United States. Thus, the educational level was high. The tables also show that the age range was narrow and that most of the participants were married. While between groups they were similar with respect to rank, length in the airforce, number of courses taken in the MBA program, number of children, father's occupation, and responsibilities in the airforce, the within variance of these factors was large.

Mulgrave and Ducanis in an effort to test the propensity of Delphi participants to change their responses as a function of dogmatism found 
TABLE I

Background of Factually-based Delphi Participants

$\begin{array}{lccccc}\text { Rank } & \text { 2nd Lt } & \text { 1st Lt } & \text { Capt. } & \text { Major } & \text { Colone1 } \\ \text { Group A } & 10 & 3 & 15 & 1 & 1 \text { (retired) } \\ \text { Group B } & 9 & 6 & 15 & & \end{array}$

How Long in

\begin{tabular}{lllllllllllllllllllllll} 
Airforce & 1 & 2 & 3 & 4 & 5 & 6 & 7 & 8 & 9 & 10 & 11 & 12 & 13 & 14 & 15 & 16 & 17 & 30 \\
\hline Group A & 6 & 2 & 1 & 0 & 4 & 2 & 3 & 4 & 3 & 1 & 1 & 0 & 0 & 1 & 0 & 0 & 1 & 1 \\
Group B & 4 & 3 & 4 & 2 & 1 & 6 & 0 & 2 & 3 & 2 & 1 & 1 & 0 & 0 & 1 & 0 & 0 & 0
\end{tabular}

Number of

Completed

Courses*

\begin{tabular}{lllllllllllllllllll}
0 & 1 & 2 & 3 & 4 & 5 & 6 & 7 & 8 & 9 & 10 & 11 & 12 & 13 & 14 & 15 & 16 & 17 & 18 \\
\hline
\end{tabular}

Group A

$\begin{array}{lllllllllllllllllllllll}4 & 1 & 2 & 3 & 4 & 1 & 4 & 1 & 1 & 1 & 0 & 1 & 0 & 0 & 4 & 1 & 0 & 0 & 2\end{array}$

Group B

$2 \quad 2 \quad 3$

$\underline{\text { Age }}$

\begin{tabular}{llllllllllllll}
23 & 24 & 25 & 26 & 27 & 28 & 29 & 30 & 31 & 32 & 33 & 34 & 35 & 52 \\
\hline
\end{tabular}

Group A

15

Group B

22

*includes prerequiste courses 


\begin{tabular}{lrrrrrrr} 
Married & Yes & No & & & \\
\hline Group A & 26 & 4 & & & & \\
Group B & 23 & 7 & & & & \\
& & & & & & & \\
$\begin{array}{l}\text { Number of } \\
\text { Children }\end{array}$ & 0 & 1 & 2 & 3 & 4 & 5 & 12 \\
\hline Group A & 15 & 8 & 5 & 1 & 0 & 0 & 1 \\
Group B & 17 & 2 & 10 & 0 & 0 & 1 & 0
\end{tabular}

Father's Occupation Group A Group B

$\begin{array}{lll}\text { Professional } & 2 & 2 \\ \text { Managerial } & 4 & 5 \\ \text { Technical or } & & \\ \quad \text { Engineering } & 3 & 1 \\ \text { Sales or Service } & 5 & 4 \\ \text { Government } & 2 & 2 \\ \text { Armed Forces } & 2 & 4 \\ \text { Skilled Blue Collar } & 4 & 8 \\ \text { Unskilled Labor } & 2 & 2 \\ \text { Other } & 6 & 2\end{array}$


TABLE II

Background of Value-1aden Delphi Participants

$\underline{\text { Rank }}$ 2nd Lt 1st Lt Capt. Major

Group A

$5 \quad 14 \quad 1$

Group B

13

$6 \quad 11$

0

How Long in Airforce $\begin{array}{lllllllllllllllll}1 & 2 & 3 & 4 & 5 & 6 & 7 & 8 & 9 & 10 & 11 & 12 & 13 & 14 & 15 & 16 & 17\end{array}$

Group A

5

Group B

$\begin{array}{llllllllllllllllll}7 & 4 & 3 & 1 & 3 & 4 & 1 & 2 & 1 & 1 & 2 & 0 & 0 & 0 & 0 & 1 & 0\end{array}$

Number of

Completed

Courses* 0

Group A

$0 \quad 1$

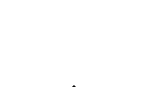

Group B

20

6

$5 \quad 6 \quad 7$

$9-10$

Age $22 \quad 23 \quad 24$

$\begin{array}{lllllllllllllll}\text { Group A } & 1 & 4 & 2 & 4 & 5 & 1 & 1 & 4 & 1 & 3 & 1 & 1 & 1 & 1 \\ \text { Group B } & 1 & 1 & 3 & 7 & 3 & 1 & 4 & 3 & 1 & 1 & 1 & 2 & 2 & 0\end{array}$

*includes prerequiste courses 
TABLE II (Continued)

\begin{tabular}{lcr} 
Married & Yes & No \\
\hline Group A & 24 & 6 \\
Group B & 22 & 8
\end{tabular}

Number of

Children $\begin{array}{llll}0 & 1 & 2 & 3\end{array}$

Group A

$\begin{array}{lllll}16 & 6 & 6 & 2 & 0\end{array}$

Group B

$\begin{array}{lllll}17 & 2 & 9 & 1 & 1\end{array}$

Father's Occupation Group A Group B

Professional

Managerial

Technical or

Engineering

Sales or Service

Government

Armed Forces

Skilled Blue Collar

Unskilled Labor

Other

$\begin{array}{ll}4 & 3 \\ 8 & 7 \\ 3 & 2 \\ 5 & 4 \\ 1 & 2 \\ 3 & 3 \\ 4 & 5 \\ 2 & 2 \\ 0 & 2\end{array}$




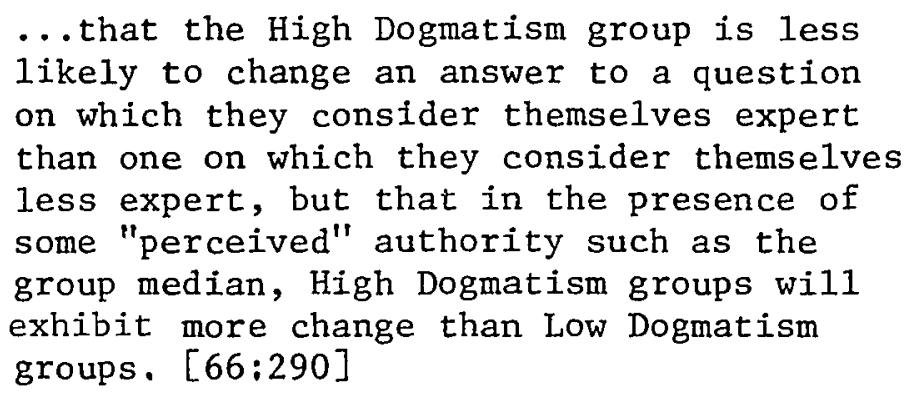

To circumvent the question that United States Air Force officers might have been highly dogmatic due to the nature of their training and work, the same test for dogmatism that Mulgrave and Ducanis used in their research (Berger's revision of Rokeach's Dogmatism Scale - the FCD Scale [4] - reference Appendix C for a copy of the scale) was administered to most of the officers who participated in this study. (The officers not tested were no longer available to be tested. They had either been transferred, were on leave, or were no longer in the AFIT program.) As Table III indicates the mean scores for each of the groups who participated in the Delphis were in the neighborhood of 122.

Interpreting the results of this test turned out to be a problem. Through personal correspondence, Mulgrave provided a copy of Berger's test. In an effort to administer the test at a time when the students were able to participate, the test was run before a copy of Berger's thesis arrived. When Berger's thesis arrived, it was discovered that he was primarily concerned with testing the effects of a certain phenomenon (when unsure of an answer, a participant will answer in the affirmative a larger percentage of the time) on several different pschological tests (the FCD scale being one of them). For this reason, Berger was not concerned with determining what ranges of scores represented low, medium, or high dogmatism. Since Berger used the statements in Rokeach's test 


\section{TABLE III}

Results of Berger's Revision of Rokeach's Dogmatism Scale (the FCD Scale)

\begin{tabular}{lcc} 
& $\begin{array}{c}\text { Number } \\
\text { Tested }\end{array}$ & $\begin{array}{c}\text { Mean } \\
\text { Dogmatism } \\
\text { Score }\end{array}$ \\
\hline Section A factually-based Delphi & 23 & 122.8 \\
Section B factually-based Delphi & 19 & 121.7 \\
Section A value-1aden Delphi & 27 & 121.3 \\
Section B value-laden Delphi & 25 & 122.4 \\
All participants & 67 & 122.2
\end{tabular}


in devising his test, it was felt that it would not be possible to rerun Rokeach's test.

The procedure used to determine if a score of 122 represented high dogmatism was to calculate the scores of the participants in Berger's thesis to see what value they scored on Rokeach's test and Berger's test and to see if the scores for Rokeach's test represented high or low dogmatism. Berger's participants scored 124 on his test and 143 on Rokeach's test (medium dogmatism). Since Berger found there was a positive correlation between his test and Rokeach's test, a score of 122 should also be considered as representing medium dogmatism.

After doing the above analysis, Dr. Berger was contacted and asked whether the analysis appeared proper. His remark was that, while it had been a long time since he had done anything with that test and its main purpose was other than what I was doing, my analysis seemed proper. Therefore, while the results were not conclusive, it appeared as though the United States Air. Force officers who participated in these Delphi studies were not highly dogmatic.

It should be cautioned that the panel of experts participating in this study was not representative of all possible panels of experts. For example, the panel was somewhat of a homogeneous group (more so than one might have wanted to see in a Policy Delphi). Another example is the lack of women on the panel. The panel was, however, representative of a group of experts who would have participated in the Delphis since the Delphis were designed to fit the area of expertise of the panel members. 
SUBJECT MATTER OF THE DELPHIS

Factually-based Delphls are fact probing Delph1s which are used to profect quantitative values for statements that will eventually prove to be true or false. Examples are the forecasting Delphis used to profect when a certain capability will occur or what capability will exist at a point in the future. Almanac Delphis are of a similar nature to forecasting Delphis, except they project something that has already occurred. Projecting something that has already occurred has the distinct advantage of allowing one to verify immediately certain aspects of the Delphi technique such as accuracy. For this reason, almanac Delphis have been used In many Delphi experiments. For the purpose of this study, it will be assumed that an almanac Delphi will be representative of factually-based Delphis.

In choosing the subject matter for the statements to be used in the almanac Delphi, primary consideration was given to choosing statements of which the particlpants would have some knowledge. Thus the statemente were al1 concerned with Grand Forks, North Dakota, Grand Forks Air Force Base, Unfted States Air Force, and the MBA program of which the participants were a part. The data was gathered from various resources such as The World Almanac, Air Force Almanac, brochures pubIished by Grand Forks, and the MBA program's record. Out of forty questions developed, thirty were chosen to be used in the study. Appendix A contains a sample of the Almanac Delphi used. Value-laden Delphis are value probing Delphis which cannot eventually be judged as true or false (who is to say one man's values are rlght or wrong). While factually-based Delphis tend toward the 
objective, value-laden Delphis are highly subjective in nature. Most Policy Delph1s are value-laden Delphis in that they oubject1vely rate the necessity, desirability, importance, etc., of some statement. For this reason, a Policy Delphi rating the importance of a list of objectives for the MBA program in which the participants were participating was used as the value-laden Delphi. It is assumed it is representative of a value-laden Delphi. The subject matter was chosen in that it was something in which all the participants were currently involved and was thus something about which they had some ideas or concerns.

The statements were developed by reviewing a series of simflar studies which tried to identify institutional goals $[2,12,16,17,39$, $43,49,50,69,89,96]$ and by selecting from their results a series of statements that appeared applicable to the MBA program. Appendix $B$ contalns a sample of the value-laden Delphi used.

GENERAL PROCEDURE FOR ADMINISTERING THE DELPHIS

As indicated, there were two groups of participants for each Delph1 (group A and group B). The personal contact of the participants of one group with the participants of the other group was minimized since they attended classes on different days and as a result were generally assigned to their Air Force duties on different schedules. This minimized the interaction between groups. The interaction within a group was minimized by requesting that the participants not discuss the Delphi with anyone. Several students who were not participating in the study and who were aware of what was being done reported they did not detect any violation of this request. 
The selection of the Delphi statements that were manipulated for each group was done randomly by flipping a coin. If the coin landed heads, the statement was manipulated in group $A$ and not manipulated in group B. Vice versa if it landed tails. Thus, all thirty almanac Delphi statements were both manipulated and not manipulated. The same procedure was used for the value-laden Delphi except a Monte Carlo technique was used to select thirty of the total number of statements. The coin flipping procedure was then applied to these thirty statements. The Delphi participants were not told they were being manipulated and to the best of this authors knowledge they were unaware of it throughout the study.

The process used to determine the desired value (that value which one is attempting to obtain through manipulation of statistical feedback) was very subjective. It was originally desired to use the objective procedure of manfpulating the first round response by plus or minus one as measured by the error form of measurement. (The error form of measurement is discussed in a later section in this chapter entitled "Measurement of Success.") Problems were experienced by this procedure, however, since it did not take into consideration the distribution of the participants answers and the range of believability of the answers to a Delphi statement. For example, if the median response to the almanac Delphi statement "The highest temperature ever recorded in North Dakota was ___ (OF)." was 115 , one would have to try to achieve a median of 312 or 42 to accomplish manipulating the response by plus one or minus one respectively using the error form of measurement. Obviously neither of these values was believable. For this reason, a more subjective procedure was used. It involved the following steps: 
1. determine the range of bellevable answers for each statement before the Delphi is run;

2. after considering the above range and the distribution of responses for round 1, chose a value that takes into consideration the following:

a. the value should be in the direction of the true answer but beyond it unless the true answer is sufficiently distant from the initial response (this will combine the pull of the true as well as the pull of the median);

b. the value chosen should be sufficiently distant from the initial response so that the movement cannot be attributable to accident; and

c. a strategy of manipulation by the full desired amount during the first round and then maintaining it around that point for each of the remaining rounds should be used.

One should notice this procedure used the distribution of responses from round 1 to decide the desired value rather than deciding it before the Delphi was run. The primary reason for this was to avoid creating a desired value that the participants might have achieved at the end of round 1 (i.e. to avoid problems with $2 . \mathrm{b}$ above).

In hindsight, a prospective algorithim which might have been used to calculate the above desired answer might have looked like the following:

1) Calculate the range of believable answers where

$$
\begin{aligned}
& \text { LHS }=\text { left-hand side of range } \\
& \text { RHS }=\text { right-hand side of range }
\end{aligned}
$$

2) Calculate the distance between the round 1 median or index (R1) and the range of believable answers

$$
\begin{aligned}
& \mathrm{DL}=|\mathrm{LHS}-\mathrm{RI}| \\
& \mathrm{DR}=|\mathrm{RHS}-\mathrm{RI}|
\end{aligned}
$$




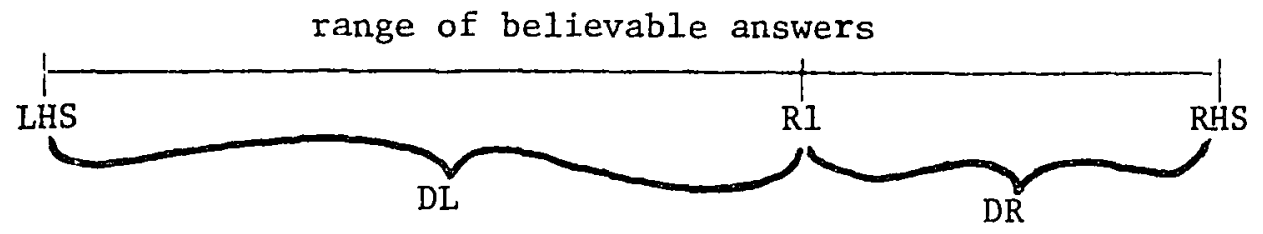

3) Determine which distance is larger

$$
\text { if } \mathrm{DL}>\mathrm{DR} \begin{aligned}
\text { than } & \mathrm{D}=\text { LHS-RI } \\
\text { otherwise } & \mathrm{D}=\text { RHS-R1 }
\end{aligned}
$$

4) Calculate the desired answer (AD)

$$
A D=R 1+80 \% \text { of } D
$$

The above algorithm has the disadvantage that it does not take into consideration the direction of the true answer. It is possible, however, that one could modify the algorithm to include a preference for the direction of the true answer. One such modification might be as follows:

2a) add preference to the end of range which contains the true answer ( $\mathrm{T}$ )

if $T$ is between LHS and $R 1$ and $|\mathrm{T}-\mathrm{R} 1|>10 \%$ of $\mathrm{DL}$ then $\mathrm{DL}=\mathrm{DL}+20 \%$ of $\mathrm{DL}$

if $T$ is between RHS and $R I$ and $|\mathrm{T}-\mathrm{R} 1|>10 \%$ of $\mathrm{DR}$ then $\mathrm{DR}=\mathrm{DR}+20 \%$ of $\mathrm{DR}$

The percentages used in the above algorithm $(80 \%, 10 \%$, and $20 \%)$ were subjectively chosen. Another researcher might prefer to use a different set of percentages that better fit his Delphi.

Appendices A and B contain copies of the factually-based and the value-laden Delphis respectively and the instruction sheets that were used in the Delphis. As can be seen, there were four rounds. (Four rounds were used to allow the more complete testing of the 
hypotheses concerning convergence and stability). The Delphis were administered in an eleven day period. The first and second rounds were completed on days one and two respectively. Rounds three and four were completed on days ten and eleven. (This schedule was dictated by the class schedule of the MBA program.) Upon completion of each round by the participant, the answers were punched on cards and read into a computer which computed the actual statistics and produced several reports that were useful in analyzing the results (see Appendix B). After analyzing the reports, the appropriate decisions were made as to what statistical feedback was to be used for the next round. The forms for the next round were then prepared and things were readied so the material necessary for the next round would be available by $8: 30$ the next morning.

The participants were allowed to pick up the current round anytime between 8:30 A.M. and 5:00 P.M. during the day and to fill it out at their convenience. It was to be returned by 5:00 P.M. that evening. There was a $100 \%$ completion rate.

GENERAL DESIGN CONSIDERATIONS

As indicated, this research explored the effects that manipulation of statistical feedback had on the success, convergence, and stability of Delphi statements and on the confidence of the participants. With this in mind one can recognize three basic independent variables (treatments, (i。e. manipulation and non-manipulation), participants, and Delphi statements) and four dependent variables (success, convergence, stability, and confidence). 
The usual objective of an experimental design is to derive the statistics of the responses of the dependent variables and to determine if the statistics are significantly different. One of the steps in determining their statistical significance is to look at the variances of the responses. In a properly designed experiment, it is assumed that the variances of the responses are due to differences among the treatments (i.e., one treatment is more successful than another) and due to experimental error. That is, the variations in the responses may be due to the variances within each treatment as well as the variances among treatments. The design considerations and randomization used for each experiment will now be discussed.

The within variances of the participants and the Delphi statements resulted mainly from variations in the affinity of participants and/or Delphi statements to be subjected to manipulation. This variation was minimized by randomly selecting large samples of the appropriate populations. Since the samples were large and were randomly selected, they should have been representative of the populations.

The variance between the participants and the Delphi statements was neutralized in that all the participants responded to all the Delphi statements. Thus the variances caused by participants only answering some of the Delphi statements was eliminated. The variance between the treatment (manipulation and non-manipulation) and the Delphi statements was neutralized in a similar manner. The entire sample of Delphi statements was subjected to both treatments.

The participants were divided into two groups (each representative of a random sample of the population). A coin was flipped to determine randomly which group would receive which treatment for a particular Delphi 
statement. The coin flip was done separately for each Delphi statement. Thus group A received treatment 1 for 14 (15) random factuallybased (value-laden) Delphi statements and group B received treatment I for the other 16 (15) statements. If group A received treatment 1 for a Delphi statement, group B received treatment 2 for that statement.

A treatment group error also could have affected the variance among treatments. This form of error would have resulted from the effects of extraneous factors affecting all the members of a group in a similar manner but not affecting another group in the same manner. For example, an individual participant might have added to or taken away from the conscientiousness of the group; or certain environmental conditions under which the Delphi was run might have affected the results. The only effective way to have combated this variation was to have replicated the entire experiment a number of times in a manner that would have hopefully randomized these effects. Since this experiment was bounded by resource constraints (time frame, cost, and number of participants who will cooperate), this was not attempted. With the above in mind, two experiments were run. The first experiment used an almanac (factually-based) Delphi made up of thirty almanac Delphi statements of which USAF officers would normally have some preknowledge. The second experiment used a Policy (value-laden) Delphi which attempted to establish a ranked set of goals and objectives for an MBA program. Thirty items on this Delphi were used in the experiment. Since the participants were all MBA students, they should have had some interest and knowledge about the subject. 
It was assumed that a sample of thirty Delphi statements was a large enough sample and that the Delphi statements were representative of the appropriate populations of the Delphi statements. This hopefully eliminated the within variance of the Delphi statements.

The between variances were minimized as previously indicated. All participants responded to all the Delphi statements. The participants were divided into two large randomly selected groups (group A and group B). A coin flip for each Delphi statement determined whether it was manipulated in group A or group B. Thus each statement was manipulated in one group and non-manipulated in the other group, and each participant was randomly manipulated and non-manipulated.

The officers participating were representative of the population of USAF officers enrolled in MBA programs and a sample size of thirty for each group for each Delphi was considered amply large.

\section{STATISTICAL PROCEDURES}

This section is basically divided into two parts. The first part presents a description (and the mathematical formulation where appropriate) of the measures used in the statistical analysis. The second part presents the null hypotheses used to test the research hypotheses specified in Chapter $I$.

The purpose of this section is not to justify the experimental design of this research but rather to present the experimental design in as clear and precise terms as possible (i.e. to enhance another researcher's ability to replicate the experiment). The reasons for designing the experiment in this manner should become evident when one reads the analysis of the results presented in Chapter IV. 
Measurements Used in Statistical Tests.

The measures used in expressing and testing the null hypotheses of this study will be discussed under their appropriate topic areas (success, convergence, stability, or confidence). Included for each measure will be a general description of the measure; the abbreviated form of the measure; and, where appropriate, a mathematical formulation for the measure. The above discussions will be preceded by a description of the subscript notation used to delimit the measures.

Subscript Natation. Each variable (measure) that is discussed in this section is delimited by the set of subscripts $(0, p, q, r, t, u$, $w, x, y, z)$. Each subscript specifies the variable in more detail. The absence of a subscript indicates that it is not necessary to be spectfied. The presentation of each subscript will follow the following general format:

subscript $=$ brief description of meaning of subscript list of values subscripts may assume = description of value

The subscripts are as follows:

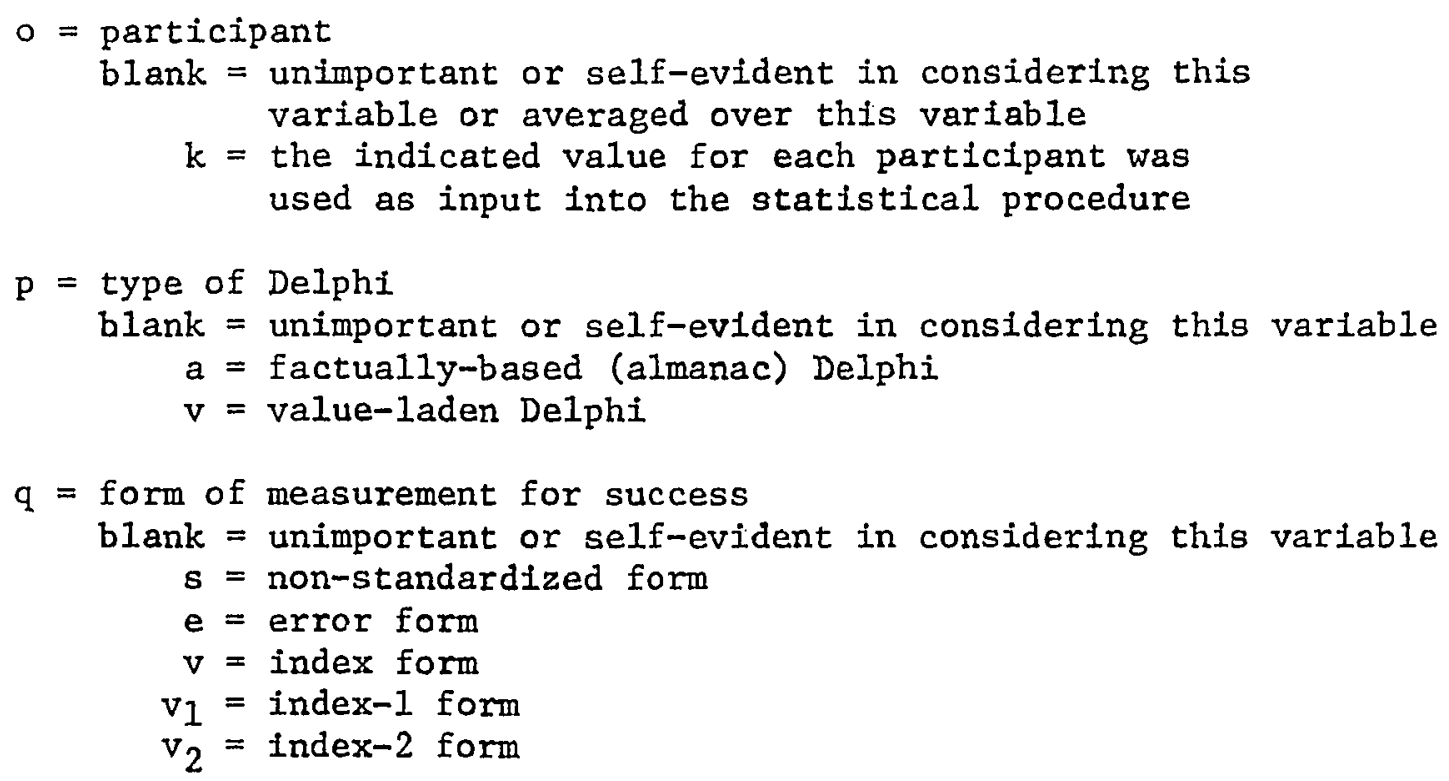


$r=$ manipulated or non-manipulated

blank = unimportant or self-evident in considering this variable

$\mathrm{m}=$ manipulated

$\mathrm{nm}=$ non-manipulated

$\mathrm{b}=$ both of the above

$t=$ measure of convergence

blank = unimportant or self-evident in considering this variable

$q=$ quartile range in error form

$\sigma=$ standard deviation

$\mathrm{d}=$ standardized standard deviation

$\mathrm{v}=$ variance

$\mathrm{u}=$ form of individual response

blank = unimportant or self-evident in considering this variable

$a=$ unaltered form, factually-based

$\mathrm{e}=$ error form, factually-based

$\mathrm{v}=$ unaltered form, value-laden

$w=$ statemer:t

blank = unimportant or self-evident in considering this variable

$i=$ the indicated value for each statement was used as input into the statistical procedure

$\mathrm{x}=$ round

blank = unimportant or self-evident in considering this variable

$j=$ the indicated value for each round was used as input into the statistical procedure

$I=$ round 1

$2=$ round 2

$3=$ round 3

$4=$ round 4

$\mathrm{y}=$ percent successfully manipulated

blank = unimportant in considering this variable

$y=$ percent must be specified individually for complete specification (this represents the individual entries in the "\% SUCCESS" column of Table IV)

$z$ = how a participant self-rates himself during round 1

blank = unimportant in considering this variable

$1=$ self-rates himself 1 during round 1

$2=$ self-rates himself 2 during round 1

$3=$ self-rates himself 3 during round 1

$4=$ self-rates himself 4 during round 1

$5=$ self-rates himself 5 during round 1 
Measurement of Success. The success in achieving a desired answer through statistical manipulation was expressed as the ratio of the distance one desired the participants to move to the distance they actually moved. The general form used for the measurement of success was $\mathrm{S}_{\mathrm{q} w \mathrm{x}}$.

$$
\mathrm{S}_{\mathrm{q} w \mathrm{x}}=\frac{\text { desired change }}{\text { actual change }}
$$

Since the units which were used to express the answers to factually-based (almanac) and value-laden Delphi statements were different, there were several ways $\mathrm{S}_{\mathrm{qwx}}$ was calculated. These will now be developed.

The measure of success $\left(\mathrm{S}_{\mathrm{qwx}}\right.$ ) for factually-based (a1manac) Delphi statements was expressed in two different forms, the nonstandardized form and the error form. The non-standardized form used the actual values resulting from each round. The error form converted the actual values to what Dalkey [21] called their "error" values. He defined the "error" of a question as the natural log of the absolute value of the result of the Delphi answer divided by the true answer. This had the advantages of (1) normalizing the values and (2) ". . if the panelist gave a response which is half of the true answer, he has made an error of the same size as though he gave an answer twice the true answer." [62:33] A third form (the standardized form) was also printed on the computer listings. It standardized each of the values [(value - mean)/ standard deviation] before they were used to calculate the measure of success. As it turned out, the standardized and non-standardized (actual) values were the same (this can be shown algebraically). The standardized form will not be discussed further 
with respect to the measure of success.

With the above in mind, the non-standardized form of $\mathrm{s}_{\mathrm{qwx}}$ was calculated in the following manner:

$$
S_{\text {six }}=\frac{A_{a i x}-A_{a i 1}}{D_{a i}-A_{a i l}}
$$

where

$$
\begin{aligned}
\mathrm{S}_{\mathrm{six}}= & \text { the non-standardized form of the degree of success } \\
& \text { achieved in manipulating almanac (factually-based) } \\
& \text { Delphi statement } i \text { in a particular round; } \\
\mathrm{D}_{\mathrm{ai}}= & \text { the desired median to which almanac Delphi state- } \\
& \text { ment } i \text { was being manipulated; and } \\
\mathrm{A}_{\mathrm{aix}}= & \text { the actual median of almanac Delphi statement } i \\
& \text { in a particular round. }
\end{aligned}
$$

The error form of Sqwx was calculated in the following manner:

$$
\begin{aligned}
& A_{e i x}-A_{e i 1} \\
& S_{e i x}=\overline{D_{e i}-A_{e i 1}} \\
& S_{\text {eix }}=\text { the error form of the degree of success achieved } \\
& \text { in manipulating almanac (factually-based) Delphi } \\
& \text { statement } i \text { in a particular round; } \\
& \mathrm{D}_{\mathrm{ei}}=\text { the error form of the desired median to which } \\
& \text { almanac Delphi statement } i \text { was being manipulated } \\
& D_{e i}=\ln \left|\begin{array}{l}
\text { desired } \\
\frac{\text { median }}{\text { true }} \\
\text { answer }
\end{array}\right| \text { for statement } i ; \text { and } \\
& \begin{aligned}
A_{\text {eix }}= & \text { the error form of the median of almanac Delphi } \\
& \text { statement } i \text { in a particular round }
\end{aligned} \\
& A_{\text {eix }}=\ln \left|\begin{array}{l}
\text { round } x \\
\text { median } \\
\begin{array}{l}
\text { true } \\
\text { answer }
\end{array}
\end{array}\right| \text { for statement } i .
\end{aligned}
$$


The use of errors could not be used to measure the success of manfpulating value-laden Delphi statements because (1) the statistical response was expressed as a frequency distribution rather than a median and quartiles and (2) a true answer does not exist. Therefore, an alternative measure had to be developed to calculate the degree of success of manipulating value-laden Delphi statements.

Since the statistical feedback of value-1aden Delphi statements was expressed as a frequency distribution on a five point scale of importance, the mean of this frequency distribution was used in the success calculations. The index ${ }^{6}$ was calculated in the following manner:

The frequency distribution contained the following five classes of importance:

1 - no importance

2 - low importance

3 - medium importance

4 - high importance

5 - extremely high importance

The index was calculated by summing the frequency of each class times its class value and dividing by the total frequecny.

An example will help illustrate. If a value-laden Delphi statement resulted in the following frequency distribution:

$\begin{array}{llllll}1 & 2 & 3 & 4 & 5 & \text { class of importance }\end{array}$

$\begin{array}{llllll}2 & 5 & 18 & 3 & 2 & \text { frequency, }\end{array}$

the index would be calculated

$((2)(1)+(5)(2)+(18)(3)+(3)(4)+(2)(5)) / 30=2.93$

${ }^{6}$ To alleviate any confusion with means of other distributions, the mean of a frequency distribution for a particular statement will be referred to as the "index" for that statement. 
The use of an index to represent the frequency distribution of a value-laden Delphi statement had the advantage of being a single value that could be directly compared wirn the index of another statement or with the index of a statistically manipulated statement. It did, however, have an important drawback that should be mentioned. A single index could represent many frequency distributions. Thus, throughout this report we will be discussing the success of achieving a mean of a frequency distribution rather than achieving a particular distribution.

The success of manipulating value-laden Delphi statements was calculated in the following manner:

$$
\begin{aligned}
& S_{v i x}=\frac{A_{v i x}-A_{v i l}}{D_{v i}-A_{v i l}} \\
& \mathrm{~S}_{\mathrm{vix}}=\text { the degree of success achieved in manipulating } \\
& \mathrm{D}_{\mathrm{vi}}=\text { the desired index to which the value-laden Delphi } \\
& \text { statement } i \text { was being manipulated; and } \\
& A_{v i x}=\text { the actual index of value-laden Delphi statement } \\
& i \text { in a particular round. }
\end{aligned}
$$


been considered $100 \%$ successful. $S_{v i j}$ was therefore further specified to differentiate between these two interpretations.

$$
\begin{aligned}
& s_{v 1 i x}=\left\{\begin{array}{ll}
s_{v i x} & \text { if } s_{v i x} \leqslant 1.00 \\
1.00-\left(s_{v i x}-1.00\right) & \text { if } s_{v i x}>1.00
\end{array}\right\} \\
& s_{v 2 i x}=\left\{\begin{array}{ll}
s_{v i x} & \text { if } s_{v i x}<1.00 \\
1.00 & \text { if } s_{v i x}>1.00
\end{array}\right\}
\end{aligned}
$$

There are some additional forms of the above measures of success that will also be used in the ensuing discussion. A brief identification of these will now be given.

$$
\begin{aligned}
\mathrm{S}_{\mathrm{qxk}}= & \text { cumulative percent of statements that were } k \\
& \text { percent successfully manipulated as measured } \\
& \text { by } \mathrm{S}_{\mathrm{qwx}} \text { (reference Table IV) } \\
\mathrm{R}_{\text {urwjo }}= & \text { individual response in the appropriate form } \\
& \text { for a statement in round } \mathrm{j} \text { for a participant }
\end{aligned}
$$

$$
\begin{aligned}
& R 4-R I_{\text {urwo }}=R_{\text {urw4 }}-R_{\text {urw } 10} \\
& A D-R I_{\text {urwo }}=D_{\text {UW }}-R_{\text {urwio }}
\end{aligned}
$$

Measurement of Convergence. When one discusses the convergence of a Delphi statement, one normally refers to the change in some measure of dispersion. While convergence of a factually-based (almanac) Delphi statement is usually measured by the shrinking of the difference between the upper and lower quartile (the quartile range), this study also viewed if from the viewpoint of its standard deviation and standardized standard deviation. Convergence of a value-laden Delphi is usually implied as a narrowing of the frequency distribution such that near-normal distribution 
results. The standard deviation, therefore, appeared to be a proper measurement. The general form used for the measurement of convergence was $C_{\text {prtwx }}$. A development of the specific forms for the measurement of convergence used in this study will now be given.

In order to compare quartile ranges with each other, they must be normalized. That is, one cannot effectively compare a quartile range of 5000 for the question "How many women Marines were there in 1945?" with a quartile range of 60 for the question "What was the in-orbit weight in pounds (weighted at sea level) of the Telstar 1 satellite?" They must first be converted to a common base. To alleviate this problem, the values of the quartiles were converted to their "error" form. Thus the measure of the quartile range of factually-based Delphi statements was calculated as follows:

$$
C_{\text {arqix }}=\left|U Q_{\text {rix }}-L_{\text {rix }}\right|
$$

where

$$
\begin{aligned}
\mathrm{C}_{\text {arqix }}= & \text { a quartile range measure of the convergence for almanac } \\
& \text { (factually-based) Delphi statement } i \text { for a particular } \\
& \text { round; }
\end{aligned}
$$

The second form used to measure the convergence of a factuallybased (almanac) Delphi statement can be expressed as: 

$\mathrm{C}_{\text {ar } \sigma i x}=$ standard deviation $(\sigma)$ of the participants' answers in a particular round of almanac (factually-based) Delphi statement $i$.

Again, since standard deviations cannot be directly compared

(for the same reasons the quartiles cannot be compared), a standardized form of the standard deviations was developed. It was calculated in the following manner:

$$
\begin{aligned}
& c_{\text {ardix }}=\frac{c_{\text {aroix }}-\bar{x}_{\text {arix }}}{c_{a r \sigma i x}} \\
& \mathrm{C}_{\text {ardix }}=\mathrm{a} \text { standardized standard deviation measure of the } \\
& \mathrm{C}_{\mathrm{ar} \sigma \mathrm{ix}}=\text { same as defined earlier; } \\
& \overline{\mathrm{X}}_{\text {arix }}=\text { mean of the participants' answers of almanac (factually- }
\end{aligned}
$$

Measurement of Stability. Scheibe, Skutsch, and Schofer [85] measured stability by the following algorithm:

(1) take the absolute differences between the frequency distributions of a question for two consecutive rounds,

(2) sum these absolute differences,

(3) divide by two (since any one participant's change of opinion is reflected in the histogram by two units of change), and 
(4) divide by the number of participants.

The result was the percent change in the frequency distribution. They empirically decided a percent change of less than $15 \%$ represented a stable condition.

One immediately runs into a problem when one tries to use this algorithm to measure stability for factually-based Delphi statements (i.e., a frequency distribution does not exist). The concept of stability, however, still can be used by merely measuring the percent change in the individual responses from round to round rather than the percent change in the frequency distribution. Therefore, in this study, a factually-based Delphi statement was considered stable when $20 \%$ or less of the participants changed their responses (or, if you prefer, when $80 \%$ or more participants did not change their responses).

In order to maintain a level of consistency between measuring stability for value-laden and factually-based Delphi statements, the same procedure was used to measure stability for value-1aden Delphi statements. This allowed direct comparison between the two types of statements.

The percent movement used here was 20 percent instead of the 15 percent as suggested by Scheibe, Skutsch, and Schofer. Their method merely subtracted the frequency distributions of one round from another round and did not allow for a double shift. A double shift can occur two different ways. The first way is if participant A changes his response from 1 to 2 and participant B changes his response from 2 to 3 . This would result in a change in the frequencies for 1 and 3 and thus only be counted as one change (from 1 to 3 ). The other way a double shift could occur is if participant A changes his response from 1 to 2 
and participant $B$ changes his responses from 2 to 1 . There would be no change in stability recorded. Since looking at each individual participant's movement would avoid these problems (would count them as two changes), it is reasonable to assume a larger value than what Scheibe, Skutsch, and Schofer recommend.

In particular, the following measures will be used in the ensuing discussion:

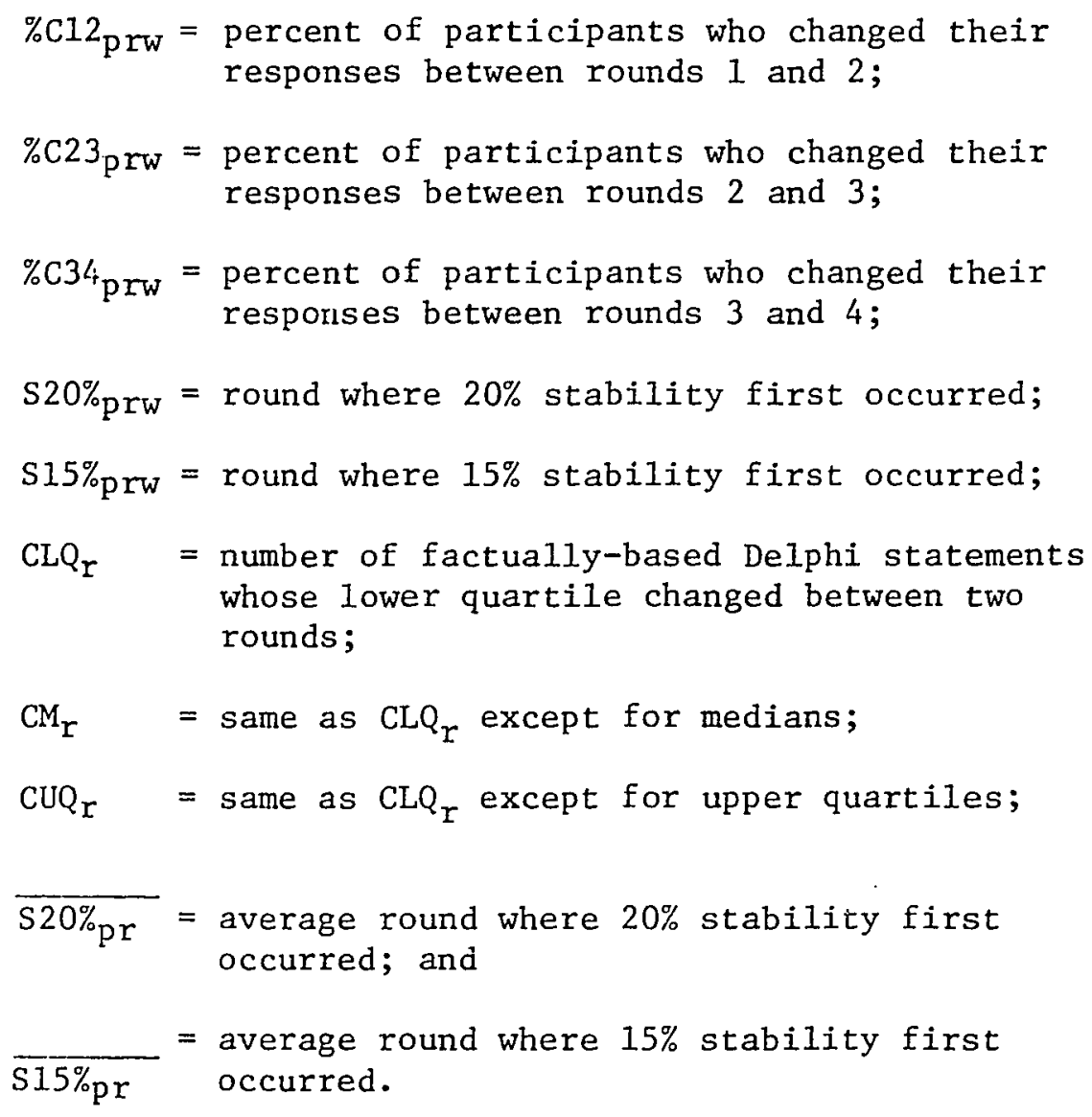

Measurement of Confidence. The effects statistical manipulation had upon the confidence of Delphi participants was measured by the use of self-rating. Before the procedure is discussed, it will be useful to review the self-rating scales used. 
Self-rating scale 1 (used during rounds 1 and 4):

Self-rating Explanation

1

Possess little or no knowledge on the subject, answer would basically be a guess.

2

Possess a limited amount of knowledge on the subject, answer would basically be an educated guess.

3.

Possess enough knowledge to make a reasonable estimate of the answer.

4

Know some pertinent details about the subject or have more than an average amount of experience in the subject that would make my estimate better than most people.

5 Considerable knowledge, either know the answer or have available knowledge that directly pertains to the statement and can make a reasonable close estimate of the actual true value.

Self-rating scale 2 (used during rounds 2 and 3):

I

If You

Changed Your Answer

A. I had misread the question.

B. I made a mistake in computation.

C. I remembered some additional facts.

D. My estimate was too far from the group median.

E. The other members of the group are likely to know more about the question than I do.
II

If You Did Not

Change Your Answer

F. I believe my original estimate.

G. The other members of the group are not likely to know more about the question than I do.

H. No good reason to change.

I. My estimate was close to the group median.

J. It would be more effort than it's worth to rethink the answer. $[8: 36]$ 
All participants were requested to use self-rating scale 1 to rate their expertise on each question during round 1 and round 4 . By comparing the self-rating for rounds 1 and 4 , it was possible to determine if there was a change in how a participant rated his expertise.

The participants also were requested to use self-rating scale 2 during rounds 2 and 3 . How participants responded to scale 2 gave insights into the reasons why the participants changed their responses and how they rationalized rerating their expertise.

The primary units of measure were the round 1 , round 4 difference in a participant's self-rating and the round 1 , round 4 difference in his answer. As before, a participant's round $I$ answer and round 4 answer were, for comparison reasons, represented by their error values (i.e., the natural log of the absolute value of the results of the answer divided by the true answer). The following abbreviations will be useful:

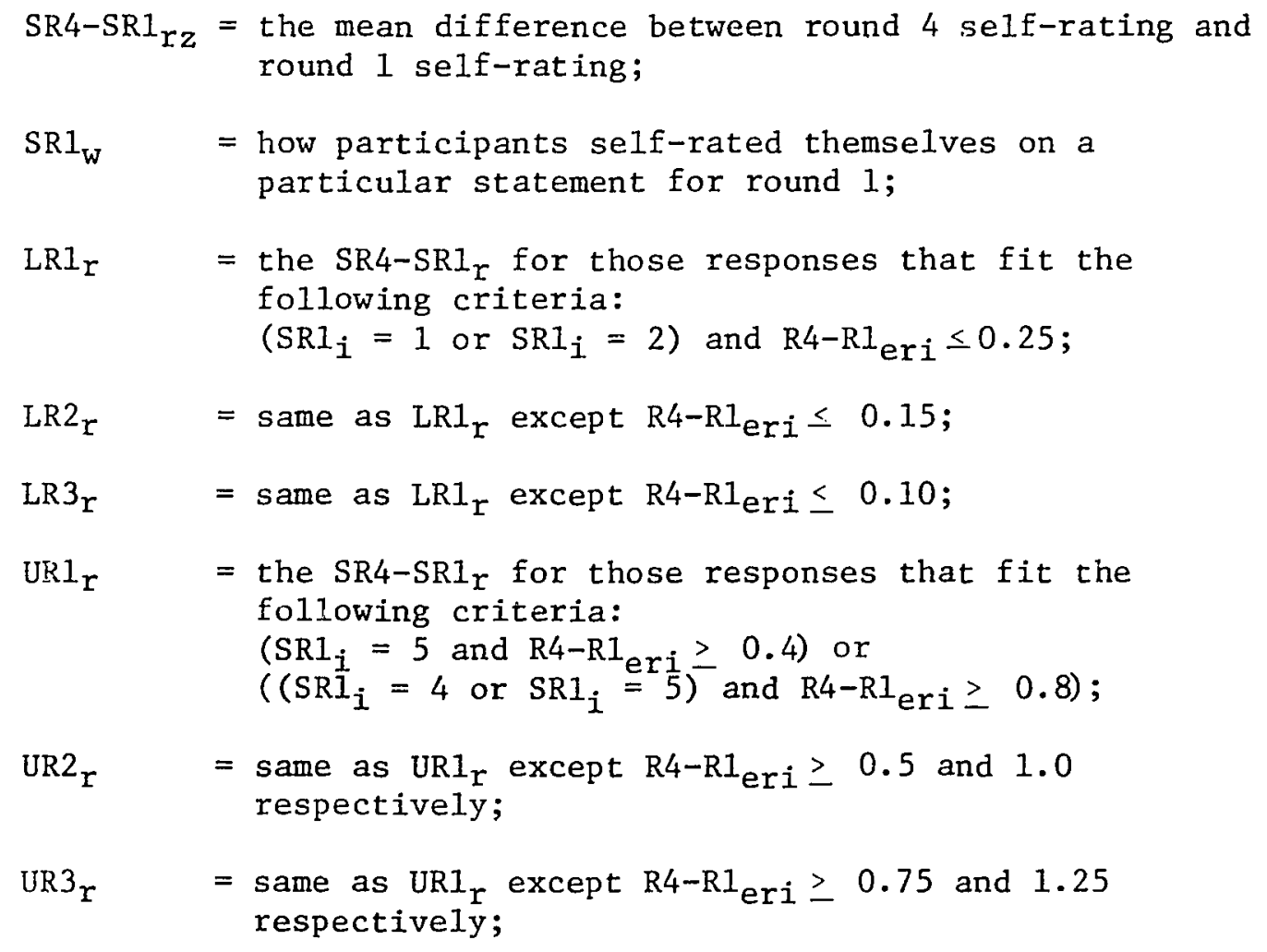



$N L R 1_{r} \quad=$ the $S R 4-S R I_{r}$ for those responses that do not meet the LRIr criteria;
NUR2 $r=$ the $S R 4-S R 1_{r}$ for those responses that do not meet the UR2 $r$ criteria; and

$\overline{\mathrm{R} 4-\mathrm{R} 1_{\mathrm{qrz}}}=$ the mean of the $\mathrm{R} 4-\mathrm{R} 1_{\text {eriz }}$ averaged over $\mathrm{i}$

\section{Statistical Methodology.}

This section will present the statistical hypotheses used to test the research hypotheses specified in Chapter I. A more complete discussion of why these statistical hypotheses were chosen and of what they are trying to prove will be given in Chapter IV when the results and the interpretation of the tests are given. The procedure will be to present the following for each of the major topic areas of this research (success, convergence, stability, and confidence): 1) a general narrative discription of the null hypotheses (this will give the reader a conceptual idea of what the null hypotheses are about), 2) the null hypotheses using the abbreviations described in the previous section (this will explicitly define the variables used to assure there is no confusion as to which variables were used), 3) the testing statistic to be used, and 4) the decision criteria used to reject or to indicate non-rejection of the statistical hypothesis.

Statistical Design for Success. The first topic area to be considered is the success of statistical manipulation. That is, can one successfully manipulate a Delphi statement through falsified statistical feedback? Success here means more than just changing the responses in some direction. It means how successful one can be in achieving a desired median (or index) for a factually-based (value-laden) Delphi statement. 
The research hypotheses stated earlier for success are as follows:

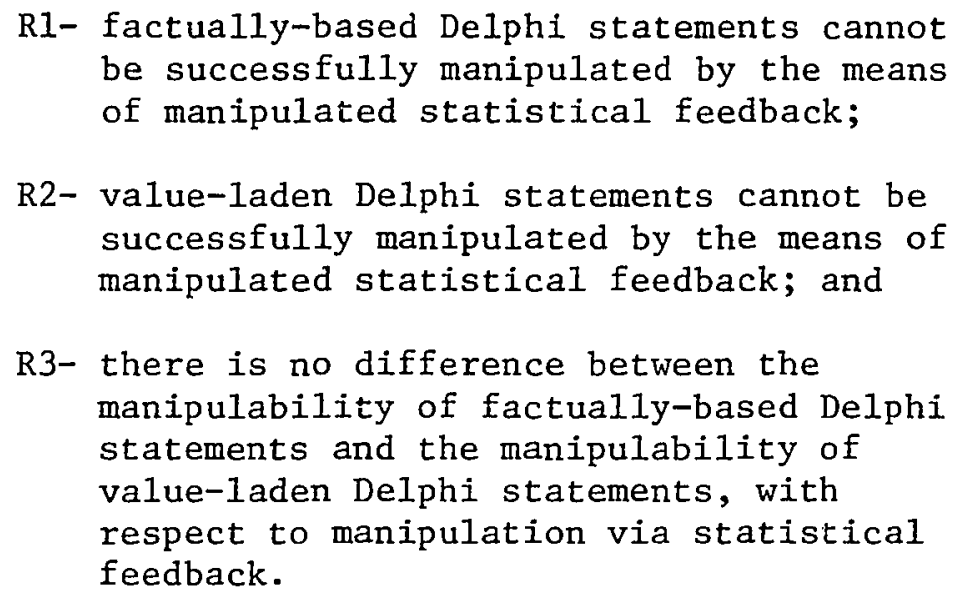

The null hypotheses that were used to address these research hypotheses will now be presented. 
Narrative HI: The percentage of statements whose success increased by more than $3 \%$ in a successive round is greater than $30 \%$ (1.e. success is enhanced by additional rounds).

Hypothesis $\mathrm{H} 1$ : (In general) $\frac{x}{n}=30 \%$

where $\mathrm{n}$ is the number of statements (30) and $\mathrm{x}$ is defined as

Hla: number of $\mathrm{S}_{\mathrm{ei} 3}-\mathrm{S}_{\mathrm{ei} 2}>.03$ for $\mathrm{i}=1$ to $\mathrm{n}$, H1b: number of $\mathrm{S}_{\mathrm{ei4}}-\mathrm{S}_{\mathrm{ei}}>.03$ for $i=1$ to $\mathrm{n}$, H1c: number of $\mathrm{S}_{\mathrm{vli}}-\mathrm{S}_{\mathrm{v} 1 i 2}>.03$ for $i=1$ to $\mathrm{n}$, and

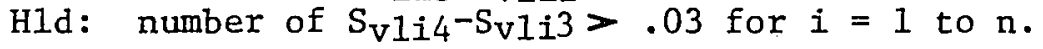

Testing Statistics: Z-statistic from $z$-test to compare two population proportions, $z=\left(\mathrm{P}_{1}-\mathrm{P}_{2}\right) / \sigma_{\Delta \mathrm{p}}$.

Decision Criterion: Reject if significant at $\alpha=0.05$, one-tail test. 
Narrative H2: The round 4 measure of success (positively or negatively) correlates with the actual change in the participants' response (i.e., there is a correlation between the success of statistical manipulation and the amount the participants changed their answers).

Hypothesis $\mathrm{H} 2 \mathrm{a}$ : The correlation between $\mathrm{S}_{\text {ai4 }}$ and $\mathrm{R} 4-\mathrm{R} \mathrm{I}_{\mathrm{ami}}=|0.9|$. $\mathrm{H} 2 \mathrm{~b}$ : The correlation between $\mathrm{S}_{\mathrm{ei} 4}$ and $\mathrm{R} 4-\mathrm{R} 1_{\mathrm{emi}}=0.9$. $\mathrm{H} 2 c$ : The correlation between $\mathrm{S}_{\mathrm{VIi}}$ and $\mathrm{R} 4-\mathrm{R} \mathrm{I}_{\mathrm{Vmi}}=|0.9|$.

Testing Statistic: F-statistic from correlation analysis.

Decision Criterion: Reject if Pearson's coefficient $\leqslant|0.90|$, onetail test. 
Narrative H3: The round 4 measure of success (positively or negatively) correlates with the desired change in the participants' responses (i.e., there is a correlation between the success of statistical manipulation and the amount the administrator wishes to change the results).

Hypothesis H3a: The correlation between $\mathrm{S}_{\text {ai4 }}$ and $\mathrm{AD}-\mathrm{R} \mathrm{I}_{\text {ami }}=|0.9|$ $\mathrm{H} 3 \mathrm{~b}:$ The correlation between $\mathrm{S}_{\mathrm{ei}} 4$ and $\mathrm{AD}-\mathrm{R} \mathrm{I}_{\mathrm{emi}}=0.9$. $\mathrm{H} 3 \mathrm{c}$ : The correlation between $\mathrm{S}_{\mathrm{v} 1 \mathrm{i} 4}$ and $\mathrm{AD}-\mathrm{R} \mathrm{I}_{\mathrm{Vmi}}=|0.9|$.

Testing Statistic: F-statistic from correlation analysis.

Decision Criterion: Reject if Pearson's coefficient $\leqslant|0.90|$, onetail test. 
Narrative H4: The actual change of a statement when it is manipulated is equal to the actual change of that statement when it is not manipulated (i.e., the median (index) of a statement when it is statistically manipulated will not move to a significantly different place than if it were not manipulated).

Hypothesis $\mathrm{H} 4 \mathrm{a}: \mathrm{R} 4-\mathrm{R} 1_{\text {emik }}=\mathrm{R} 4-\mathrm{R} 1_{\text {enmik }}$

$\mathrm{H} 4 \mathrm{~b}$ : $\quad \mathrm{R} 4-\mathrm{R} 1_{\text {vmik }}=\mathrm{R} 4-\mathrm{R} 1_{\text {vnmik }}$

Testing Statistic: F-statistic from analysis of variance.

Decision Criterion: Reject if significant for $\alpha=0.05$, two-tail test. 
Narrative H5: The desired change of a statement that is manipulated is equal to the actual change of that statement when it is not manipulated (i.e., the desired change in the median (index) is not significantly different than the actual change of the non-manipulated statement).

Hypothesis $\mathrm{H} 5 \mathrm{a}$ : $\mathrm{AD}-\mathrm{R} 1_{\mathrm{emik}}=\mathrm{R} 4-\mathrm{R} 1_{\text {enmik }}$

$\mathrm{H} 5 \mathrm{~b}: \quad \mathrm{AD}-\mathrm{R} I_{\text {vmik }}=\mathrm{R} 4-\mathrm{R} 1_{\text {vnmik }}$

Testing Statistic: F-statistic from analysis of variance.

Decision Criterion: Reject if significant for $\alpha=0.05$, two-tail test. 
Narrative H6: The cumulative percent success of factually-based Delphi statements is equal to the cumulative percent success of value-laden Delphi statements (i.e., factually-based Delphi statements are either easier or harder to manipulate than value-laden Delphi statements).

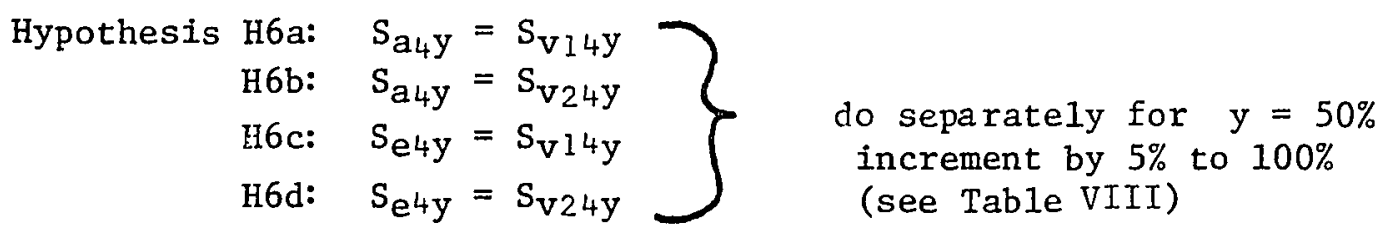

Testing Statistic: Z-statistic from $z$-test to compare two population proportions, $Z=\left(P_{1}-P_{2}\right) / \sigma_{\Delta p}$ (see Table VIII).

Decision Criterion: Reject $\mathrm{H} 6$ if fifty percent of the tests performed by $\mathrm{H} 6 \mathrm{a}$ through $\mathrm{H} 6 \mathrm{~d}$ are significant at $\alpha=0.1$, two-tail test. 
Statistical Design for Convergence. While the previous section dealt with the success of achieving a particular point (1.e., measured the success of manipulating the median or index), this section will be concerned with the effects statistical manipulation has upon the convergence (i.e., the dispersion) of the responses. Again consideration must be given to the two types of Delphis recognized in this study, factually-based and value-laden Delphis.

The research hypotheses stated earlier for convergence are as follows :

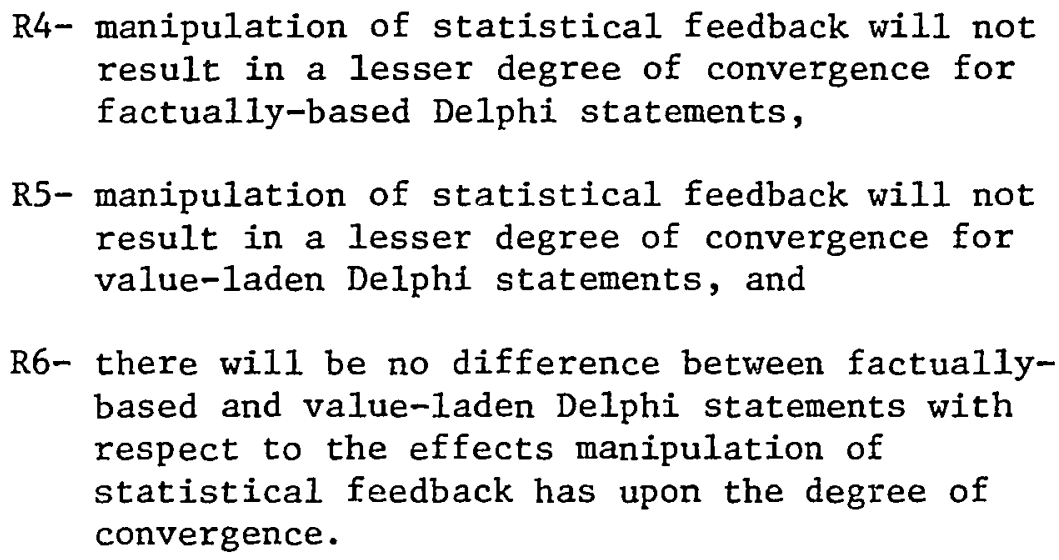
result in a lesser degree of convergence for factually-based Delphi statements,

R5- manipulation of statistical feedback will not result in a lesser degree of convergence for value-laden Delphi statements, and

R6- there will be no difference between factuallybased and value-laden Delphi statements with respect to the effects manipulation of statistical feedback has upon the degree of convergence.

The null hypotheses that were used to address these research hypotheses will now be discussed. 
Narrative H7: The following null hypotheses investigate whether manipulation of statistical feedback will affect the convergence of Delphi statements.

$\left.\begin{array}{rl}\text { Hypothesis H7a: } & C_{\text {amdix }}=C_{\text {anmdix }} \\ \text { H7b: } & C_{\text {amqix }}=C_{\text {anmqix }} \\ \text { H7c: } & C_{\text {vm } \text { ix }}=C_{\text {vnmoix }} \\ \text { H7d: } & C_{\text {amvwx }}=C_{\text {anmvwx }}\end{array}\right\} \begin{aligned} & \text { do separately for } x=1,2,3, \\ & \text { and } 4 \text { (do H6d separately for } \\ & \text { each statement (i.e., } W=1,2, \\ & \ldots, \ldots, 30)\end{aligned}$

Testing Statistic: F-statistic from analysis of variance and t-statistic from t-test for H7a through H7c. In this case, these two tests produce the same results. Therefore, one needs only to run one of them. Both have been included in this study to satisfy those who prefer to use one test over the other. This redundancy is used throughout this study. $F_{\max }$ test is run for each statement for $\mathrm{H} 7 \mathrm{~d}$.

Decision Criterion: For H7a through $\mathrm{H} 7 \mathrm{c}$, round 1 should not be significant at $\alpha=0.1$; while rounds 2,3 , and 4 should be significant at $\alpha=0.1$, two-tail test. For H7d, reject the hypothesis for individual items if significant at $\alpha=0.1$, two-tail test. If the variances of statistically manipulated statements were significantly greater (or less), one would expect a significant number $(90 \%)$ of the individual $\mathrm{F}_{\max }$ tests to indicate this. 
Statistical Design for Stability. Scheibe, Skutsch, and Schofer [65] suggest that stability is a better means of measuring consensus than convergence. It is felt that both parameters are important in considering the effects of manipulation of Delphi statements. The previous section dealt with the effects statistical manipulation has on convergence. This section will deal with the effects statistical manipulation has on stability. In particular, the question being asked is will statistical manipulation reduce the stability of Delphi statements and therefore increase the number of rounds necessary to achieve stability.

The research hypotheses stated earlier for success are as

\section{follows:}

$$
\begin{aligned}
& \text { R7- manipulation of statistical feedback will not } \\
& \text { reduce the stability (and therefore not } \\
& \text { require an extra round(s)) in factually-based } \\
& \text { Delphi statements, } \\
& \text { R8- manipulation of statistical feedback will not } \\
& \text { reduce the stability (and therefore not } \\
& \text { require an extra round(s)) in value-laden } \\
& \text { Delphi statements, and } \\
& \text { R9- there will be no difference between fact- } \\
& \text { ually-based and value-laden Delphi state- } \\
& \text { ments with respect to the effect manipu- } \\
& \text { lation of statistical feedback has upon } \\
& \text { stability (and therefore the number of } \\
& \text { rounds necessary to obtain stability). }
\end{aligned}
$$

The null hypotheses that were used to address these research hypotheses will now be presented. 
Narrative H8: The percentage of manipulated factually-based (valueladen) Delphi statements that change between two consecutive rounds is equal to the percentage of non-manipulated factually-based (value-laden) Delphi statements that change between the same two consecutive rounds. (i.e. There is no difference between manipulated and non-manipulated factually-based (value-laden) Delphi statements with respect to the percent change between rounds.)

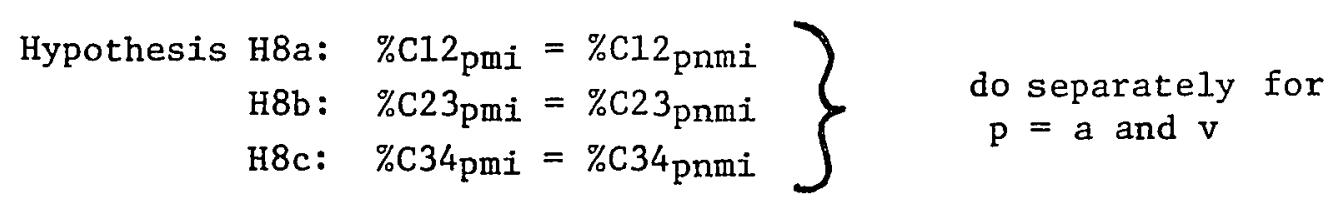

Testing Statistic: F-statistic from analysis of variance and $t-$ statistic from t-test.

Decision Criterion: Reject if significant at $\alpha=0.1$, two-tail test. 
Narrative $\mathrm{H} 9$ : The round where $20 \%$ (15\%) stability is first achieved in manipulated factually-based (value-laden) Delphi statements is equal to the round where $20 \%(15 \%)$ stability is first achieved in non-manipulated factually-based Delphi (value-laden) statements (i.e., there is no difference between manipulated and non-manipulated factually-based (value-laden) Delphi statements with respect to the round where stability is first achieved).

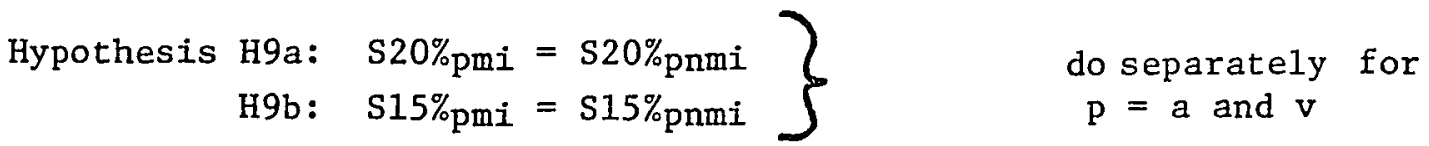

Testing Hypothesis: F-statistic from analysis of variance and $t-$ statistic from t-test.

Decision Criterion: Reject if significant at $\alpha=0.1$, two-tail test. 
Narrative H10: The average number of rounds necessary to reach $20 \%$ (15\%) stability for factually-based Delphi statements is equal to the average number of rounds necessary to reach $20 \%$ (15\%) stability for value-laden Delphi statements (i.e., there is no difference between factually-based and value-laden Delphi statements with respect to the average number of rounds necessary to obtain stability).

Narrative H11: The average number of rounds necessary to reach $20 \%$ (15\%) stability for manipulated Delphi statements is equal to the average number of rounds necessary to reach $20 \%$ (15\%) stability for non-manipulated Delphi statements (i.e., manipulation of statistical feedback has no effect on the average number of rounds necessary to obtain stability).

$$
\begin{array}{r}
\text { Hypothesis H10a: } \overline{\mathrm{S} 20 \% \mathrm{am}}=\overline{\mathrm{S} 20 \% \mathrm{vm}} \\
\text { H10b: } \overline{\mathrm{S} 20 \% \mathrm{anm}}=\overline{\mathrm{S} 20 \% \mathrm{vnm}} \\
\text { H10c: } \overline{\mathrm{S} 15 \% \mathrm{am}}=\overline{\mathrm{S} 15 \% \mathrm{vm}} \\
\text { Hypothesis H1la: } \overline{\mathrm{S} 15 \% \mathrm{anm}}=\overline{\mathrm{S} 15 \% \mathrm{vnm}} \\
\text { H11b: } \overline{\mathrm{S} 20 \% \mathrm{am}}=\overline{\mathrm{S} 20 \% \mathrm{anm}} \\
\text { H11c: } \overline{\mathrm{S} 15 \% \mathrm{am}}=\overline{\mathrm{S} 15 \% \mathrm{anm}} \\
\text { H11d: } \overline{\mathrm{S} 15 \% \mathrm{vm}}=\overline{\mathrm{S} 15 \% \mathrm{vnm}}
\end{array}
$$

Testing Statistic: F-statistic of $2 \times 2$ analysis of variance run on the following sets of values:

\begin{tabular}{l|c|c||c|c|}
\multirow{2}{*}{ Factually-based } & \multicolumn{2}{|c|}{$20 \%$ Stability } & \multicolumn{2}{c|}{$15 \%$ Stability } \\
\cline { 2 - 5 } & non-manip. & manip. & non-manip. & manip. \\
\cline { 2 - 5 } & $\overline{\mathrm{S} 20 \%}$ & $\overline{\mathrm{S} 20 \%}$ & $\overline{\mathrm{S} 15 \%}$ & $\overline{\mathrm{S} 15 \%}$ \\
\hline Value-1aden & $\overline{\mathrm{S} 20 \%}$ & $\overline{\mathrm{S} 20 \%}$ & $\overline{\mathrm{S} 15 \%}$ & $\overline{\mathrm{S} 15 \%}$ \\
\hline
\end{tabular}

t-statistics from t-test to test two means on each of the above pairs (see Table XVIII). It is assumed the sample size is large enough to counter the problem that the distribution may be skewed to the right.

Decision Criterion: Reject if significant at $\alpha=0.05$ two-tail test. 
Narrative H12: The average number of rounds necessary to reach $20 \%$ (15\%) stability for non-manipulated factually-based Delphi statements is equal to the average number of rounds necessary to reach $20 \%(15 \%)$ stability for manipulated value-laden Delphi statements.

Narrative H13: The average number of rounds necessary to reach $20 \%$ (15\%) stability for manipulated factually-based Delphi statements is equal to the average number of rounds necessary to reach $20 \%$ (15\%) stability for non-manipulated value-laden Delphi statements. (Where HIO and H1l compared stability of factually-based verses value-laden and stability of manipulated verses non-manipulated, $\mathrm{H} 12$ and $\mathrm{H} 13$ try to rank the stability of manipulated factually-based, non-manipulated factually-based, manipulated value-laden, and non-manipulated valueladen Delphi statements.)

$$
\begin{aligned}
\text { Hypothesis } \mathrm{H} 12 \mathrm{a}: & \overline{\mathrm{S} 20 \% \mathrm{anm}}=\overline{\mathrm{S} 20 \% \mathrm{vm}} \\
\text { HH12b: } & \overline{\mathrm{S} 15 \% \mathrm{anm}}=\overline{\mathrm{S} 15 \% \mathrm{vm}} \\
\text { Hypothesis } \mathrm{H} 13 \mathrm{a}: \overline{\mathrm{S} 20 \% \mathrm{am}} & =\overline{\mathrm{S} 20 \% \mathrm{vnm}} \\
\mathrm{H} 13 \mathrm{~b}: & \overline{\mathrm{S} 15 \% \mathrm{am}}=\overline{\mathrm{S} 15 \% \mathrm{vnm}}
\end{aligned}
$$

Testing Statistic: t-statistic from t-test to test two means (see Table XVIII). It is assumed the sample size is large enough to counter the problem that the distribution may be skewed to the right.

Decision Criterion: Reject if significant at $\alpha=0.05$, two-tail test. 
Statistical Design for Confidence. It was suggested in Chapter

II that manipulation of statistical feedback may affect the confidence that Delphi participants have in their responses. It was also suggested that changes in self-rating could be used as a measure of changes in confidence. This was expressed in Chapter $I$ as the following research hypothesis:

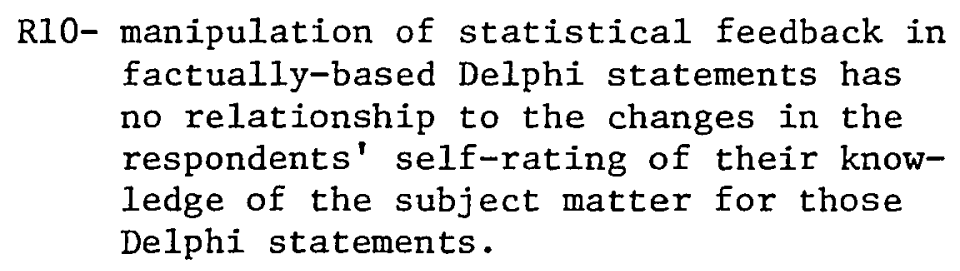

The null hypotheses that were used to investigate this research hypothesis will now be presented. 
Narrative H14: The following null hypotheses deal with the question of whether the participants' confidence in their ability (as measured by self-rating) to respond to a Delphi statement increases as a result of the Delphi process. This is measured both in terms of the change in self-rating being different from zero and from the mean of all the non-manipulated Delphi statements.

Hypothesis HI4a: $\mathrm{SR}_{4-S R I_{\mathrm{b}}}=0$

H14b: $S R 4-S R 1_{m}=0$

$\mathrm{H} 14 \mathrm{c}: \quad \mathrm{SR} 4-\mathrm{SR} 1_{\mathrm{nm}}=0$

H14d: $S R 4-S R 1_{m}=0.47$ (value of $S R 4-S R 1_{n m}$ )

H14e: $\mathrm{SR} 4-\mathrm{SR} 1_{\mathrm{m}}=\mathrm{SR} 4-\mathrm{SR} 1_{\mathrm{nm}}$

Testing Statistic: t-statistic from single-mean t-test for $\mathrm{H} 14 \mathrm{a}$ through H14d. t-statistic from t-test to test two means for H14e.

Decision Criterion: Reject if significant at $\alpha=0.5$, one-tail test. 
Narrative H15: The following set of null hypotheses investigate whether there is a tendency for Delphi participants to shift their self-rating toward the widdle after having participated in several rounds and whether there is a tendency for participants to shift their self-rating less at the lower end of the self-rating scale and more at the higher end of the scale on statements that have been statistically manipulated than on statements that have not been statistically manipulated.

$$
\begin{aligned}
& \text { Hypothesis H15a: } S R 4-S R 1_{m z}=0 \text { do separately for each } z
\end{aligned}
$$

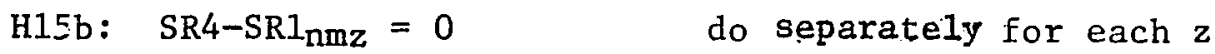

$$
\begin{aligned}
& \text { H15c: } S R 4-S R I_{m z}=0.47 \text { do separately for each } z \\
& \left(0.47 \text { is value of } S R 4-S R 1_{\mathrm{nm}}\right) \text {. } \\
& \text { H15d: } S R 4-S R I_{n m z}=0.47 \text { do separately for each } z \\
& \text { H15e: } S R 4-S R 1_{m z}=S R 4-S R I_{n m z} \text { do separately for each } z \\
& \mathrm{H} 15 \mathrm{f}: \mathrm{SR} 4-\mathrm{SR} 1_{\mathrm{b} 1}=\mathrm{SR} 4-\mathrm{SR} 1_{\mathrm{b} 2}=\mathrm{SR} 4-\mathrm{SR} I_{\mathrm{b} 3}=\mathrm{SR} 4-\mathrm{SR} I_{\mathrm{b} 4}= \\
& \mathrm{SR} 4-\mathrm{SR} 1_{\mathrm{b} 5} \\
& \mathrm{H} 15 \mathrm{~g}: \mathrm{SR} 4-\mathrm{SR} 1_{\mathrm{m}}=\mathrm{SR} 4-\mathrm{SR} 1_{\mathrm{nm}}
\end{aligned}
$$

Testing Statistic: t-statistic from single-mean t-test for H15a through H15d. t-statistic from t-test to test two means for H15e. F-statistic from two-way analysis of variance for H15f and H15g.

Decision Criterion: Reject if significant at $\alpha=0.05$, two-tail test. 
Narrative H16: The following null hypotheses examine whether those participants who originally self-rated themselves low but whose answers were closely supported by the reported median will have a propensity to increase their self-ratings more than those whose answers were not closeiy supported by the median and whether those participants who originally self-rated themselves high but whose answers were distant from the reported median will have a propensity to decrease their self-rating more than those whose answers were not as distant from the median.

$$
\begin{aligned}
& \text { Hypothesis H16aa: } L R 1_{r}=0 \\
& \text { H16ab: LR2 } r=0 \\
& \text { H16ac: LR3r }=0 \\
& \text { H16ad: UR1 } \mathbf{r}=0 \\
& \text { H16ae: UR2 } r=0 \\
& \text { H16af: UR3 } r=0 \\
& \text { H16ag: } N L R I_{r}=0 \\
& \text { H16ah: NUR2 } r=0 \\
& \text { H16ba: } \text { LR1 }_{r}=0.47 \\
& \text { H16bb: LR2 } 2_{r}=0.47 \\
& \text { H16bc: } L R 3_{r}=0.47 \\
& \text { H16bd: UR1r }=0.47 \\
& \text { H16be: UR2 } 2_{r}=0.47 \\
& \text { H16bf: UR3 } r=0.47 \\
& \text { H16bg: } N L R 1_{r}=0.47 \\
& \text { H16bh: NUR2r }=0.47 \\
& \text { H16ca: } L R 1_{m}=L R 1_{\mathrm{nm}} \\
& \mathrm{H} 16 \mathrm{cb}: \mathrm{LR} 2 \mathrm{~m}=\mathrm{LR} 2 \mathrm{~nm} \\
& \mathrm{H} 16 \mathrm{cc}: \mathrm{LR}_{3}=\mathrm{LR}_{\mathrm{m}} \mathrm{nm} \\
& \mathrm{H} 16 \mathrm{~cd}: U R I_{\mathrm{m}}=U R I_{\mathrm{nm}} \\
& \text { H16ce: UR } 2_{m}=U R 2 n m \\
& \mathrm{H} 16 \mathrm{cf}: \mathrm{UR} 3_{\mathrm{m}}=\mathrm{UR} 3_{\mathrm{nm}} \\
& \mathrm{H} 16 \mathrm{cg}: \mathrm{NLR} 1_{\mathrm{m}}=\mathrm{NLR}_{\mathrm{nm}} \\
& \mathrm{H} 16 \mathrm{ch}: \mathrm{NUR} 2 \mathrm{~m}=\mathrm{NUR} 2 \mathrm{~nm} \\
& \text { H16da: } L R 1_{m}=\mathrm{NLR}_{\mathrm{m}} \\
& \mathrm{H} 16 \mathrm{db}: L R l_{\mathrm{nm}}=\mathrm{NLR}_{\mathrm{nm}} \\
& \text { HI6dc: } U R 2 m=N U R 2 m \\
& \mathrm{H} 16 \mathrm{dd}: \mathrm{UR} \mathrm{nm}=\mathrm{NUR} 2_{\mathrm{nm}}
\end{aligned}
$$


Testing Statistic: t-statistic from single-mean t-test from H16aa through Hl6bh. t-statistic from t-test to test two means for Hl6ca through Hl6dd.

Decision Criterion: Reject if significant at $\alpha=0.05$, one-tail test. Since there are a large number of tests here and an $\alpha=0.05$ is being used, one would expect $5 \%$ of the tests to fail. 
Narrative H17: The following null hypotheses investigate whether the average shift in responses between round 1 and round 4 for those participants in each of the self-rating classifications will decrease as the self-rating classification increases and whether the average shift in responses between round 1 and round 4 in each of the selfrating classifications for participants manipulated via statistical feedback will be greater than those for non-manipulated participants.

Hypothesis H17a: $\mathrm{R} 4-\mathrm{R} 1_{\mathrm{ebl}}=\mathrm{R} 4-\mathrm{R} 1_{\mathrm{eb}_{2}}=\mathrm{R} 4-\mathrm{R} 1_{\mathrm{eb}_{3}}=\mathrm{R} 4-\mathrm{R} 1_{\mathrm{eb}}=\mathrm{R} 4-\mathrm{R} 1_{\mathrm{eb}}$

$\mathrm{H} 17 \mathrm{~b}: \mathrm{R} 4-\mathrm{R} I_{\text {em }}=\mathrm{R} 4-\mathrm{R} I_{\text {enm }}$

$\mathrm{H} 17 \mathrm{c}: \mathrm{R} 4-\mathrm{R} 1_{\mathrm{emz}}=\mathrm{R} 4-\mathrm{R} 1_{\mathrm{enmz}}$ do separately for each $z$.

Testing Statistic: F-statistic from two-way analysis of variance for $\mathrm{H} 17 \mathrm{a}$ and $\mathrm{H} 17 \mathrm{~b}$. $t$-statistic from $t$-test to test two means for $\mathrm{HI7c}$.

Decision Criterion: Reject if significant at $\alpha=0.5$, one-tail test. 
SUMMARY

This chapter has presented the experimental design and methodology for this research. It began with a discussion of the characteristics of the participants and the subject matter of the Delphis to be used in this study. A review of the general procedures for administering the Delphis was then given. This was followed with a discussion of the design considerations that were used to reduce the within and between variances of the independent variables. This in turn was followed by a detailed discussion of the measurements used in the statistical tests and the statistical methodology (which included the null hypotheses tested).

The next chapter will discuss the results of the experiment. 


\section{CHAPTER IV}

\section{RESULTS}

The purpose of this research was to investigate empirically the success of statistical manipulation of factually-based and value-laden Delphi statements in achieving a desired point and to explore the effects such manipulation had upon the convergence and the stability of the responses to Delphi statements and the confidence of Delphi participants. The presentation of the results of the experiments and their analysis will follow the order of the major topic areas presented in the purpose and the research hypotheses stated in Chapter I (success, convergence, stability, and confidence). Each of these sections will contain a brief restatement of the research hypotheses, a discusston of the factually-based Delphi results, a discussion of the valueladen Delphi results, and a comparison of the two types of Delphis. A brief synopsis of the results will be given in flowchart form at the end of the chapter.

\section{SUCCESS AND STATISTICAL MANIPULATION}

The major purpose of this study was to investigate the success of statistical manipulation of Delphi statements in achieving a particular desired value. It was hypothesized that the success may be different depending on whether the Delphi was factually-based or value-laden. This was expressed in Chapter $I$ as the following three research hypotheses: 
RI - factually-based Delphi statements can not be successfully manipulated by the means of manipulated statistical feedback,

R2 - value-iaden Delphi statements can not be successfully manipulated by the means of manipulated statistical feedback, and

R3 - there is no difference between the manipulability of factually-based Delphi statements and the manipulab11ity of value-laden Delphi statements, with respect to manipulation via statistical feedback.

Factually-based Delphi Results

The success of statistical manipulation of factually-based Delphi statements is summarized in Table IV. Using the "error" measure of success, $100 \%$ success was achieved in thirteen percent (four) of the cases. This means that the median of thirteen percent of the statements were successfully manipulated to the desired value. In fifty percent of the statements, the medians vere successfully manipulated at least ninety percent of the desired distance (i.e. ninety percent of the distance between the first round median and the desired median). Eighty-five percent or more of the desired distance was accomplished in two-thirds of the cases.

There were only three statements (ten percent) that were not moved at least fifty-five percent of the desired distance. As it turned out, these were bad questions in as much as the range of reasonable answers was small and the desired answer chosen was at the outer end of these ranges. This, combined with a high amount of knowledge for these questions, made them difficult to manipulate. With the above in mind, each of the three statements will be discussed. 
TABLE IV

Success of Nanipulation - Round 4

\begin{tabular}{|c|}
\hline $\begin{array}{c}\% \\
\text { SUCMESS }\end{array}$ \\
\hline$\{00$ \\
\hline $85-5.9 .9$ \\
\hline $90-94.9$ \\
\hline $85-89.9$ \\
\hline $80-8.9$ \\
\hline $75-79.9$ \\
\hline $70-74.9$ \\
\hline $65-69.8$ \\
\hline $60-6+.4$ \\
\hline $55-59.9$ \\
\hline $50-54.9$ \\
\hline $45-49.9$ \\
\hline $40-44.9$ \\
\hline $.35-39.9$ \\
\hline $30-34.9$ \\
\hline $25-29.9$ \\
\hline $20-24.9$ \\
\hline$\{5-i 9.9$ \\
\hline$\{0-j+\}$ \\
\hline $5-9.8$ \\
\hline $0-4.9$ \\
\hline
\end{tabular}

FACTUALLY BASED - (FI-KA)/(AD-FY

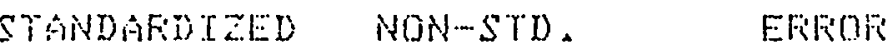

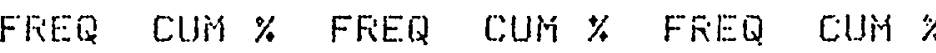

$\begin{array}{ll}4 & 0.13 \\ 4 & 0.27 \\ 5 & 0.43 \\ 5 & 0.60 \\ 4 & 0.73 \\ 0 & 0.73 \\ 1 & 0.77 \\ 2 & 0.83 \\ 2 & 0.90 \\ 0 & 0.90 \\ 0 & 0.90 \\ 0 & 0.90 \\ 1 & 0.93 \\ 1 & 0.97 \\ 0 & 0.97 \\ 0 & 0.97 \\ 0 & 0.97 \\ 1 & 1.00 \\ 0 & 1.00 \\ 0 & 1.00 \\ 0 & 1.00\end{array}$

$\begin{array}{ll}4 & 0.43 \\ 4 & 0.27 \\ 5 & 0.43 \\ 5 & 0.00 \\ 4 & 0.73 \\ 0 & 0.73 \\ 1 & 0.77 \\ 2 & 0.83 \\ 2 & 0.90 \\ 0 & 0.90 \\ 0 & 0.90 \\ 0 & 0.90 \\ 1 & 0.93 \\ 1 & 0.97 \\ 0 & 0.97 \\ 0 & 0.97 \\ 0 & 0.97 \\ 1 & 1.00 \\ 0 & 1.00 \\ 0 & 1.00 \\ 0 & 1.00\end{array}$

$\begin{array}{ll}4 & 0.13 \\ 0 & 0.33 \\ 5 & 0.30 \\ 5 & 0.67 \\ 0 & 0.07 \\ 2 & 0.73 \\ 3 & 0.63 \\ 4 & 0.67 \\ 0 & 0.07 \\ 1 & 0.90 \\ 0 & 0.90 \\ 0 & 0.90 \\ 2 & 0.97 \\ 0 & 0.97 \\ 0 & 0.97 \\ 0 & 0.97 \\ 1 & 1.00 \\ 0 & 1.00 \\ 0 & 1.00 \\ 0 & 1.00 \\ 0 & 1.09\end{array}$

UALUE LADEN T.NDEXX-4 TROEX - 2 FREQ GHA \% FFEQ CUi \%

\begin{tabular}{|c|c|c|c|}
\hline 3 & $\theta+10$ & 93 & 0.43 \\
\hline 5 & 0.27 & 2 & 0.50 \\
\hline 5 & 0.43 & 3 & 0.60 \\
\hline$\theta$ & 0.43 & ()) & 0.60 \\
\hline 3 & 0.53 & 3 & 0.70 \\
\hline 6 & 6.73 & 3 & 0.80 \\
\hline$?$ & 6.30 & 2 & 0.87 \\
\hline 2 & 0.87 & 2 & $0.9 z$ \\
\hline 3 & 0.97 & \{ & 0.97 \\
\hline$\theta$ & 0.57 & 6 & 0.97 \\
\hline 0 & $0.9 \%$ & 6 & $\theta .57$ \\
\hline$\theta$ & 0.97 & 6 & 0.97 \\
\hline$\theta$ & $\Leftrightarrow .97$ & 0 & 0.97 \\
\hline 0 & 0.97 & $\Theta$ & 0.97 \\
\hline\{ & 1.00 & $i$ & 1.06 \\
\hline 0 & $\{.00$ & $\Theta$ & $3 . \leqslant 0$ \\
\hline 0 & 4.00 & 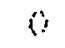 & $i \therefore \theta$ \\
\hline 6 & 90\% & 3 & 3.00 \\
\hline$\dot{ن}$ & $1.8 \overline{0}$ & $\therefore$ & $1 . \because \hat{\theta}$ \\
\hline$\hat{0}$ & i. is & i & 1.96 \\
\hline 0 & $\div \ldots$ & is & $i . \therefore$ \\
\hline
\end{tabular}


Statement six (see Appendix A) was the statement with the least degree of success. It was concerned with the altitude of Grand Forks, North Dakota. The actual altitude was 834 feet. The desired altitude was 1400 feet. The resulting median was 910 feet. The altitude of Grand Forks Air Force Base is 911 . feet. This coupled with the fact that the country between the air base and the city makes a pool table look lumpy indicates that many of the participants knew the altitude of the air base. Since many of the participants were pilots (or navigators), the result was not surprising.

Statement fourteen was concerned with the average age of an Air Force officer. It was surprising that the success of this statement was forty percent. The vast majortty of officers in the Air Force are second or first lieutenants, with captains being the next most numerous rank. These were the same ranks that made up the majority of the participants. The participants knew their age and the relative age of those around them. They therefore had a fairly good 1dea of the average age (first round median $=31$, last round median $=34$, true answer $=33.2$ ). A desired answer of 39 was too far from the range of acceptable answers.

Statement twenty-four dealt with the highest temperature ever recorded in North Dakota. Its success was forty-one percent. This was another example of a bad choice of a desired answer in that it was too close to the outer edge of believability. North Dakota is known for its severe cold winters. Only five states have had as cold or colder a recorded low temperature $\left(-60^{\circ} \mathrm{F}\right)$. This Delphi was run at the end of one of these winters. While only four states 
have had as high or higher a recorded temperature $\left(121^{\circ} \mathrm{F}\right)$, temperatures over $100^{\circ} \mathrm{F}$ are not common, thus it was difficult to make the participants believe the desired value of $1.30^{\circ} \mathrm{F}$. (It is interesting to note that the $-60^{\circ} \mathrm{F}$ and the $121^{\circ} \mathrm{F}$ were recorded in the same year, 1936.)

If one disqualified these three statements, the success of moving the first round answer $85 \%$ or more of the distance to the desired answer would be $74 \%$. This certainly would be indicative of the manipulability of factually-based Delphi statements by statistical manipulation. Even if one does not eliminate these three questions, a $67 \%$ success of moving the median $85 \%$ or more of the desired distance is indicative of successful manipulability.

Value-laden Delphi Results

The success of statistical manipulation of value-laden Delphi statements is also summarized in Table IV. As the table indicates, there are two ways one can interpret the success of statistical manipulation of value-laden Delphi statements. Index-1 specifies anything over 100\% will be deducted from 100\% since the objective is to achieve a particular index exactly (i.e., $110 \%$ success would be considered $90 \%$ success). Index -2 specifies anything over $100 \%$ will be considered $100 \%$ since the objective is to achieve at least the desired index (i.e., 110\% success would be considered $100 \%$ success).

Using Index-1 as a measure of success, $100 \%$ success was achieved in ten percent (three) of the statements. This means that the index 
of ten percent of the statements was successfully manipulated to the exact desired index. In forty-three percent of the statements, the indexes were successfully manipulated to within at least ninety percent of the desired distance (i.e., ninety percent of the distance between the first round index and the desired index). As was in the case of the factually-based Delphi statements, eighty-five percent or more of the desired distance was accomplished in two-thirds of the cases.

Using Index-2, the success was even more dramatic. $100 \%$ success was achieved in forty-three percent of the statements. This means the index was successfully manipulated to or beyond the desired index in forty-three percent (thirteen) of the statements. In sixty percent of the statements, the indexes were successfully manipulated to within at least ninety percent or more of the desired distance. Ninety-three percent or more of the desired distance was accomplished in two-thirds of the cases.

There was only one statement that was not moved at least sixty percent of the desired distance. Unlike the three statements that were under fifty percent success in the almanac Delphi, no clear explanation can be made as to why this statement did not respond to the manipulation.

While the success of Index-1 obviously was less than Index-2, both demonstrated a high level of success of manipulability of valueladen Delphi statements by statistical manipulation. 
Additional Results Using the Success Data

By arranging the data into the format shown in Table $V$, one can determine how the success of each question changed during each round. By further examination of the table, one can calculate for the factually-based Delphi that success increased in $93 \%$ (28) of the statements for round 3 and $60 \%$ (18) of the statements for round 4 . For the value-laden Delphi, success also increased in $93 \%$ (28) of the statements for round 3 and $80 \%$ (24) of the statements in round 4. This indicates that success was enhanced by additional rounds. (Hypothesis H1)

Also included in Table $V$ are the actual and desired movements of the medians. Correlation analyses were run to see if there were correlations between the degree of success and the amount of movement that occurred or was desired to occur. This would test if it was more difficult to achieve success when the range was limited, or put another way, if the statements with the greatest movement desired were also the most successful. Table VI shows the results of the correlations. In all cases, the analyses showed a low to median correlation. (Hypotheses $\mathrm{H} 2$ and $\mathrm{H} 3$ )

Another form of analysis run was an analysis of variance on the actual change of the manipulated statements for each participant by the actual change of the non-manipulated statements for each participant. Table VII shows that the results were significant at the .001 level for both the factually-based Delphi and the value-laden Delphi. This would indicate that the medians (indexes) of the manipulated 
TABLE V

Success of Manipulation - Detail

SLECESS OF HFNIFULATIDN - TETATL

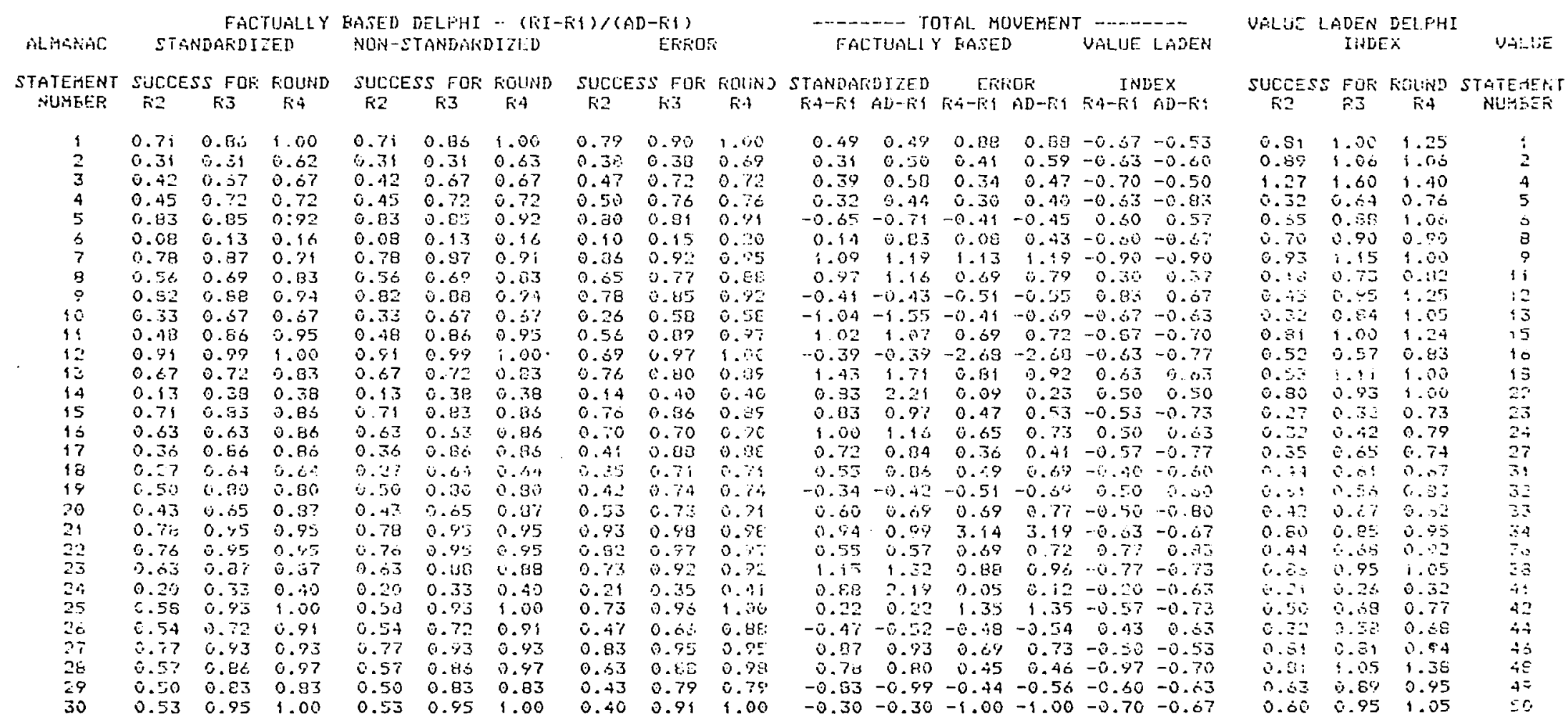


TABIE VI

Results of Correlation of Round 4 Degree of Success and Amount of Movement

\begin{tabular}{|c|c|c|c|c|}
\hline $\begin{array}{c}\text { Round } 4 \\
\text { degree of } \\
\text { success }\end{array}$ & $\begin{array}{l}\text { amount of } \\
\text { movement }\end{array}$ & $\begin{array}{l}\text { Pearson's } \\
\text { correlation } \\
\text { coefficient }\end{array}$ & $\begin{array}{c}\text { coefficient } \\
\text { of } \\
\text { determination }\end{array}$ & $\begin{array}{c}\text { standard } \\
\text { error of } \\
\text { the estimate }\end{array}$ \\
\hline $\begin{array}{l}\text { R4 (non-standardized) } \\
\text { (Factually-based Delphi) }\end{array}$ & $\begin{array}{l}\mathrm{R} 4-\mathrm{R} 1 \\
\mathrm{AD}-\mathrm{R} 1\end{array}$ & $\begin{array}{r}0.12200 \\
-0.48485\end{array}$ & $\begin{array}{l}0.01488 \\
0.23508\end{array}$ & $\begin{array}{l}0.20513 \\
0.18076\end{array}$ \\
\hline 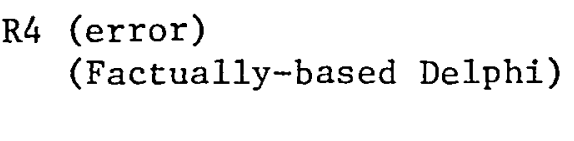 & $\begin{array}{l}\mathrm{R} 4-\mathrm{R} 1 \\
\mathrm{AD}-\mathrm{R} 1\end{array}$ & $\begin{array}{l}0.51994 \\
0.43908\end{array}$ & $\begin{array}{l}0.27033 \\
0.19279\end{array}$ & $\begin{array}{l}0.17372 \\
0.18272\end{array}$ \\
\hline 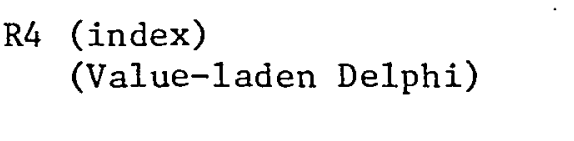 & $\begin{array}{l}\mathrm{R} 4-\mathrm{R} 1 \\
\mathrm{AD}-\mathrm{R} 1\end{array}$ & $\begin{array}{r}0.78194 \\
-0.18526\end{array}$ & $\begin{array}{l}0.61143 \\
0.03432\end{array}$ & $\begin{array}{l}0.14892 \\
0.23477\end{array}$ \\
\hline
\end{tabular}


TABLE VII

Results of Analysis of Variances on the Change of Each Manipulated Participant by the Change of Each Non-Manipulated Participant

\begin{tabular}{l|l|l|l|l|l} 
Factually-based Delphi & $\begin{array}{l}\text { sum of } \\
\text { squares }\end{array}$ & $\mathrm{df}$ & $\begin{array}{c}\text { mean } \\
\text { square }\end{array}$ & $\mathrm{F}$ & $\begin{array}{l}\text { sign. } \\
\text { of F }\end{array}$ \\
\hline $\begin{array}{l}\text { actual change (R4-R1)- } \\
\text { manipulated verses } \\
\text { non-manipulated }\end{array}$ & 44.402 & 1 & 44.402 & 44.711 & 0.001 \\
\hline $\begin{array}{l}\text { actual change (R4-RI) } \\
\text { for non-manipulated } \\
\begin{array}{l}\text { verses } \\
\text { desired change (AD-RI) } \\
\text { for manipulated }\end{array}\end{array}$ & 105.430 & 1 & 105.400 & 113.906 & 0.001 \\
\hline
\end{tabular}

\begin{tabular}{l|c|c|c|c|c} 
Value-laden Delphi & $\begin{array}{l}\text { sum of } \\
\text { squares }\end{array}$ & df & $\begin{array}{c}\text { mean } \\
\text { square }\end{array}$ & F & $\begin{array}{l}\text { sign. } \\
\text { of F }\end{array}$ \\
\hline $\begin{array}{l}\text { actual change (R4-R1)- } \\
\text { manipulated verses } \\
\text { non-manipulated }\end{array}$ & 33.076 & 1 & 33.076 & 67.540 & 0.001 \\
\hline $\begin{array}{l}\text { actual change (R4-RI) } \\
\text { for non-manipulated } \\
\begin{array}{l}\text { verses } \\
\text { desired change (AD-RI) } \\
\text { for manipulated }\end{array}\end{array}$ & 117.518 & 1 & 117.518 & 226.746 & 0.001 \\
\hline
\end{tabular}


statements were moved to a significantly different place than the nonmanipulated statements. (Hypothesis H4)

Table VII also shows the results of running an analysis of var1ance on the desired change of the manipulated statements by the actual change of the corresponding non-manipulated statements for each partfcipant. The results show the desired change for a manipulated statement was significantly different from the actual change that occurred for that statement when it was not manipulated. Thus, the desired change was significantly different from the change that would have normally occurred. (Eypothesis H5)

Comparison of Factually-Based and Value-Laden Delphis

The third research hypothesis (R3) to be tested (Hypothesis H6) concerns itself with whether it was easier to manipulate factuallybased Delphi statements or value-laden Delph1 statements or whether there was no signiffcant difference. If one considers the cumulative percentage of statements that were manipulated to a certain degree of success as being a measure of success in manipulation, one can use a Z-test to compare two population proportions to test if there was a significant difference between the two percentages. Table VIII contains the results of such a statistical test for degrees of success ranging from fifty to one hundred percent.

The overall results strongly suggest that one cannot reject research hypothesis $\mathrm{R} 3$. That 1s, the results strongly indicate there was no significant difference between factually-based and value-laden Delphi statements, with respect to manipulation via statistical feedback. The one notable exception was at the $100 \%$ degree of success. 


\section{TABLE VIII}

Results of Comparing the Success of the Factually-based Delphi with the Success of the Value-laden Delphi

- Cummulative \%

$\%$

Success

$\begin{array}{rrr}100 & 0.13 & 0.13 \\ 95 & 0.27 & 0.33 \\ 90 & 0.43 & 0.50 \\ 85 & 0.60 & 0.67 \\ 80 & 0.73 & 0.67 \\ 75 & 0.73 & 0.73 \\ 70 & 0.77 & 0.83 \\ 65 & 0.83 & 0.87 \\ 60 & 0.90 & 0.87 \\ 55 & 0.90 & 0.90 \\ 50 & 0.90 & 0.90\end{array}$

0.53

0.73

0.80

0.87

0.97

0.97

0.97
Z Value

0.70

0.80

0.87

0.93

0.97

0.97

0.97

$\overline{\mathrm{P}}=\frac{\mathrm{n}_{1} \mathrm{P}_{1}+\mathrm{n}_{2} \mathrm{P}_{2}}{\mathrm{n}_{1}+\mathrm{n}_{2}}$
Index-1

0,36

0.00

0.00

1.32

1.60

0.00 Index-2 Index-1 Index-2 Index-1

$$
-2.59
$$$$
-1.83
$$

0.36

0.51

$-2.59$

$-1.34$

$-1.32$

0.54

$-0.78$

0.00

1.87

0.56

$-0.25$

$\begin{array}{lll}-0.64 & 0.00 & -0.64\end{array}$

$\begin{array}{lll}-1.01 & -0.73 & -0.43\end{array}$

$\begin{array}{ll}-1.19 & 0.00\end{array}$

$-0.77$

$-0.73$

$-1.10$

$-1.10$

$-1.10$

$-1.10$

$-1.43$

$-1.10$

$-1.43$

$-1.10$

$-1.10-1.10 \quad-1.10$
Significant at

STD. Error Error Index-2 Index-1 Index-2

0.01

0.01

0.1

$\mathrm{Z}=\frac{\mathrm{P}_{1}+\mathrm{P}_{2}}{\hat{\sigma}_{\Delta \mathrm{p}}}$ 
When one uses Index-2 as the measure of success for value-laden Delphis (i.e., anything over $100 \%$ successful is considered $100 \%$ successful), the value-laden Delphi statements were significantly $(\alpha=0.01)$ more successfully manipulated. This significance, however, quickly fades away as one accepts lower levels of success as indicating successful manipulation (i.e., if one considered moving the final round answer ninety percent of the distance between the first round answer and the desired answer, there would be no significant difference as to whether it was a factually-based or a value-laden Delphi statement).

The acceptance of these results must be cautioned by two considerations. First, the above tests were only indirectly testing the true relationship since the measures of success in both cases were different. The second consideration is the choice of the desired answers was somewhat subjective. Therefore, there was no guarantee that the values chosen for the value-laden Delphi statements were more easily obtainable than those for the factually-based Delphi statements or vice versa.

Summary of Success Results

The above results indicate that statistical manipulation did cause a highly significant shift in the answers of the participants and that a high degree of success of obtaining a desired value existed and that this success was enhanced by running additional rounds. It was also determined there was no significant difference between the manipulability of factually-based Delphi statements and of valueladen Delphi statements. 
STATISTICAL MANIPULATION AND CONVERGENCE OF DELPHI STATEMENTS

It was hypothesized that statistical manipulation could affect the convergence of Delphi statements. With this in mind the following research hypotheses were developed:

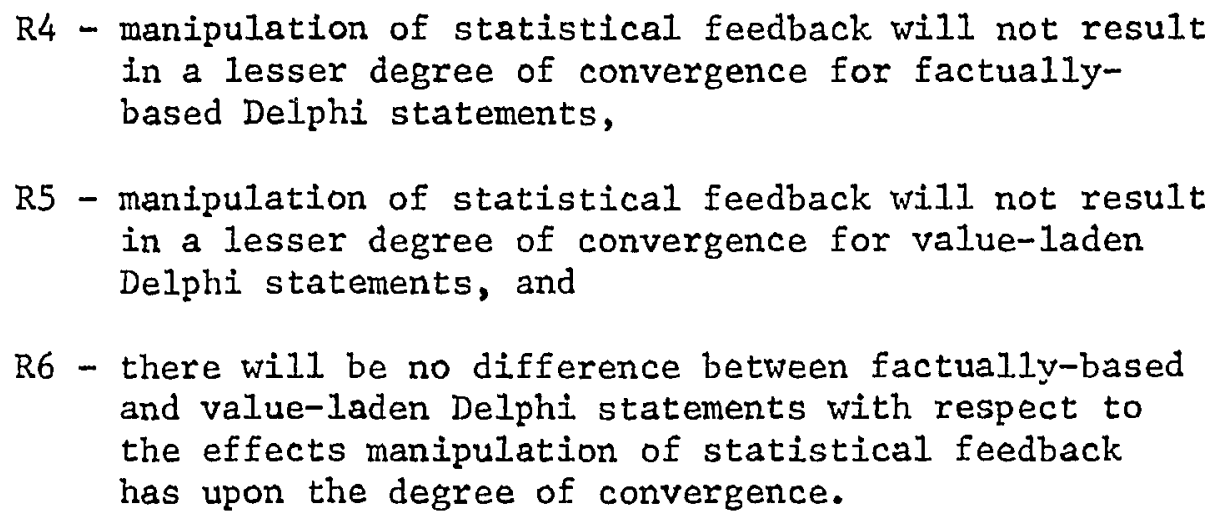

Factually-based Delphi Results

Convergence of factually-based Delphi statements is usually measured by changes in the quartile range. There are some people, however, who would argue that the standard deviation is a better answer. Both measures are considered in this analysis.

T-tests and analysis of variances were run on the statistically manipulated and non-manipulated quartiles and standardized standard deviations for each round of the Delphi. $F_{\max }$ tests were also run on the variances for each question to see if the variances of each individual question were equal (Hypothesis H7).

The t-tests and analysis of variances on the standardized standard deviations showed no significant difference between the statistically manipulated and the non-manipulated Delphi statements (see Table IX). The $F_{\max }$ tests on the variances of each question for 
TABLE IX

Results of Statistical Tests on Convergence Factually-based Delphi

\begin{tabular}{|c|c|c|c|c|c|c|c|c|}
\hline \multirow[b]{3}{*}{ Round } & \multicolumn{4}{|c|}{ Quartile Values } & \multicolumn{4}{|c|}{ Standardized Standard Deviations } \\
\hline & \multicolumn{2}{|c|}{ t-test $(\mathrm{df}=58)$} & \multicolumn{2}{|c|}{ anal. of var. $(\mathrm{df}=1,58)$} & \multicolumn{2}{|c|}{$t$-test $(\mathrm{d} f=58)$} & \multicolumn{2}{|c|}{ anal. of var. $(\mathrm{df}=1,58)$} \\
\hline & \pm value & $t$ sign. at & $\mathrm{F}$ value & $\mathrm{F}$ sign. at & $t$ value & $t$ sign. at & F value & $\mathrm{F}$ sign. at \\
\hline 1 & 0.338 & - & 0.114 & 0.999 & 0.072 & - & 0.005 & 0.999 \\
\hline 2 & -1.794 & 0.1 & 3.216 & 0.075 & 0.098 & - & 0.010 & 0.999 \\
\hline 3 & -1.946 & 0.1 & 3.788 & 0.053 & 0.240 & - & 0.058 & 0.999 \\
\hline 4 & -1.757 & 0.1 & 3.087 & 0.081 & 0.239 & - & 0.057 & 0.999 \\
\hline
\end{tabular}


each round did not indicate that the statistically manipulated variances were greater than or less than the non-manipulated statements (see Table X).

The t-tests and analysis of variances of the quartile ranges, however, indicated a significant difference (at the $\alpha=0.1$ leve1) existed from the second round to the last round (see Table IX). Thus one can say, whlle statistical manipulation did not have any effect on the standard deviation, it did have a significant effect on the convergence of the quartile range. That is, statistical manipulation tended to increase the convergence of the quartile range. One must treat this result carefully, however, for two reasons. First, the level of significance was rather low, $\alpha=0.1$. Second the quartile ranges used in the manipulated statistical feedback tended to be rather close. It stands to reason that if people demonstrate a desire to be within the quartile range (even if fust at the end of the range) a tighter range in the statistical feedback will force people to compromise to a tighter range for the next round. It was interesting to note, however, even if this is true, this movement was not uniform enough to reduce the standard deviation by a significant amount.

\section{Value-laden Delphi Results}

Convergence of value-laden Delphi statements is best measured by the changes in the standard deviation. One would expect the standard deviation of a statement to get smaller with each round. The question to be answered here is does statistical manipulation affect the convergence of the standard deviation? 
TABLE X

Results of Fmax Test for Equal Variances

\begin{tabular}{|c|c|c|c|c|c|c|c|c|c|c|}
\hline Statement & $\begin{array}{c}\text { Fmax } \\
\text { RI }\end{array}$ & $\begin{array}{c}\text { Value } \\
\text { R2 }\end{array}$ & \multicolumn{2}{|c|}{ For Round } & R1 & $\begin{array}{c}\text { Fmax } \\
\text { (For } \\
\text { R2 }\end{array}$ & \multicolumn{2}{|c|}{$\begin{array}{l}\text { Sign. at } \\
\text { ( Round) }\end{array}$} & \multicolumn{2}{|c|}{$\begin{array}{l}\text { Which is } \\
\text { Greater at } \\
\text { Round } 4 \\
M=\text { Manip. }\end{array}$} \\
\hline 1 & 3.86 & 2.37 & 2.43 & 2.33 & .01 & .05 & .05 & .05 & $M$ & \\
\hline 2 & 1.37 & 2.66 & 1.94 & 1.81 & & .05 & .10 & & & \\
\hline 3 & 1.47 & 4.18 & 1.10 & 1.01 & & .01 & & & & \\
\hline 4 & 2.71 & 1.85 & 1.18 & 1.17 & .01 & .10 & & & & \\
\hline 5 & 1.15 & 1.97 & 1.72 & 1.75 & & .10 & & & & \\
\hline 6 & 2.21 & 2.31 & 2.98 & 8.85 & .05 & .05 & .01 & .01 & M & \\
\hline 7 & 1.37 & 2.78 & 2.14 & 1.76 & & .01 & .05 & & & \\
\hline 8 & 1.75 & 1.87 & 1.95 & 1.80 & & .10 & .10 & & & \\
\hline 9 & 1.00 & 3.24 & 4.89 & 4.15 & & .01 & .01 & .01 & NM & \\
\hline 10 & 1.11 & 1.35 & 1.84 & 1.86 & & & & .10 & NM & \\
\hline 11 & 1.10 & 3.05 & 5.97 & 3.13 & & .01 & .01 & .01 & M & \\
\hline 12 & 17.74 & 1.89 & 12.59 & 16.09 & .01 & .10 & .01 & .01 & NM & \\
\hline 13 & 2.04 & 3.75 & 2.38 & 2.66 & .10 & .01 & .05 & .05 & M & \\
\hline 14 & 1.57 & 1.92 & 2.59 & 3.39 & & .10 & .05 & .01 & M & \\
\hline 15 & 5.94 & 1.45 & 1.65 & 1.37 & .01 & & & & & \\
\hline 16 & 1.90 & 2.03 & 1.44 & 1.56 & .10 & .10 & & & & \\
\hline 17 & 1.15 & 1.14 & 1.47 & 1.09 & & & & & & \\
\hline 18 & 8.27 & 1.17 & 1.08 & 2.27 & .01 & & & .05 & M & \\
\hline 19 & 2.13 & 1.70 & 1.77 & 2.97 & .05 & & & .01 & NM & \\
\hline 20 & 3.43 & 2.94 & 2.59 & 2.83 & .01 & .01 & .05 & .01 & M & \\
\hline 21 & 1.55 & 1.27 & 1.21 & 1.60 & & & & & & \\
\hline 22 & 1.03 & 1.10 & 1.72 & 1.61 & & & & & & \\
\hline 23 & 1.50 & 1.35 & 2.05 & 1.74 & & & .10 & & & \\
\hline 24 & 1.34 & 1.47 & 2.06 & 2.36 & & & .10 & .05 & M & \\
\hline 25 & 3.30 & 2.05 & 17.81 & 17.70 & .01 & .10 & .01 & .01 & $M$ & \\
\hline 26 & 1.04 & 1.99 & 2.61 & 2.57 & & .10 & .05 & .05 & NM & \\
\hline 27 & 1.45 & 6.18 & 1.91 & 1.08 & & .01 & .10 & & & $\cdots-$ \\
\hline 28 & 2.25 & 1.18 & 1.18 & 1.14 & .05 & & & & & \\
\hline 29 & 1.28 & 2.30 & 1.15 & 1.03 & & .05 & & & & \\
\hline 30 & 1.93 & 4.95 & 7.45 & 7.89 & .10 & .01 & .01 & .01 & M & \\
\hline
\end{tabular}


Table XI shows the results of running t-tests and analysis of variances on the standard deviations of the manipulated and nonmanipulated value-laden Delphi statements for each round of the Delphi. The results show a significant difference existed for each round except the first round.

The interpretation of the above indlcates there was no significant difference in the standard deviations during the first round, which was as one would expect (1.e., no manipulation had yet taken place). Beginning with the second round, however, the standard deviation of the manipulated group was significantly different from the non-manipulated group. About two-thirds of the manipulated standard deviations were greater than the non-manipulated statements and about one-third were smaller. Thus, one cannot say which way statistical manipulation affected the standard deviations of the value-iaden Delphi statements, only that it significantly affected them. The cautions indicated for the factually-based Delphi results also apply here.

Comparison of Factually-based and Value-laden Delphis

The outcome of the above results made it very difficult to compare the two types of Delphis. The results for the standard deviation of the two types of Delphis were in direct conflict with each other. The results of the quartile range (factually-based Delphi) and the standard deviation (value-laden Delphi) were, however, consistent with each other; but these two measures could not be directly compared. The best one could do was to compare the resulting $t$ and $z$-values and see if they were consistent with each other. Such a comparison 
TABLE XI

Results of Statisticai Tests on Convergence-

Value-laden Delphi

Standard Deviation

\begin{tabular}{|c|c|c|c|c|}
\hline \multirow[b]{2}{*}{ Round } & \multicolumn{2}{|c|}{$t$-test $(\mathrm{df}=58)$} & \multicolumn{2}{|c|}{ anal. of var. $(\mathrm{df}=1,58)$} \\
\hline & $t$ value & $\mathrm{t}$ sign. at & F value & F sign. at \\
\hline 1 & 0.692 & - & 0.479 & 0.999 \\
\hline 2 & 2.192 & 0.05 & 4.805 & 0.030 \\
\hline 3 & 2.070 & 0.05 & 4.284 & 0.040 \\
\hline 4 & 2.570 & 0.02 & 6.607 & 0.012 \\
\hline
\end{tabular}


Indicated they were reasonably close to each other with the standard deviation (value-laden Delphi) being slightly more significant. This difference did not appear to be significant enough to indicate there was a significant difference between the two types of Delphis.

Summary of Convergence Results

The above results indicate a cautious rejection of research hypotheses $R 4$ and $R 5$ and the acceptance of research hypothesis $R 6$. While statistical manipulation did not have any significant effect on the standard deviation of factually-based Delphi statements, it did have a significant effect on the convergence of the quartile range. Statistical manipulation also had a significant effect on the convergence of value-laden Delphi statements, although nothing could be said as to whether it increased or decreased the convergence. It did not appear that convergence of factually-based Delphi statements were more or less affected by statistical mantpulation than convergence of value-laden Delphi statements.

STATISTICAL MANIPULATION AND STABILITY OF DELPHI STATEMENTS

Stability as defined earlier, is a measure of the number of changes participants make between two consecutive rounds. It was hypothesfzed that the effects of statistical manipulation would increase the number of changes that occurred and thus reduce the stability of Delphi statements. To test the research hypotheses

R7 - manipulation of statistical feedback will not reduce the stability (and therefore not require an extra round(s)) in factually-based Delphi statements, 


$$
\begin{aligned}
& \text { R8 - manipulation of statistical feedback will not reduce } \\
& \text { the stability (and therefore not require an extra } \\
& \text { round(s)) in value-laden Delphi statements, and } \\
& \text { R9 - there will be no difference between factually-based } \\
& \text { and value-laden Delphi statements with respect to } \\
& \text { the effect manipulation of statistical feedback has } \\
& \text { upon stability (and therefore the number of rounds } \\
& \text { necessary to obtain stability), }
\end{aligned}
$$

it was decided to test the following research subhypotheses separately for both the factually-based Delphi statements and the value-laden Delphi statements:

N1 - there is no difference between manipulated and nonmanipulated statements with respect to the percent change between rounds $I$ and 2 ,

N2 - same as N1 except percent change is for rounds 2 and 3 ,

N3 - same as NI except percent change is for rounds 3 and 4 , and

$\mathrm{N}_{4}$ - there is no difference between manipulated and nonmanipulated statements with respect to the round where stability is first achieved.

A strong acceptance of $\mathrm{N} 1$ through $\mathrm{N4}$ would indicate a strong acceptance of $R 7$ ( $R 8$ ). A comparison of the mean round where stability occurred for manipulated and non-manipulated stateinents for the factually-based Delphi and the value-laden Delphi will allow for the acceptance or refection of the following research subhypotheses:

N5 - there is no difference between factually-based and value-laden Delphi statements with respect to the number of rounds necessary to obtain stability and

N6 - manipulation of statistical feedback has no effect on the number of rounds necessary to obtain stability.

The acceptance or rejection of these subhypotheses (N5-N6) will throw additional light on the original set of research hypotheses (R7-R9). 
(N1, N2, and $N 3$ are tested by $H 8 ; N 4$ is tested by $H 9$; and $N 5$ and $N 6$ are tested by H1O through H13.)

Factually-based Delphi Results

To test N1 through N4, t-tests and analysis of variance were run on the percent change between rounds 1 and 2 , rounds 2 and 3 , and rounds 3 and 4 and on the round where $20 \%$ stability was first achieved (reference Table XII for data). They were also run on the round where $15 \%$ stability was first achieved (for those who feel more comfortable with Scheibe, Skutsch, and Schofer's [85] estimate of where stability should occur). As Table XIV indicates, there was a highly significant difference between the statistically manipulated and non-manipulated Delphi statements in all cases. Thus null hypotheses NI through N4 were rejected at the highly significant level. These results support a strong rejection of the research hypothesis $R 7$. Since in all cases, the mean of the statistically manipulated Delphi statements was greater than the mean of the non-manipulated Delphi statements, one must accept the alternative hypothesis that statistical manipulation had a highly significant destabilizing effect on factually-based Delphi statements.

\section{Value-laden Delphi Results}

The procedure used to test research subhypotheses N1 through $N 4$ for the value-laden Delphi statements was the same that was used for the factually-based Delphi statements. The results were also the same. Table XIII contains the data used in the analysis. Table XIV reports the results. Similar to the factually-based Delphi, there 
TABLE XII

Stability of Manipulation - Factually-based Delphi

Statemen
Number

1
2
3
4
5
6
7
8
9
10
11
12
13
14
15
16
17
18
19
20
21
22
23
24
25
26

$\%$ Change Between Rounds Manipulated

$\begin{array}{lll}1-2 & 2-3 & 3-4 \\ 0.70 & 0.40 & 0.17 \\ 0.57 & 0.20 & 0.20 \\ 0.60 & 0.27 & 0.20 \\ 0.67 & 0.33 & 0.23 \\ 0.53 & 0.27 & 0.23 \\ 0.40 & 0.23 & 0.10 \\ 0.67 & 0.33 & 0.20 \\ 0.67 & 0.40 & 0.33 \\ 0.40 & 0.30 & 0.13 \\ 0.57 & 0.50 & 0.20 \\ 0.60 & 0.50 & 0.27 \\ 0.70 & 0.47 & 0.33 \\ 0.73 & 0.43 & 0.20 \\ 0.33 & 0.20 & 0.30 \\ 0.50 & 0.20 & 0.23 \\ 0.57 & 0.23 & 0.20 \\ 0.57 & 0.37 & 0.27 \\ 0.50 & 0.37 & 0.20 \\ 0.60 & 0.27 & 0.17 \\ 0.53 & 0.37 & 0.33 \\ 0.67 & 0.27 & 0.30 \\ 0.67 & 0.23 & 0.30 \\ 0.67 & 0.30 & 0.30 \\ 0.33 & 0.33 & 0.07 \\ 0.77 & 0.50 & 0.20 \\ 0.43 & 0.47 & 0.23\end{array}$

Non-manipulated

$\begin{array}{lll}1-2 & 2-3 & 3-4\end{array}$

\section{$\begin{array}{lll}0.47 & 0.17 & 0.07\end{array}$}

$\begin{array}{llll}0.47 & 0.30 & 0.17\end{array}$

$\begin{array}{lll}0.47 & 0.37 & 0.20\end{array}$

$\begin{array}{llll}0.47 & 0.20 & 0.13\end{array}$

$\begin{array}{lll}0.43 & 0.33 & 0.17\end{array}$

$\begin{array}{llll}0.53 & 0.23 & 0.23\end{array}$

$\begin{array}{lll}0.60 & 0.20 & 0.17\end{array}$

$\begin{array}{llll}0.33 & 0.23 & 0.13\end{array}$

$\begin{array}{lll}0.50 & 0.37 & 0.23\end{array}$

$\begin{array}{lll}0.23 & 0.13 & 0.20\end{array}$

$\begin{array}{lll}0.53 & 0.40 & 0.10\end{array}$

$\begin{array}{lll}0.43 & 0.30 & 0.07\end{array}$

$\begin{array}{lll}0.37 & 0.13 & 0.17\end{array}$

$\begin{array}{llll}0.20 & 0.10 & 0.13\end{array}$

$\begin{array}{lll}0.60 & 0.30 & 0.23\end{array}$

$\begin{array}{lll}0.47 & 0.30 & 0.17\end{array}$

$\begin{array}{lll}0.30 & 0.27 & 0.20\end{array}$

$\begin{array}{lll}0.47 & 0.23 & 0.23\end{array}$

$\begin{array}{lll}0.50 & 0.33 & 0.20\end{array}$

$\begin{array}{lll}0.27 & 0.17 & 0.20\end{array}$

$\begin{array}{lll}0.47 & 0.30 & 0.37\end{array}$

$\begin{array}{lll}0.37 & 0.23 & 0.13\end{array}$

$\begin{array}{lll}0.43 & 0.20 & 0.10\end{array}$

$\begin{array}{llll}0.03 & 0.17 & 0.07\end{array}$

$\begin{array}{lll}0.50 & 0.43 & 0.10\end{array}$

$\begin{array}{lll}0.33 & 0.23 & 0.17\end{array}$
$20 \%$

Stability First

Reached in Round

Manip Non-Manip

$\begin{array}{ll}4 & 3 \\ 3 & 4 \\ 4 & 4 \\ 5 & 3 \\ 5 & 4 \\ 4 & 5 \\ 4 & 3 \\ 5 & 4 \\ 4 & 5 \\ 4 & 3 \\ 5 & 4 \\ 5 & 4 \\ 4 & 3 \\ 3 & 2 \\ 3 & 5 \\ 4 & 4 \\ 5 & 4 \\ 4 & 5 \\ 4 & 4 \\ 5 & 3 \\ 5 & 5 \\ 5 & 4 \\ 5 & 3 \\ 4 & 2 \\ 4 & 4 \\ 5 & 4\end{array}$

$15 \%$

Stability First

Reached in Round

Manip Non-Manip

$\begin{array}{ll}5 & 4 \\ 5 & 5 \\ 5 & 5 \\ 5 & 4 \\ 5 & 5 \\ 4 & 5 \\ 5 & 5 \\ 5 & 4 \\ 4 & 5 \\ 5 & 3 \\ 5 & 4 \\ 5 & 4 \\ 5 & 3 \\ 5 & 3 \\ 5 & 5 \\ 5 & 5 \\ 5 & 5 \\ 5 & 5 \\ 5 & 5 \\ 5 & 5 \\ 5 & 5 \\ 5 & 4 \\ 5 & 4 \\ 4 & 2 \\ 5 & 4 \\ 5 & 5\end{array}$


TABLE XII--Continued

\begin{tabular}{|c|c|c|c|c|c|c|c|c|c|c|}
\hline \multirow{4}{*}{$\begin{array}{l}\text { Statement } \\
\text { Number }\end{array}$} & \multirow{2}{*}{\multicolumn{6}{|c|}{$\%$ Change Between Rounds }} & \multicolumn{2}{|r|}{$20 \%$} & \multicolumn{2}{|r|}{$15 \%$} \\
\hline & & & & & & & \multirow{2}{*}{\multicolumn{2}{|c|}{ Reached in Round }} & \multirow{2}{*}{\multicolumn{2}{|c|}{$\begin{array}{l}\text { Stability First } \\
\text { Reached in Round }\end{array}$}} \\
\hline & \multicolumn{3}{|c|}{$\begin{array}{l}\% \text { Change } \\
\text { Manipulated }\end{array}$} & \multicolumn{3}{|c|}{ Non-manipulated } & & & & \\
\hline & & & $3-4$ & & & $3-4$ & Nenip & & & \\
\hline 27 & 0.57 & 0.43 & 0.23 & 0.57 & 0.37 & 0.27 & 5 & 5 & 5 & 5 \\
\hline 28 & 0.50 & 0.37 & 0.17 & 0.40 & 0.23 & 0.20 & 4 & 4 & 5 & 5 \\
\hline 29 & 0.47 & 0.30 & 0.10 & 0.43 & 0.20 & 0.13 & 4 & 3 & 4 & 4 \\
\hline 30 & 0.67 & 0.47 & 0.23 & 0.43 & 0.17 & 0.03 & 5 & 3 & 5 & 4 \\
\hline Averages & 0.57 & 0.34 & 0.22 & 0.42 & 0.25 & 0.17 & 4.33 & 3.77 & 4.87 & 4.37 \\
\hline
\end{tabular}


TABLE XIII

Stability of Manipulation - Value-laden Delpht

\begin{tabular}{|c|c|c|c|c|c|c|c|c|c|c|}
\hline \multirow{2}{*}{$\begin{array}{l}\text { Statement } \\
\text { Number }\end{array}$} & \multicolumn{6}{|c|}{ \% Change Between Rounds } & \multicolumn{2}{|c|}{$\begin{array}{l}\quad 20 \% \\
\text { Stability First } \\
\text { Reached in Round }\end{array}$} & \multicolumn{2}{|c|}{$\begin{array}{l}15 \% \\
\text { Stability First } \\
\text { Reached in Round }\end{array}$} \\
\hline & $1-2$ & $2-3$ & $3-4$ & $1-2$ & $2-3$ & $3-4$ & Manip & Non-Manip & & \\
\hline 1 & 0.37 & 0.17 & 0.20 & 0.17 & 0.10 & 0.07 & 3 & 2 & 5 & 3 \\
\hline 2 & 0.47 & 0.30 & 0.13 & 0.30 & 0.03 & 0.10 & 4 & 3 & 4 & 3 \\
\hline 4 & 0.67 & 0.27 & 0.10 & 0.37 & 0.10 & 0.20 & 4 & 3 & 4 & 3 \\
\hline 5 & 0.30 & 0.30 & 0.23 & 0.40 & 0.20 & 0.10 & 5 & 3 & 5 & 4 \\
\hline 6 & 0.37 & 0.13 & 0.10 & 0.33 & 0.07 & 0.10 & 3 & 3 & 3 & 3 \\
\hline 8 & 0.47 & 0.20 & 0.07 & 0.23 & 0.07 & 0.10 & 3 & 3 & 4 & 3 \\
\hline 9 & 0.57 & 0.33 & 0.20 & 0.27 & 0.10 & 0.10 & 4 & 3 & 5 & 3 \\
\hline 11 & 0.20 & 0.17 & 0.17 & 0.30 & 0.10 & 0.03 & 2 & 3 & 5 & 3 \\
\hline 12 & 0.53 & 0.33 & 0.30 & 0.27 & 0.20 & 0.13 & 5 & 3 & 5 & 4 \\
\hline 13 & 0.27 & 0.27 & 0.23 & 0.37 & 0.27 & 0.20 & 5 & 4 & 5 & 5 \\
\hline 15 & 0.47 & 0.33 & 0.27 & 0.27 & 0.30 & 0.23 & 5 & 5 & 5 & 5 \\
\hline 16 & 0.37 & 0.23 & 0.27 & 0.33 & 0.23 & 0.17 & 5 & 4 & 5 & 5 \\
\hline 18 & 0.33 & 0.27 & 0.13 & 0.17 & 0.20 & 0.10 & 4 & 2 & 4 & 4 \\
\hline 22 & 0.37 & 0.13 & 0.17 & 0.33 & 0.13 & 0.13 & 3 & 3 & 3 & 3 \\
\hline 23 & 0.13 & 0.30 & 0.27 & 0.27 & 0.23 & 0.17 & 2 & 4 & 2 & 5 \\
\hline 24 & 0.40 & 0.37 & 0.23 & 0.33 & 0.20 & 0.10 & 5 & 3 & 5 & 4 \\
\hline 27 & 0.43 & 0.43 & 0.13 & 0.20 & 0.20 & 0.13 & 4 & 2 & 4 & 4 \\
\hline 31 & 0.23 & 0.23 & 0.07 & 0.30 & 0.17 & 0.20 & 4 & 3 & 4 & 5 \\
\hline 32 & 0.43 & 0.03 & 0.13 & 0.30 & 0.13 & 0.23 & 3 & 3 & 3 & 3 \\
\hline 33 & 0.40 & 0.20 & 0.17 & 0.40 & 0.07 & 0.07 & 3 & 3 & 5 & 3 \\
\hline 34 & 0.53 & 0.23 & 0.17 & 0.30 & 0.13 & 0.17 & 4 & 3 & 5 & 3 \\
\hline 36 & 0.37 & 0.27 & 0.17 & 0.20 & 0.17 & 0.10 & 4 & 2 & 5 & 4 \\
\hline 38 & 0.50 & 0.20 & 0.13 & 0.27 & 0.23 & 0.07 & 3 & 4 & 4 & 4 \\
\hline 41 & 0.33 & 0.20 & 0.03 & 0.17 & 0.27 & 0.17 & 3 & 2 & 4 & 5 \\
\hline 42 & 0.53 & 0.20 & 0.10 & 0.43 & 0.20 & 0.10 & 3 & 3 & 4 & 4 \\
\hline 44 & 0.37 & 0.17 & 0.10 & 0.33 & 0.23 & 0.13 & 3 & 4 & 4 & 4 \\
\hline
\end{tabular}


TABLE XIII--Continued

\begin{tabular}{|c|c|c|c|c|c|c|c|c|c|c|}
\hline \multirow{2}{*}{$\begin{array}{l}\text { Statement } \\
\text { Number }\end{array}$} & \multicolumn{6}{|c|}{ \% Change Between Rounds } & \multicolumn{2}{|c|}{$\begin{array}{l}20 \% \\
\text { Stability First } \\
\text { Reached in Round }\end{array}$} & \multicolumn{2}{|c|}{$\begin{array}{l}15 \% \\
\text { Stability First } \\
\text { Reached in Round }\end{array}$} \\
\hline & $1-2$ & $2-3$ & $3-4$ & $\begin{array}{l}\text { Non- } \\
1-2\end{array}$ & 2-3 & $\begin{array}{r}\text { ated } \\
3-4\end{array}$ & $\begin{array}{l}\text { Reache } \\
\text { Manip }\end{array}$ & Non-Manip & Manip & Non-Manip \\
\hline $\begin{array}{l}46 \\
48 \\
49 \\
50\end{array}$ & $\begin{array}{l}0.40 \\
0.37 \\
0.40 \\
0.50\end{array}$ & $\begin{array}{l}0.07 \\
0.23 \\
0.23 \\
0.27\end{array}$ & $\begin{array}{l}0.13 \\
0.17 \\
0.20 \\
0.07\end{array}$ & $\begin{array}{l}0.27 \\
0.33 \\
0.43 \\
0.30\end{array}$ & $\begin{array}{l}0.17 \\
0.03 \\
0.23 \\
0.13\end{array}$ & $\begin{array}{l}0.17 \\
0.03 \\
0.13 \\
0.23\end{array}$ & $\begin{array}{l}3 \\
4 \\
4 \\
4\end{array}$ & $\begin{array}{l}3 \\
3 \\
4 \\
3\end{array}$ & $\begin{array}{l}3 \\
5 \\
5 \\
4\end{array}$ & $\begin{array}{l}5 \\
3 \\
4 \\
3\end{array}$ \\
\hline Averages & 0.40 & 0.24 & 0.16 & 0.30 & 0.16 & 0.13 & 3.70 & 3.10 & 4.27 & 3.80 \\
\hline
\end{tabular}


TABLE XIV

Results of Statistical Tests on Stability

\begin{tabular}{lcccc} 
Factually-based Delphi & \multicolumn{2}{c}{$t$-test } & Analysis of Variance \\
\hline & $t$ value & $t$ sign. at & F value & F sign. at \\
R1-R2 changes & 4.902 & 0.001 & 24.038 & 0.001 \\
R2-R3 changes & 3.833 & 0.001 & 14.694 & 0.001 \\
R3-R4 changes & 3.071 & 0.01 & 9.429 & 0.004 \\
When 20\% stability occurred & 2.865 & 0.01 & 8.209 & 0.006 \\
When 15\% stability occurred & 3.114 & 0.01 & 9.695 & 0.003 \\
\hline
\end{tabular}

Value-laden Delphi -test Analysis of Variance $t$ value $t$ sign. at $F$ value $F$ sign. at

R1-R2 changes

4.267

0.001

18.209

0.001

R2-R3 changes

3.525

0.001

12.424

0.001

R3-R4 changes

1.810

0.1

3.277

0.072

When $20 \%$ stability occurred

2.909

0.01

8.465

0.005

When $15 \%$ stability occurred

2.214

0.05

4.900

0.029 
was a significant difference between the statistically manipulated and non-manipulated Delph1 statements in all cases. Thus, research subhypotheses NI through N4 were refected. These results support a strong rejection of the research hypothesis $\mathrm{R} 8$. Since in all cases, the mean of the statistically manipulated Delphi statements was greater than the mean of the non-manipulated Delphi statements, one must accept the alternative hypothesis that statistical manipulation had a highly significant destabilizing effect on value-laden Delphi statements.

\section{Additional Results Using the Stabllity Data}

It has been reported in numerous articles that the value of going more than two rounds is questionable and that to go beyond three rounds is almost surely unnecessary. The results of these Delphis, however, indicate there is still a considerable amount of changing of answers taking place.

The average round that $20 \%$ stability took place in the nonmanipulated Delphi was 3.77 for the factually-based Delphi (see Table XII) and 3.10 for the value-laden DelphI (see Table XIII), which was considerably later than the second round. The average percent of changes between rounds for the factually-based non-manipulated Delphi statements was $25 \%$ between rounds 2 and 3 and $17 \%$ between rounds 3 and 4 . This indicates that it would have been better to run at least three rounds. The average percent of change between rounds for the value-laden nonmanipulated Delphi statements, however, was 16\% between rounds 2 and 3 and $13 \%$ between rounds 3 and 4 . This was somewhat contrary to the average round where $20 \%$ stability took place (3.10). This indicates that while some value statements achieved stability early (by round 2), 
others (almost half in this case) required at least three rounds to reach the desired stability (20\%).

If the above results are proven consistent in other studies, it will add credibility to the use of stability in determining when to eliminate a Delphi statement from further consideration or in determining the optimal number of rounds to run a Delphi.

An argument can be made that stability is irrelevant to factuallybased Delphis, that the main concern is whether there are significant changes in the median and quartile ranges. Table XV shows a tally of the number of changes in the quartiles and means of both the manipulated and non-manipulated Delphis. As can be seen, there was significant movement in the quartiles of the non-manipulated Delphi between rounds 2 and 3 and a lesser but still significant change between rounds 3 and 4. The median, however, did not show a significant movement after round 2. This is somewhat typical of most Delphis (i.e. the median tends to stay stationary or only slight movement occurs after the second round while the quartiles converge). The question then becomes is it worth the additional costs (time, money, and other resources) to run another round to achieve a higher level of convergence?

Table XV also demonstrates some other interesting points when one compares the manipulated Delphi with the non-manipulated Delphi. From the results of the earlier t-tests and analysis of variances on stability, one would expect the number of changes that occur between rounds to be greater for manipulated Delphi statements than for nonmanipulated. While there were more changes, the additional number 
TABLE XV

Number of Factually-Based Delphi Statements that Changed Between Rounds

\begin{tabular}{|c|c|c|c|c|c|c|c|c|c|c|}
\hline \multirow{2}{*}{\multicolumn{2}{|c|}{$\begin{array}{l}\text { number of Delphi } \\
\text { statements that }\end{array}$}} & \multicolumn{3}{|c|}{ Lower Quartile } & \multicolumn{3}{|c|}{ Median } & \multicolumn{3}{|c|}{ Upper Quartile } \\
\hline & & $\mathrm{R} 1-\mathrm{R} 2$ & $\mathrm{R} 2-\mathrm{R} 3$ & $\mathrm{R} 3-\mathrm{R} 4$ & $\mathrm{R} 1-\mathrm{R} 2$ & $\mathrm{R} 2-\mathrm{R} 3$ & R3-R4 & $\mathrm{R} 1-\mathrm{R} 2$ & $\mathrm{R} 2-\mathrm{R} 3$ & $\mathrm{R} 3-\mathrm{R} 4$ \\
\hline \multirow{2}{*}{$\begin{array}{l}\text { Non- } \\
\text { Manip. }\end{array}$} & & 23 & 18 & 10 & 9 & 4 & 3 & 23 & 20 & 7 \\
\hline & no change & 7 & 12 & 20 & 21 & 26 & 27 & 7 & 10 & 23 \\
\hline \multirow{2}{*}{ Manip. } & changed & 26 & 19 & 11 & 30 & 28 & 18 & 27 & 23 & 8 \\
\hline & no change & 4 & 11 & 19 & 0 & 2 & 12 & 3 & 7 & 22 \\
\hline
\end{tabular}


was not significantly greater. This was probably due to the large. number of changes that occurred normally under the non-manipulated conditions. Therefore while the number of participants changing their answers were significantly larger for statistically manipulated Delphi statements, there was not a significantly larger number of changes in the quartiles between rounds. There was, however, as Table XV demonstrates, a highly significant difference between the number of changes that occurred in the median.

Comparison of Factually-based and Value-laden Delphis

The results of running a 2-way analysis of variance on the average round where $20 \%$ and $15 \%$ stability took place are shown in Tables XVI and XVII (Hypotheses HIO and HII). As can be seen from the results there was a significant difference in the degree of stability obtained between the types of Delphi as well as whether the Delphi was manipulated or not. This would indicate a rejection of research subhypotheses N5 and N6. Since the mean round where $20 \%$ stability (15\% stability) occurred was greater for factually-based Delphi statements than for value-laden Delphi statements, one must accept the alternative hypothesis that the factually-based Delphi statements took longer to reach stability than the value-laden Delphi statements, regardless of whether they were manipulated or not. Since the mean round where $20 \%$ stability (15\% stability) occurred was greater for statistically manipulated Delphi statements than for non-manipulated Delphi statements, one must also accept the alternative hypothesis that statistical manipulation had a signfficant destabilizing effect on the responses to the Delphi statements regardless of what type of 


\section{TABLE XVI}

Analysis of Variance on Summarized 20\% Stabilj.ty Data

\section{$20 \%$ Stability}

\begin{tabular}{|c|c|c|c|}
\hline & non-manip. & manip. & $\underline{t_{i}}$ \\
\hline Factually-based & 3.77 & 4.33 & 8.10 \\
\hline Value-based & 3.10 & 3.70 & 6.80 \\
\hline$t \cdot j$ & 6.87 & 8.03 & 14.9 \\
\hline $\bar{y}_{. j}$ & 3.435 & 4.015 & \\
\hline
\end{tabular}

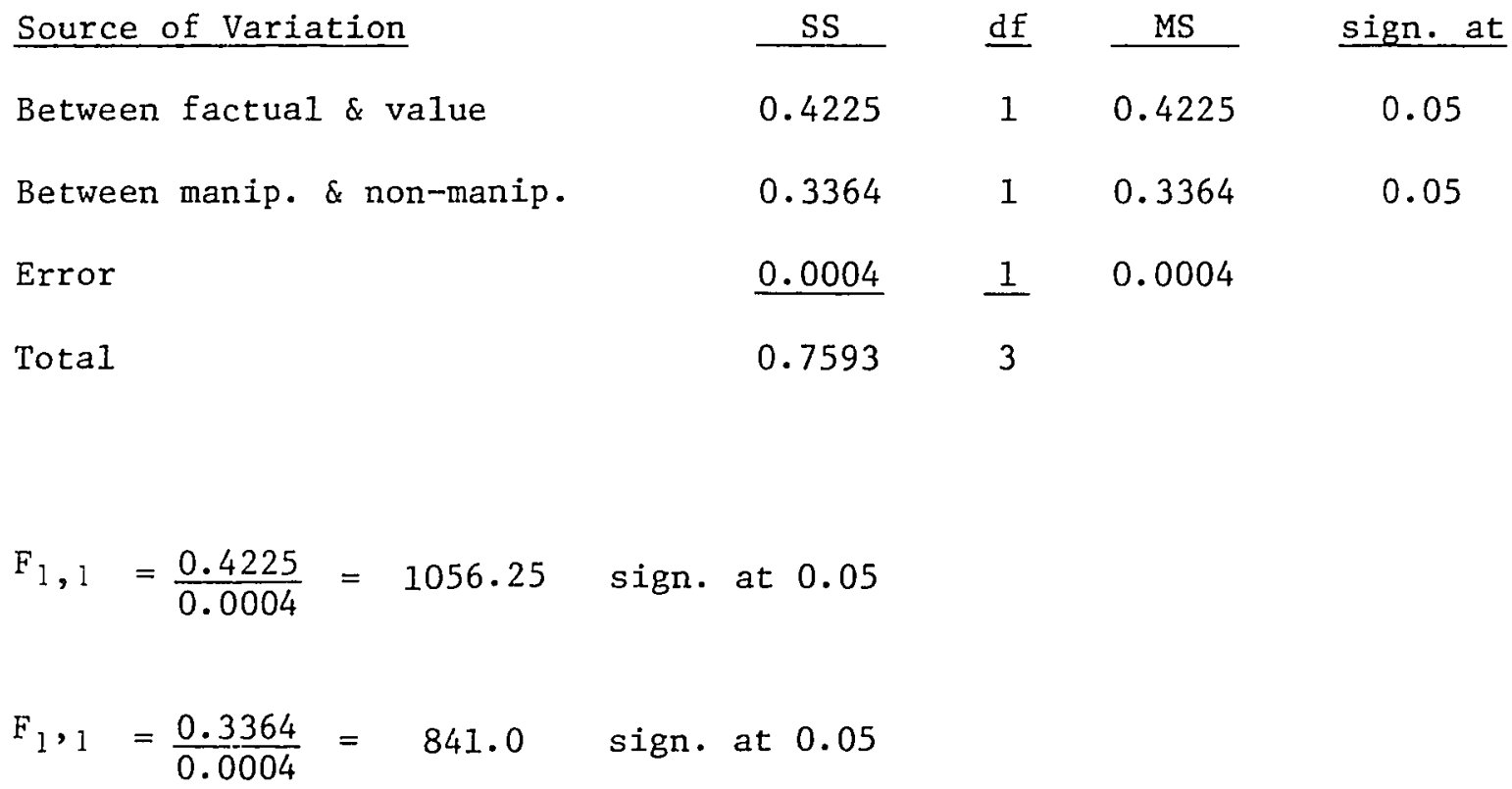


TABLE XVII

Analysis of Variance on Summarized 15\% Stability Data

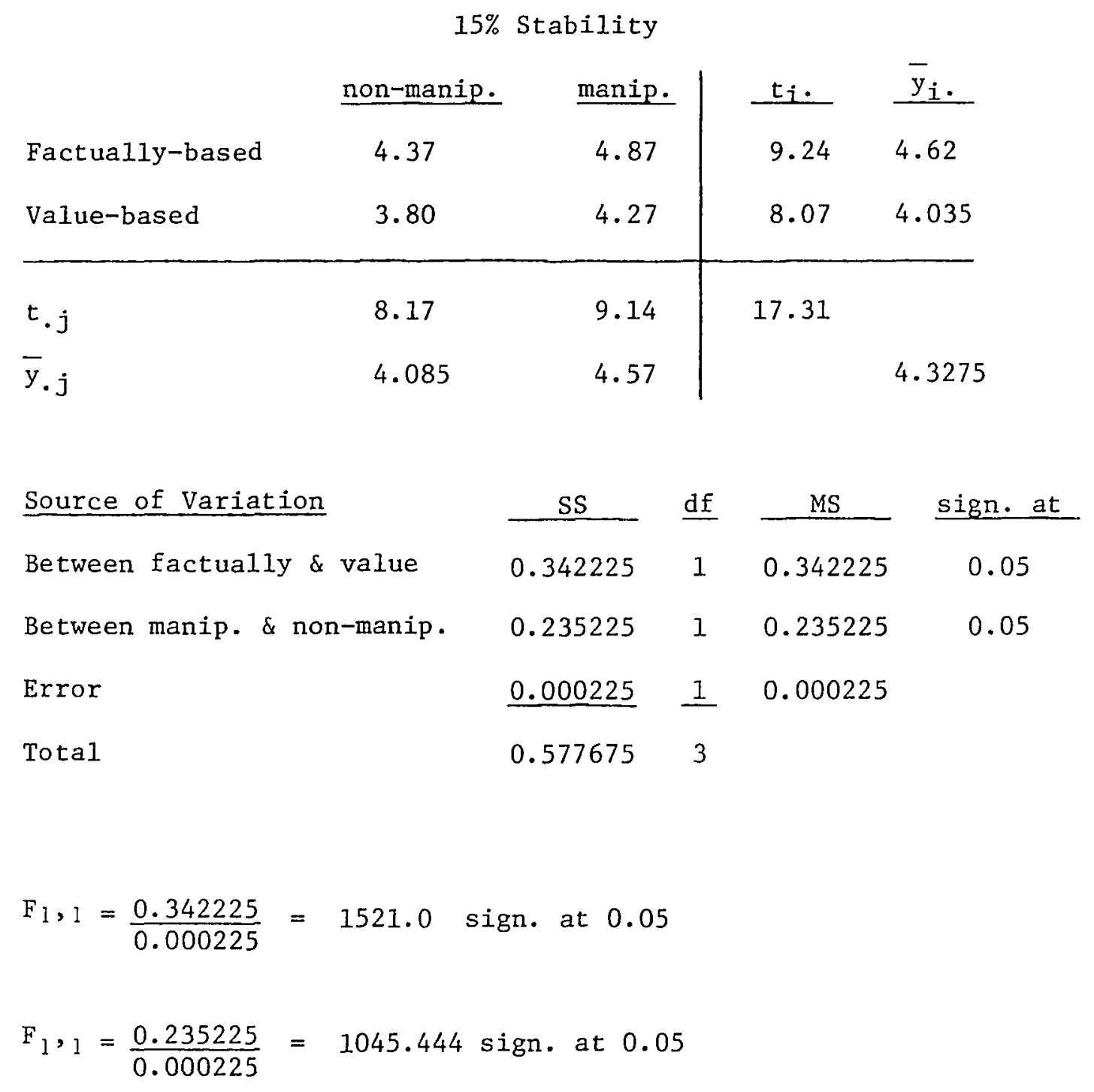


statements they were.

Table XVIII shows the results of running t-tests on the above data (Hypotheses HIO through H13). The t-test results substantiate the results of the above analysis of variance. In addition one can also see that manipulated factually-based Delphi statements were the most unstable while the non-manipulated value-based Delphi statements were the most stable (even though their mean stability did not occur until round 3 ). One can also notice that the manipulated value-based Delphi statements had about the same stability as the non-manipulated factually-based Delphi statements (i.e., they were not significantly different).

The results of the above analysis suggest the rejection of research hypothesis $R 9$. As demonstrated there was a significant difference between factually-based Delphi statements and value-laden Delphi statements with respect to the effect manipulation of statistical feedback had upon stability.

Summary of Stability Results

The above results call for the rejection of all three research hypotheses, $R 7, R 8$, and $R 9$. Statistical manipulation did have a highly significant destabilizing effect on both types of Delphi statements. There also was a difference in the effects statistical manipulation had on the two types of Delphi statements. Manipulated factually-based Delphi statements were the most unstable, while nonmanipulated value-1aden Delphi statements were the most stable. Nonmanipulated factually-based Delphi statements had about the same degree of stability as manipulated value-laden Delphi statements. 
TABLE XVIII

t-tests on Summarized Stability Data

\begin{tabular}{l|c|c|c|c}
\cline { 2 - 5 } & \multicolumn{2}{c}{$20 \%$ Stability } & \multicolumn{2}{c}{$15 \%$ Stability } \\
\cline { 2 - 5 } factually-based & $\overline{\mathrm{x}}_{11}=3.77$ & $\overline{\mathrm{x}}_{12}=4.33$ & $\overline{\mathrm{x}}_{13}=4.37$ & $\overline{\mathrm{x}}_{14}=4.87$ \\
& $\sigma_{11}=0.844$ & $\sigma_{12}=0.795$ & $\sigma_{13}=0.795$ & $\sigma_{14}=0.340$ \\
\hline \multirow{2}{*}{ value-based } & $\overline{\mathrm{X}}_{21}=3.10$ & $\overline{\mathrm{x}}_{22}=3.70$ & $\overline{\mathrm{X}}_{23}=3.80$ & $\overline{\mathrm{x}}_{24}=4.27$ \\
& $\sigma_{21}=0.700$ & $\sigma_{22}=0.862$ & $\sigma_{23}=0.792$ & $\sigma_{24}=0.814$ \\
\hline
\end{tabular}

$\hat{\sigma}=\sqrt{\frac{n_{1} s_{1}{ }^{2}+n_{2} S_{2}^{2}}{n_{1}+n_{2}-2}}=\sqrt{\frac{15\left(s_{1}^{2}+s_{2}^{2}\right)}{58}}$ since $n_{1}=n_{2}=30$

$\hat{\sigma}_{\Delta \bar{x}}=\hat{\sigma} \sqrt{\frac{\mathrm{n}_{1}+\mathrm{n}_{2}}{\mathrm{n}_{1} \mathrm{n}_{2}}} \quad=\quad \sqrt{\frac{\mathrm{s}_{1}^{2}+\mathrm{s}_{2}^{2}}{29}}$

$t=\frac{\bar{x}_{1}-\bar{x}_{2}}{\hat{\sigma}_{\Delta \bar{x}}} \quad d f=n_{1}+n_{2}-2=58$

\begin{tabular}{|c|c|c|c|c|c|c|c|}
\hline \multicolumn{4}{|c|}{$20 \%$ Stability } & \multicolumn{4}{|c|}{$15 \%$ Stability } \\
\hline$\overline{\mathrm{x}}_{1}$ & $\bar{x}_{2}$ & $t$ & sign. at & $\underline{\bar{X}_{1}}$ & $\underline{\mathrm{X}}_{2}$ & $t$ & sign. at \\
\hline$\overline{\mathrm{X}}_{11}$ & $\bar{x}_{12}$ & -2.83 & 0.01 & $\overline{\mathrm{x}}_{13}$ & $\overline{\mathrm{X}}_{14}$ & -3.11 & 0.01 \\
\hline $\bar{x}_{21}$ & $\overline{\mathrm{X}}_{22}$ & -2.91 & 0.01 & $\bar{x}_{23}$ & $\bar{x}_{24}$ & -2.23 & 0.05 \\
\hline $\bar{x}_{11}$ & $\overline{\mathrm{X}}_{2 \mathrm{I}}$ & 3.29 & 0.01 & $\bar{x}_{13}$ & $\overline{\mathrm{x}}_{23}$ & 2.75 & 0.01 \\
\hline $\bar{x}_{12}$ & $\bar{X}_{22}$ & 3.14 & 0.01 & $\bar{x}_{14}$ & $\bar{x}_{24}$ & 3.66 & 0.001 \\
\hline $\bar{x}_{11}$ & $\bar{x}_{22}$ & 0.31 & - & $\bar{x}_{13}$ & $\bar{x}_{24}$ & 0.47 & - \\
\hline $\bar{x}_{21}$ & $\bar{x}_{12}$ & -6.25 & 0.001 & $\bar{X}_{23}$ & $\bar{x}_{14}$ & -6.69 & 0.001 \\
\hline
\end{tabular}


Overal1, value-laden Delphi statements were more stable than factuallybased Delphi statements, regardless of whether they were manipulated or not. If one were to use stability as a criteria for determining the number of rounds to run a Delphi, the results of this experiment ind1cated running at least three rounds.

\section{STATISTICAL MANIPULATION AND CONFIDENCE OF DELPHI PARTICIPANTS}

It was hypothesized that statistical manipulation might have an effect on the confidence (as expressed by self-rating) of a participant. The following research hypothesis was thus created:

$$
\begin{aligned}
& \text { R10 - manipulation of statistical feedback in factually- } \\
& \text { based Delphi statements has no relationship to the } \\
& \text { changes in the respondents' self-rating of their } \\
& \text { knowledge of the subject matter for those Delphi } \\
& \text { statements. }
\end{aligned}
$$

In order to gain better insights into the behavior of change in self-rating and to determine how manipulation of statistical feedback can affect this behavior, the following research subhypotheses were proposed:

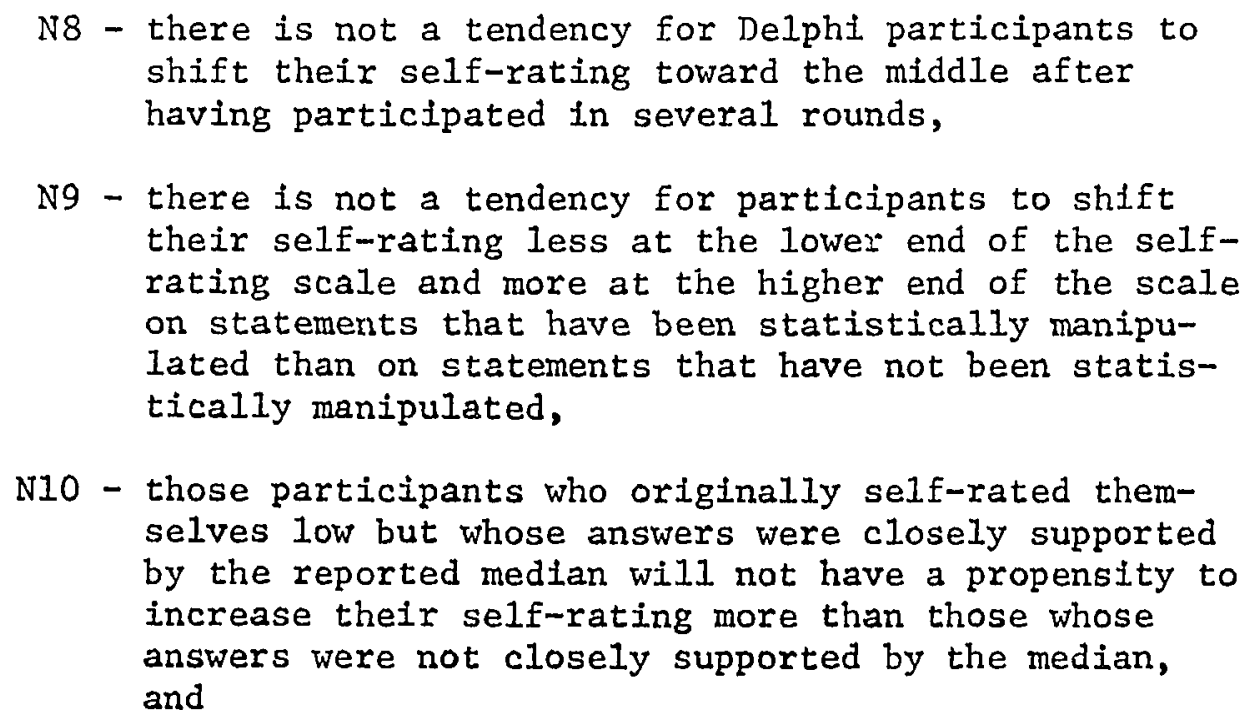


N11 - those participants who originally self-rated themselves high but whose answers were distant from the reported median will not have a propensity to decrease their self-ratings more than those whose answers were not as distant from the median.

It was also questioned if there was a relationship between an individual's round 1 self-rating and the amount he changed his answer. This was expressed as the following research subhypotheses:

N12 - the average shift in responses between round 1 and round 4 for those participants in each of the selfrating classifications will not decrease as the selfrating classification increases, and

N13 - the average shift in responses between round 1 and round $4 \mathrm{in}$ each of the self-rating classifications for participancs manipulated via statistical feedback will not be greater than those for nonmanipulated participants.

(N8 and N9 are tested by $\mathrm{H} 15$; $\mathrm{N} 10$ and $\mathrm{N} 11$ are tested by $\mathrm{H16}$; and $\mathrm{N} 12$ and $\mathrm{N} 13$ are tested by H17.)

Factually-based Delphi Results

The average difference between the round 4 self-rating and the round 1 self-rating of all the participants for several special cases can be found in Table XIX. The table also contains the standard deviation and the results of two significant tests for a single mean using the t-distribution. The purpose of the first single mean t-test was to determine if the mean change in the self-rating from round 1 to round 4 was significantly different from zero. Thus the test assumed that people would not or should not change their self-rating of all the non-manipulated Delphi statements (Hypothesis H14). The second test assumed that people changed thelr self-rating to reflect an increase in confidence that was gained from the greater familiarlty 
TABLE XIX

Results of Statistical Tests on the Average Differences Between Round 1 and Round 4 Self-rating by Manipulated and Non-manipulated Participants

\section{Explanation}

\section{All data}

$\mathrm{SR} 1=1$

$\mathrm{SRI}=2$

$\mathrm{SR} 1=3$

$\mathrm{SR} 1=4$

$\mathrm{SR} 1=5$

Lower range 1

Lower range 2

Lower range 3

Upper range 1

Upper range 2

Upper range 3

Not lower range 1

Not upper range 2 \begin{tabular}{llcl} 
& \multicolumn{3}{c}{ Manip. } \\
SR4-SRI std & $\bar{x}-0 /(\sigma / \sqrt{n-1})$ & $\bar{x}-0.47 /(\sigma / \sqrt{n-1})$ \\
Mean & dev & $t-c a l c ~ s i g n$ at & $t-c a l c ~ s i g n$ at \\
\hline
\end{tabular}

\subsection{0}

0.60

0.20

$-0.22$

$-0.63$

$-1.26$

0.49

0.60

0.72

$-1.11$

$-1.39$

$-1.57$

0.39

$-0.60$

\section{$\begin{array}{lll}0.94 & 6.525 \quad .001\end{array}$}

$0.78 \quad 14.311 \quad .001$

$0.79 \quad 4.550$

$0.89-3.060$

$1.19-4.609$

$0.78 \quad 8.629$

$0.79 \quad 6.030$

$0.79 \quad 5.654$

$\begin{array}{ll}1.29 & -4.554 \\ 1.20 & -4.600\end{array}$

$1.09-5.397$

$0.81 \quad 11.387$

$1.12-3.941$
$1.14-4.021$

\subsection{1}

3.12

6.10

$-9.68$

$-6.89$

$-6.16$

0.27

1.30

1.95

$-6.37$

$-6.39$

$-6.76$

$-2.33$

$-6.82$

.001
.01
.001
.001
.001
.001
.01
.2
.1
.001
.001
.001
.02
.001

SRI = self-rating during round 1

Lower range $1 \mathrm{SRI}=1$ or 2 and $A D-R I * \leqslant .25$

Lower range $2 \quad \mathrm{SRI}=1$ or 2 and $\mathrm{AD}-\mathrm{RI} * .15$

Lower range $3 \mathrm{SR} 1=1$ or 2 and $\mathrm{AD}-\mathrm{RI} * \leqslant .10$

*for non-manipulated statements $A D-R I$ is replaced by $R 3-R I$
iron-Manip.

\begin{tabular}{llcc} 
SR4-SR1 std & $\bar{x}-0 /(\sigma / \sqrt{n-1})$ & $\bar{x}-0.47 /(\sigma / \sqrt{n-1})$ \\
Mean & dev & $t-c a l c$ & sign at \\
\hline
\end{tabular}

df Mean dev t-calc sign at t-calc signat df

$\begin{array}{cccccccc}899 & 0.47 & 0.93 & 15.123 & .001 & 0 & & 899 \\ 351 & 0.82 & 0.84 & 19.113 & .001 & 8.17 & .001 & 384\end{array}$

$\begin{array}{llllllll}319 & 0.44 & 0.86 & 9.136 & .001 & -0.63 & .6 & 322\end{array}$

$\begin{array}{llllllll}319 & 0.44 & 0.86 & 9.136 & .001 & -0.63 & .6 & 322 \\ 156 & -0.09 & 0.78 & -1.398 & .2 & -8.56 & .001 & 142\end{array}$

$\begin{array}{llllllll}51 & -0.45 & 0.93 & -3.053 & .01 & -6.17 & .001 & 39\end{array}$

$\begin{array}{llllllll}18 & -0.56 & 1.01 & -1.644 & .2 & -2.89 & .02 & 8\end{array}$

$\begin{array}{llllllll}112 & 0.74 & 0.93 & 12.069 & .001 & 4.39 & .001 & 229\end{array}$

$\begin{array}{llllllll}62 & 0.73 & 0.90 & 10.096 & .001 & 3.60 & .001 & 155\end{array}$

$\begin{array}{llllllll}38 & 0.72 & 0.87 & 9.359 & .001 & 3.24 & .01 & 127\end{array}$

$\begin{array}{llllllll}27 & -1.17 & 1.11 & -3.626 & .01 & -4.90 & .001 & 11\end{array}$

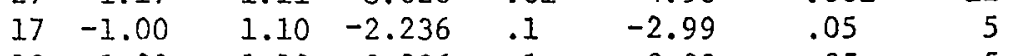

$\begin{array}{llllllll}13 & -1.00 & 1.10 & -2.236 & .1 & -2.99 & .05 & 5\end{array}$

$\begin{array}{llllllll}558 & 0.60 & 0.84 & 15.472 & .001 & 3.36 & .001 & 471\end{array}$

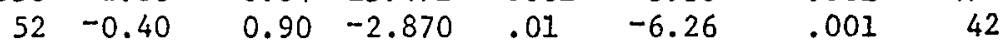

Upper range 1 SRI $=5$ and $A D-R I * \geqslant 0.4$ $\mathrm{SRI}=4$ or 5 and $\mathrm{AD}-\mathrm{RI} * \geqslant 0.8$

Upper range $2 \mathrm{SR} 1=5$ and $A D-R 1 * \geqslant 0.5$ $\mathrm{SRI}=4$ or 5 and $A D-R I^{*} \geqslant 1.0$

Upper range $3 \mathrm{SR} 1=5$ and $A D-R I^{*} \geqslant 0.75$ $\mathrm{SR} I=4$ or 5 and $\mathrm{AD}-\mathrm{RI} * \geqslant 1.25$ 
and knowledge obtained from the thought and consideration given the statement through several rounds of the Delphi. The latter test also assumed that the mean of all the non-manipulated Delphi statements was representative of the overall increase in self-rating attributable to these statements. An analysis of this information will now be given. As one might expect, the mean change in the self-ratings of the participants for the non-manipulated Delphi statements was greater than the mean change for the manipulated statements. Both cases were significantly different from zero. This indicates that as Delphi participants were forced to think about each statement and as they saw how others reacted to the statement, they increased both their base of knowledge relative to that statement and their familiarity with that statement. Thus when they were asked to self-rate themselves during a later round, they felt more confident in their ability to respond. This is supportive of the idea that the Delphi can be used as an information dissemination device as well as an information collection device. ${ }^{7}$ The significantly lower mean change in the manipulated statements indicates that while the participants felt more confident in their ability to respond as a result of the above reasons, their confidence was undermined by the problem that the statistical feedback did not agree with what they anticipated.

While the above lends support to the rejection of research hypothesis R1O, it presents a sumary view. More can be learned if one subdivides the self-rating changes according to how the

7This directly supports the results of Ludlow's study [57] and is suggested by Linstone and Turoff in their definition of Delphi as a "communication" tool [56]. 
participants originally self-rated themselves. When one studies the means presented in the second through the slxth rows (SR $1=1$ through $S R 1=5)$ of Table $X I X$, one sees that those who originally self-rated themselves low increased their self-rating in later rounds and those who originally self-rated themselves high decreased their self-rating during later rounds. (In the case of the manipulated participants, the mean of the self-rating changes appears to be almost a linear function of the first round self-rating.) The results of the analysis of variance presented in Table XX veriffed there was a highly significant difference between the round 1 self-ratings with respect to how much change occurred. The results of the analysis of variance also showed the change depended upon whether the participant was manipulated or not. In this case the manipulated participants did not change their self-ratings as much at the lower end of the scale but changed them more at the higher end of the scale.

The above is strong evidence to reject research subhypotheses N8 and N9. This would indicate that there was a significant tendency for Delphi participants to shift their self-ratings during later rounds toward the middle. That is, those who originally self-rated themselves low increased their self-rating during later rounds; and those who originally self-rated themselves high decreased their selfrating during later rounds. The further a participant's original self-rating was from the middle, the greater was his tendency to move toward the middle. While statistically manipulated participants who originally self-rated themselves low significantly increased their self-rating during later rounds, they did not increase it as 
TABLE XX

Analysis of Varlance to Test the Significance of the Shift of Self-rating Towards the Middle in Later Rounds

\begin{tabular}{lccccc} 
& $\frac{\text { SR4-SRI Mean }}{\text { non-manip }}$ & $\frac{t_{i}}{\text { manip }}$ & & $\bar{y}_{i}$ \\
$S R I=1$ & 0.82 & 0.60 & 1.42 & 0.71 \\
$S R I=2$ & 0.44 & 0.20 & 0.64 & 0.32 \\
$S R 1=3$ & -0.09 & -0.22 & -0.31 & -0.155 \\
$S R I=4$ & -0.45 & -0.63 & -1.08 & -0.54 \\
$S R I=5$ & -0.56 & -1.26 & -1.82 & -0.91 \\
\hline$t . j$ & 0.16 & -1.31 & -1.15 & \\
$\bar{y} . j$ & 0.032 & -0.262 & & -0.115
\end{tabular}

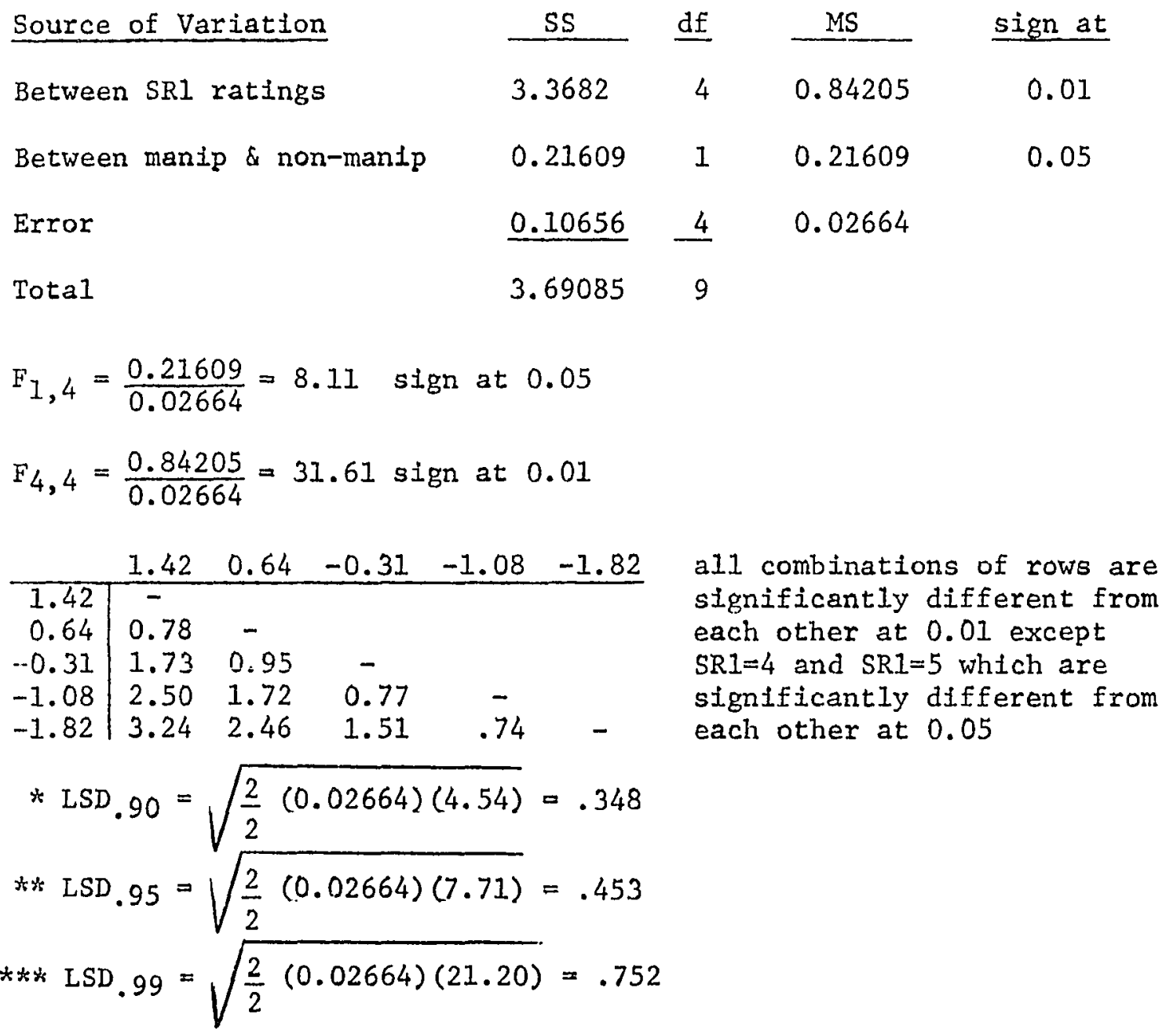


much as non-manipulated participants. The opposite was true for those who originally self-rated themselves high. The statistically manipulated participants who originally self-rated themselves high decreased their self-rating during later rounds by a significantly greater anount than the non-manipulated participants. This signified an overall decrease in the confidence of the participants who were statistically manipulated regardless of their original self-rating. The rejection of research subhypotheses $\mathrm{N} 8$ and $\mathrm{N} 9$ gives more credence to and exp1a-m nation behind, the rejection of research hypothesis $R 10$.

The last eight rows of Table XIX and XXI address themselves to the changes that occurred in self-rating for those participants who originally self-rated themselves low ( 1 or 2 ) but whose initial response was quite close to the median reported during round 4 (low ranges 1, 2, and 3) and those participants who orfginally self-rated themselves high ( 4 or 5 ) but whose initial response was quite distant from the median reported during round 4 (upper ranges 1,2 , and 3 ). It was hypothesized that the former particlpants would increase their self-rating more than other participants who self-rated themselves low since the falsified median would act in a reinforcing manner, making them feel as though they knew more than they thought. It was also hypothesized the latter would show a tendency to reduce their self-rating more than other participants who self-rated themselves high, since the considerably different median would act to undercut their confidence in their ability to respond to the statement. Table XXII shows there was a significant difference between the non-manipulated participants who originally self-rated themselves 
TABLE XXI

Significance of Differences Between Means of Self-rating Between Round 1 and Round 4 for Manipulated and Non-manipulated Participants (reference Table XIX).

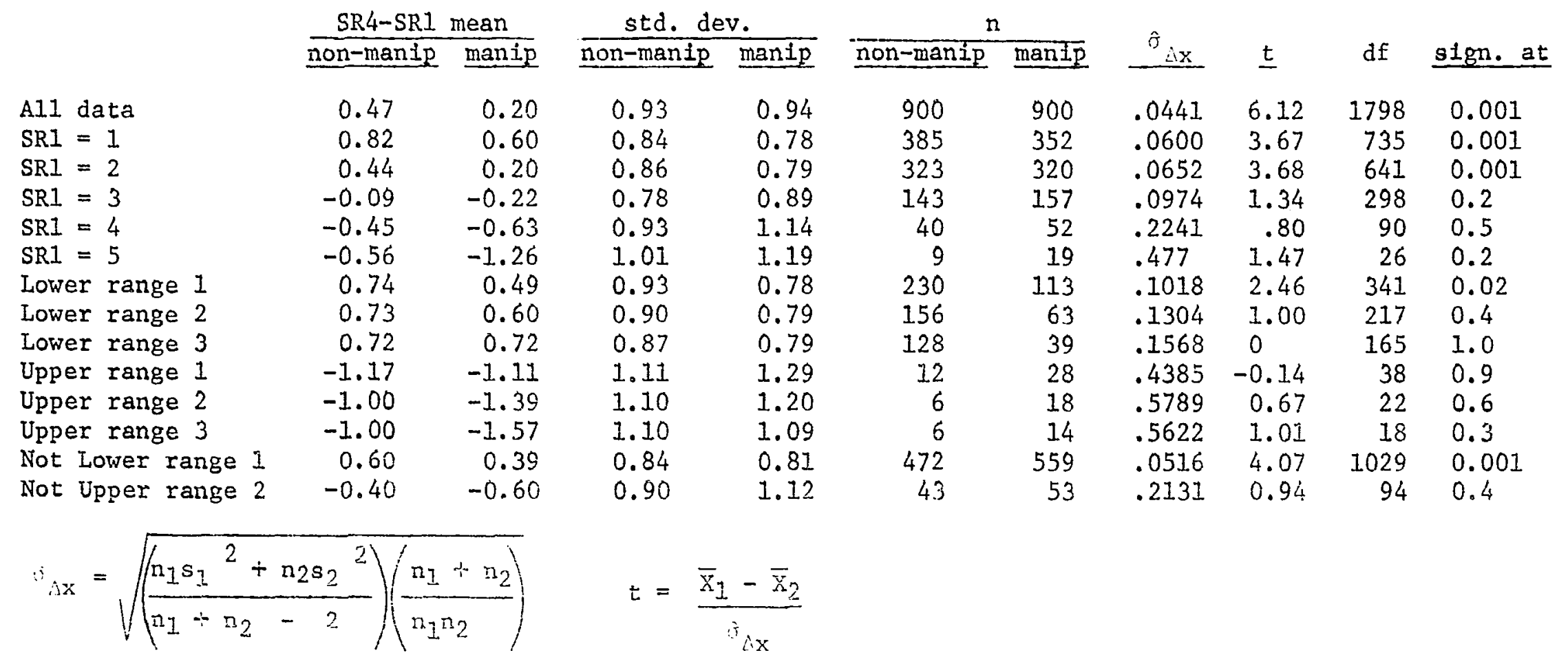


TABLE XXII

Significance of Differences Between Means of Self-reting Change for Those in Lower Range 1 and Those Not in Lower Range 1

\begin{tabular}{|c|c|c|c|c|c|c|c|c|c|c|}
\hline & \multicolumn{2}{|c|}{ SR4-SR1 mean } & \multicolumn{2}{|c|}{ std. dev. } & \multicolumn{2}{|l|}{ n } & \multirow[b]{2}{*}{$\hat{\sigma}_{\Delta \mathrm{x}}$} & \multirow[b]{2}{*}{$\underline{\tau}$} & \multirow[b]{2}{*}{$\underline{d f}$} & \multirow[b]{2}{*}{$\begin{array}{l}\text { sign. } \\
\text { at }\end{array}$} \\
\hline & $\begin{array}{l}\text { lower } \\
\text { range } 1 \\
\end{array}$ & $\begin{array}{l}\text { not lower } \\
\text { range } 1\end{array}$ & $\begin{array}{l}\text { lower } \\
\text { range I }\end{array}$ & $\begin{array}{l}\text { not lower } \\
\text { range } 1\end{array}$ & $\begin{array}{l}\text { lower } \\
\text { range } 1\end{array}$ & $\begin{array}{l}\text { not lower } \\
\text { range } 1\end{array}$ & & & & \\
\hline non-mantp & 0.74 & 0.60 & 0.93 & 0.84 & 230 & 472 & .0701 & 2.00 & 700 & 0.05 \\
\hline manip & 0.49 & 0.39 & 0.78 & 0.81 & 113 & 559 & .0832 & 1.20 & 670 & 0.3 \\
\hline
\end{tabular}


low but whose responses were closely supported by the reported median and the non-manipulated participants who originally self-rated themselves low but whose responses were not closely supported by the reported median. This relationship was not significant for the manipulated particlpants. Table XXIII shows the opposite was true for the upper range figures. There was a significant difference between the manipulated participants who originally self-rated themselves high but whose responses were distant from the reported median and the manipulated participants who orlginally self-rated themselves high but whose responses were not distant from the reported median. This relationship was not signiflcant for the non-manipulated particIpants. Had the sample size of the non-manipulated upper range 2 been larger, the results might have been different. This is illustrated by the comparison of the data for upper range 1 where a significant result was found for the non-manipulated participants. The interpretation of the results thus becomes difficult due to the inherent contradictions. Therefore, the results for research subhypotheses N10 and NII are inclusive. The distance between a participant's original estimate and the median reported to him may or may not contribute significantly to the change in his self-rating. Table XXIV presents the results of a two-way analysis of variance run on the mean change of the responses (round 4 answer minus round 1 answer) for each self-ratirg category, according to whether the participant was manipulated or not. The results indicate the self-rating category had a highly significant $(\alpha=0.01)$ effect on the amount of change in the responses. With the exception of the 


\section{TABLE XXIII}

Significance of Differences Between Means of Self-rating Change for Those in Upper Range 2 and Those Not in Upper Range 2

\begin{tabular}{|c|c|c|c|c|c|c|c|c|c|c|}
\hline & \multicolumn{2}{|c|}{ SR4-SRI mean } & \multicolumn{2}{|c|}{ std. dev. } & \multicolumn{2}{|l|}{$n$} & \multirow[b]{2}{*}{$\hat{\sigma}_{\Delta \mathrm{x}}$} & \multirow[b]{2}{*}{$\underline{t}$} & \multirow[b]{2}{*}{$\underline{\mathrm{df}}$} & \multirow[b]{2}{*}{$\begin{array}{l}\text { sign. } \\
\text { at }\end{array}$} \\
\hline & $\begin{array}{l}\text { upper } \\
\text { range } 2\end{array}$ & $\begin{array}{l}\text { not upper } \\
\text { range } 2\end{array}$ & $\begin{array}{l}\text { upper } \\
\text { range } \mathbf{2} \\
\end{array}$ & $\begin{array}{l}\text { not upper } \\
\text { range } 2\end{array}$ & $\begin{array}{l}\text { upper } \\
\text { range } 2 \\
\end{array}$ & $\begin{array}{l}\text { not upper } \\
\text { range } 2\end{array}$ & & & & \\
\hline non-manip & -1.00 & -0.40 & 1.10 & 0.90 & 6 & 43 & .4124 & -1.45 & 47 & 0.2 \\
\hline manip & -1.39 & -0.60 & 1.20 & 1.12 & 18 & 53 & .3157 & 2.50 & 69 & 0.02 \\
\hline $\begin{array}{l}\text { non-manfp } \\
\text { (upper } \\
\text { range 1) }\end{array}$ & -1.17 & -0.32 & 1.11 & 0.86 & 12 & 40 & .3115 & -2.73 & 50 & 0.01 \\
\hline
\end{tabular}


TABLE XXIV

Analysis of Variance to Test the Significance of the Mean Change in Answers

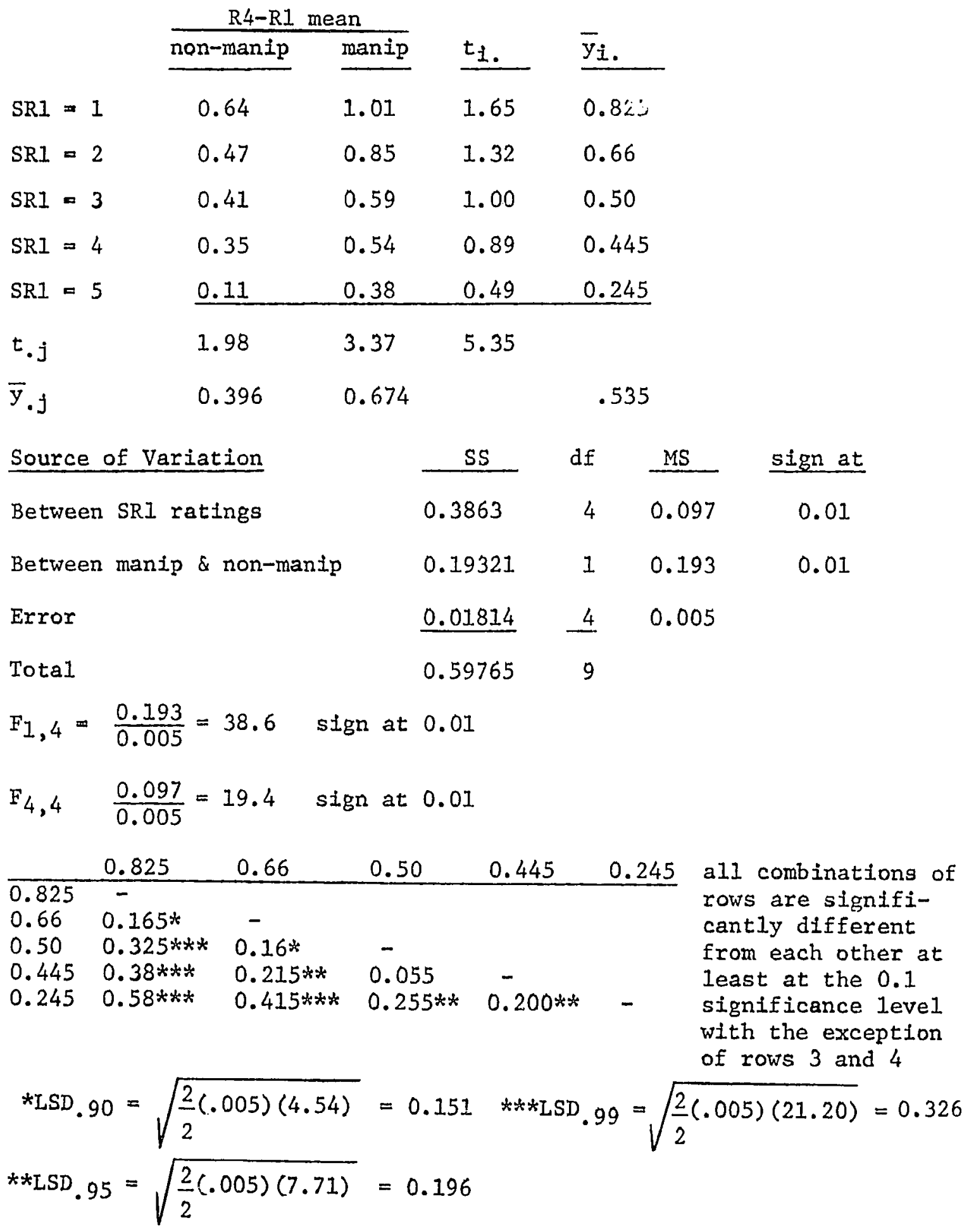


combinations of rows 3 and 4, all comblnations of rows were significantly different from each other at least at the 0.1 significance level. The results also indicate there was a highly significant $(\alpha=$ 0.01) difference between whether the participant was manipulated or not. However, looking at Table XXV one notices this highly significant difference holds only for a low self-rating (SR=1 or 2). The middle self-rating $(S R I=3)$ was significant at the $\alpha=0.01$ level. There was not a signiflcant difference for those who self-rated themselves high even though the relative difference between the manipulated and non-manipulated participants was as great or greater than the low self-raters. Had there been more participants in this category, the results might have been different. The results of Tables XXIV and XXV indicate the rejection of research subhypothesis $N 12$ and the quallfied rejection of research subhypothesis N13. The higher a participant self-rated himself, the less likely he was to change his response. This was true for both non-manipulated and manipulated participants. In further support of the rejection of research hypothesis R10, manipulated participants changed their responses by a significantly greater amount than non-manipulated participants, although this was primarily true for those who did not self-rate themselves high.

\section{Summary of Confidence Results}

The results of the above statistical tests and the implications of the resulting acceptance or rejection of the research subhypotheses N8 through N13 strongly support the rejection of research 
TABLE XXV

Signiflcance of Differences Between Means of Change in Answers for Manipulated and Non-mantpulated Participants Depending on Their Round 1 Self-rating

\begin{tabular}{|c|c|c|c|c|c|c|c|c|c|c|}
\hline & \multicolumn{2}{|c|}{ R4-R1 mean } & \multicolumn{2}{|c|}{ std. dev. } & \multicolumn{2}{|c|}{$\mathrm{n}$} & \multirow[b]{2}{*}{$\hat{\sigma}_{\Delta \mathrm{x}}$} & \multirow[b]{2}{*}{$\underline{t}$} & \multirow[b]{2}{*}{ df } & \multirow[b]{2}{*}{ sign. at } \\
\hline & non-manip & mantp & non-manlp & manlp & non-mantp & manip & & & & \\
\hline$S R 1=1$ & .64 & 1.01 & 1.05 & 1.34 & 385 & 352 & .0884 & -4.18 & 735 & .001 \\
\hline$S R I=2$ & .47 & .85 & 0.77 & 1.21 & 323 & 320 & .0300 & -4.75 & 641 & .001 \\
\hline SRI $=3$ & .41 & .59 & 0.79 & .82 & 143 & 157 & .0935 & -1.93 & 298 & .1 \\
\hline SRI $=4$ & .35 & .54 & 0.64 & .92 & 40 & 52 & .1723 & -1.10 & 90 & .3 \\
\hline$S R I=5$ & .11 & .38 & 0.19 & .93 & 9 & 19 & .3249 & -0.83 & 26 & .5 \\
\hline
\end{tabular}


hypothesis RIO, indicating mantpulation of statistical feedback does tend to affect the confidence and, as a result, the response of a participant.

\section{SUMMARY OF RESULTS}

Figure 3 provides a brief synopsis of the results. It was written to closely follow the design of Figure 2 at the beginning of Chapter III. 


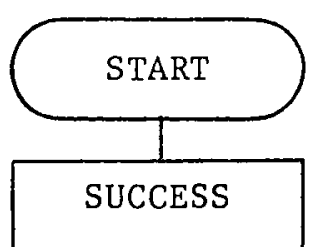

H1

\begin{tabular}{l}
\hline $\begin{array}{l}\text { success } 1 s \text { enhanced by running } \\
\text { additional rounds }\end{array}$ \\
\hline
\end{tabular}

$73 \%$ success in moving median

$75 \%$ or more of desired distance

for both types of Delphi in 4

rounds

H2

there was a low to medium correlation

between success of statistical manip-

ulation and amount participants

changed their answers

H3

there was a low to medium correlation

between success of statistical manip-

ulation and amount administrator

desired to change results

the medians (indexes) of manipulated

statements were moved to a signif-

icantly different place than non-manip-

ulated statements

the desired change was significantly

different from the change that would

have normally occurred

there is no significant difference

between FBDS* and VLDS** with respect

to manipulation via statistical feedback

H6

A

*FBDS = factually-based Delphi statement

**VLDS $=$ value-laden Delphi statement

Figure 3. Flowchart of the results of the statistical tests. 


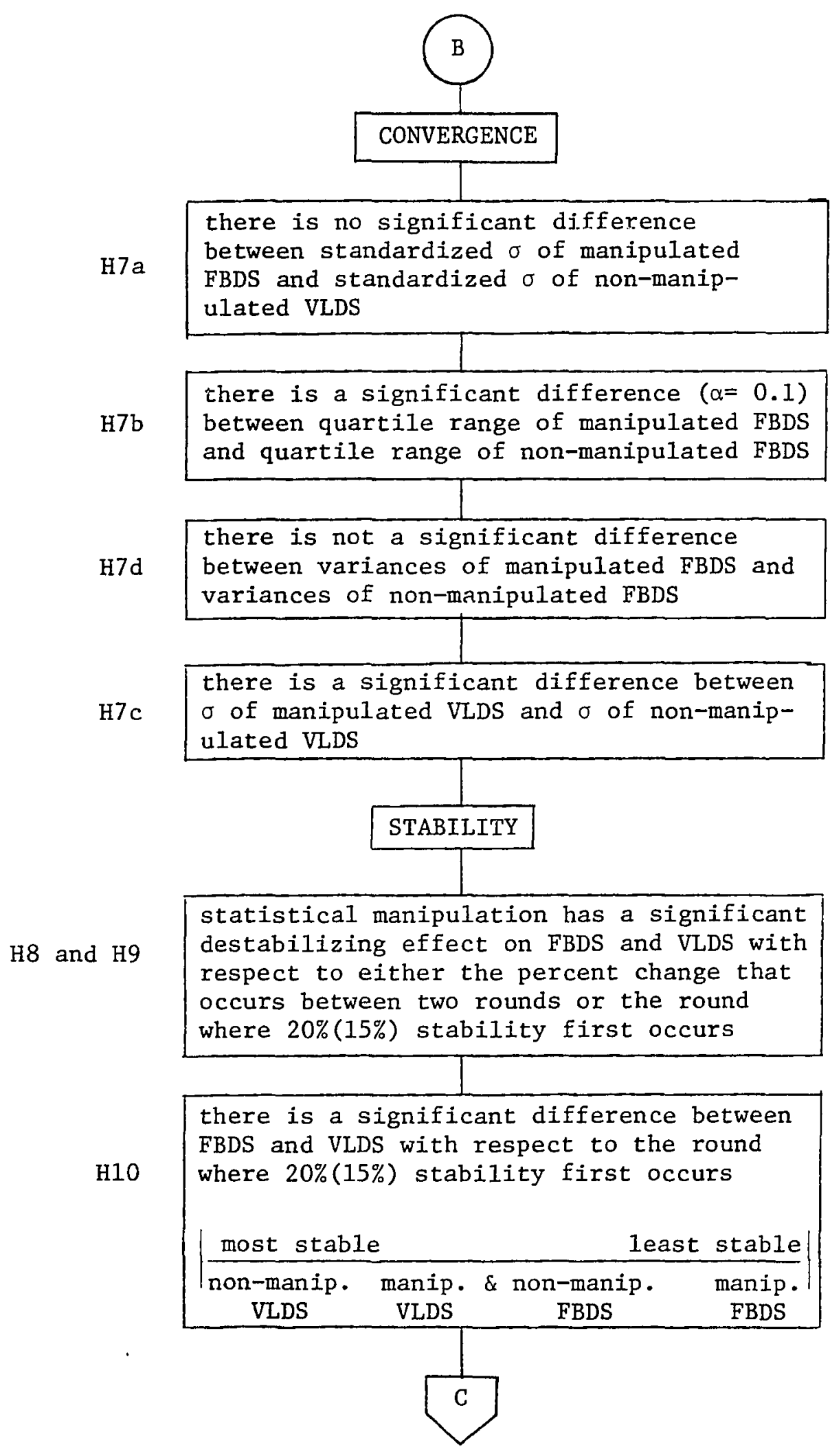




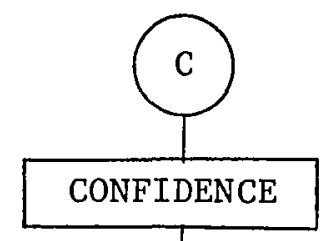

the mean change in self-ratings of participants for non-manipulated Delphi statements $>$ mean change for manipulated statements and both cases were $>$ zero

there is tendency for Delphi participants to shift their self-ratings towards the middle; however, in all cases, the shifts for particiH15 pants who respond to manipulated Delphi statements is less at the lower self-ratings and greater at the higher self-ratings, indicating statistical manipulation undermines the confidence of participants

the distance between a participant's original estimate and the median reported back to him may or may not contribute significantly to the change in his self-ratings. The results were inconclusive.

the higher cre self-rates himself the less likely he will change his response, and manipH17 ulated participants will change their responses by a significantly greater amount than nonmanipulated participants (although this is primarily true for those who do not self-rate themselves high.)

DONE 


\section{CHAPTER V}

\section{CONCLUSIONS AND EXTENSIONS}

The purpose of this research was to investigate empirically the statistical manipulation of factually-based and value-laden Delphi statements to see if it was possible to achieve a particular desired point and to explore the effects such manipulation had upon the convergence and stability of the responses to Delphi statements. The effects of statistical manipulation upon the confidence of the Delphi participant (as measured by self-rating) was also explored.

The signiflcance of the problem is evident in the increased use of the Delphi technique in providing input to polfcy decision making bodies in government, defense, business, education, etc. and the Increased concern expressed in the literature about the possibilities of manipulation.

\section{CONCLUSIONS}

The results of the research with respect to the original ten research hypotheses proposed can be summarized as follows:

Success: R1 and R2 were rejected while R3 was accepted. Statistical manipulation did cause a highly significant shift in the answers of participants and a high degree of success existed in obtaining a desired value. This success was enhanced by running additional rounds. The above was true for both factually-based 
and value-laden Delphi statements. There was, however, no significant difference between the statistical manipulability of factually-based and value-laden Delphi statements.

Convergence: R4 and R5 were rejected and R6 was accepted. While statistical manipulation did not have any significant effect on the standard deviation of factually-based Delpht statements, it did have a significant effect on the convergence of the quartile range. Statistical manipulation also had a significant effect on the convergence of value-laden Delphi statements, although nothing can be said as to whether it increased or decreased the convergence. It did not appear that convergence of factually-based Delphi statements was more or less affected by statistical manipulation than convergence of value-laden Delphi statements.

Stability: All three research hypotheses (R7, R8, and R9) were rejected. Statistical manipulation did have a highly significant destabilizing effect on both types of Delphi statements. There also was a difference in the effects statistical manipulation had on the two types of Delphi statements. Manipulated factually-based Delphi statements were the most unstable, while non-manipulated value-laden Delphi statements were the most stable. Non-manipulated factuallybased Delphi statements had about the same degree of stability as manipulated value-laden Delphi statements. Overall, value-laden Delphi statements were more stable than factually-based Delphi statements, regardless of whether they were manipulated or not. If one were to use stability as a criteria for determining the number of rounds to run a Delphi, the results of this experiment 
indicated running at least three rounds.

Confidence: $R 10$ was rejected. There was a signiflcant tendency for Delphi participants to shift their self-rating during later rounds toward the middle. While statistically manipulated participants who originally self-rated themselves low significantly increased their self-rating during later rounds, they did not increase it as much as non-manipulated participants. The opposite was true for those who originally self-rated themselves high. The statistically manipulated participants who originally self-rated themselves high decreased their self-rating during later rounds by a significantly greater amount than the non-manipulated participants. This signified an overall decrease in the confidence of the participants who were statistically manipulated, regardless of their original self-rating. The distance between a participant's original estimate and the median reported back to him may or may not contribute significantly to the change in his self-rating. The results were inconsistent. The higher a participant self-rated himself the less likely he was to change his response. This was true for both non-manipulated and manipulated participants. Manipulated participants, however, changed their responses by a significantly greater amount than non-manipulated participants, although this was primarily true for those who did not self-rate themselves high.

RECOMMENDATIONS FOR AVOIDING STATISTICAL MANIPULATION

The probity of the results of a Delphi must ultimately rely upon the integrity of those who have administered the Delphi. 
The more impervious a tool is to fraudulent misuse the less one has to worry about such actlons. But because fraudulent misuse can occur does not lessen the value of the procedure, for the same is true for most tools. If one were to discard a tool because it could be misused through either fraudulent intent or ignorance, one would have to throw away such valuable tools as statistics, linear programing and other operations research tools, economics, engineering, and most of the tools of other disciplines. The fundamental problem of misuse of these techniques lies not in that it may happen but in why it may happen.

Perhaps the most fundamental recommendation in avolding any form of manipulation of a Delphi is that the administrators of a Delpht should have no vested interest in the results of the Delphi. If an administrator has a vested interest, he belongs on the panel, not as an administrator. If one choses a consultant whose livelihood depends upon developing and administering procedures such as Delphis, it is unlikely that he will risk his reputation and the reputation of one of his primary tools for the whim or desires of a client. It is, therefore, recommended that as an initial protection against manipulation one hire a reputable consultant who has experience in designing and administering Delphis.

When manipulating a Delphi statement via statistical feedback, the biggest adjustment of the statistical feedback usually is made to the first round statistics. It is like straightening out a clothes hanger. If one does not bend it to at least the straight position, it will not end up straight. If one bends it to exactly 
the straight position and lets it go, 1t will spring back to a position somewhere between 1ts original position and the straight position. What one must do is bend it just enough beyond the straight position so that when it springs back it will be straight. The key is knowing just how much to bend it beyond where one wants $1 t$. While this large adjustment at the beginning is necessary to accomplish the desired manipulation, it can also result in some early warning signals.

Discrepancles in factually-based Delphi statements are not easily detectable due to the form of statistical feedback (quartiles and medians). However, if the frequency distribution of the previous round is used as the statistical feedback for a value-1aden Delphi, the corrupt administrator may run into several problems unless he is careful. These problems in turn can warn the alert particlpant that there may be discrepancles in the statistical feedback he is recelving. In trying to force answers to the desired results, he may leave blank a category where some participants have voted. The absence of a tally of their vote should quickly warn the participants. Durlng the first round, he may also leave just a few people (1, 2, or 3 ) in an extreme category where there originally were several people (e.g. 8 or 9). The administrator will then experience trouble during later rounds when there is movement out of this extreme category. If he does not reduce the tally in the category in the next round of feedback, the people who moved might become susplcious. If he does reduce the tally he may run out of people or end up with only one person left in that category at the end of the Delphi. If there was more than one person left and the tally showed only one person, 
the administrator exposes himself to a high risk situation of being exposed if the respondents begin discussing the Delphi with each other. Radical changes in later rounds (in particular the final results) may be a telltale sign of manipulation (i.e. an attempt to report the final tally to avoid the above problem).

The above naturally leads us to another measure that could expose manipulation if it took place. An administrator would be considerably more reluctant to use statistical manipulation if he knew the participants would be actively discussing the results with each other (either formally or informally). Such a meeting(s) could also have other useful benefits, but it may destroy some of the anonymity desired.

The success of statistical manipulation tends to be enhanced by additional rounds. Limiting the rounds where statistical feedback is returned to two or three rounds would thus reduce some of the success that could be achieved; however, the desired stability and/ or convergence may not be achieved.

As will be discussed in the next section, inclusion of narrative feedback may or may not enhance the ability of the administrator to manfpulate Delphi statements.

One last method one could use to try to determine if manipulation has taken place is to audit the results. One possible way to do this would be to have a disinterested third party request the participants to recast their flnal votes on several statements (a small percent of the total statements) that appear to be in question. This recasted vote distribution could then be compared with the 
reported distribution. The candidate statements for investigation could be chosen by selecting those statements whose results are counter-intuitive and/or whose stability is low. Running such an audit, however, may have the effect of compromising anonymity and/ or destroying the creditability of the results and must be handled very delicately.

\section{EXTENSIONS}

As stated in the very beginning of this report, this research is not the final word on the topic of manipulation of the Delphi technique or, for that matter, the broader topic of the misuse of the Delphi technique. To try to test all the ramifications of manipulation would have been over ambitious for anyone. It has been shown, however, that a group of individuals participating in a Delphi have been manipulated to produce significant changes in their responses. This in itself is reason enough to point to the need for further research in this area. Suggestions pertalning to the direction this research can take will now be discussed.

One obvious change in the normal Delpht procedure in the expertment was the elimination of narrative feedback. The mafor reason for this was to eliminate any possible influence from another primary form of manipulation, the language used in narrative feedback. That is, it is possible to add certain levels of bias and ambiguity when synthesizing the individual dissenting opinion into the generic dissenting statements that make up narrative feedback. (The same form of mantpulation can also be applied to the original wording of the 
of the statement itself.) Murray Turoff in personal correspondence agrees that while such a form of mantpulation may be successful, the risk of discovery or of dissension of the participants increases greatly. This results from the fact that it would be obvious to a participant if his argument was not included or was worded in such a manner as not to convey the intent desired. However, while manipulation of narrative feedback increases the risk of discovery or of dissension of the participants, this risk does not preclude the possibility of manipulation of narrative feedback being a successful form of manipulation.

The implications of narrative feedback on this research and on the question of menipulability suggests three possible extensions of this work. First it would be interesting to see how the inclusion of non-manipulated narrative feedback would affect the success of statistical manipulation. To do this one could replicate the above experiments but include the provision for, and encourage the use of, narrative feedback.

A second possible extension would be to test the success of manipulating Delphi statements only through the use of manipulated narrative feedback (i.e. the statistical feedback would not be manipulated). One can explore this extension with three experiments. The first experiment would test to see if arguments representing the desired viewpoint could be presented well enough to overcome arguments supplied by the participants that are counter to the desired viewpoint. This would involve allowing the unsupportive arguments to appear in the narrative feedback in a form that would be 
commensurate to a valid Delphi. However, it would also permit one to Interfect additional carefully worded narrative feedback statements which express arguments for the desired position. This technIque of manipulation tends to be a 11ttle more subtle and has the least risk associated with it. The question being investigated here is can the administrator through the Interjection of additional narrative feedback significantly influence the results of a Delphi statement?

The second experiment would Involve only allowing arguments that are supportive of the deslred viewpoint to appear in the narrative feedback. This means that feedback supplied by the participants that are counter to the deslred viewpoint would not be allowed in the narrative feedback. As in the first experiment, the administrator could interject fabricated arguments supporting his point of view. This form of manipulation would have a high degree of rlsk assoclated with it since it should be clearly visible to the participants that their arguments are belng ignored and only arguments counter to thelr opinion are belng registered. Thus the question being asked in this case is will the particlpants rebel when they expertence such discrepancies occurring in a Delphi or will they submit to the pressures and allow themselves to be manipulated? If they do rebel, how far can they be pushed before they rebel and what forms will their rebellion take?

While the first experiment tested the one extreme of allowing unsupportive arguments from the participants to appear in a valid form and the second experiment tested the other extreme of not 
allowing them to appear at all, the third experiment tests the gray area in between the two extremes. This experiment would involve fabricating and interjecting many arguments in favor of the desired viewpoint and combining all the unsupportive arguments from the participants Into a few statements that are carefully worded to include the ideas expressed but to express them in a somewhat bland or unforceful manner. To accomplish this, one would have to have a command of the English language and to be aware of the feelings expressed by each word. A background in linguistics, psychology, and soclology would be useful. The risk in this experiment is somewhat compromised. All of the arguments expressed are included, but the unsupportive ones are comiined into a few watered down statements. Thus the participants may be upset that their arguments do not contain the strength they meant them to have, but they can at least see their arguments are included in the narrative feedback.

To run only one of the three experiments in the second extension would be to only answer part of the questions posed. To be able to synergistically view the problem of manipulation through the use of manipulated narrative feedback, one should run all three experiments and investigate the difference in their results.

The third extension involving narrative feedback would be to use a combination of both statistical and narrative feedback to manipulate to the desired answer. The suggested way to approach this extension would be to replicate the three experiments discussed for the second extension but include the use of manipulated statist1cal feedback. Thus one would not only be able to compare the 
results amongst the three experiments but also between the two extenslons. One would expect the success to be greater when the two forms of manipulation are used in combination. If this is true, by using the strength of both one could reduce the risk of discovery by not having to use one procedure as extenslvely as one would if he only used one method. It is concelvable, however, that one could get into trouble if one is not careful of avolding conflicting situations between the narrative and statistical feedback.

The above three extensions, if written in the form of research hypotheses, would take on the following form:

$E_{1}$ - the inclusion of non-manipulated narrative feedback would not significantly reduce the success achieved through manipulated statistical feedback,

$E_{2}$ - the administrator through interjection of additional fabricated narrative feedback cannot significantly influence the results of a Delphi statement,

$E_{3}$ - the administrator cannot significantly manipulate Delphi statements by including only supportive arguments in the narrative feedback (i.e. not include any arguments supplied by the participants that do not support the desired viewpoint and allowling the interjection of fabricated arguments by the administrator),

$E_{4}$ - Corollary to $E_{3}$ - the Delphi partlcipants will not rebel when they experience the discrepancies occurring as a result of $E_{3}$ ( 1 .e. they will submit to the pressures and a.llow themselves to be manipulated),

$E_{5}$ - the administrator cannot significantly manipulate Delphi statements by including additional fabricated supportive arguments in the narrative feedback and by combining the unsupportive statements of the participants into a few somewhat bland and unforceful arguments in the narrative feedback,

$E_{6}$ - the administrator through the use of statistical manipulation and the interjection of additional fabricated 
narrative feedback cannot significantly influence the results of a Delphi statement (this assumes the proper inclusion of unsupportive narrative feedback),

$E_{7}$ - the administrator cannot significantly manipulate Delph1 statements by the use of statistical manipulation and by the Inclusion of only supportive arguments in the narrative feedback (i.e. not include any arguments supplied the the participants that do not support the desired viewpoint and allowing the interfection of fabricated arguments by the administrator),

$E_{8}$ - Corollary to $E_{7}$ - the Delph1 participants w1ll not rebel when they experience the discrepancles occurring as a result of $E_{7}$ (i.e. they will submit to the pressures and allow themselves to be manipulated), and

$E_{9}$ - the administrator cannot significantly manipulate Delphi statements by using statistical manipulation, by including additional fabricated supportive arguments in the narrative feedback, and by combining the unsupportive arguments of the participants into a few somewhat bland and unforceful arguments in the narrative feedback.

Each of the above hypotheses can be Further specified to Investigate factually-based Delphi statements and value-laden Delphi statements separately and then Into investigating the differences between the two types of Delphi statements. Specifylng the hypotheses in this manner would follow the same procedure used in this research.

There are many other factors that may or may not influence the manipulation of a Delphi. Many of these were discussed in the review of the literature (Chapter II) and are presented in a sumarized form in Figures 4 through 6. Each of these factors represent a potential extension of this research, although some are more important than others. This taxonomy does not exhaust the universe of potential factors. As time progresses and more people view the subject, many additional parameters will be added. This inftial set of factors, however, will be a useful and necessary tool in the analysis of the subject. 

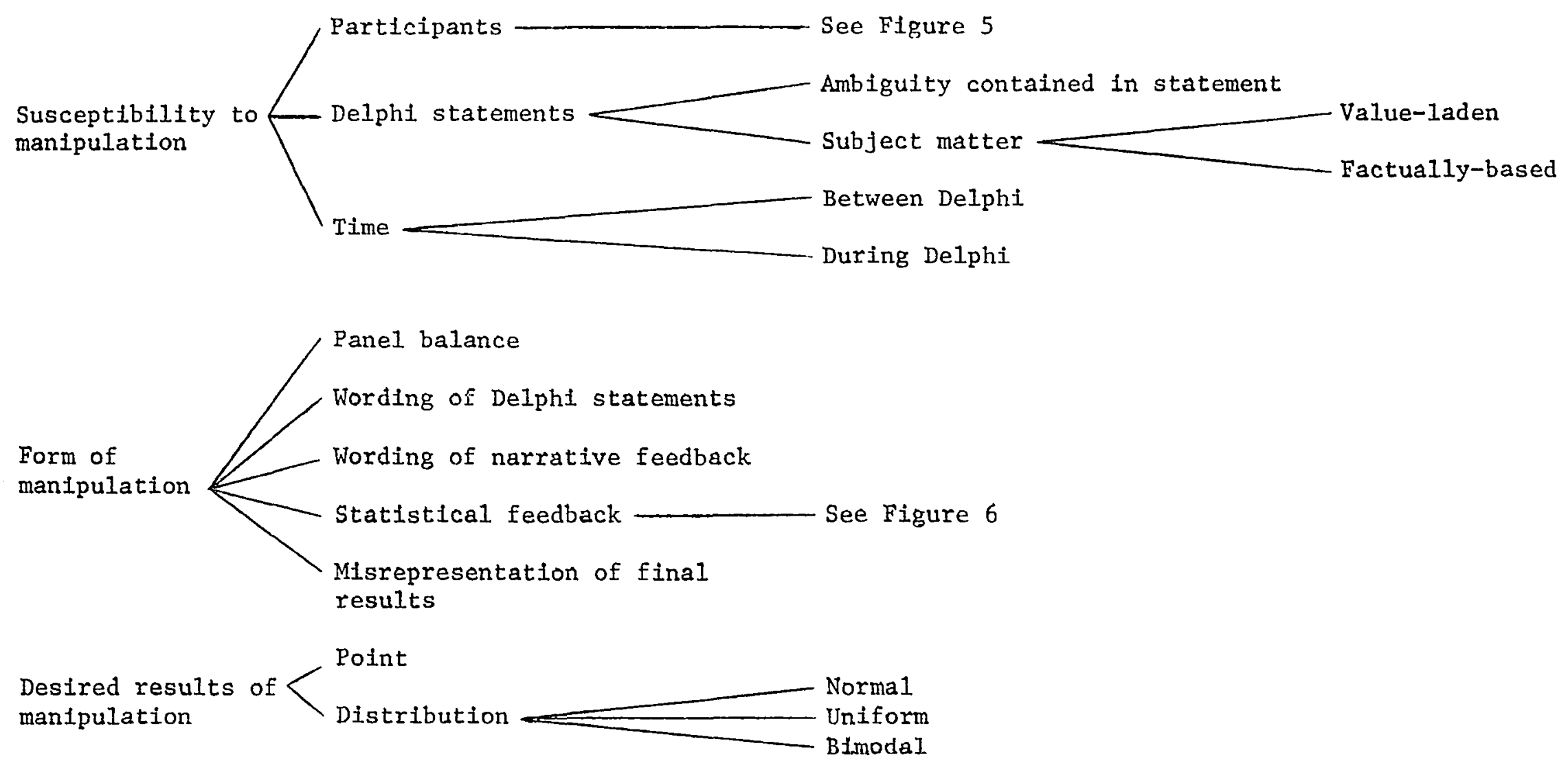

Figure 4. Factors that may determine the degree of manipulability of Delphi statements. 


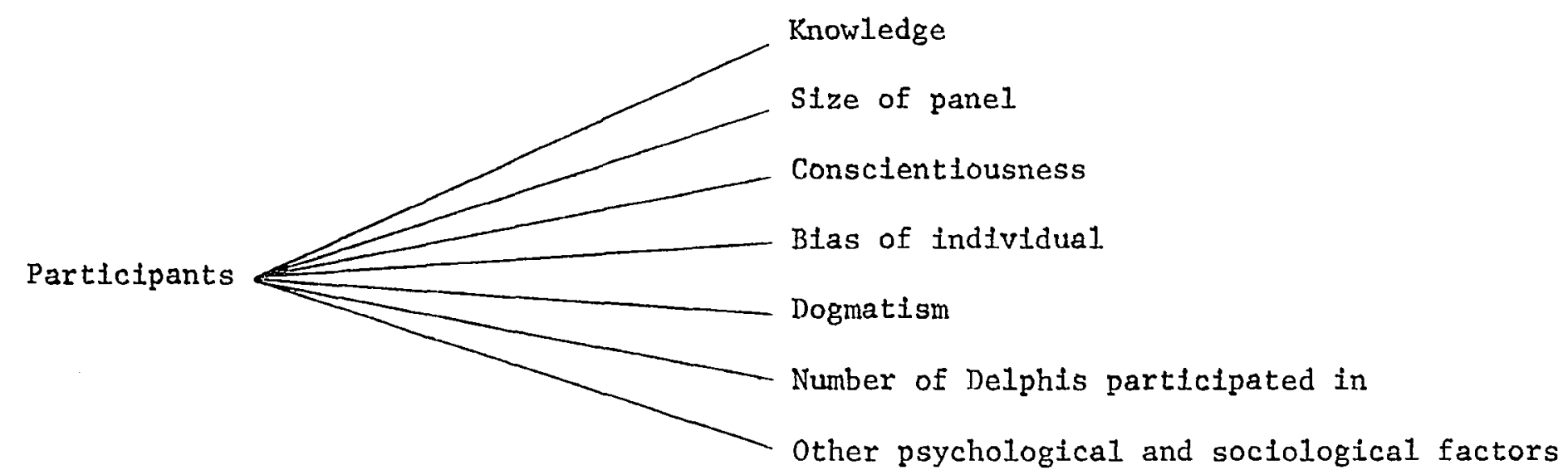

Figure 5. Factors that may determine the susceptibility of participants to be manipulated. 


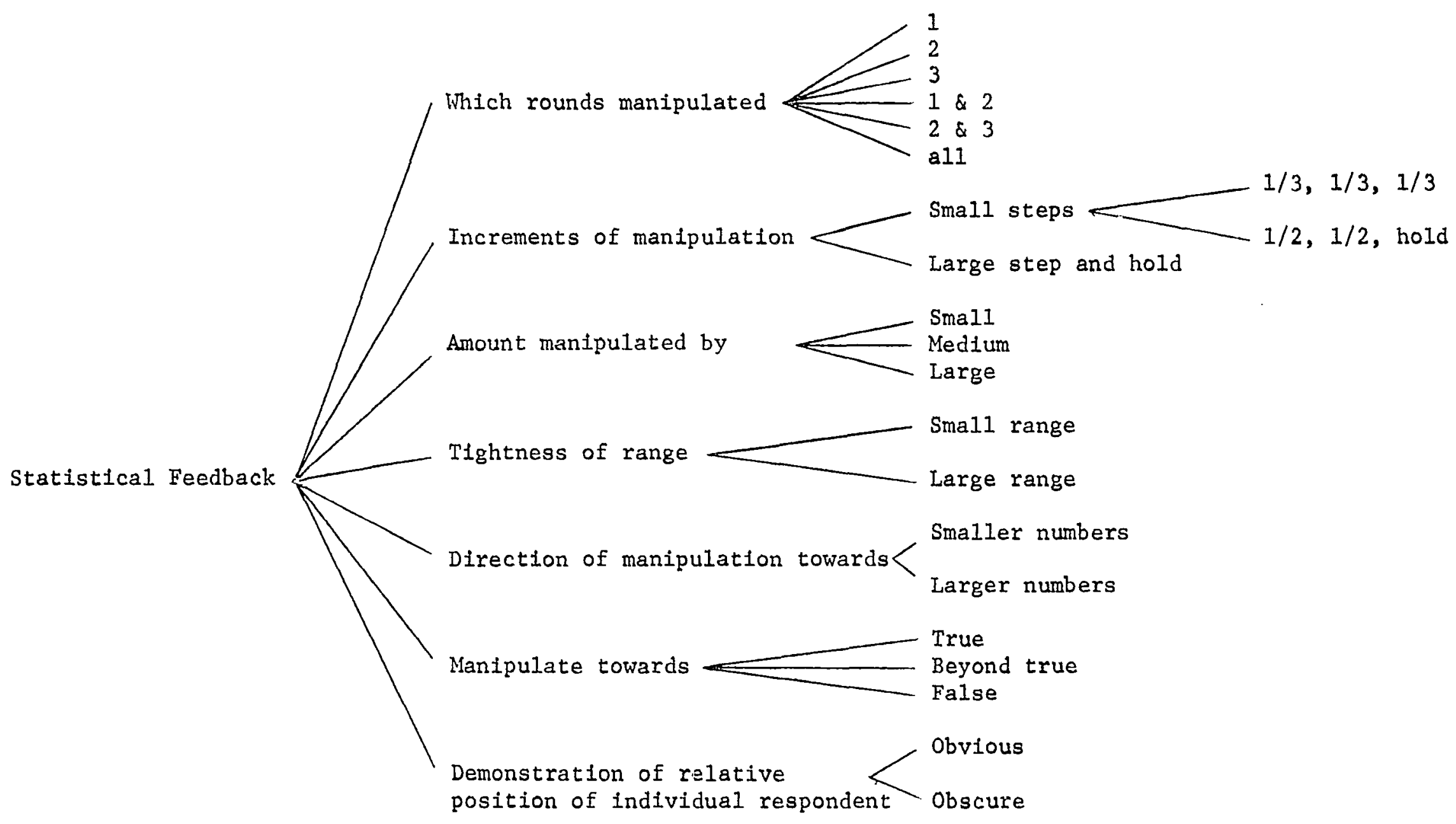

Figure 6. Factors that may determine the effectiveness of statistical feedback in mantpulation. 


\section{GLOSSARY}

The following is a limited glossary. It is intended to define some of the terms used in this thesis that may be unfamiliar to the reader. Where a term is adequately defined or elaborated in the text, a reference to the appropriate page is made in lieu of a definition.

administrator: one who administers a Delphi

almanac Delphi: see page 49

anonymous response: see page 4

confidence: how assured a person is that his response is correct, see page 70

convergence: see page 64

Delphi: see page 3

desired value - the value (median or index) one is attempting to achieve through manipulation of statistical feedback

dogmatism: how authoritative, positive, or arrogant one is in his assertion of opinions

factually-based Delphi: see page 49

iterative and controlled feedback: see page 4

participant: one who participates in a Delphi as a panel member

policy Delphi: see page 50

pul1 of the median: see page 30

pull of the true: see page 30

response: an individual participant's reply for a particular round of Delphi

round: an iteration of a Delphi (what is involved in a particular round of a Delphi depends on the Delphi in question) 
stability: see page 66

statistical group response: see page 4

value-laden Delphi: see page 49 
REFERENCES 
[1] Ament, Robert H. "Comparison of Delphi Forecasting Studies in 1964 and 1969." Futures. II (March, 1970), 35-44.

[2] Anderson, D. P. "Clarifying and Setting Objectives on an Intermediate School District's Objectives Utilizing the Delphi Technique." Paper presented at the American Educational Research Association symposium on "Exploring the Potential of the Delphi Technique by Analyzing Its Application," March 4, 1970, Minneapolis, Minnesota.

[3] Bender, Douglas A.; Strack, Alvin E.; and von Haunalter, George. "Delphic Study Examines Developments in Medicine." Futures. I (June, 1969), 289-303.

[4] Berger, Vincent F. "Effects of Repression and Acquiescence Response Set on Scales of Authoritarianism and Dogmatism." Unpublished masters thesis, University of Oklahoma, 1967.

[5] Bjerrum, Chresten A. "Forecast of Computer Developments and Applications, 1968-2000." Futures, I (June, 1969), 331-338.

[6] Brockhoff, Klaus. "The Performance of Forecasting Groups in Computer Dialogue and Face-to-Face Discussion." The Delphi Method: Techniques and Applications. Edited by Harold A. Linstone and Murray Turoff. Reading, Massachusetts: Addison-Wesley Publlshing Company, Advanced Book Program, 1975.

[7] Brown, Bernice B. Delpht Process: A Methodology Used for the Elicitation of Opinions of Experts. Santa Monica, California: Rand Memorandum RM-3925, September 1968.

[8] Brown, B.; Cochran, S.; and Dalkey, N. The Delphi Method II: Structure of Experiments. Santa Monica, California: Rand Memorandum RM-5957-PR, June 1969.

[9] Brown, Bernice, and Helmer, Olaf. Improving the Reliabillty of Estimates Obtained from a Consensus of Experts. Santa Monlca, California: Rand Memorandum P-2986, September 1964.

[10] Campbel1, Robert M. "A Methodological Study of the Utilization of Experts in Business Forecasting." Ph.D. Thesis, University of California, Los Angeles, August, 1966.

[11] Campbe11, Robert M., and Hitchin, David. "The Delphi Technique: Implementation in the Corporate Environment." Management Services, November-December 1968, pp. 37-42.

[12] Chickering, Arthur W., et al. Research and Action. Third Annual Progress Report, Project on Student Development at Selected Small Colleges, March 1968. 
[13] Chow, Ya-1un. Statistical Analysis: With Business and Economic Applications. New York, lNew York: Holt, Rinehart and Winston, 1969.

[14] Coates, Joseph F. "In Defense of Delphi: A Review of Delph1 Assessment, Expert Opinion, and Group Process, by H. Sackman." Technological Forecasting and Social Change. VII, No. 2 (1975), 193-194.

[15] Coffin, Thomas E. "Some Conditions of Suggestion and Suggestiblitty: A Study of Certain Attitudinal and Situational Factors Influencing the Process of Suggestion." Psychological Monographs, LIII, No. 4 (194I).

[16] Cyphert, Frederick, R., and Gant, Walter I. "The Delphi Technique: A Case Study." Phi Delta Kappan. January, 1971, pp. 272-273.

[17] Cyphert, Frederick R., and Gant, Walter L. "The Delphi Technique: A Tool for Collecting Opinions in Teacher Education." Journal of Teacher Education. XXI, No. 3 (1970), 417-425.

[18] Dalkey, Norman C. "A Delphi Study of Factors Affecting the Quality of Life." The Delphi Method: Techniques and Applications. Edited by Harold A. Iinstone and Murray Turoff. Reading, Massachusetts: Addison-Wesley Publishing Company, Advanced Book Program, 1975.

[19] Dalkey, Norman C. "An Experimental Study of Group Opinion: The Delph1 Method." Futures. II, No. 3 (1969), 408-426.

[20] Dalkey, Norman C. Delphi. Santa Monica, California: Rand Memorandum $\mathrm{P}-3704, \frac{1967 .}{196}$

[21] Dalkey, Norman C. The Delphi Method: An Experimental Study of Group Opinion. Santa Monica, California: Rand Memorandum R'1-5888-PR, June, 1969.

[22] Dalkey, Norman C. "Toward a Theory of Group Estimation." The Delphi Method: Techniques and Applications. Edited by Harold A. Linstone and Murray Turoff. Reading, Massachusetts: Addison-Wesley Publishing Company, Advanced Book Program, 1975.

[23] Dalkey, N.; Brown, B.; and Cochran, S. "Use of Self-ratings to Improve Group Estimates." Technological Forecasting. I (1970), 283-291.

[24] Dalkey, N., and Helmer, 0. The Use of Experts for the Estimation of Bombing Requirements: A Project Delphi Experiment. Santa Monica, California: Rand Memorandum RM-727, November 14, 1951. 
[25] Dalkey, Norman C., and Brown, Bernice. Comparison of Group Judgment Techniques with Short-Range Predictions and Almanac Questions. Santa Montca, California: Rand Memorandum R-678-ARPA, May, 1971.

[26] Dalkey, Norman C., and Helmer, 0laf. An Experimental Application of the Delphi Method to the Use of Experts. Santa Monica, California: Rand Memorandum RM-727-PR(abridged), July, 1962 .

[27] Dalkey, Norman C., and Rourke, Daniel L. Experimental Assessment of Delphi Procedures with Group Value Judgments. Santa Monica, Callfornia: Rand Memorandum R-612-ARPA, February, 1971.

[28] Dalkey, Norman C.; Brown, B.; and Cochran, S. W. The Delphi Method, IV: Effect of Percentile Feedback and Feed-In. Santa Monica, Calfformia: Rand Memorandum RM-6118-PR, March 1970.

[29] Doyon, L. R.; Sheehan, T. V.; and Zagor, H. I. "Classroom Exercises in Applying the Delphi Method for Decision-Making." Socio-Economic Planning Sclences. V, No. 4 (1971) 363-375.

[30] Enzer, Selwyn. "Delphi and Cross-Impact Techniques-Effective Combination for Systematic Futures Analysis." Futures. III, No. 1 (1971) 48-61.

[31] Estes, Gerald M. and Knespert, Don. "Delphi In Industrial Forecasting." Chemical and Engineering News, (August 23, 1976), 40-47.

[32] Games, Paul A. and Klaire, George R. Elementary Statistics: Data Analysis for the Behavioral Sciences. New York, New York: McGraw-Hill Book Company, 1967.

[33] Goldschmidt, Peter G. "Scientific Inquiry of Political Critique? Remarks on Delphi Assessment: Expert Oplnion, Forecasting and Group Process, by H. Sackman." Technologlcal Forecasting and Social Change. VII, No. 2 (1975), 195-214.

[34] Goodman, Joel M. "DelphI and the Law of Diminishing Returns." Technological Forecasting and Social Change. II, No. 2 $(1970), 225-226$.

[35] Goodwill, Daniel. "A Look at the Future Impact of ComputerCommunications on Everyday Life." Technological Forecasting and Soctal Change. IV, No. 2 (1972), 227-233.

[36] Gordon, Theordore J. "New Approaches to Delphi." Technological Forecasting for Industry and Government. Edited by James Bright. Englewood Cliffs, New Jersey: Prentice Hall, Inc., 1968. 
[37] Gordon, T. J., and Helmer, Olaf. Report on a Long Range Forecasting Study. Santa Monica, California: Rand Memorandum P-2982, September, 1964.

[38] Grabbe, Eugene M., and Pyke, Donald I. "An Evaluation of the Forecasting of Information Processing Technology and App11cations." Technological Forecasting and Social Change. IV, No. 2 (1972), 143-150.

[39] Gross, E. J., and Grambasch, P. V. University Goals and Academic Power. Washington, D. C.: American Council on Education, 1968.

[40] Helmer, 01af. Analysis of the Future: The Delphi Method. Santa Monica, California: Rand Memorandum P-3558, March 1967.

[41] Helmer, Olaf. Convergence of Expert Consensus Through Feedback. Santa Monica, California: Rand Memorandum P-2970, September, 1964.

[42] Helmer, 01af. The Systematic Use of Expert Judgment in Operations Research. Santa Monlca, California: Rand Memorandum P-2795, September, 1963.

[43] Helmer, Olaf. The Use of the Delphi Technique in Problems of Educational Innovations. Santa Monlca, California: Rand Memorandum P-3499, December 1966.

[44] Helmer, Olaf, and Quadi, E. S. An Approach to the Study of a Developing Economy by Operetional Gaming. Santa Monica, California: Rand Memorandum P-2718, March 1963.

[45] Hill, Kim Quaile, and Fowles, Jib. "The Methodological Worth of the Delphi Forecasting Technique." Technological Forecasting and Social Change. VII, No. 2 (1975), 179-192.

[46] Jillson, Irene Anne. National Drug Abuse Policy Delphi. National Coordinating Council on Drug Education, 1526 18th Street, N.W., Washington, D.C. 20009, 1975.

[47] Jolson, Marvin A., and Rossow, Gerald L. "The Delphi Process in Marketing Dectsion Making." Journal of Marketing Research. VIII (November 1971), 443-448.

[48] Jones, Chester G. "Delphi Evaluation of Agreement Between Organizations." The Delpht Method: Techniques and Applications. Edited by Harold A. Linstone and Murray Turoff. Reading, Massachusetts: Addison-Wesley Publishing Company, Advanced Book Program, 1975.

[49] Judd, Robert C. "Delphi Applications for Decision Making." Planning and Changing. II (1971), 151-156. 
[50] Judd, Robert C. "Use of Delphi Methods in Higher Education." Technological Forecasting and Social Change. IV, No. 2 (1972), 173-186.

[51] Kaplan, A.; Skogstad, A.; and Girshick, M. A. The Prediction of Social and Technological Events. Santa Monlca, California: Rand Memorandum P-93, April 1, 1969.

[52] Lachmann, 01e. "Personnel Administration in 1930: A Delph1 Study." Long Range Planning. V, No. 2 (1972), 21-24.

[53] Lapin, Lawrence L. Statistics for Modern Business Decisions. New York, New York: Harcourt Brace Jovanovich, 1973.

[54] Lindquist, Everet F. Design and Analysis of Experiments in Psychology and Education. Boston, Massachusetts: Houghton Mifflin Company, 1956.

[55] Linstone, Harold A. "Eight Basic Pitfalls: A Checklist." The Delphi Method: Technlques and Applications. Edited by Harold A. Iinstone and Murray Turoff. Reading, Massachusetts: Addison-Wesley Publishing Company, Advanced Book Program, 1975.

[56] Linstone, Harold A., and Turoff, Murray, eds. The Delphi Method: Techniques and Applications. Reading, Massachusetts: Addison-Wesley Publishing Company, Advanced Book Program, 1975.

[57] Ludlow, John. "Delphi Inquires and Knowledge Utilization." The Delphi Method: Techniques and Applications. Edited by Harold A. Iinstone and Murray Turoff. Reading, Massachusetts: Addison-Wesley Publishing Company, Advanced Book Program, 1975.

[58] McCurdy, William 0. A Practical Design for the Use of the Focus Delphi Survey Process th Urban Soclal Pollcy Planning and Research. Report to Texas Department of Community Affairs, State Program on Drug Abuse, December, 1974. Austin, Texas: Texas Department of Community Affairs, State Program on Drug Abuse, P.0. Box 1.3166, 78711, 1974.

[59] Martino, Joseph. "The Loxnormality of Delphi Estimates." Technology Forecasting. I (1970), 355-358.

[60] Martino, Joseph. "The Optimism/Pessimism Consistency of Delph1 Panelists." Technological Forecasting and Social Change. II, No. 2 (1970), 221-224.

[61] Martino, Joseph. "The Precision of Delph1 Estimates." Technological Forecasting and Social Change. I, No. 3 (1970), 293-299. 
[62] Martino, Joseph. Technological Forecasting for Decision Making. New York: American Elsevier Publishing Co., 1972.

[63] Matthews, M. E.; Mahaffey, M. J.; Lerner, R. N.; and Bunch, W. I. "Profiles of the Future for Administrative Dietitians Via the Delpht Technique." Journal of the American Dietetic Assoctation. CXVI (1975), 494-499.

[64] Milkovich, George T.; Annont, Anthony; and Mahoney, Thomas A. "The Use of Delphi Procedures in Manpower Forecasting." Management Sclence, Application. IXX, No. 4 (1972), 381388 .

[65] Mitfoff, Ian A., and Turoff, Murray. "Philosophical and Methodological Foundations of Delphi." The Delphi Method: Techniques and Applications. Edited by Harold A. IInstone and Murray Turoff. Reading, Massachusetts: Addison-Wesley Publishing Company, Advanced Book Program, 1975.

[66] Mulgrave, Norman W., and Ducanis, Alex J. "Propensity to Change Responses in a Delph1 Round as a Function of Dogmatism." The Delphi Method: Techniques and Applications. Edited by Harold A. IInstone and Murray Turoff. Reading, Massachusetts: Addison-Wesley Publishing Company, Advanced Book Program, 1975.

[67] Nie, Norman H., et al. Statistical Package for the Social Sclences, Second Edition. New York, New York: McGrawH111 Book Company, 1975.

[68] North, Harper Q., and Pyke, Donald I. "Technological ForecastIng in Planning for Company Growth." IEEE Spectrum. January, 1969, p. 30-36.

[69] Norton, Daniel P. Governors State University, Needs Assessment Survey. Evanston, Illinois: Educational Testing Service, Midwestern Office, Apri1, 1970. ERIC number ED 078014.

[70] Overbury, R. E. "Technological Forecasting: A Criticism of the Delphi Technique." Long Range Planning. June, 1969, p. 76-77.

[71] Parker, E. F. "British Chemical Industry in the 1980's--A Delphi Method Profile." Chemistry and Industry. January 31, 1970, p. 138-145.

[72] Parker, E. F. "Some Experfence with the Application of the Delphi Method." Chemistry and Industry. September 20, 1969 , p. 1317-1318.

[73] Paxson, Edwin. A Delphi Examination of C1vil Defense. Santa Monica, California: Rand Memorandum RM-6247-ARPA, May, 1970. 
[74] Peabody, D. "Att1tude Contest and Agreement Set in Scales of Authoritarianism, Dogmatism, Antisemitism, and Economic Conservatism." Journal of Abnormal and Soctal Psychology, LXIII (1961), 1-11.

[75] Pyke, Donald L. "A Practical Approach to Delphi." Futures. III, No. 2 (1970), 143-152.

[76] Rescher, Nicholas. "A Questionnaire Study of American Values by 2000 A.D." Values and the Future. Edited by Kurt Baler. The Free Press, 1969, p. 133-147.

[77] Rescher, Nicholas. Delphi and Values. Santa Monica, California: Rand Memorandum P-4182, September, 1969.

[78] Rescher, N. "The Study of Value Change." Journal of Value Inquiry. I (1967), 12-23.

[79] Rokeach, Milton. The Open and Closed Mind. New York: Basic Books, 1960.

[80] Rowlands, D. G. "Technological Forecasting and the Delpht Technique-A Reply." Long Range Planning. II (December, 1969), $78-79$.

[81] Sackman, H. Delphi Assessment: Expert Opinton, Forecasting, and Group Process. Santa Monica, California: Rand Memorandum R-1283-PR, Apri1, 1974.

[82] Saha1, Devendra, and Yee, King. "Delphi: An Investigation from a Bayesian Viewpoint." Technological Forecasting and Social Change. VII, No. 2 (1975), 165-178.

[83] Salancik, J. R.; Wenger, Wllliam; and Helfer, Ellen. "The Construction of Delphi Event Statements." Technologlcal Forecasting and Social Change. III, No. 1 (1971), 65-73.

[84] Scheele, D. Sam. "Consumerism Comes to Delphi: Comments on Delphi Assessment: Expert Opinion, Forecasting, and Group Process, by H. Sackman." Technological Forecasting and Social Change. VII, No. 2 (1975), p. 215-219.

[85] Scheibe, M.; Skutsch, M.; and Schofer, J. "Experiments in Delphi Methodology." The Delphi Method: Technlques and Applications. Edited by Harold A. IInstone and Murray Turoff. Reading, Massachusetts: Addison-Wesley Publishing Company, Advanced Book Program, 1975.

[86] Schmidt, D. I. Creativity in Industrial Engineering. Santa Monica, California: Rand Memorandum P-4601, March 1971. 
[87] Schnelder, Jerry B. "The Policy Delphi: A Regional Planning Application." Technological Forecasting and Soctal Change. III, No. $4(1972)$, p. 481-497.

[88] Schofer, J.; Scheibe, M.; and Skutsch, M. "Experiments in Delph1 Methodology." Urban Systems Engineering Center Research Report, Northwestern University, 1972.

[89] Steber, S. D., et al. A Taxonomy of Higher Education. New York: Bureau of Applied Social Research, Columbia University, March 1968.

[90] Skutsch, Margaret. "Goals and Goal Sett1ng: A Delphi Research." Unpublished masters thesis, Northwestern University, Evanston, Illinois, August, 1972.

[91] Skutsch, Margaret, and Schofer, J. L. "Goals-Delphis for Urban Planning: Concepts in Their Design." Socio-Economic Planning Sclences. VII (1973), p. 305-313.

[92] Teeling-Smith, George. "Medicines in the 1990's: Experience with a Delphi Forecast." Long Range Planning. III, No. 4 (1971), p. 69-74.

[93] Turoff, Murray. "Delphi Conferencing: Computer-Based Conferencing with Anonymity." Technological Forecasting and Soctal Change. III, No. 2(1970), p. 159-204.

[94] Turoff, Murray. "The Design of a Pollcy Delphi." Technologlcal Forecasting and Social Change. II, No. 2 (1970), p. 149-171.

[95] Turoff, Murray. "The Policy Delph1." The Delphi Method: Technlques and Applications. Edited by Harold A. Linstone and Murray Turoff. Reading, Massachusetts: Addison-Wesley Publishing Company, Advanced Book Program, 1975.

[96] Uhl, Norman P. Identifying Institutional Goals: Encouraging Convergence of Opinion Through the Delphi Technique. NLHE Research Monograph Number Two. Durham, North Carolina: National Laboratory for Higher Education, 1971. ERIC number ED 049713.

[97] Welty, Gordon. "A Crltique of Some Long-Range Forecasting Deve1opments." Bulletin of the International Statistical Inst1tute. IVL (1971), p. 403-408.

[98] Welty, Gordon. "A Critique of the Delphi Technique." ProceedIngs of the American Statistical Association. Washington, D.C., 1971, p. 377-382.

[99] Welty, Gordon. "Plato and Delph1." Futures. V, No. 3 (1973), p. 281-286. 
[100] Welty, Gordon. "Problems of Selecting Experts for Delph1 Exerc1ses." Academy of Management Journal. XV, No. 1 (1972), p. $121-124$.

[101] Welty, Gordon A. "The Selection and Deflection of Expertise in Delphi Exercises." Joint ORSA-TIMS Meeting. Atlantic City, November, 1972.

[102] Yamane, Taro. Stat1stics: An Introductory Analysis. New York, New York: Harper and Row, 1967. 
APPENDIX A

FACTUALLY-BASED DELPHI USED IN THIS EXPERIMENT 
ALMANAC DELI'II

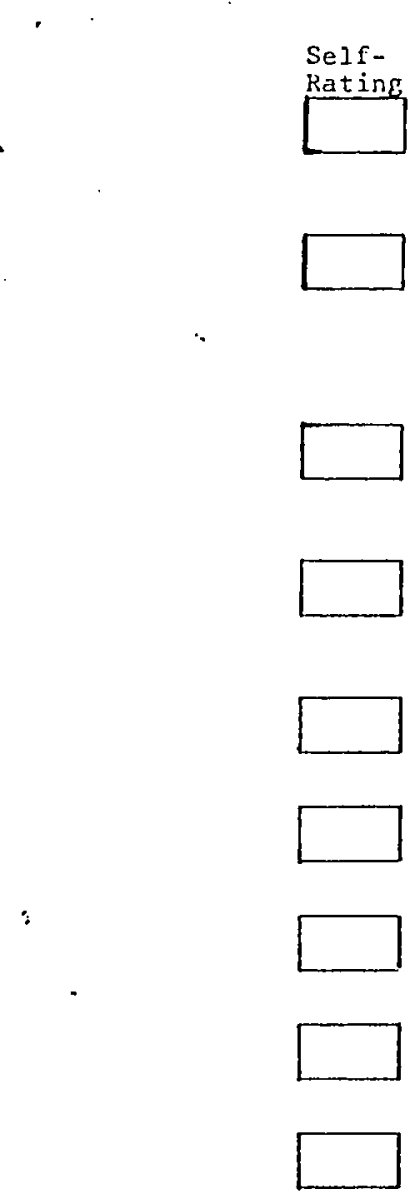

1. There werc training centers in 1974 .

last 4 digits of Soc. Sec. H STATJS'ICAI, FEEUBATK Lower Upper

Self-

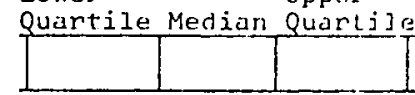

2. The total amount spent for book reimbursenents for this program (GFAFB AFIT program) from July 1 , 1975 to April 1, 1976 was (dollars).

3. The 1970 U.S. Census reported East Grand lorks as having population of

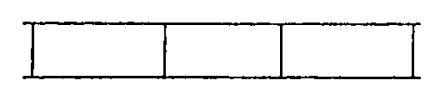

4. There were students enrolied in the schools located on GFAFB on sept. 30,1974 . (Public Schools)

5. The total number of GFAFB AFIT students who registered for courses in Term 76-1 (last-term) was

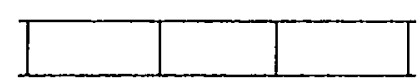

6. The altitude of Grand Forks is

(feet).

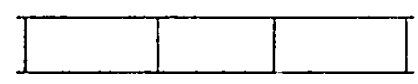

7. The launch weight of a Titan II (official configuration) is (pounds).
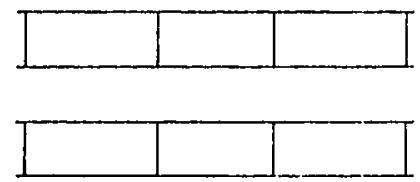

8. There were bomber and tanker squadrons in the USAF in February 1974.

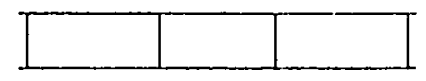

9. There were telepone numbers in Grand Forks in March, 1976 (this does nol include extensions, Centrex phone systems (e. $\varepsilon_{0}$. University of North Dakota and GFAFB), East Grand rorks, or GFAFB).

10. The average wind velocity (in knotts) at at GFAFB in January 1976 was
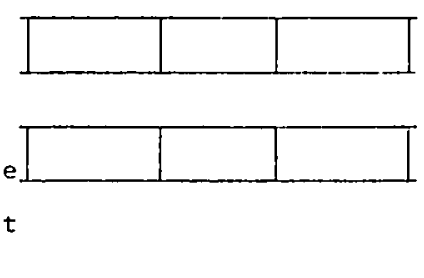
Self-

Rating
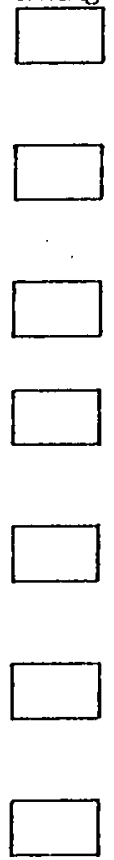

$i$

.
12. The total number of deaths of USAF personnel in the Vietnarn war between June 1,1961 and Jan 25, 1973 was

13. A Captain with 6-8 years in the USAF neceived a percent increase in military basic pay firom 1963 to 1973.

14. The average age of a USAF officer on Dec. 31, 1974 was

15. There were military personne? (officers and enlisted) in the USAF on June $30,1972$.

16. On Decenber 31, 1974 , pencent of USAF of ficers were women (use fraction of a percent if desired).

17. Thre 25 ycar average anrual preciptation (inciludes rain and rain equilivant of snow) in Grand rorks is (inches).

18. On Decenber 29, 1973, there were USAF personncl missing in action in southeast Asia.

19. According to the 1970 census, there were blacks (including dependents) living at GFAFB.

20. The ratio of military personnel to civilian personnel workind at GFNFB on December 31, 1974 was (you may use fractions if desired).

21. The USAT outlays (expenditures) for 1972 (in millions of dollars) was

22. The estimated nonagricultural wage and salary employnent in Grand Forks on July J., 1975, was - (i.e. the number of jobs)

23. The total active aircraft in the USAF in June 1973 was
S'TATISTICAL, TILDBACK

Lower

Upper
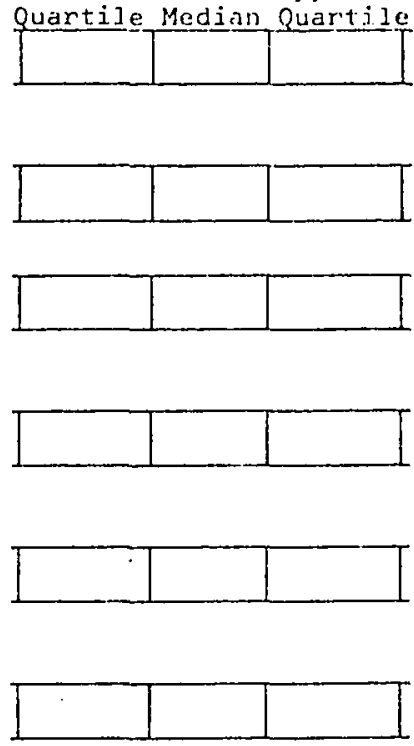

$\sim$
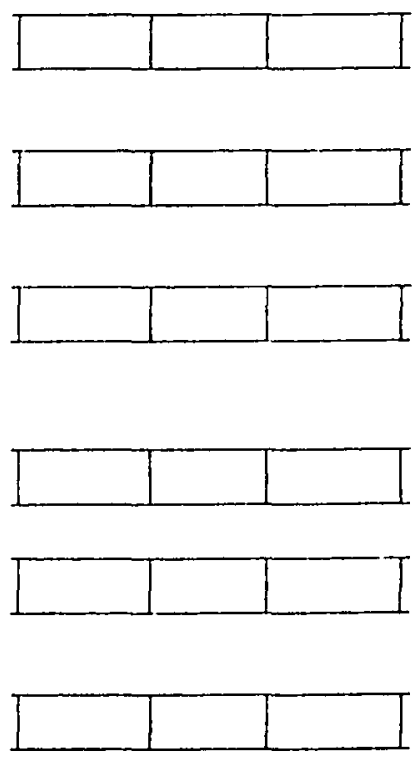
Self-

Rating
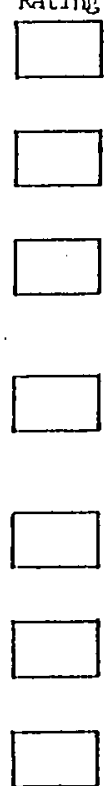

21. The highest temperature ever recorded in North Dakota was (OF).

25. Thene ane Grund Forks. acres of city parks in

26. The total number of semester hours completed by GFAFB AFIT students in the MMEP between July 1, 1975 and Dec. 31, 1975 was

27. The FI5 Eagle's time to clinb for $0-12,000$ meters set in Jan. 1975 at GFAFB was (seconds).

28. Tikere were in 1970. Ain Fonce Acaderny Cadets

29. In July 1973 , there were Minuteman II missiles deployed.

30. The USAF accepted or scheduled acceptance for fixed wing aircraft in 1974 (not the number that was budgetcd for, but the nunber that money was actually expended for).
ST'ATISTICAL TFEDIBCK Lower Upper Quartile Median Querrtile
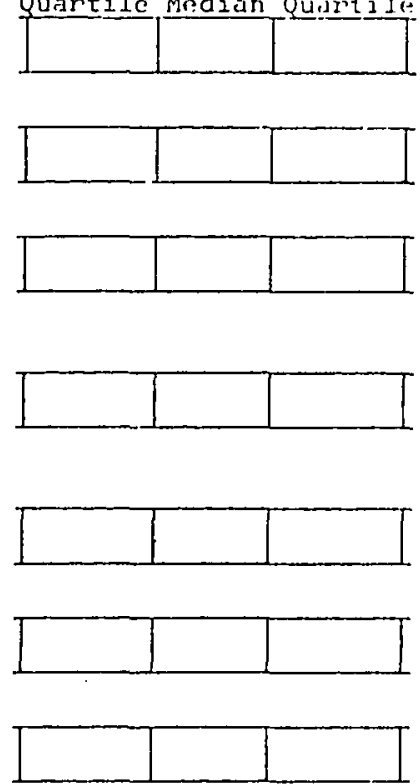
INSTRUCTION SHEET FOR ALMANAC IDELPHI

Round 1

The experiment in which you are taking part is an effort to investigate human information processing. Your primary task will. be to answer thirty questions of a general information type. The questionnaire is not a quiz or examination, nor is it a test of social influence. It will not be graded. Since $j t$ is done with total anonymity, no one will know how you answer a question nur how you may change it during later rounds. I am interested in the way groups use incomplete information to arrive at factual conclusions.

The experimental session will consist of four rounds. In the first, you will ariswer the thirty questions relying on what background information you may have. In the second round, you will be furnished a sumnary of the answers for this group. The summary will consist of the median answers of the group, and the two quartiles, that is, the range in which fifty percent of the grouf's answers are found. "This summary is a form of "pooling" of the information of dil the members of your group and will serve as a basis for revising your answers if it seems appropriate. The third and fourth rounds will contain the same type of information supplied in round two.

It is not expected that you will know the exact answer to any of the questions. However, for most of them, you will have some general knowledere that will enable you to make an estimate of the answer. You are to make as good an estimate as you can; but in any case, answer every question as best as you can. Captain Porter has verified that the answers to all the questions are publicly available (i:e., there is no classified information requested). You are not required to give the answers in whole numbers (numbers with decimal fractions are acceptable).

In addition to answering the questions, you are requested to rate each question with respect to the amount of knowledge you feel you have concerning the answers. Please use the following scalc and record the appropriate self-rating number in the self-rating box for each question:

\section{Self-rating Explanation}

1

possess ljttle or no knowledge on the subject, answer would basically be a guess

2

possess a limited amount of knowledge on the subject, answer would basicaliy be an educated guess

3

possess enough knowledge to make a reasonable estimate of the answer 
Instructions Round 1

Page 2

5

considerable knowledge, either know the answer or have available knowledge that directiy pretains to the statement and can make a reasonably close estimate of the actual true value.

During the second, third, and forth rounds you may request to see your previous round answers to help you recall how you answered a question.

It is imperative that you do not discuss the questions or the experiment with anyone (especially other participants) and that you do not look up the answer's. 
INSTRUCTION SHEET FOR ALMANAC DELIPHI

Rounds 2 and 3

Your task for this round will be to reconsider your answers to the thirty questjons, and make any revisions which, on second thought, you feel are calied for. Do not hurry, but rethink each question, considering whether there were factors you might have overlooked, or computations which might have contained numerical mistakes. However, kecp in mind that you are still being asked only for your best estimate: based on what you know.

Following each statement is a summary of the answers of all the other participants from the preceding round. This summary is given in terms of the hedian and the Quartile interval. The median is the middle response for that question; that is, 50 percent of the responses were sreater than this number and 50 percent were less than this number. The quartile interval is comprised of the lower quartile and the upper quartile; that is, 25 percent of the responses were less than the lower quartile and 25 percent of the responses were greatcr than the upper quartile. The quartile interval thus gives you some indication of how widely the answers differ from one another. Taking this information into account, you may revise your answers where you thirk it appropriate.

Instead of self-rating yourself on each question as you did in round one, you are requested to indicate the reason why you did or did not change your estimate. Choose the number for the entry that best corresponds to your new estimate and enter it into the self-rating box. Thus, if you changed your answer because you realized you had made an error in computation, you would enter a 2 in the self-rating box. If you did not change your answer because you believed it to be correct whatever the group opinion, you would enter a 6 in the self-rating box.

\section{BASIS FOR ESTIMATE}

\section{If You \\ Changed Your Answer}

1. I had misread the question.

2. I made a mistake in computation

3. I remembered some aduitional facts.

4. My cstinate was too far from the group median.

5. The other members of the group are likely to know more about the question than I do.
II

If You Did Not Change your Answer

6. I believe my original cstimate.

7. The other nucubers of the group are not likely to know more about the question than I do.

8. No good reason to change.

9. My estimatc was close to the group inedian.

10. It would be more effort than it's worth to rethink the answer. 
Instructions Rounds 2-3

Page 2

If you would like to see your previous round of the Delphi to see how you answered some questions, I will provide them.

Again, plcase do not discuss the questions or the experinent with anyone (cspecially other participants) and do not look up any answers. 
INSTRUCTION SHEE'S TOR ALMANAC DEITPHI

Round 4

Your task for this round will be to reconsider your answers to the thirty questions, and make any revisions which, on sccond thought, you fecl arc called for. Do not hurry, but rethink each question, considering whether there were factors you might have overlooked, or computations which might have contained numerical mistakes. However, keep in mind that you are still being asked only for your best estimate, hased on what you know.

Following each statement is a summary of the answers of all the other participants from the preceding round. This summary is piven in terms of the Median and the Quartile interval. The median is the middle response for that question; that is, 50 percent of the responses were greater than this number and 50 percent were less than this number. The quartile interval is comprised of the lower quartile and the upper quartile; that is, 25 percent of the responses were less than the lower quartilc and 25 percent of the responses were greater than the upper quartile. The quartile interval thus gives you some indication of how widely the alswers differ from one another. Taking this information into account, you may revise your answers where you think it appropriate.

Thi.s is the last round and you are requested to use the same self-rating scale that you used in round l. As the scale indicater, you are requested to rate each question with respect to the amount of knowledge you feel you have concerning the answers. Record the appropriate self-rating number in the self-rating box for each question.

\section{Sclf-rating Explanation}

1

possese little or no knowledge on the subject, answer would basically be a guess

possess eriough knowledge to make a reasonable estinate of the answer

know some pertinent details about the subject or have more than an average amount of experience in the subject that would make my estimate better than most people

considerable knowledfe, either know the answer or have available knowledge that directly pretains to the statcment and can make a reasonably close estimate of the actuaj. true value.

If you would like to see your previous round of the Delphi to see how you ansiwercd some questions, I will provide them. 
APPENDIX B

VALUE-LADEN DELPHI USED IN THIS EXPERIMENT 
Policy Delphi to Establish Objectives of MBA Program at UND

ROUND

Last 4 digits of Soc. Sec. Num.

1. To provide a supportive environment for highly creative individuals.

2. To prepare an environment conducive to informal, comfortable, human relationships.

3. To help students develop social skills, poise, and confidence.

4. To roward excellence in research and scholarly inquiry through promotions and salary increases.

5. To prepare students for service in the community.

6. To help students firvelop the ability to synthesize knowledge from different sources.

7. To respond to internal needs and goals of the institution, rather than to external pressure.

8. To select faculty who have diverse backgrounds and attitudes.

9. To encourage applied research (attempt to find solutions to actual problems) for government, business, or industry by the faculty to enhance their intellectual growth and experience.

10. To promote concern in students for the well-being of others.

11. I'o model the new MBA program in the established patterns of the more successful MBA programs.
Current Statistical Feedback Rating of Previous Round
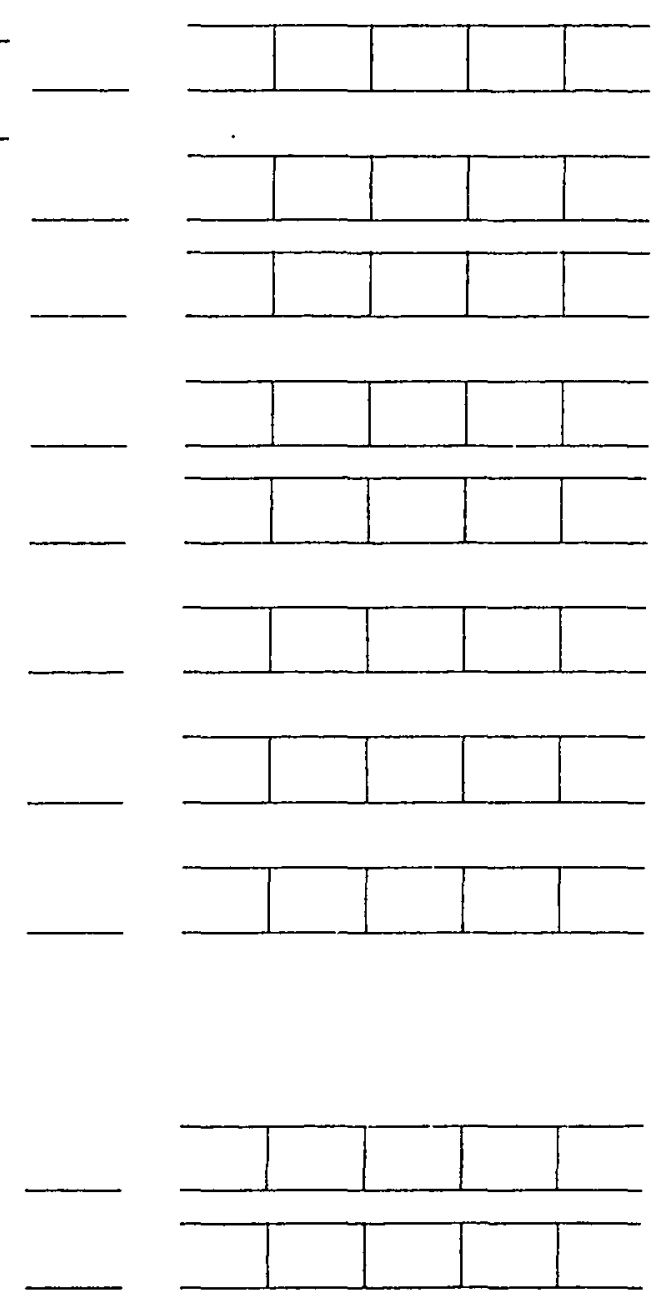
Current Statistical Feedback Rating of Previous Round

12. To be receptive to and to encourage experimentation with new ideas for educational practices at all levels.

13. To help students acquire the ability to adapt to new occupational requirements as technology and society change.

14. To apply resources of the program to the solution of major national problems.

15. To establish a long-range plan for the institution.

16. To provide critical evaluations of prevailing practices and values of the business community.

17. To insure faculty participation in the program's decision making.

18. To help students develop the ability to speak and write effectively.

19. To provide the student with the skilis, attitudes, and experiences which maximize the likelihood of his occupying a high status in life and a position of leadership in society.

20. To establish and clearly define the purposes the institution will serve.

21. To provide advisory assistance to the USAF (GFAF in particular).

22. To help students develop the capacity to assume leadership.

23. To provide a continuing plan of curricular and institutional evaluation and change for all programs.
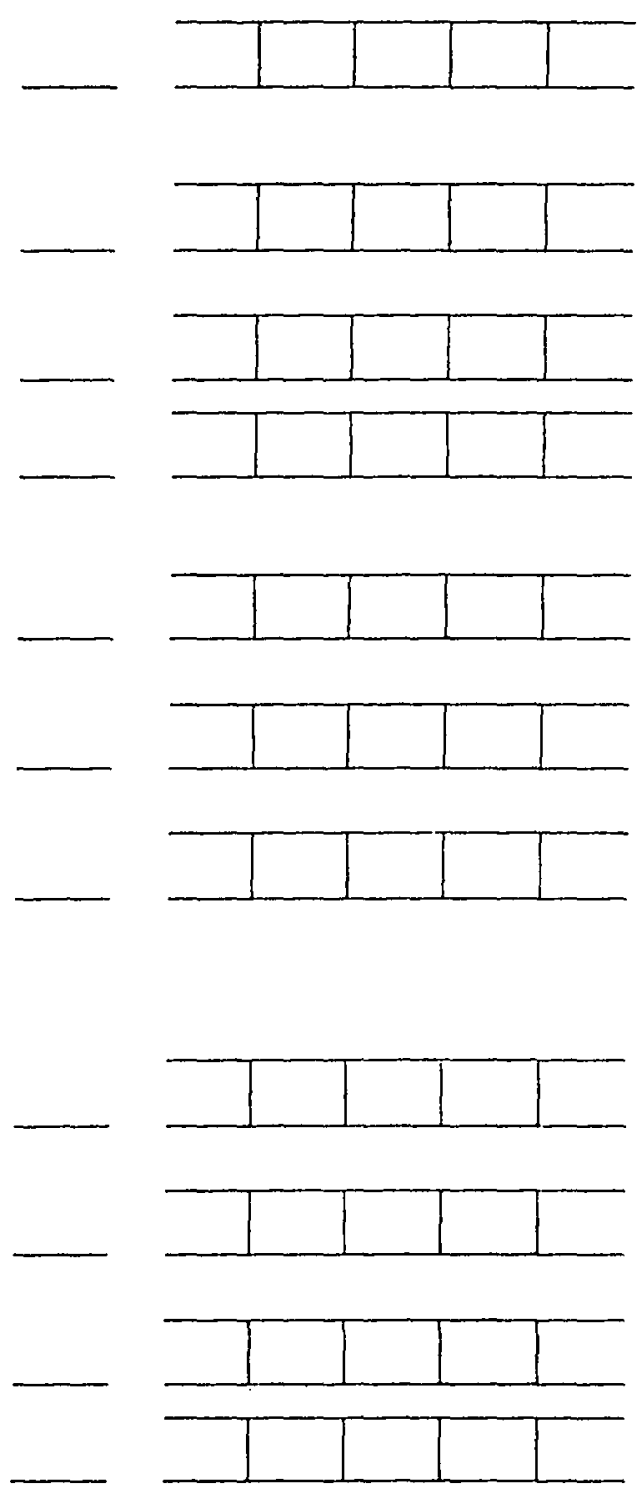$$
-
$$
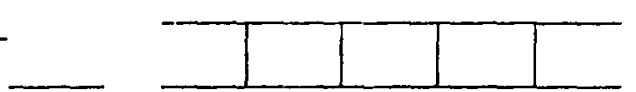
Current Statistical Feedback Rating of Provious Round

24. To assure academic freedom for faculty.

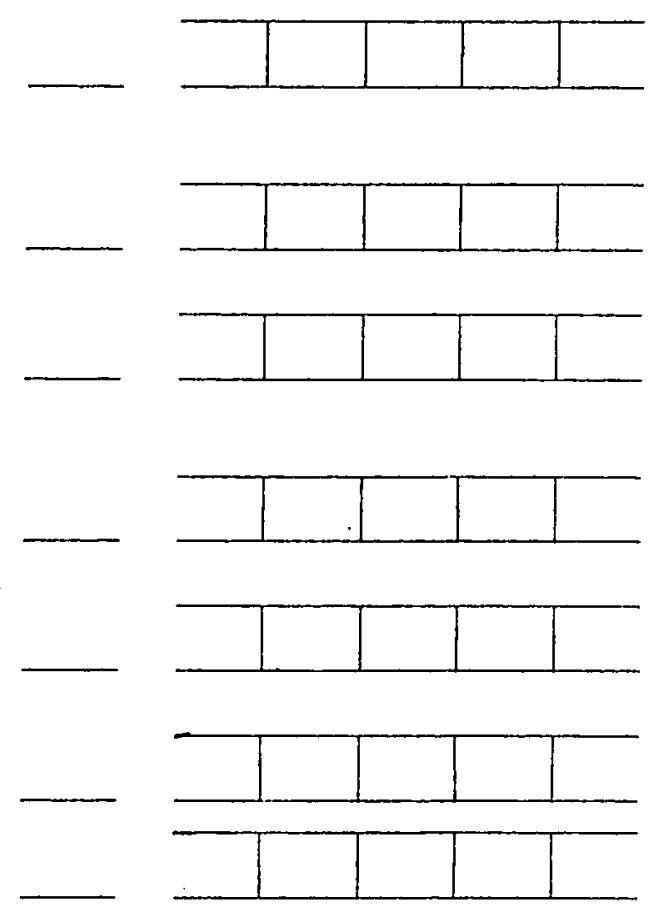

31. To encourage involvement of students in research and/or community involvement $(\mathrm{e} . \mathrm{g}$. consulting, volunteer work, etc.) with the faculty.

32. To provide for freedom of student expression and to clarify and protect student's rights.

33. To enable students to develop a a set of principles to guide their business behavior.

34. To apply the technical expertise available in the program to the solution of state and regional problems.

35. To encourage a concern for the welfare of the institution among faculty members, students, and administrators.

25. To maintain an atmosphere of intellectual excitement among faculty, students, and administrators. uportunity to acquire a broad understanding of the variety of in selecting take towards his degree.
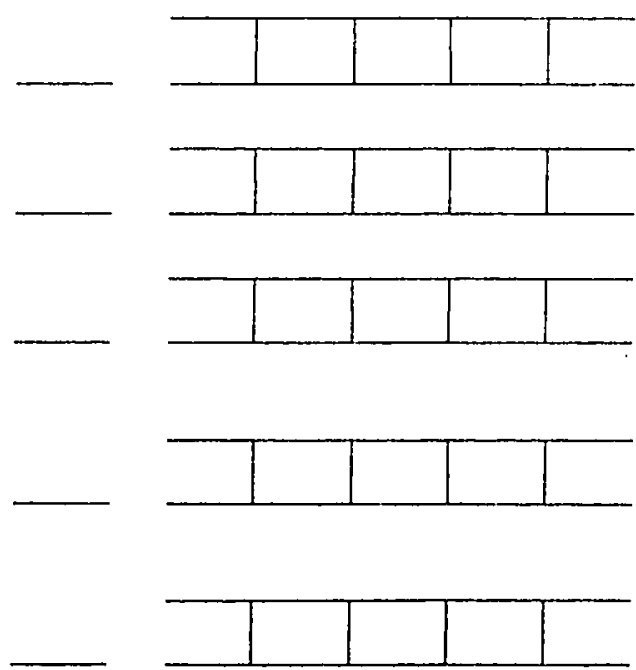


\section{Current Statistical Feedback Rating of Previous Round}

36. To involve students in curricular and instructional evaluation.

37. To base faculty promotions more on an estimate of teaching effectiveness than on the value of scholarly research and publications.

38. To help students develop a respect for their own abilities and an understanding of their limitations.

39. To insure that students have the opportunity to hear all points of view.

40. To help students to lead satisfying personal and social lives.

41. To help students develop the ability to apply critical thought to all areas of life.

42. To help students develop a sense of responsible membership in the world community.

43. To encourage pure research (research for the sake of knowledge) for government, business, or industry by the faculty to enhance their intellectual growth and experience.

44. To maintain a distinctiveness that sets the institution apart from other institutions.

45. To increase the desire and ability of students to undertake self-directed study.

16. To help solve business community problems in the immediate geographical area.
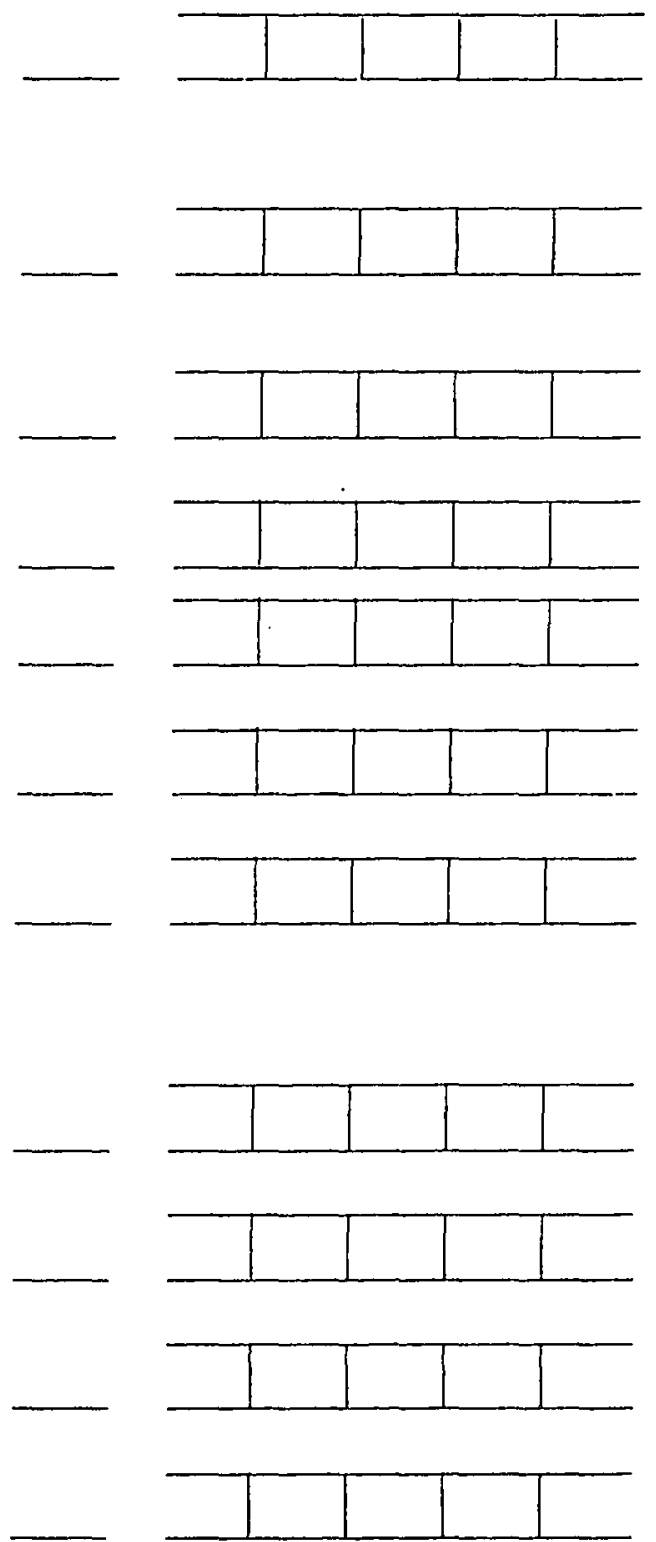


\section{Current Statistical Feedback Rating of Previous Round}

47. To assure that work experience or specially assessed performances may be substituted for specific course requirements.
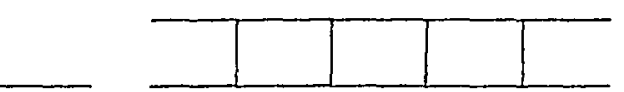

48. To avoid having the reputation of the institution damaged by the action of a few students or faculty.

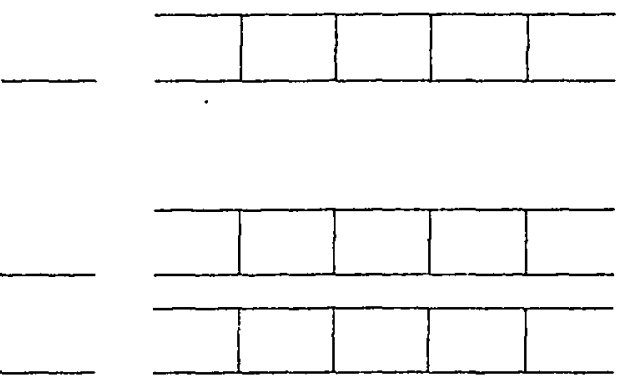

49. To encourage community involvement (e.g. consulting, volunteer work, etc.) by the faculty to enhance their background and experience.

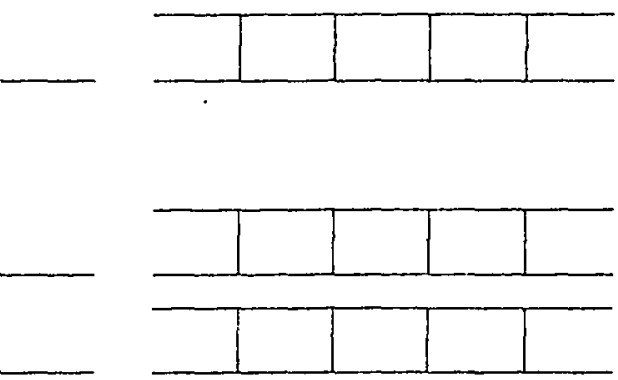

50. To help students in the choice of a personaliy satisfying vocation. 


\section{ATTENTION ALL AFIT STUDENTS}

ANNOUNCEMENT

ANNOUNCEMENT

In discussing the status of my thesis with Dean Rowe, he requested that I run a special Delphi for him. As many of you know, the downtown campus will be offering an MBA program, beginning this fall. They are also in the process of trying to acquire accreditation for the new program. Part of the accreditation procedures require a discussion of the orientation and goals of the MBA program. Since a later part of the accreditation procedure will test the attainment of these goals, it is best to establish goals that are desired by a consortium of administrators, faculty and students. Since the new program does not yet have students and the summer is an inconvient time to use undergraduate students, Dean Rowe has asked me to run a Delphi using AFIT students. He has supplied me with fifty (50) statements which he has selected from a number of similar studies and has asked that you rate their importance. Since this is in addition to my normal teaching load and writing my thesis, he has consented to allow me to set it up using the same procedures as the one I used on the previous Almanac Delphi. This does have an additional advantage for me, since it will enable me to see if the Delphi characteristics I was looking for in the Almanac Delphi will also exist in a Policy Delphi. If they do, it will add some additional strength to my original hypotheses and allow me to generalize the results more. 
Because of the above decision there will be two Delphis run (one in Section A and the other in Section B). Each Delphi will have thirty (30) participants. (This allows me to use the same computer programs to do the analysis.) As before, there will be four rounds one each day of the next two AFIT sessions.

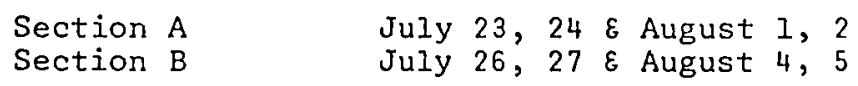

There will be fifty (50) statements of the following nature:

$\begin{array}{llll}\text { of extremely } & \text { of high } & \text { of medium of low } & \text { of no } \\ \text { high importance } & \text { importance } & \text { importance } & \text { importance importance }\end{array}$

To decentralize decision-making to the greatest extent feasible.
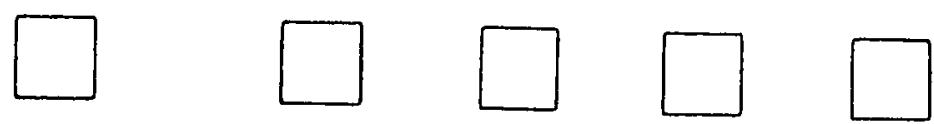

To provide an architectural climate conducive to learning.
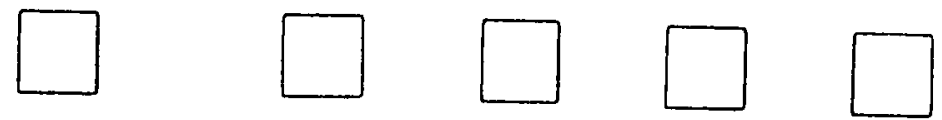

Since there will be no self-rating, it is anticipated it will take about the same time to complete as the Almanac Delphi (around 45 minutes the first round and less than 30 minutes on succeeding rounds).

Those interested in participating in the study should contact Brad Nelson as soon as possible. 
Instruction Sheet for Policy Delphi to Establish objectives for UND's New MBA Progam ROUND I

- As you already are aware, the objective of this Delphi study is to provide viable input to Dean Rowe and those who have the authority to establish the objectives of the new MBA program that is now being created on campus at UND. It is necessary to establish these objectives for two reasons. First and most important, they will give direction and guidance to the new program. Secondly, they are a necessary part of the accreditation procedures for establishing accreditation for the new program.

This Delphi will consist of four rounds. In the first round, you will individually rate the importance of fifty objectives. During the second, third and forth rounds you will be given back a frequency distribution of how people responded in the previous round. You in turn will be requested to rethink the objective in light of the statistical feedback (the frequency distribution) given you and any new thoughts that may have occurred to you since the previous rounds.

Since the objectives established may have some impact on you as a student in this program, it is important that you give each statement some deep consideration.

The procedure you will be using to rate the importance of each Delphi statement is as follows:

5 - of extremely high importance

4 - of high importance

3 - of medium importance 


$$
\begin{aligned}
& 2 \text { - of low importance } \\
& 1 \text { - of no importance }
\end{aligned}
$$

Please use only these five values since the computer will only accept the values $1,2,3,4$, or 5 (i.e., it will not accept fractional values). An example will help illustrate the procedure. Assume the following objective:

To provide an architectural climate

(current rating) conducive to learning.

If you decide this is "of high importance," you would put a "4" in the space under "current rating." If you feel it has "no importance" you would put a "l" in the space under "current rating."

As with all Delphis, the results of each individual participant are completely confidential and total anonymity will exist throughout the study. If you deam if necessary, you may request to see your previous round answers to help you recall how you rated a statement.

As it is with all Delphis, it is imperative that you do not discuss the statements or the experiment with anyone (especially other participants). If there is enough interest shown, a special session will be held at the end of the study for those who wish to discuss the results. The next round will be tomorrow. 
APPENDIX C

BERGER'S REVISION OF ROKEACH'S DOGMATISM SCALE 
The following is a study of what the general public thinks and feels about a number of important social and personal questions. The best answer to each statement below is your personal opinion. We have tried to cover many different and opposing points of view; you may find yourself agreeing strongly with some of the statements, disagreeing just as strongly with others, and perhaps uncertain about others; whether you agree or disagree with any statement, you can be sure that many people feel the same as you do.

Mark each statement in the left margin according to how much you agree or disagree with it. please mark every one. Write $+1,+2,+3$, or $-1,-2,-3$, depending on how you feel in each case.

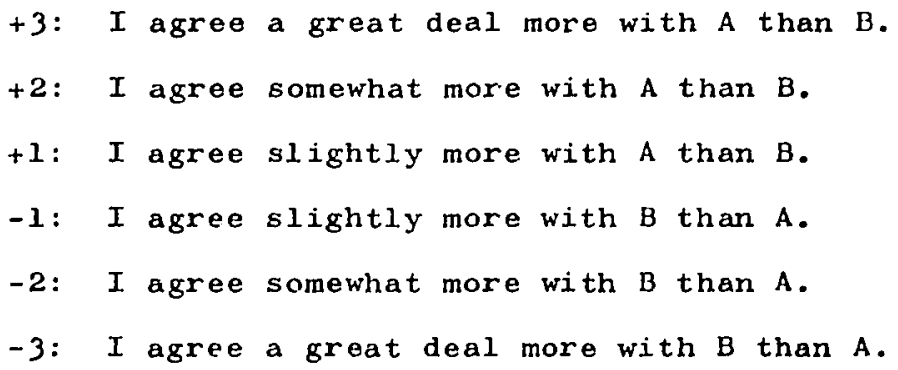




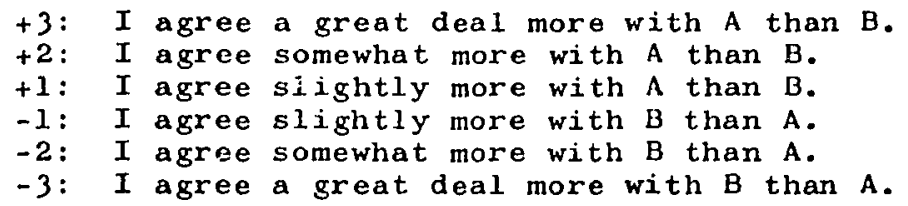

1. A. There may be crucial differences between the United States and Russia, but there are also many important features they have in common.

B. The United States and Russia have just about nothing in common.

2. A. To really believe in democracy means that the less intelligent will have an equal share in the government.

B. The highest form of government is a democracy and the highest form of democracy is a government run by those who are most intelligent.

3. A. Even though freedom of speech for all groups is a worthwhile goal, it is unfortunately necessary to restrict the freedom of certain political groups.

B. To believe seriously in freedom of speech means that freedom of even those political groups we disagree with cannot be restricted.

4. A. It is only natural that a person would have a much better acquaintance with ideas he believes in than with ideas he opposes.

B. It is natural for a person to be nearly as well acquainted with ideas he opposes as with ideas he believes in.

5. A. Man on his own is a helpless and miserable creature. B. Man on his own has many resources within himself, and is neither helpless nor miserable.

6. A. The world is fundamentally more a place full of friendly people than a lonesome place.

B. Fundamentally, the world we live in is a pretty lonesome place.

7. A. Most people generally care about others.

B. Most people just don't give a "damn" for others. 


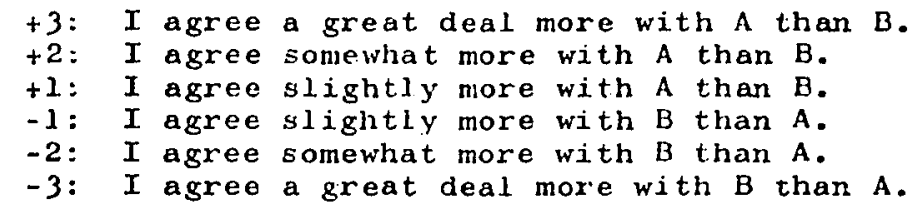

8. A. I'd like it if I could find someone who would tell me how to solve my personal problems. B. If I have personal problems I'd rather try to work tham out by myself than find someone who would tell me how to solve them.

9. A. There's no need to be afraid of the future. B. It is only natural for a person to be rather fearful of the future.

10. A. What I really hope to accomplish is limited enough so that I dor't feel rushed about i.t.

B. There is so much to be done and so little time to do it in.

11. A. Once I get wound up in a heated discussion I just can't stop.

B. I'm able to stop even if I get wound up in a heated discussion.

12. A. I do not find it necessary to repeat myseif several times in a discussion to make sure I'm being understood.

B. In a discussion I often find it necessary to repeat myself several times to make sure $I$ am being understood.

13. A. In a heated discussion I generally become so absorbed in what I am going to say that I forget to listen to what the others are saying.

B. I generally listen to what others are saying in a heated discussion rather thar becoming absorbed in what I am going to say.

14. A. It is better to be alive and not at all a hero, than to be a dead hero.

B. It is better to be a dead hero than to be a live coward. 


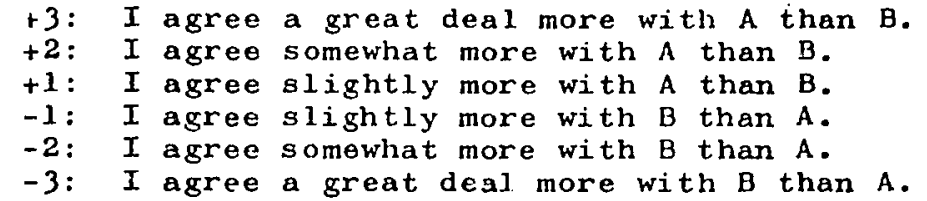

15. A. While like most people $I$ would like to make some small accomplishment in life, I have no secret ambition to become a great man; if I had I would certainly admit it to myself.

B. While I don't like to admit this even to myself, my secret ambition is to become a great man, like Einstein, or Beethoven, or Shakespeare.

16. A. The main thing in life is for a person to want to do something important.

B. There are things in life that matter at least as much as for a person to want to do something important.

17. A. If given the chance $I$ would do something of great benefit to the world.

B. While most poople would probably want to do something of great benefit to the world if given a chance, I wouldn't care if it were done by someone else rather than myself.

18. A. In the history of markind there have probably beeri just a handful of really great thirikers.

B. There have been many really great thinkers in the history of mankind who have had different ideas.

19. A. There are a number of people I have come to hate because of the things they stand for.

B. I do not hate anyone because he stands for things different from me.

20. A. A man who does not believe in some great cause has not really lived.

B. Whether a man has really lived or not is not determined by whether or not he believes in some great cause.

21. A. Whether or not a person devotes himself to an ideal or cause, life can be meaningful.

B. It is only when a person devotes himself to an ideal or cause that life becomes meaningful. 


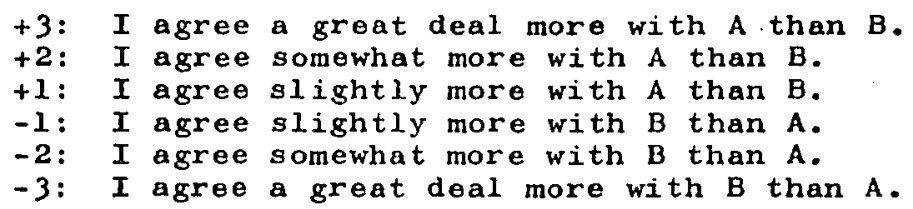

22. A. Many of the different philosophies in this world are partly ture, probably none of them is entirely correct.

B. Of all the different philosophies which exist in this world there is probably only one which is correct.

23. A. A person who gets enthusiastic about too many causes is likely to be a pretty "wishywashy" sort of person.

B. A person who gets enthusiastic about many causes is as likely to be a person of integrity as one who gets enthusiastic about a single cause.

24. A. In order to achieve anything we often have to compromise with our political opponents; this isn't likely to lead to the betrayal of our own side.

B. To compromise with our political opponents is dangerous because it usually leads to the betrayal of our own side.

25. A. When it comes to differences of opinion in religion we must be careful not to compromise with those who believe differently from the way we do.

B. We should be willing to compromise with those who believe differently from the way we do as regards differences of opinion and religion.

26. A. In times like these, a person must be pretty selfish if he considers primarily his own happiness.

B. It is not necessarily selfish for a person to consider primarily his own happiness.

27. A. If a person feels that those who believe in the same thing he does are going wrong he should say so, publicly if necessary.

B. The worst crime a person could commit is to attack publicly the people who believe in the same thing he does. 


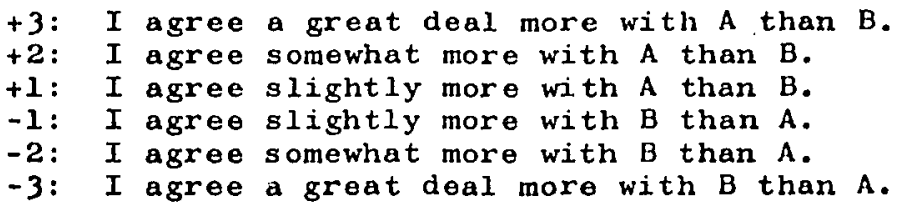

28. A. Nowadays one should try to come to terms with different ideas of people or groups in our own camp, rather than being on guard against them as wo might with ideas from the opposing camp.

B. In times like these it is often necessary to be more on guard against ideas put out by people or groups in one's own camp than by those in the opposing camp.

29. A. The best chance for a group to exist in the long run is to tolerate as much difference of opinion as there may be among its members.

B. A group which tolerates too much differences of opinion among its own members cannot exist ior long.

30. A. There are two kinds of people in this world: those who are for the truth and those who are against the truth.

B. It doesn't make sense to divide people into two distinct kinds, like those for the truth and those against the truth since almost everyone tries to be for the truth as he sees it.

31. A. My blood boils whenever a person stubbornly refuses to admit he's wrong.

B. I'm not likely to feel intense anger when a person refuses to admit he's wrong, even if ho seems stubborn.

32. A. One should be tolerant of a person who thinks primarily of his own happiness, not consider him to be beneath contempt.

B. A person who thinks primarily of his own happiness is beneath contempt.

33. A. Most of the ideas which get printed nowadays aren't worth the paper they are printed on.

B. It's a good thing that many different ideas get printed nowadays since there may be something of value in many of them and this is the only way we can find out. 


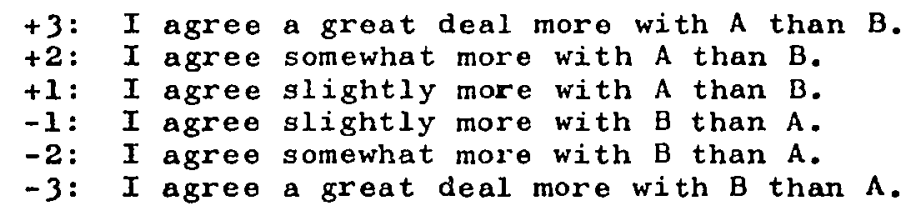

34. A. In this complicated world of ours the only way we can know what's going on is to rely on leaders or experts who can be trusted.

B. In trying to know what's going on in our complex world there are matters where we can not avoid relying on leaders or experts, but there are many issues that we should try to decide ourselves on their own merits.

35. A. It is often desirable to reserve judgment about what's going on until one has had a chance to hear the opinions of those one respects.

B. Before hearing the opinions of those one respects, one should try to have an opinion of one's own about what's going on.

36. A. In the long run rather than have only friends and associates whose tastes and beliefs are the same as ones own, it is better to include some friends and associates with different tastes and beliefs.

B. In the long run the best way to live is to pick friends and associates whose tastes and beliefs are the same as one's own.

37. A. It's important to live life in the present; one can never be sure what the future may bring.

B. The present is all too often full of unhappiness. It is only the future that counts.

38. A. If a man is to accomplish his mission in life it is sometimes necessary to gamble "all or nothing at all".

B. Since a man cannot know how it will turn out, he should not risk everything in a single gamble if he wants to accomplish his mission in life.

39. A. People with whom I have discussed important social and moral problems tend to understand what's going on as much as $I$ do.

B. Unfortunately, a good many people with whom I have discussed important social and moral problems don't really understand what's going on. 
+3: I agree a great deal more with $A$ than $B$.

+2: I agree somewhat more with $A$ than B.

+1: I agree slightly more with A than B.

-1: I agree slightly more with B than A.

-2: I agree somewhat more with $B$ than $A$.

-3: I agree a great deal more with B than A.

40. A. Most people know what's good for tinem as well as anyone else does.

B. Most people just don't know what's good for them. 
APPENDIX D

COMPUTER PROGRAM TO CALCULATE IN'TERMEDIATE STATISTICS 


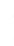

6

7

9

10

12

13
14

15

6

8

20

\$JOE (14646316), BFADLEY NELSON', LINES $=60$, PAGES $=80$, TIME 200 DIMENSION ANS $(40,31), \operatorname{SUMA}(30), \operatorname{SUMA} 2(30)$, WS $(40), \operatorname{NDKM}(62)$, STDIDEV 62 )

, TANS (30), ISSN(40), ICUMDS (62), CUMPRO (62), FEEDEK $(4,30,24)$

I $C D=5$

$I F \cdot R=6$

50 ISWaI

YLOW=0.0

Nis $S T=0$

DO $60 \quad I=1,30$

SUHA ( I ) $=0.0$

$\therefore \operatorname{VitA} Z(I)=0.0$

NDFiH $(I)=0$

60 COHTINUE

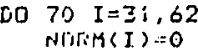

70 CONT INUE

REALY ICD, 9000$) \mathrm{N}, \mathrm{M}$, ISEC, IROUND

IF (IKIJUND.EO.9) GO TO 2000

KEE $R,[;] C D, \eta 0\{())(T A N S(I), I=1, M)$

DO $100 \quad I=\{, N$

I) 0 100 $K=1, M, 7$

$k 6=k+\dot{0}$

IF (KG.GT.M) KG

100 COHTINUE

FEG $[$ (ICD,90?0) ISSN(I), (ANS $(I, J), J=K, K G)$

WRITE (IFF, 9700) ISEC, IFOUND, $(J, J=4,15$ )

WHITE (IFF, 9770) (ISSN(I), (ANS $(I, J), J=1,15), I=1, N)$

WHITE $(1 F, 4,4700)$ ISEC, IKCiUNAi), $(J, J=16, M)$

Lก $150 \quad I=1, N$

WFITE (IFF, 9720) ISSN(I), (ANS (I,J), J=16,M)

150 COHTIIIUE

9700 FORMAT?'AECTION ', AI,' ROUND ', IY/

1 'OFAFTICIF'ANTS ANSWEF'S TO QUESTIONS',

2 PARTT,$\{X, I 2, B X, 5(I 2,6 X), 1 X, B(I 2,6 X), 2 X, 121)$

9720 FORTAT (I5,F7.1,F10.1, 4FB. 1,F9.1,7FB.1,F10.1)

WRITL (IFF̈,9140) ISEC, IFOUND

200 WRITE (IF'F, 9100 )

220 DO $1000 \quad J=\{, H$

NWS $=N$

$K=0$

Lo $300 \quad I=1, N$

IF (ANS $(I, J) . N E .999999 .0)$ GO TO 250

HWS - HWS -1

Go Tif 300

250

WS $(K)=\operatorname{ArtS}(I, J)$

IF (ISW.FO. 2) GO TO 300

$\operatorname{SIMAR}(J)=\operatorname{SUMA}(J)+W S(K)$

$S U M(12(J)=S U M A 2(J)+W S(K) * W S(K)$

300

CONIITIJE

ATEEAH = SUIMA (J)/NWS

$S T \Gamma=(S U M A Z(J)-N W S * A M E A N * A M E A N) /(N W S-1)$

$S T D=S Q R T C S T D)$

GUEELE SORT OF ANSWERS TO A QUESTION

DO $500 k=2$, NWS

$L=K-1$

DO $400 \quad I=K$, NWS

400

IF (WS
CONTINUE

TEMP $=W S(K-1)$

WS $(K-\{)=W S(L)$

$W S(L)=T E M F$

500 CONTINUE

CALE WHICH INDEX WILL EE USED FOR LQ, MED, UQ

$X=N W S / 4.0$

IX $X=N$ NS $/ 4$

$R=X-I X$

$L Q=I \%+1$

$M E D=2 * I X$

IUG $=3 * I X$

IF (R.LT.O.\}) GO TO 560 


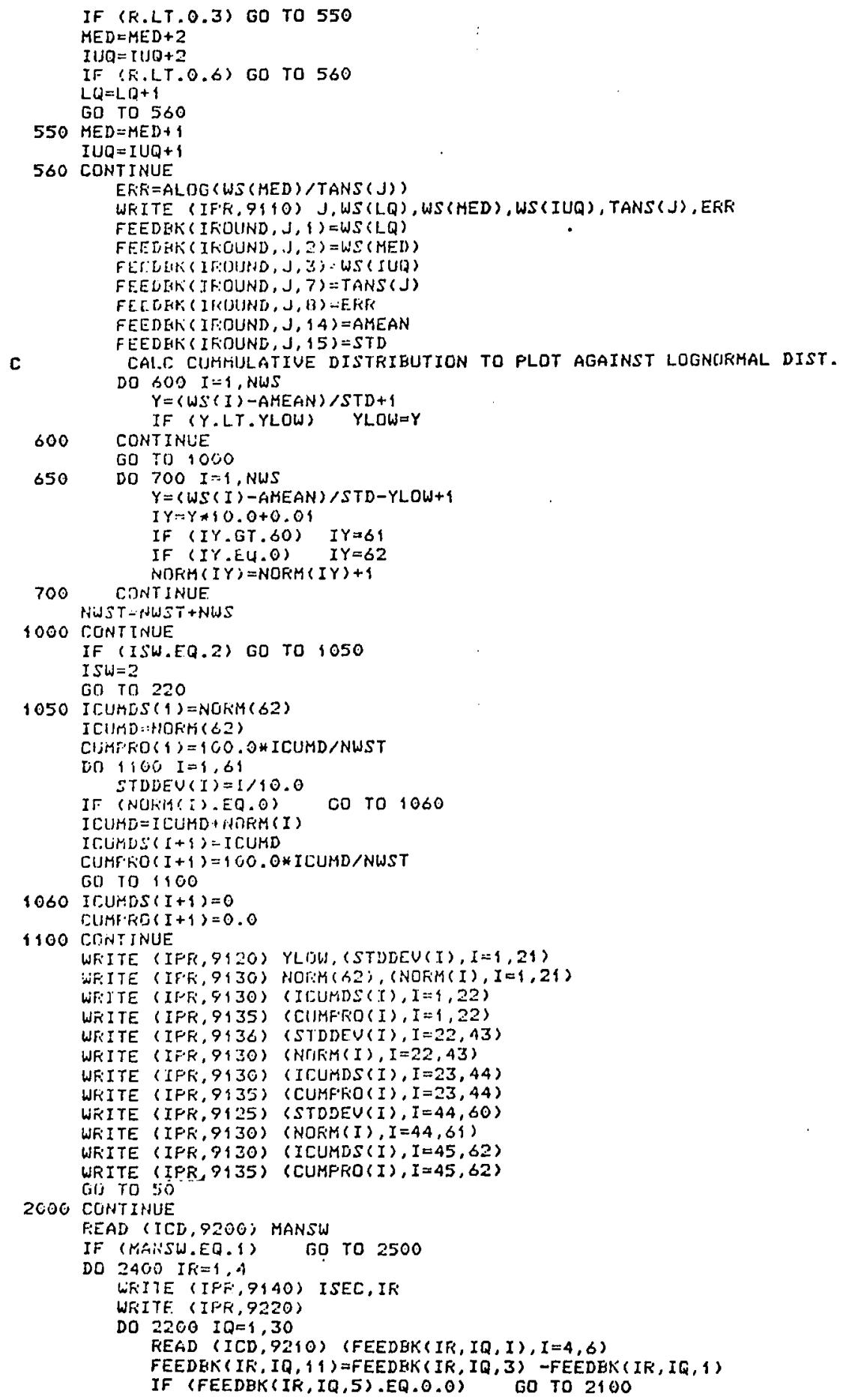




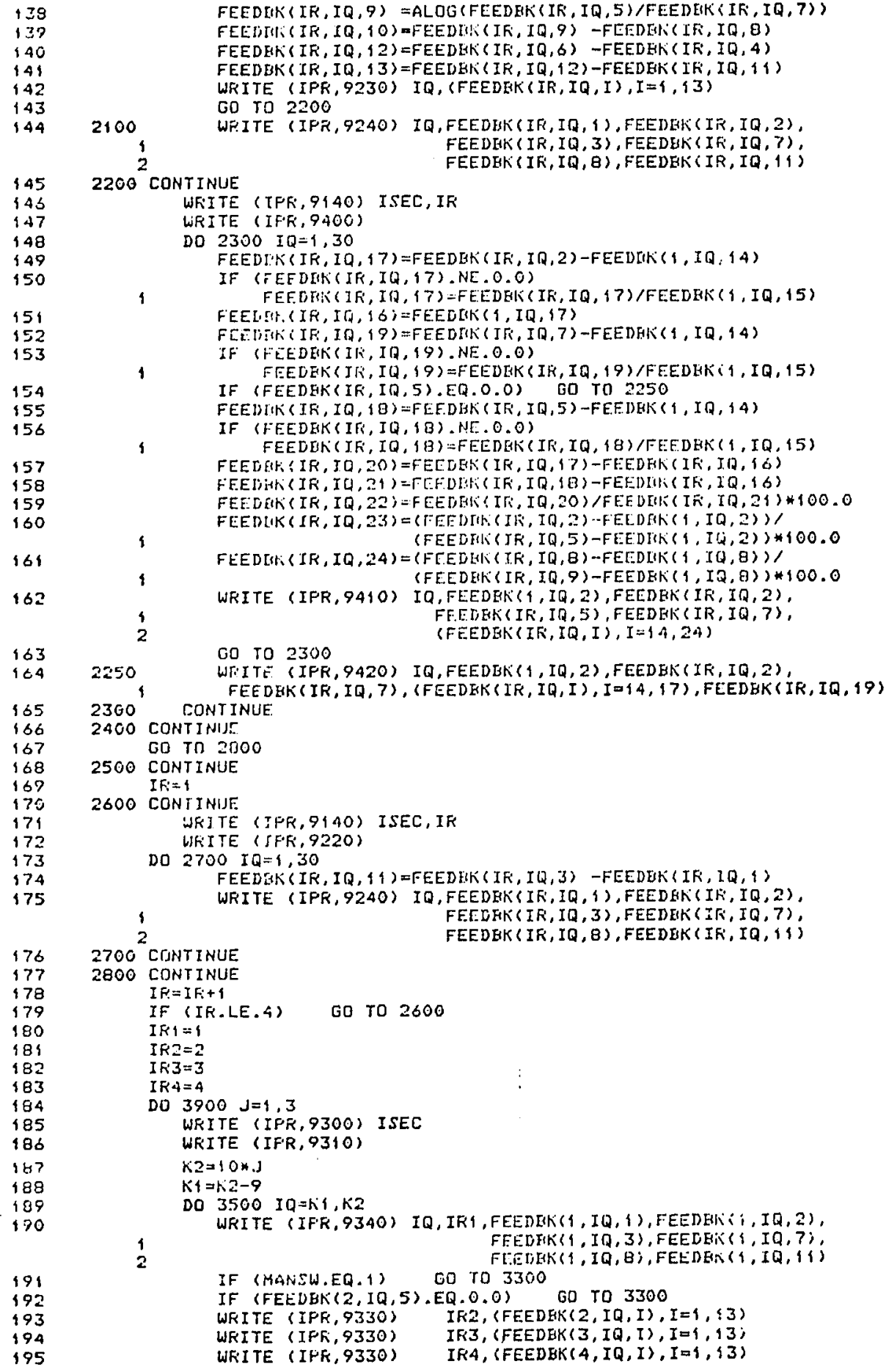




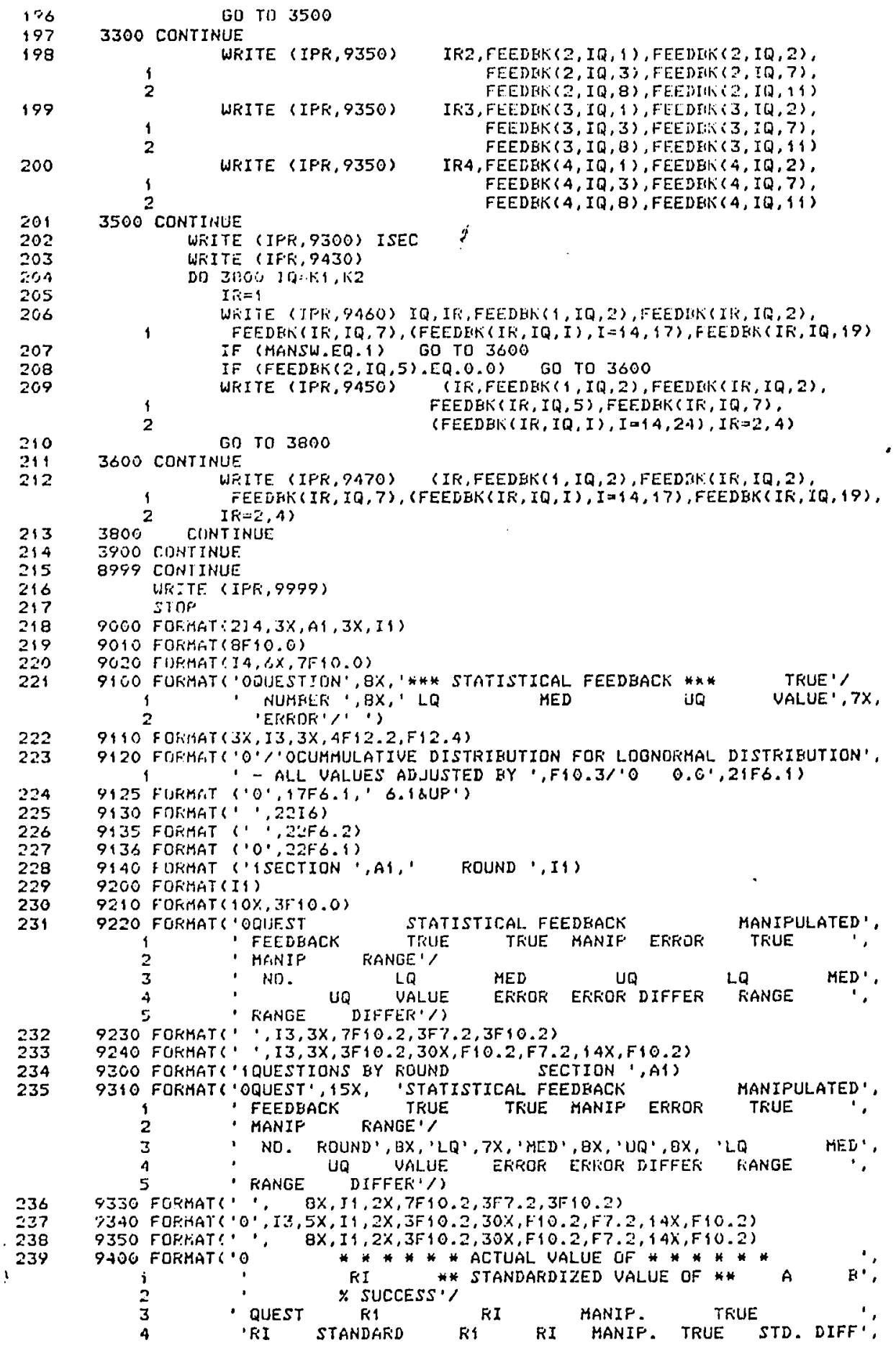




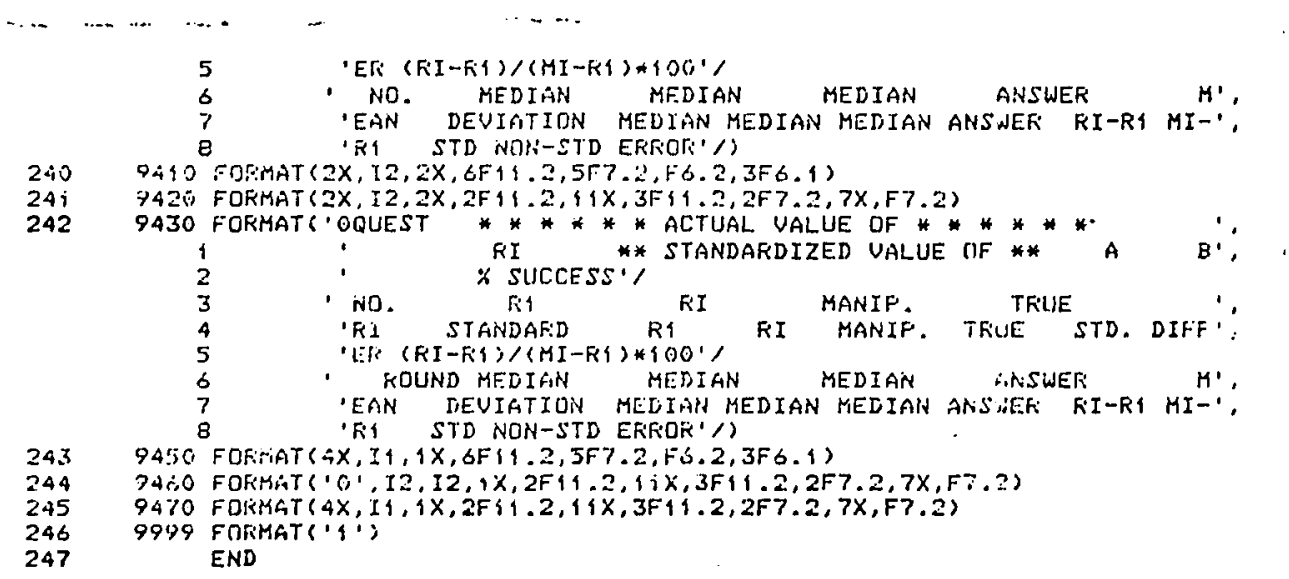


SECTIUH A ROUND 1

PARTICIFANTS ANSWERS TO QUESIIONS

\begin{tabular}{|c|c|c|c|c|}
\hline 684 & 45.0 & & & 00.0 \\
\hline & 10.9 & 00.0 & 8005.0 & 900.0 \\
\hline & & & & \\
\hline & 10. & 000.0 & 2000 & 0 \\
\hline 85 & 30 & 9995 & 435 & 2000 \\
\hline & 10. & 3000.0 & 420 & 600.0 \\
\hline & 15. & 00.0 & 100 & a \\
\hline & 1. & & & \\
\hline & & & & \\
\hline & 30. & & $90 \mathrm{O}$ & 1500.0 \\
\hline 89 & 8. & & $\because 20$ & 2000.0 \\
\hline & & & & \\
\hline & & & & \\
\hline 477 & 150.0 & & & 150 \\
\hline 15 & 15. & & & 300.0 \\
\hline$E$ & & & 350 & \\
\hline & 10. & & & \\
\hline 7 & 1. & & & 100 \\
\hline 82 & 10. & & 200 & \\
\hline & & & & \\
\hline $4:-3$ & 0. & & & \\
\hline & 25. & & 201 & 1000 \\
\hline 56 & 15. & & & \\
\hline 8244 & & & & \\
\hline $2 ? 3$ & & & & \\
\hline & 50. & $=0$ & 150 & 1500.0 \\
\hline & & & & Oap \\
\hline & & & & \\
\hline$G_{\tilde{C}}$ & 1. & & 75 & 800 \\
\hline & & & 180000 & 400 \\
\hline
\end{tabular}

$80.0 \quad 1500.0550000 .0$ $19.0 \quad 1100.0 \quad 8000$ $100.0 \quad 911.0 \quad 3000.0$ $210.0,1000.0 \quad 100000.0$ $318.0 \quad 840.0 \quad 30000.0$ $120.0 \quad 63.0700000 .0$ $\begin{array}{lll}165.0 & 1200.0 & 1000 \hat{0} .0\end{array}$ $\begin{array}{llll}180.0 & 400.0 \quad 90000.0\end{array}$ 800.0225000 .0 80.0600 .0200600 .0 10.025000 .0 $520.0 \quad 6000.0$ 775.0250000 .0 275.0235000 .0 20.0750 .025000000 800.046000 .0 $300.0 \quad 1000.0 \quad 80000.0$ $200.0 \quad 290.0 \quad 120000.0$ 97.020000 .0 $911.0 \quad 8000.0$ 100.025000 .0 $275.0 \quad 6000.0$ $126.0 \quad 845.0200000 .0$ $63.0 \quad 1250.0 \quad 540000.0$ 160.0911 .0160000 .0 $160.0 \quad 150.0 \quad 25000.0$ $200.0 \quad 890.0320600 .0$ $200.05000 .0 \quad 8000.0$
8

50.0999999.0 30.010000 .0 36.020000 .0 408.042100 .0 32.020000 .0 20.035000 .0 35.039000 .0 85.013000 .0 36.010000 .0 50.010000 .0 19.020000 .0 25.023000 .0 43.075000 .0 20.038000 .0 20.025000 .0 30.015000 .0 23.011500 .0

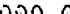
$30.0 \quad 10000.0$ 45.061000 .0 500.0 40000.0 30.013000 .0 $30.0 \quad 12000.0$ $\begin{array}{rr}20.0 & 10000.0 \\ 110.0 & 1000.0\end{array}$
20.07000 .020000 .0 $15.0 \quad 15000.0 \quad 8000.0$ 15.030000 .055000 .0 $20.0 \quad 0000.0 \quad 5000.0$ 15.080000 .050000 .0 18.048000 .0600000 .0 23.045000 .0500000 .0 $13.079000 .0 \quad 1500.0$ $18.0 \quad 38000.0 \quad 8500.0$ $20.0 \quad 8000.025000 .0$ $28.011000 .0 \quad 9000.0$ $14.033000 .0 \quad 9500.0$ $20.05000 .0 \quad 400.0$ 12.020000 .015000 .0 $4.0 \quad 5000.0 \quad 3.200 .0$ $-5.020000 .0500000 .0$ 15.041000 .015000 .0 15.030000 .0500000 $18.050000 .0 \quad 15000.0$ 15.07500 .055000 .0 $22.0 \quad 40000.0 \quad 2500.0$ 12.015000 .018000 .0 18.0999999 .02500 .0 $26.014000 .0 \quad 4000.0$ $18.0 \quad 5000.050000 .0$ 4.040000 .053000 .0 30.025000 .0150000 .0
$13 \quad 14 \quad 15$

$75.0 \quad 27.0 \quad 10400.0$

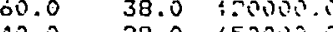
$40.0 \quad 39.0$ 65c000 $40.0999999 .0 \quad 300000.0$ $100.0 \quad 28.0 \quad 6100000.0$ $110.0 \quad 28.0 \quad 75000.0$ $110.0 \quad 32.0790000 .0$ 60.0 35075000 $40.0 \quad 20.02000000$ .0500000 .0 $50.0 \quad 33.0 \quad 900000.0$ 34.0100000 .1 $125.2 \quad 35.03750000 .0$

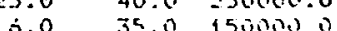
$-.5 \quad 2-.0$ 150000 $28.0 \quad 31.0 \quad 550000.0$ $20.0 \quad 28.0$ 250000. $25.0 \quad 28.0 \quad 90000.0$ $35.0 \quad 28.0 \quad 700000.0$ $20.0 \quad 25.0 \quad 800000.0$

$24.0 \quad 29.0 \quad 690000.0$

$30.0 \quad 28.0 \quad 500000.0$

$\begin{array}{lll}50.0 & 28.0 & 1200000.0\end{array}$ 
SECTIGHA ROUND 1

\begin{tabular}{|c|c|c|c|c|c|}
\hline $\begin{array}{l}\text { QUESTIGN } \\
\text { NUMEER }\end{array}$ & K* & $\begin{array}{r}\text { STATISTICAL } \\
\text { MED }\end{array}$ & $\begin{array}{c}\text { FEEDBACK } \\
\text { UQ }\end{array}$ & $\begin{array}{l}\text { TRLJE } \\
\text { UALUE }\end{array}$ & EKFOK \\
\hline 1 & 1.00 & 10.00 & 15.00 & 18.00 & -0.5878 \\
\hline 2 & 1000.00 & $20 \pi 0.00$ & 3000.00 & 2750.00 & -0.3185 \\
\hline 3 & 8000.00 & 13000.00 & 20000.00 & 7607.00 & 0.5354 \\
\hline 4 & 750.00 & 1500.00 & 2000.00 & 1549.00 & $-0.03: 1$ \\
\hline 5 & 120.00 & 160.00 & 218.00 & 151.00 & 0.1757 \\
\hline$c$ & 290.00 & 890.00 & 1000.00 & 834.00 & $0.00 \% 2$ \\
\hline 7 & 25000.00 & 100000.00 & 250000.00 & 330000.00 & -1.1939 \\
\hline 8 & 28.00 & 32.00 & 50.00 & 66.00 & -0.7239 \\
\hline 9 & 10000.60 & 20000.00 & 38000.00 & 16704.00 & 0.1803 \\
\hline 10 & 15.00 & 48.00 & 20.00 & 10.00 & 0.5878 \\
\hline 11 & 8000.00 & 20000000 & 38000.00 & 39914.00 & -0.6910 \\
\hline 12 & 4000.00 & 15000.00 & 55000.00 & 984.00 & 2.7242 \\
\hline$\{3$ & 28.00 & 50.00 & 75.00 & 150.00 & $-1.09 d \dot{0}$ \\
\hline 14 & 28.00 & 31.00 & 33.00 & 33.20 & $-0.06 i 36$ \\
\hline 15 & 170000.00 & 500000.00 & 750000.00 & $72144 \% .00$ & -0.3607 \\
\hline is & 1.50 & 4.00 & 8.00 & 4.60 & -0.1398 \\
\hline 17 & 20.00 & 213.00 & 35.00 & 17.40 & 0.3659 \\
\hline ia & 200.60 & 500.00 & 1000.00 & 586.00 & -0.1587 \\
\hline 19 & 500.00 & 1000.00 & 1500.00 & $07 \% .00$ & 0.1270 \\
\hline 20 & $\therefore .00$ & 4.00 & 6.00 & 7.80 & -0.6678 \\
\hline 21 & 500.00 & 780.00 & 7000.00 & 248.45 .00 & -3.4614 \\
\hline 22 & 8500.00 & 10000000 & 28600.00 & 18890.00 & -0.6350 \\
\hline 23 & 3500.00 & 0600.00 & 8000.00 & 12840.00 & -0.7613 \\
\hline 24 & 108.00 & 115.00 & 120.00 & 121.00 & -0.0509 \\
\hline 25 & 35.00 & 80.00 & 200.00 & 254.00 & -1.1553 \\
\hline 26 & 900.00 & 1290.00 & 2000.00 & 1157.00 & 0.1038 \\
\hline 27 & 12.00 & 25.00 & 40.00 & 59.40 & -0.8654 \\
\hline 28 & 1000.00 & 3000.00 & 4500.00 & 4144.00 & -0.3230 \\
\hline 29 & 400.00 & 700.00 & 1000.00 & 510.00 & 0.3167 \\
\hline 30 & 75.00 & 200.00 & 300.00 & 117.00 & 0.5361 \\
\hline
\end{tabular}

CUMMULATIUE DISTRIBUTION FOF LOGNOKMAL DISTRIBUTION - ALL UALUES ADJUSTED BY - 1.435

$$
\begin{aligned}
& \begin{array}{rrrrrrrrrrrrrrrrrrrrrr}
0.0 & 0.1 & 0.2 & 0.3 & 0.4 & 0.5 & 0.6 & 0.7 & 0.8 & 0.9 & 1.0 & 1.1 & 1.2 & 1.3 & 1.4 & 1.5 & 1.6 & 1.7 & 1.8 & 1.9 & 2.0 & 2.1 \\
1 & 0 & 0 & 0 & 0 & 2 & 1 & 1 & 1 & 3 & 3 & 12 & 12 & 15 & 26 & 32 & 53 & 52 & 46 & 97 & 56 & 4.4
\end{array}
\end{aligned}
$$

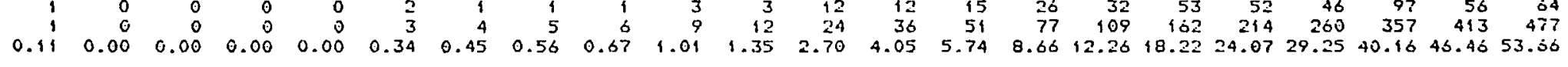

$$
\begin{aligned}
& \begin{array}{rrrrrrrrrrrrrrrrrrrrrr}
2.2 & 2.3 & 2.4 & 2.5 & 2.6 & 2.7 & 2.8 & 2.9 & 3.0 & 3.1 & 3.2 & 3.3 & 3.4 & 3.5 & 3.6 & 3.7 & 3.8 & 3.9 & 4.0 & 4.1 & 4.2 & 4.3
\end{array}
\end{aligned}
$$

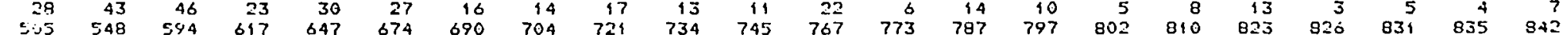

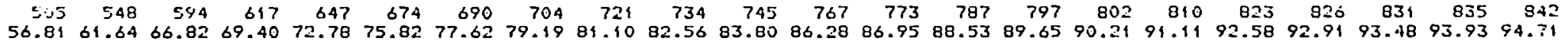

$$
\begin{aligned}
& \begin{array}{rrrrrrrrrrrrrrrrrr}
4.4 & 4.5 & 4.6 & 4.7 & 4.8 & 4.9 & 5.0 & 5.1 & 5.2 & 5.3 & 5.4 & 5.5 & 5.6 & 5.7 & 5.8 & 5.9 & 6.0 & 6.184 u F
\end{array}
\end{aligned}
$$

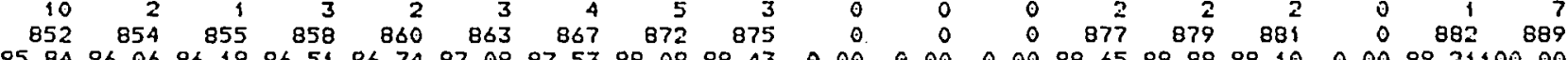


EECTIÜH A ROUND 2

\begin{tabular}{|c|c|c|c|c|c|c|c|c|c|c|c|c|c|}
\hline QUEST & $S T A$ & TISTICAL F & FEEDEACK & MAN & NIPULATED F & FEEDBACK & TRUUE & TRUE & MANIP & ERFOK & TRUE & MANIF & RANGE \\
\hline No. & LQ & MED & UQ & LQ & MED & UQ & UALUE & ERROR & ERKROR & DIFFER & RANGE & RANGE & DIFFER \\
\hline $\begin{array}{l}1 \\
2\end{array}$ & $\begin{array}{r}15.00 \\
200000\end{array}$ & 20.00 & $\begin{array}{r}25.00 \\
3.000 .00\end{array}$ & $\begin{array}{r}10.00 \\
1900.00\end{array}$ & 2 & $\begin{array}{r}34.00 \\
4000.00\end{array}$ & 0 & $\begin{array}{r}0 \\
-0\end{array}$ & 0.37 & 0.26 & 0 & & \\
\hline 3 & 850 & $\$ 2000$ & 15000.00 & & & & $\begin{array}{r}2750.00 \\
7607.00\end{array}$ & -0.1 & & & $\begin{array}{l}1000.00 \\
6500.00\end{array}$ & & \\
\hline 4 & 1 & 150 & 17 & & & & 154 & -0.0 & & & 70 & & \\
\hline 5 & 0 & 12 & 160. & 80.00 & 110.00 & 145.00 & 151.00 & -0.18 & -0.32 & -0.14 & 40. & 65.00 & 25.00 \\
\hline 6 & 600.00 & 850.00 & 914.00 & & & & 834.00 & 0.02 & & & $31+.00$ & & \\
\hline 7 & 000 & 280000.00 & 320000.00 & 100000.00 & 300000.00 & +20000.00 & .330000 .00 & -0.16 & -0.10 & 0.07 & 120000.00 & 320000.00 & 200000.00 \\
\hline 8 & 30.00 & 22.60 & 45.00 & & & & 66.00 & -0 & & & 13.00 & & \\
\hline 9 & 10000.00 & $\$ 300 r .00$ & 20000.00 & 10000.00 & 0 & 5000.00 & 704 & -0 . & -0.42 & -0 & $00 \% 0$ & 5000.00 & -5000.00 \\
\hline 10 & & & . & & & & & & & & & & 0 \\
\hline i! & 24000 & 30000 & 3600 & 20000.00 & 42000.00 & 50000.00 & $3: 91$ & -0.29 & 0.05 & & $12000^{\circ}$ & 300 & 15000.00 \\
\hline is & & & & & & & & & & & $\{4\}$ & & \\
\hline 13 & & & & & & & & -1 & & & & & \\
\hline 14 & 31.00 & 32.00 & 35.00 & 0 & & & 0 & -6.04 & & 0.20 & 4.00 & 10 & \\
\hline$\llbracket 5$ & ODOG.5 & 750000 & 000000.00 & 60000 & 9000 & 0 & $\{44$ & & & & 0000.00 & 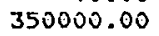 & 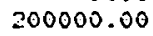 \\
\hline io & 2.00 & & & & & & & & & & & & \\
\hline 17 & 30. & 33 & 40 . & 28.00 & 40.00 & 52.00 & & & 0.72 & .19 & & 24.00 & 14.00 \\
\hline i & & & & & & & & & & & & & \\
\hline 18 & 500. & 750 & 9 & 400.00 & & & 374. & -0.16 & -0.56 & -0. & & 400 & -10 \\
\hline 30 & 3.00 & 4. & & & & & & & & & & & \\
\hline 21 & 000.00 & $1500 \%$ & $\mathrm{E}(\mathrm{n})$ & is & & & & & & & & & \\
\hline 32 & $i=0,00,00$ & 1toog & 2000 & 1000 & 200 & 280 & 180 & & & & & & \\
\hline 23 & 5000 & $7(10)$ & 000 & & & & 1213 & -0 & & & 300 & & \\
\hline 24 & 112.00 & 118 & 122.00 & 120.00 & 130.00 & 133.00 & & -0. & 0.07 & 0.10 & & 13.00 & 3.00 \\
\hline 25 & & & & & & & & & & & & & \\
\hline$=5$ & 72 & 100 & 12 & 600.00 & 700.00 & 1200.00 & & & -0.50 & -0.36 & & 600.00 & 30.00 \\
\hline 27 & 15 & & & & & & & & & & & & \\
\hline 28 & 3500.00 & 4060.00 & 4000.60 & 3000.00 & 4800.00 & 5200.00 & 4144. & -0.04 & 0.15 & 0.18 & 1300 & 2200.00 & 900.00 \\
\hline 29 & 500 & 700 & 900. & & & & & 0. & & & & & \\
\hline 3n) & .00 & 0 & 250.00 & & & & & 0.54 & & & & & \\
\hline
\end{tabular}




\section{SECTIOR कA R:CUND 2}

****** actual Value of*******

QUEST KI
NO. REDIAN MEDIAN MANIF MED TRUE
MEN ANSWEF 2000.00 3000.00

15.00 .00

180.00

00050.00

32.00

18.00

20000.00

15000.00

50.00

500000.00

4.00

28.60

1000.00

4.00

780.00

10000.00

6000.00

115.00

80.00

1290.00

25.00
3000.00

700.00

200.00
20.00

500.0

126.00

0000.00

3600.00

110.00

32.00

35.00
15.00

8000.00

50.00

750000.00

4.00

33.00
400.00

750.00

15000.00

18000.00

198.00

100.00

1000.00

4000.00

700.00

700.00
200.00

500.00
* STANDARdized Value of **

Fi RII MANIF. TRUE

A $B$ RTD 2 SUCCESS

TFUE STD. DIFFER (RI-EI)/(MI-KI) $* 100$ DEUIFIIIN MEDIFIN MEDIAN MEDIAN ANSWER RI-Fi MI-RI STD NON-STD ER̃Ẽ

19.93
2405.00
13093.33
1398.33
142.57
807.50

$\begin{array}{rrr}9.25 & -0.24 & 0.10 \\ 804.19 & -0.30 & -0.15\end{array}$

$\begin{array}{ll}0.31 & 0.03 \\ 0.30 & -0.07\end{array}$ $\begin{array}{lllll}0.35 & 0.56 & 02.5 & 02.5 & 72.5 \\ 0.16 & 0.50 & 31.3 & 31.3 & 38.0\end{array}$ $7378.10-0.30-0.38$ $698.21-0.32-0.32$

$\begin{array}{lllll}-0.59 & -0.76 \quad 77.1 \quad 77.1 \quad 72.4\end{array}$ 0.66 $0.93 \quad 1.04 \quad 90.0 \quad 90.0 \quad 93.7$ $\begin{array}{llll}35.47 & 43.29 & -0.39 & -0.39\end{array}$ $14000.00 \quad 16701.00$ $82060.00 \quad 39914.00$
400

1567.47

$\begin{array}{rr}0.73 & 0.44 \\ -0.0 .44 & -1.40\end{array}$ $\begin{array}{lllll}724+3.30 & -0.94 & -0.54 & -1.74 & -1.40\end{array}$ 984.00 150.00 $39.00 \quad 33.20$ 215.00 $10505.19-0.33-0.42$ $22.79-0.13 \quad-0.13$ $\begin{array}{rrrr}32.27 & 3.42 & 0.05 & 0.32 \\ 710833.00 & 190357.80 & -0.02 & 0.47\end{array}$ $40.00 \quad 4.60$ 19.10 878.00 3.86 $\begin{array}{rrr}3.80 & -0.02 & 0.67 \\ 2.52 & -0.09 & -0.09\end{array}$ $\begin{array}{llll}469.43 & 302.82 & -0.29 & -0.35\end{array}$ $638.23-0.29-0.50$ $18000.00 \quad 24845.00$ 18890.00 12846.00
121.00 16344.53 10950.00 6736.66
116.63 215.00 1140.37 24.64 1157.00 4144.00 510.00 698.33 $\begin{array}{rrr}2.25 & -0.25 & -0.25 \\ 15606.57 & -0.46 & 0.31\end{array}$ $7243.51-0.50-0.06$ $\begin{array}{llll}3426.32 & -0.20 & 0.00\end{array}$ $\begin{array}{rrr}7.013 & 0.21 & 0.05 \\ 397.31 & -0.40 & -0.36\end{array}$ $\begin{array}{lll}340.87 & -0.26 & -0.53\end{array}$ $\begin{array}{lll}12.53 & -0.30 & -0.38\end{array}$ $\begin{array}{rrr}1331.10 & -0.02 & 0.43 \\ 220.85 & 0.09 & 0.09\end{array}$ $\begin{array}{rrr}220.85 & 0.09 & 0.09 \\ 117.39 & -0.13 & -0.13\end{array}$

\subsection{9}

$2.26 \quad 0.66$ $\begin{array}{ll}1.08 & 0.59 \\ 0.07 & 0.07\end{array}$ $0.60-0.64 \quad 0.30 \quad 0.72 \quad 41.7 \quad 41.7 \quad 40.1$ $-0.71 \quad-0.24$ $\begin{array}{lllllll}0.48 & 0.05 & 0.78 & 0.94 & 82.0 & 32.6 & 94.2\end{array}$ i.01 $\begin{array}{lllllll}2.40 & 1.09 & 0.44 & 2.19 & 20.0 & 20.0 & 21.0\end{array}$ $0.82 \quad 0.52$ $\begin{array}{lllll}-0.28 & -0.56 & 49.2 & 49.2 & 41.7\end{array}$ $\begin{array}{lllll}0.46 & 0.83 & 55.6 & 55.6 & 61.2\end{array}$ 


\begin{tabular}{|c|c|c|c|c|c|c|c|c|c|c|c|c|c|c|c|}
\hline $\begin{array}{c}\text { QLIEST } \\
\text { NO. }\end{array}$ & ROUND & $\begin{array}{r}S \\
L Q\end{array}$ & $\begin{array}{r}\text { TATISTICAL } \\
\text { HED }\end{array}$ & $\begin{array}{c}\text { FEEDEACK } \\
\text { UQ }\end{array}$ & LQA & $\begin{array}{r}\text { ANIPULATED } \\
\text { MED }\end{array}$ & $\begin{array}{c}\text { FEEDEACK } \\
\text { UQ }\end{array}$ & $\begin{array}{l}\text { TRUE } \\
\text { UALUE }\end{array}$ & $\begin{array}{l}\text { TRUE } \\
\text { EF:ROR }\end{array}$ & $\begin{array}{l}\text { MANIP } \\
\text { ERKOK }\end{array}$ & $\begin{array}{l}\text { ERROR } \\
\text { DIFFEF }\end{array}$ & $\begin{array}{r}\text { TRUE } \\
\text { RANGE }\end{array}$ & $\begin{array}{l}\text { MANIF. } \\
\text { RANGE }\end{array}$ & $\begin{array}{l}\text { FAANGE } \\
\text { DIFFES }\end{array}$ & \\
\hline 1 & $\begin{array}{l}1 \\
2 \\
3 \\
4\end{array}$ & $\begin{array}{r}1.00 \\
15.00 \\
18.00 \\
20.00\end{array}$ & $\begin{array}{l}10.00 \\
20.00 \\
22.00 \\
24.00\end{array}$ & $\begin{array}{l}15.00 \\
25.00 \\
26.00 \\
26.00\end{array}$ & $\begin{array}{l}10.00 \\
21.00 \\
23.00\end{array}$ & $\begin{array}{l}26.00 \\
26.00 \\
24.00\end{array}$ & $\begin{array}{l}34.00 \\
32.00 \\
39.00\end{array}$ & $\begin{array}{l}18.00 \\
18.00 \\
18.00 \\
18.00\end{array}$ & $\begin{array}{r}-0.59 \\
0.14 \\
0.20 \\
0.29\end{array}$ & $\begin{array}{l}0.37 \\
0.37 \\
0.29\end{array}$ & $\begin{array}{l}0.26 \\
0.17 \\
0.00\end{array}$ & $\begin{array}{r}14.00 \\
10.00 \\
8.00 \\
0.00\end{array}$ & $\begin{array}{r}24.00 \\
11.00 \\
8.00\end{array}$ & $\begin{array}{r}14.00 \\
3.00 \\
2.00\end{array}$ & \\
\hline 2 & $\begin{array}{l}1 \\
2 \\
3 \\
4\end{array}$ & $\begin{array}{l}1000.00 \\
2000.00 \\
=000.00 \\
2000.00\end{array}$ & $\begin{array}{l}2000.00 \\
2500.00 \\
\because 200.00 \\
2020.00\end{array}$ & $\begin{array}{l}3000.00 \\
3000.00 \\
3500.00 \\
3500.00\end{array}$ & $\begin{array}{l}1900.00 \\
3500.00 \\
3500.00\end{array}$ & $\begin{array}{l}3600.00 \\
3600.00 \\
3600.00\end{array}$ & $\begin{array}{l}\$ 000.00 \\
\therefore 800.00 \\
\$ 800.00\end{array}$ & $\begin{array}{l}2750.00 \\
2750.00 \\
2750.00 \\
2750.00\end{array}$ & $\begin{array}{r}-0.32 \\
-0.10 \\
-0.10 \\
0.09\end{array}$ & $\begin{array}{l}0.27 \\
0.27 \\
0.27\end{array}$ & $\begin{array}{l}0.36 \\
0.36 \\
0.18\end{array}$ & $\begin{array}{l}2000.00 \\
1000.00 \\
1500.00 \\
1500.00\end{array}$ & $\begin{array}{r}2100.00 \\
300.00 \\
300.00\end{array}$ & $\begin{array}{r}1100.00 \\
-1200.00 \\
-1: 000.00\end{array}$ & \\
\hline 3 & $\begin{array}{l}1 \\
2 \\
3 \\
4\end{array}$ & $\begin{array}{l}8000.00 \\
8500.00 \\
9000.00 \\
9000.00\end{array}$ & $\begin{array}{l}13000.00 \\
12000.00 \\
12000.00 \\
12000.00\end{array}$ & $\begin{array}{l}20000.00 \\
15000.00 \\
14000.00 \\
13000.00\end{array}$ & & & & $\begin{array}{l}7607.00 \\
7607.00 \\
7607.00 \\
7607.00\end{array}$ & $\begin{array}{l}0.54 \\
0.46 \\
0.46 \\
0.46\end{array}$ & & & $\begin{array}{r}12000.00 \\
0500.00 \\
5000.00 \\
400000\end{array}$ & & & \\
\hline 4 & $\begin{array}{l}1 \\
2 \\
3 \\
4\end{array}$ & $\begin{array}{r}750.00 \\
1000.00 \\
1005.00 \\
1000.00\end{array}$ & $\begin{array}{l}1500.00 \\
1500.00 \\
1500.00 \\
1500.00\end{array}$ & $\begin{array}{l}2000.00 \\
1700.00 \\
1500.00 \\
1500.00\end{array}$ & & & & $\begin{array}{l}1549.00 \\
1549.00 \\
1549.00 \\
1549.00\end{array}$ & $\begin{array}{l}-0.03 \\
-0.03 \\
-0.03 \\
-0.03\end{array}$ & & & $\begin{array}{r}1250.00 \\
700.00 \\
500.00 \\
500.00\end{array}$ & & & \\
\hline 5 & $\begin{array}{l}1 \\
2 \\
3 \\
4 \\
4\end{array}$ & $\begin{array}{l}120.00 \\
120.00 \\
145.00 \\
115.00\end{array}$ & $\begin{array}{l}180.00 \\
126.00 \\
125.00 \\
120.00\end{array}$ & $\begin{array}{l}211.00 \\
160.00 \\
130.00 \\
130.00\end{array}$ & $\begin{array}{r}80.00 \\
100.00 \\
100.00\end{array}$ & $\begin{array}{l}110.00 \\
115.00 \\
115.00\end{array}$ & $\begin{array}{l}145.00 \\
130.00 \\
120.00\end{array}$ & $\begin{array}{l}151.00 \\
151.00 \\
151.00 \\
151.00\end{array}$ & $\begin{array}{r}0.18 \\
-0.18 \\
-0.19 \\
-0.23\end{array}$ & $\begin{array}{l}-0.32 \\
-0.27 \\
-0.27\end{array}$ & $\begin{array}{l}-0.14 \\
-0.08 \\
-0.04\end{array}$ & $\begin{array}{l}98.00 \\
40.00 \\
15.00 \\
15.00\end{array}$ & $\begin{array}{l}65.00 \\
30.00 \\
20.00\end{array}$ & $\begin{array}{r}25.00 \\
15.00 \\
5.00\end{array}$ & \\
\hline 6 & $\begin{array}{l}1 \\
2 \\
3 \\
4\end{array}$ & $\begin{array}{l}290.00 \\
600.00 \\
760.00 \\
300.00\end{array}$ & $\begin{array}{l}840.00 \\
850.00 \\
350.00 \\
850.00\end{array}$ & $\begin{array}{r}1000.00 \\
911.00 \\
911.00 \\
911.00\end{array}$ & & & & $\begin{array}{l}834.00 \\
834.00 \\
834.00 \\
834.00\end{array}$ & $\begin{array}{l}0.01 \\
0.02 \\
0.02 \\
0.02\end{array}$ & & & $\begin{array}{l}710.00 \\
311.00 \\
151.00 \\
111.00\end{array}$ & & & \\
\hline 7 & $\begin{array}{l}1 \\
2 \\
3 \\
4\end{array}$ & $\begin{array}{r}25000.00 \\
200600.00 \\
280000.00 \\
300000.00\end{array}$ & $\begin{array}{l}100000.00 \\
200000.00 \\
300000.00 \\
310000.00\end{array}$ & $\begin{array}{l}250000.00 \\
320000.00 \\
330000.00 \\
330000.00\end{array}$ & $\begin{array}{l}100000.00 \\
280000.00 \\
310000.00\end{array}$ & $\begin{array}{l}300000.00 \\
330000.00 \\
330000.00\end{array}$ & $\begin{array}{l}420000.00 \\
+100000.00 \\
300000.00\end{array}$ & $\begin{array}{l}330000.00 \\
330000.00 \\
330000.00 \\
330000.00\end{array}$ & $\begin{array}{l}-1.19 \\
-0.16 \\
-0.10 \\
-0.06\end{array}$ & $\begin{array}{r}-0.10 \\
0.00 \\
0.00\end{array}$ & $\begin{array}{l}0.07 \\
0.10 \\
0.06\end{array}$ & $\begin{array}{r}225000.00 \\
120000.00 \\
50000.00 \\
30000.00\end{array}$ & $\begin{array}{l}320000.00 \\
120000.00 \\
70000.00\end{array}$ & $\begin{array}{r}200000.00 \\
70000.00 \\
40000.00\end{array}$ & 1 \\
\hline 8 & $\begin{array}{l}1 \\
2 \\
3 \\
4\end{array}$ & $\begin{array}{l}28.00 \\
30.00 \\
30.000 \\
30.00\end{array}$ & $\begin{array}{l}32.00 \\
32.00 \\
32.00 \\
32.00\end{array}$ & $\begin{array}{l}50.00 \\
45.00 \\
40.00 \\
38.00\end{array}$ & & & & $\begin{array}{l}66.00 \\
56.00 \\
63.00 \\
65.00\end{array}$ & $\begin{array}{l}-0.72 \\
-0.72 \\
-0.72 \\
-0.72\end{array}$ & & & $\begin{array}{r}22.00 \\
15.00 \\
10.00 \\
8.00\end{array}$ & & $\cdot$ & ! \\
\hline 9 & $\begin{array}{l}1 \\
2 \\
3 \\
4\end{array}$ & $\begin{array}{l}10000.00 \\
10000.00 \\
10000.00 \\
10000.00\end{array}$ & $\begin{array}{l}20000.00 \\
13000.00 \\
12500.00 \\
12000.00\end{array}$ & $\begin{array}{l}38000.00 \\
20000.00 \\
15000.00 \\
15000.00\end{array}$ & $\begin{array}{l}10000.00 \\
10000.00 \\
10000.00\end{array}$ & $\begin{array}{l}11000.00 \\
11500.00 \\
11500.00\end{array}$ & $\begin{array}{l}15000.00 \\
13000.00 \\
12500.00\end{array}$ & $\begin{array}{l}16701.00 \\
16709.00 \\
16701.00 \\
16701.00\end{array}$ & $\begin{array}{r}0.18 \\
-0.25 \\
-0.29 \\
-0.33\end{array}$ & $\begin{array}{l}-0.42 \\
-0.37 \\
-0.37\end{array}$ & $\begin{array}{l}-0.17 \\
-0.08 \\
-0.04\end{array}$ & $\begin{array}{r}28000.00 \\
10000.00 \\
5000.00 \\
5000.00\end{array}$ & $\begin{array}{l}5000.00 \\
3000.00 \\
2500.00\end{array}$ & $\begin{array}{l}-5000.00 \\
-2000.00 \\
-2500.00\end{array}$ & ' \\
\hline 10 & $\begin{array}{l}1 \\
2 \\
3 \\
4\end{array}$ & $\begin{array}{l}15.00 \\
11.00 \\
10.00 \\
10.00\end{array}$ & $\begin{array}{l}18.00 \\
15.00 \\
12.00 \\
12.00\end{array}$ & $\begin{array}{l}20.00 \\
18.00 \\
15.00 \\
15.00\end{array}$ & $\begin{array}{l}7.00 \\
7.00 \\
7.00\end{array}$ & $\begin{array}{l}8.00 \\
8.00 \\
9.00\end{array}$ & $\begin{array}{r}18.00 \\
10.00 \\
9.00\end{array}$ & $\begin{array}{l}10.00 \\
10.00 \\
10.00 \\
10.00\end{array}$ & $\begin{array}{l}0.59 \\
0.41 \\
0.18 \\
0.18\end{array}$ & $\begin{array}{l}-0.22 \\
-0.22 \\
-0.11\end{array}$ & $\begin{array}{l}-0.63 \\
-0.41 \\
-0.29\end{array}$ & $\begin{array}{l}5.00 \\
7.00 \\
5.00 \\
5.00\end{array}$ & $\begin{array}{r}19.00 \\
3.00 \\
2.00\end{array}$ & $\begin{array}{r}4.00 \\
-2.00 \\
-3.00\end{array}$ & $\stackrel{N}{\models}$ \\
\hline
\end{tabular}




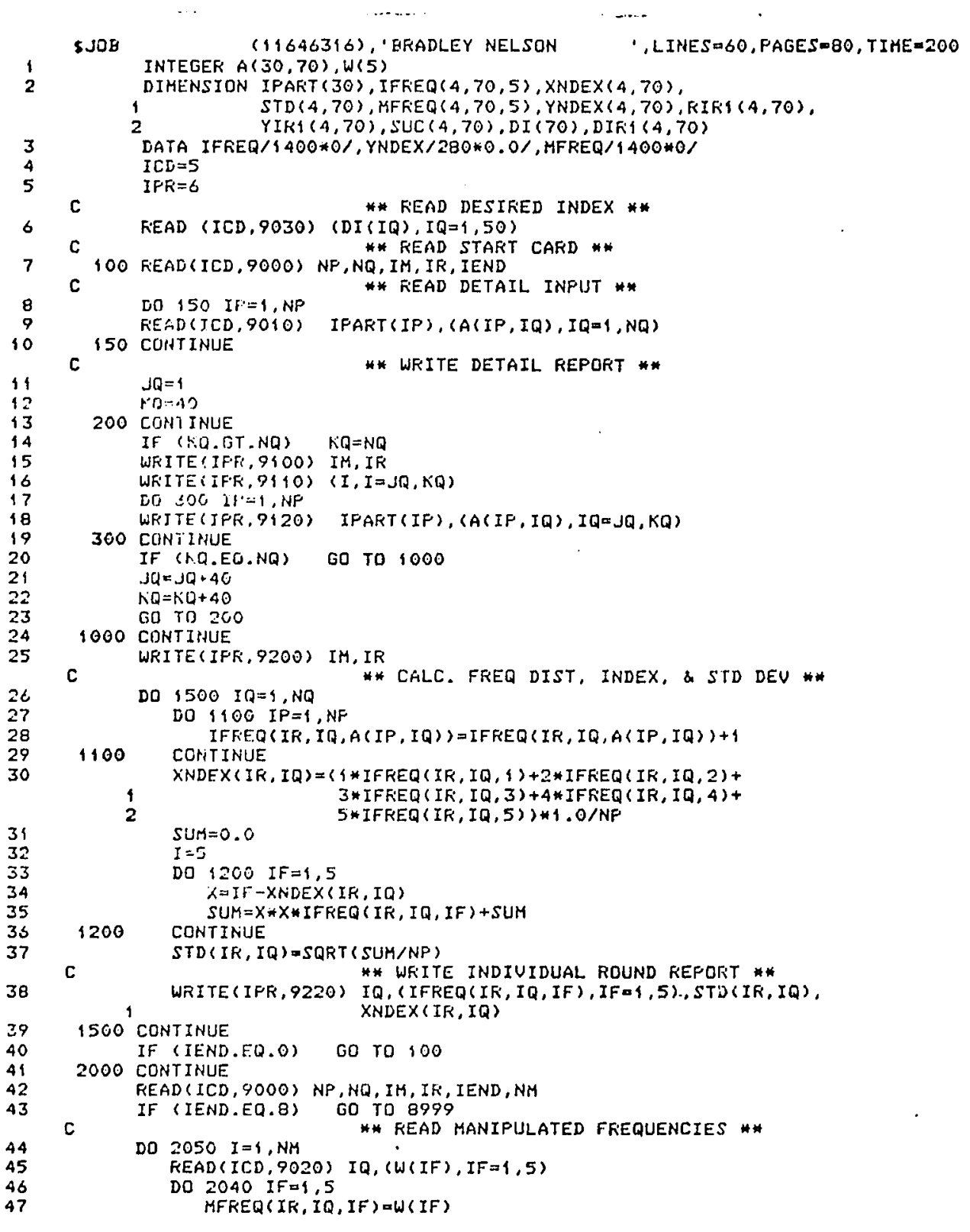




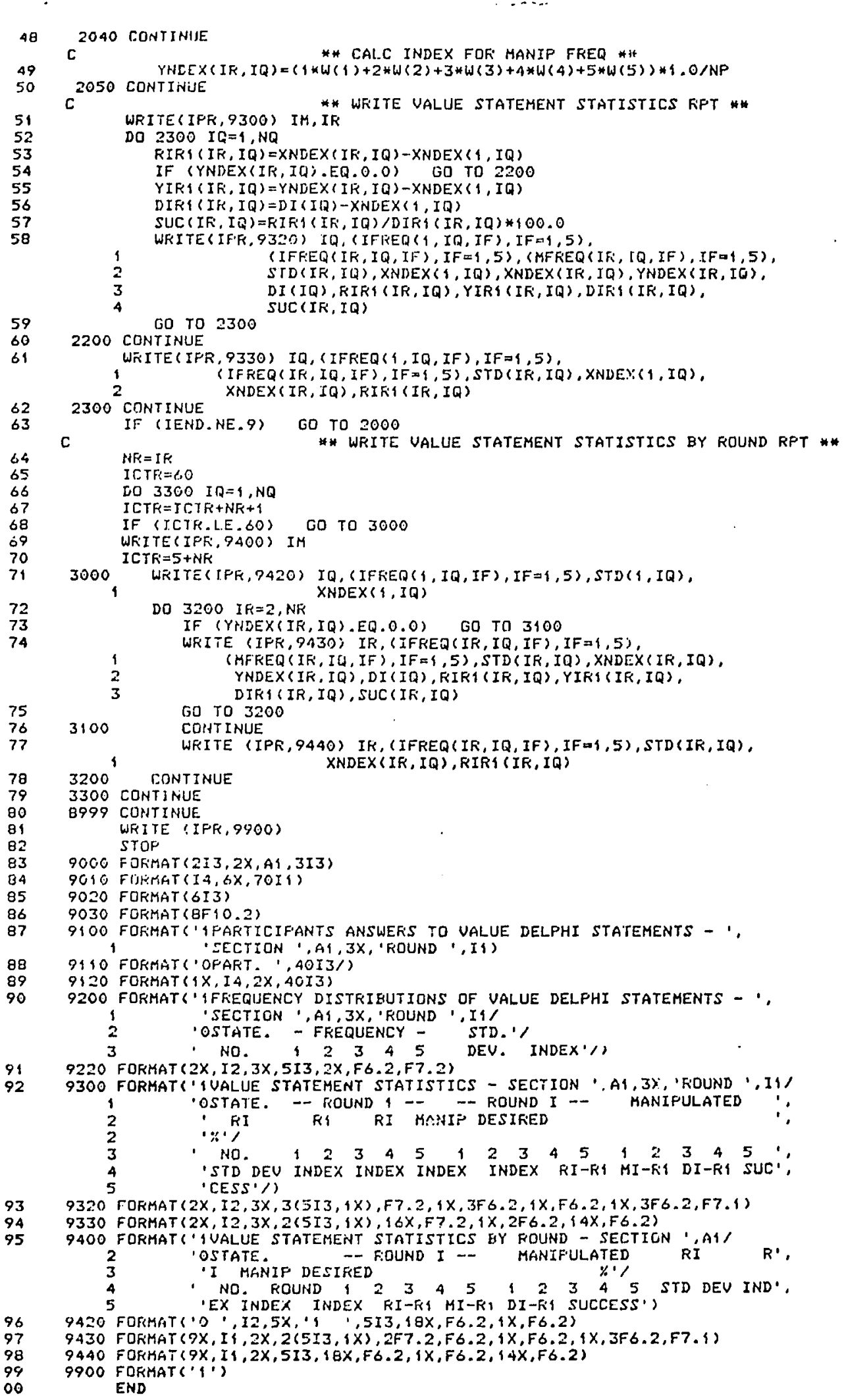


FARTICIFAHTS ANSWERS TO VALUE DELFHI STATEMENTS - SECTION A ROLIND

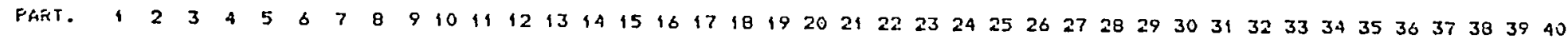

\begin{tabular}{|c|c|c|c|c|c|c|c|c|c|c|c|c|c|c|c|c|c|c|c|c|c|c|c|c|c|c|c|c|c|c|c|c|c|c|c|c|c|c|c|c|}
\hline 418 & & & & & & & & & & & & & & & & & & & & & & & & & & & & & & & & & & & & & & & & \\
\hline 723 & & & & 1 & 2 & 4 & 3 & 4 & 2 & 2 & 3 & 4 & 5 & 3 & 2 & 5 & 4 & 4 & 3 & $t$ & 1 & 5 & 3 & 4 & 3 & & 4 & & & & & & & & & & & & & \\
\hline 807 & 3 & & 3 & 3 & 4 & 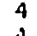 & $=$ & 3 & 4 & 3 & 3 & 4 & 4 & 4 & 4 & 5 & 4 & 3 & 3 & 4 & 4 & 3 & 4 & 4 & 4 & 4 & 4 & 4 & 4 & 4 & 4 & 4 & 5 & 4 & & & $\begin{array}{l}3 \\
5\end{array}$ & 5 & 4 & 5 \\
\hline 859 & 4 & 5 & $\begin{array}{l}4 \\
3\end{array}$ & 3 & 4 & $\stackrel{4}{5}$ & 2 & 4 & 4 & 3 & 3 & 2 & 4 & 3 & 4 & 3 & 3 & 5 & 3 & 3 & 3 & 3 & 3 & 2 & 3 & 4 & 4 & 3 & 4 & 3 & 3 & 2 & 4 & 4 & 3 & 4 & 5 & 4 & 3 & $\begin{array}{l}5 \\
4\end{array}$ \\
\hline 1078 & 4 & 2 & 3 & 4 & 5 & 4 & 1 & $\begin{array}{l}4 \\
3\end{array}$ & & 4 & 4 & 5 & 5 & 3 & 4 & 4 & 4 & 2 & 3 & 5 & 3 & & 5 & 3 & 4 & $i$ & 5 & 5 & 5 & 4 & 5 & 4 & 5 & 1 & 3 & 2 & & & 5 & \\
\hline 1459 & 3 & 2 & 2 & 2 & 4 & 4 & 2 & 3 & 4 & 3 & $\begin{array}{l}1 \\
3\end{array}$ & $\frac{4}{x}$ & 3 & 2 & 1 & 4 & 2 & 3 & 1 & 1 & 1 & 5 & 3 & 4 & 3 & 2 & 2 & 2 & 5 & 1 & 4 & 5 & 5 & 3 & 1 & I & 2 & 5 & 5 & \\
\hline 73 & 3 & 3 & 2 & 3 & 2 & 3 & 3 & 3 & 4 & 3 & 3 & 3 & 3 & 3 & 3 & 3 & 4 & 4 & 4 & 3 & 2 & 4 & 3 & 4 & 4 & 2 & 3 & 3 & 4 & 9 & 3 & 4 & 3 & 2 & 2 & 3 & 3 & . & & \\
\hline & & 3 & 4 & 3 & 4 & 4 & 5 & 3 & 4 & 3 & $\begin{array}{l}4 \\
3\end{array}$ & 3 & 4 & 4 & 3 & 3 & 3 & 2 & 5 & 3 & 2 & 3 & & 3 & & & & & 4 & 3 & & 3 & & & 3 & & $=$ & 4 & 4 & \\
\hline & 3 & 3 & 4 & 5 & 4 & 5 & 3 & 5 & 1 & 3 & 3 & $\begin{array}{l}4 \\
4\end{array}$ & $\begin{array}{l}5 \\
5\end{array}$ & $\begin{array}{l}5 \\
4\end{array}$ & $\begin{array}{l}4 \\
5\end{array}$ & $\begin{array}{l}4 \\
5\end{array}$ & & & $\begin{array}{l}2 \\
5\end{array}$ & $\stackrel{4}{5}$ & $\begin{array}{l}4 \\
5\end{array}$ & 5 & & 3 & $=$ & 7 & & 7 & 5 & 4 & 5 & 4 & 4 & 5 & 4 & 3 & 4 & 4 & 3 & \\
\hline 2376 & 3 & 4 & 4 & 4 & 3 & 5 & 2 & 3 & 2 & i & 5 & 3 & 4 & 4 & 3 & 4 & $\begin{array}{l}3 \\
5\end{array}$ & & 5 & $\begin{array}{l}5 \\
5\end{array}$ & 5 & 5 & 4 & 4 & 5 & 2 & 5 & 3 & 5 & 5 & 5 & 3 & 5 & 3 & 3 & 3 & 5 & 5 & 5 & \\
\hline 2451 & 3 & 4 & 4 & 3 & 5 & 5 & 2 & 4 & 5 & 4 & 4 & 3 & 5 & 3 & 2 & 5 & $\overrightarrow{4}$ & 5 & 3 & 3 & $\begin{array}{l}1 \\
2\end{array}$ & 5 & 4 & 1 & 4 & 2 & 1 & 3 & 3 & 4 & 2 & 4 & 4 & 2 & & 3 & 5 & 5 & 4 & \\
\hline 63 & 3 & 4 & 2 & 3 & 4 & 4 & 3 & 5 & 4 & 2 & 3 & 3 & 5 & 2 & 4 & 3 & 3 & 4 & 4 & 2 & $\frac{3}{3}$ & & 4 & 3 & 7 & & 5 & 5 & 5 & 3 & 5 & 3 & 5 & 3 & $\overline{3}$ & 3 & 4 & & 4 & \\
\hline & & 3 & 2 & $t$ & 1 & 4 & 3 & 4 & 2 & 2 & 3 & 2 & 3 & 3 & 3 & 4 & 3 & $\overrightarrow{4}$ & 4 & 4 & 3 & & & 4 & & & & & & & & & & & 3 & & & & & \\
\hline 10 & 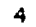 & & 3 & 3 & 5 & 5 & 4 & 4 & 2 & 3 & 4 & 4 & 5 & 4 & 3 & 4 & 3 & $\begin{array}{l}4 \\
3\end{array}$ & 4 & 3 & 2 & & & 3 & & & 4 & & & & & & & & & & 4 & & & \\
\hline & 4 & 3 & 5 & 3 & 5 & 4 & 2 & 3 & 4 & 3 & 5 & 4 & 5 & 5 & 5 & $\begin{array}{l}4 \\
5\end{array}$ & 4 & 4 & 4 & & 3 & 4 & - & 5 & 5 & 3 & 4 & 4 & 5 & 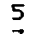 & & 4 & & 4 & 3 & & & 5 & & \\
\hline 3374 & 4 & 3 & 2 & 3 & 3 & 5 & 3 & 2 & 4 & 2 & 4 & 4 & 3 & 3 & 4 & 3 & 4 & 3 & 3 & $\frac{2}{3}$ & 3 & & 4 & & & & 4 & 4 & 4 & 3 & & 3 & 4 & 4 & 4 & 3 & 4 & 3 & 4 & \\
\hline 371 & 3 & 4 & 4 & 2 & 3 & 5 & 2 & 5 & 3 & 2 & 2 & 5 & 5 & & ? & 3 & 3 & 2 & 3 & $=$ & & & 2 & & & 2 & 4 & 4 & 4 & 5 & & & & & & & & & 4 & \\
\hline & & & 2 & i & 4 & 3 & 1 & 4 & 4 & 3 & 3 & 2 & 4 & 4 & 5 & 5 & & & & & 3 & 2 & 3 & 3 & & & & 5 & 5 & 2 & & & & & & & & & & \\
\hline 4 & & 5 & 3 & 4 & 5 & 3 & 3 & 5 & 3 & 2 & 3 & 3 & & 3 & $\pi$ & & 4 & $?$ & $\begin{array}{l}4 \\
2\end{array}$ & 2 & 2 & 2 & 4 & 4 & 4 & 3 & 2 & 1 & 5 & 1 & - & 1 & 4 & 4 & 2 & & 4 & \{ & 5 & \\
\hline 65. & 4 & 3 & 4 & 5 & 4 & 4 & 4 & 4 & 4 & 4 & & & & & & & 5 & & 5 & 4 & & 2 & & & & & & & 5 & 3 & & & & & 4 & & & 2 & & \\
\hline $6 E_{2}$ & 4 & 5 & 5 & 4 & 5 & 5 & 5 & 4 & 4 & 5 & 5 & 4 & 4 & 3 & 3 & 4 & 4 & 5 & 3 & $A$ & 3 & 5 & 5 & & & 4 & & & & 4 & & & & & & & & & 4 & \\
\hline 600 & 5 & 4 & 4 & 3 & 5 & 4 & 4 & & & & & & & & & & 5 & & 3 & 5 & 3 & & 3 & 3 & 5 & 4 & 5 & 4 & 5 & 5 & & & & & & & & & & \\
\hline 73 & 7 & $A$ & 5 & 3 & 5 & 4 & 1 & 3 & 5 & 3 & 1 & 2 & 4 & 2 & 2 & 4 & 4 & 5 & 5 & 3 & 4 & $\begin{array}{l}4 \\
4\end{array}$ & 5 & 4 & 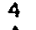 & $=$ & & & 4 & & & 4 & & & & 4 & 4 & & & \\
\hline & & 3 & 3 & 2 & 2 & 3 & 2 & 3 & 2 & 2 & 3 & 2 & 3 & 2 & 4 & 3 & 4 & 3 & 5 & 5 & 3 & 4 & 4 & 2 & $\begin{array}{l}4 \\
3\end{array}$ & $\frac{2}{1}$ & $\begin{array}{l}3 \\
4\end{array}$ & $\begin{array}{l}4 \\
4\end{array}$ & $\begin{array}{l}5 \\
3\end{array}$ & $\begin{array}{l}1 \\
4\end{array}$ & & & & & & & & 2 & & \\
\hline 878 & 3 & 4 & 3 & 3 & 4 & 5 & 1 & 4 & 4 & 2 & 5 & 4 & 4 & 3 & 2 & 4 & 5 & 5 & 5 & 2 & 1 & 5 & 4 & $=$ & 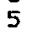 & 2 & 4 & 7 & 3 & 5 & & & & & & & & & & \\
\hline E98 & 4 & 5 & 4 & 3 & 4 & 5 & 3 & 5 & 4 & 3 & 3 & 3 & 4 & 2 & 2 & 3 & 4 & 4 & 3 & 4 & 3 & 5 & 4 & 4 & 5 & 3 & 4 & 5 & 5 & 3 & 4 & 3 & & & & & & 4 & 5 & \\
\hline 909 & $\begin{array}{l}4 \\
3\end{array}$ & & 4 & 3 & 5 & 5 & 3 & 4 & 4 & 4 & 3 & 4 & 4 & 3 & 4 & 3 & 3 & 4 & 4 & 5 & 4 & 4 & 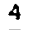 & 4 & 4 & 3 & 4 & 3 & 5 & 4 & & & 4 & 3 & 4 & & & 1 & 4 & \\
\hline 78 & 3 & 4 & $\begin{array}{l}4 \\
4\end{array}$ & 3 & 5 & 4 & 5 & 5 & 3 & 3 & 3 & $\frac{3}{3}$ & 5 & 4 & 4 & 3 & 3 & 5 & 4 & 4 & 4 & 4 & 5 & 3 & & 3 & 5 & & & & & & & & & & & & & \\
\hline 30 & 2 & 4 & 3 & 2 & 7 & & $\begin{array}{l}4 \\
3\end{array}$ & & & 7 & 4 & 3 & & & & & 3 & & & & & & & & & & & & & & & & & & & & & & & \\
\hline & & & & & & & & & & & & & & & & & & & & & & & & & & & & & & & & & & & & & & & & \\
\hline
\end{tabular}


FREQUENCY DISTRIBUTIONS OF VALUE DELPHI STATEMENTS - SECTION A ROUND 1

\begin{tabular}{|c|c|c|c|c|c|c|c|}
\hline $\begin{array}{c}\text { STATE. } \\
\text { NO. }\end{array}$ & 1 & $\begin{array}{c}\text { FRE } \\
\mathbf{2}\end{array}$ & QQUE & $\begin{array}{r}\text { ENC } \\
4\end{array}$ & $\gamma=$ & $\begin{array}{l}\text { STD. } \\
\text { DEU. }\end{array}$ & INDEX \\
\hline 1 & 2 & 3 & 12 & 12 & $\mathfrak{i}$ & 0.92 & 3.23 \\
\hline 2 & & 2 & 10 & 13 & 4 & 0.92 & 3.57 \\
\hline 3 & 0 & 6 & 8 & 13 & 3 & 0.92 & 3.43 \\
\hline 4 & 4 & 4 & 16 & 4 & 2 & 1.02 & 2.87 \\
\hline 5 & 4 & 3 & 6 & 10 & 10 & 1.10 & 3.83 \\
\hline 6 & 0 & 0 & 4 & 15 & 11 & 0.67 & 4.23 \\
\hline 7 & 5 & $1 \theta$ & 9 & 3 & 3 & 1.17 & 2.63 \\
\hline 8 & $\theta$ & i & 9 & 13 & 7 & 0.81 & 3.87 \\
\hline 9 & $\mathfrak{i}$ & 6 & 4 & 16 & 3 & 1.02 & 3.47 \\
\hline 10 & , & 8 & 14 & 6 & 1 & 0.35 & 2.93 \\
\hline 11 & 2 & 2 & 15 & 6 & 5 & 1.04 & 3.33 \\
\hline 12 & 0 & 6 & 9 & 11 & 4 & 0.76 & 3.43 \\
\hline 13 & & 1 & 5 & 10 & 14 & 0.84 & 4.23 \\
\hline 14 & 0 & 7 & 13 & $B$ & 2 & 0.86 & 3.47 \\
\hline is & . & 8 & 8 & 9 & 4 & 1.09 & 3.23 \\
\hline 16 & 0 & 2 & 10 & 14 & 7 & 0.88 & 3.77 \\
\hline 17 & 9 & 3 & 10 & 19 & 5 & 0.49 & 3.53 \\
\hline 18 & 1 & 5 & 7 & 7 & 40 & 1.19 & 3.67 \\
\hline 19 & 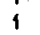 & $\overrightarrow{3}$ & 9 & 10 & 7 & 1.05 & 3.63 \\
\hline 20 & 2 & 5 & 6 & 9 & $\theta$ & 1.23 & 3.53 \\
\hline 21 & $\bar{E}$ & 7 & 9 & B & \{ & 9.12 & 2.77 \\
\hline 22 & 0 & 3 & 4 & 13 & 10 & 0.93 & 4.00 \\
\hline 23 & 0 & 1 & 10 & 12 & 7 & 0.832 & 3.83 \\
\hline 24 & 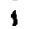 & 4 & 12 & 19 & 2 & 0.90 & 3.30 \\
\hline 25 & $\theta$ & $\theta$ & 9 & 13 & 8 & .75 & 3.97 \\
\hline 26 & 2 & 11 & 12 & 5 & 0 & 0.83 & 2.67 \\
\hline 27 & 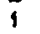 & 3 & 4 & 43 & 9 & & 3.87 \\
\hline 28 & $f$ & 3 & 9 & 11 & 6 & 1.02 & 3.60 \\
\hline 29 & 0 & 0 & 2 & 12 & 16 & 62 & 4.47 \\
\hline 30 & 4 & 5 & 7 & 9 & 5 & & 3.20 \\
\hline 31 & 0 & 5 & 9 & 9 & 7 & 1.02 & 3.60 \\
\hline 32 & . & 4 & 9 & 13 & 3 & 86 & 3.43 \\
\hline 33 & 0 & 3 & 5 & 94 & 94 & & 1.00 \\
\hline 3 & 1 & 5 & 12 & 9 & 3 & $\theta$. & 3.27 \\
\hline 35 & 2 & 7 & 13 & $\theta$ & 0 & 37 & 2.90 \\
\hline 36 & & 2 & 19 & 6 & 2 & & 3.20 \\
\hline 37 & 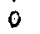 & 1 & 9 & 12 & $\bar{B}$ & 0.83 & 3.90 \\
\hline 38 & $i$ & 2 & 1 & 14 & 12 & 0 & 4.13 \\
\hline 39 & 0 & 0 & 6 & 43 & 11 & & 4.17 \\
\hline 40 & 4 & 8 & 10 & 6 & 2 & 1.11 & 2.80 \\
\hline 41 & $\dot{\theta}$ & 3 & 6 & 14 & 7 & 0.90 & 3.83 \\
\hline & 0 & & 11 & 10 & 5 & & 3.53 \\
\hline 43 & 3 & 6 & 14 & 7 & 0 & & 2.83 \\
\hline 44 & 9 & 6 & 8 & 6 & $i$ & 1.20 & 2.47 \\
\hline 45 & 0 & 2 & 5 & 18 & 5 & & 3.87 \\
\hline 46 & $v$ & $\tilde{7}$ & 10 & 9 & 4 & 0. & 3.33 \\
\hline 47 & & 3 & 16 & 9 & 1 & 0.79 & 3.20 \\
\hline 48 & 5 & 6 & 10 & 5 & 4 & 1.25 & 2.90 \\
\hline 49 & 1 & 10 & 1 & 17 & 1 & 1.05 & 3.23 \\
\hline 50 & 4 & 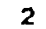 & 12 & 5 & 10 & 1.10 & 3.70 \\
\hline
\end{tabular}


VALUE STATEHENT STATISTICS - SECTION A ROUND 2

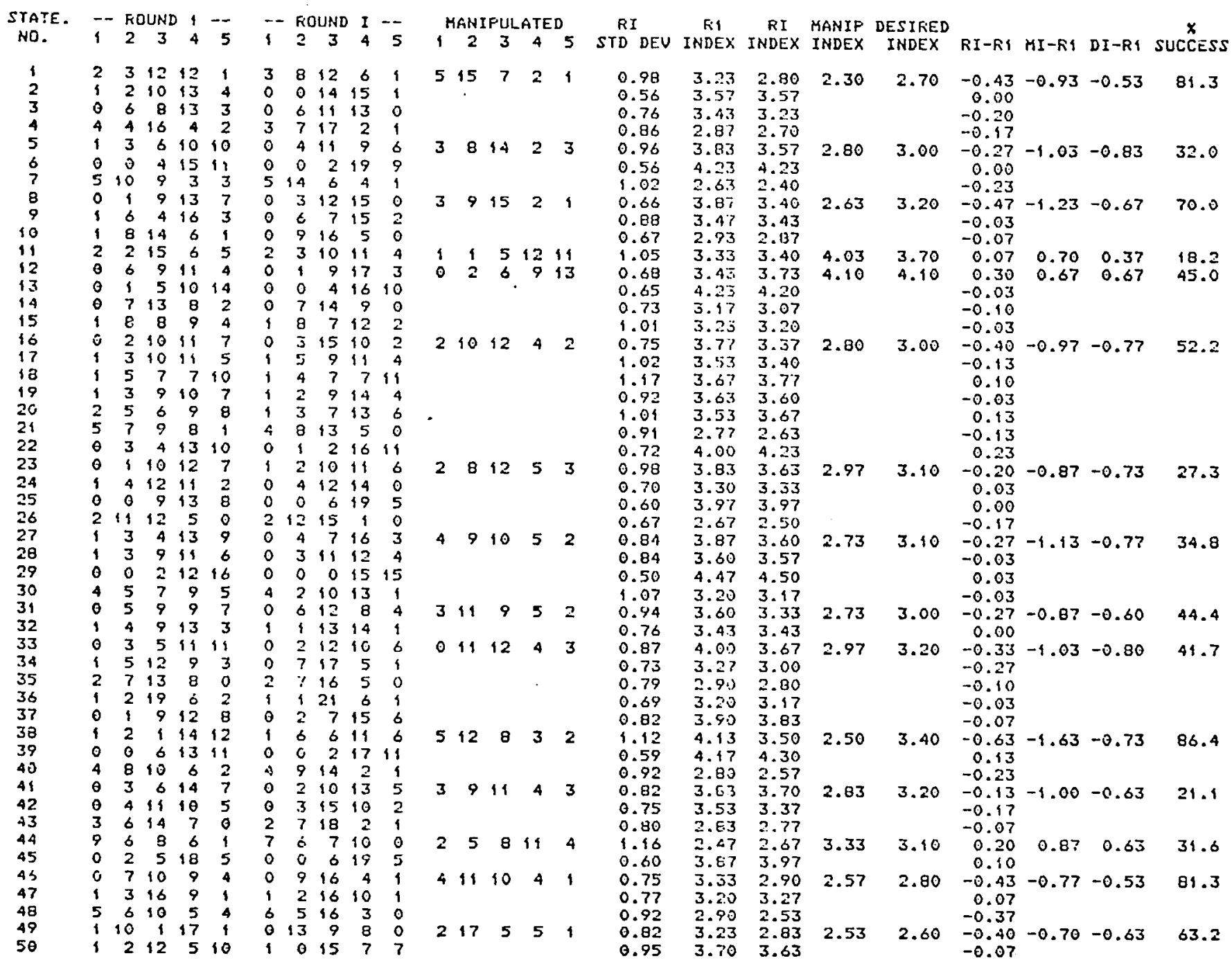


VALUE STATEMENT STATISTICS BY ROUND - SECTION A

\begin{tabular}{|c|c|c|c|c|c|c|c|c|c|c|c|c|c|c|c|c|c|c|c|}
\hline $\begin{array}{c}\text { STATE } \\
\text { NO. }\end{array}$ & - ROUND & -- & $\begin{array}{l}\text { ROL } \\
2\end{array}$ & $\begin{array}{l}\text { UND } \\
3\end{array}$ & $\begin{array}{l}I \\
4\end{array}$ & $-\overline{5}$ & $i^{H F}$ & $\begin{array}{c}\text { ANI } \\
2\end{array}$ & FUL & ${ }_{4}^{A T E}$ & & $\begin{array}{c}\text { RI } \\
\text { STD DEV }\end{array}$ & $\begin{array}{c}\text { RII } \\
\text { INDEX }\end{array}$ & $\begin{array}{l}\text { MANIF } \\
\text { INDEX }\end{array}$ & $\begin{array}{l}\text { DESIRED } \\
\text { INDEX }\end{array}$ & $R I-R I$ & $M I-R I$ & $D I-F 1$ & $\stackrel{*}{\text { SUCCESS }}$ \\
\hline 1 & $\begin{array}{l}1 \\
2 \\
3 \\
4\end{array}$ & $\begin{array}{l}2 \\
3 \\
3 \\
2\end{array}$ & $\begin{array}{rr}3 & 1 \\
8 & 1 \\
9 & 1 \\
13 & 1\end{array}$ & $\begin{array}{l}12 \\
12 \\
13 \\
11\end{array}$ & $\begin{array}{r}12 \\
6 \\
4 \\
4\end{array}$ & $\begin{array}{l}1 \\
1 \\
1 \\
0\end{array}$ & $\begin{array}{l}5 \\
6 \\
3\end{array}$ & $\begin{array}{l}15 \\
16 \\
20\end{array}$ & $\begin{array}{l}7 \\
5 \\
4\end{array}$ & $\begin{array}{l}2 \\
2 \\
2\end{array}$ & $\begin{array}{l}1 \\
1 \\
1\end{array}$ & $\begin{array}{l}0.92 \\
0.98 \\
0.94 \\
0.80\end{array}$ & $\begin{array}{l}3.23 \\
2.80 \\
2.70 \\
2.57\end{array}$ & $\begin{array}{l}2.30 \\
2.20 \\
2.27\end{array}$ & $\begin{array}{l}2.70 \\
2.70 \\
2.70\end{array}$ & $\begin{array}{l}-0.43 \\
-0.53 \\
-0.67\end{array}$ & $\begin{array}{l}-0.93 \\
-1.03 \\
-0.97\end{array}$ & $\begin{array}{l}-0.53 \\
-0.53 \\
-0.53\end{array}$ & $\begin{array}{r}81.3 \\
100.0 \\
125.0\end{array}$ \\
\hline 2 & $\begin{array}{l}1 \\
2 \\
3 \\
4\end{array}$ & $\begin{array}{l}1 \\
0 \\
0 \\
0\end{array}$ & $\begin{array}{ll}2 & 1 \\
0 & 1 \\
0 & 1 \\
0 & 1\end{array}$ & $\begin{array}{l}10 \\
14 \\
15 \\
13\end{array}$ & $\begin{array}{l}13 \\
15 \\
14 \\
17\end{array}$ & $\begin{array}{l}4 \\
1 \\
1 \\
0\end{array}$ & & & & & & $\begin{array}{l}0.92 \\
0.56 \\
0.56 \\
0.50\end{array}$ & $\begin{array}{l}3.57 \\
3.57 \\
3.53 \\
3.57\end{array}$ & & & $\begin{array}{r}0.00 \\
-0.03 \\
0.00\end{array}$ & & & \\
\hline 3 & $\begin{array}{l}1 \\
2 \\
3 \\
4\end{array}$ & $\begin{array}{l}0 \\
0 \\
0 \\
0\end{array}$ & $\begin{array}{ll}6 & \\
6 & 1 \\
6 & 1 \\
5 & 1\end{array}$ & $\begin{array}{l}8 \\
11 \\
13 \\
16\end{array}$ & $\begin{array}{r}13 \\
13 \\
11 \\
9\end{array}$ & $\begin{array}{l}3 \\
0 \\
0 \\
0\end{array}$ & & & & & & $\begin{array}{l}0.92 \\
0.76 \\
0.73 \\
0.67\end{array}$ & $\begin{array}{l}3.43 \\
3.23 \\
3.17 \\
3.13\end{array}$ & & & $\begin{array}{l}-0.20 \\
-0.27 \\
-0.30\end{array}$ & & & \\
\hline 4 & $\begin{array}{l}1 \\
2 \\
3 \\
4\end{array}$ & $\begin{array}{l}4 \\
3 \\
2 \\
2\end{array}$ & $\begin{array}{ll}4 & 9 \\
7 & 1 \\
8 & 1 \\
2 & 2\end{array}$ & $\begin{array}{l}16 \\
17 \\
17 \\
23\end{array}$ & $\begin{array}{l}4 \\
2 \\
2 \\
2\end{array}$ & $\begin{array}{l}2 \\
1 \\
1 \\
1\end{array}$ & & & & & & $\begin{array}{l}1.02 \\
0.86 \\
0.81 \\
0.73\end{array}$ & $\begin{array}{l}2.07 \\
2.76 \\
2.73 \\
2.93\end{array}$ & & & $\begin{array}{r}-0.17 \\
-0.13 \\
0.07\end{array}$ & & & \\
\hline 5 & $\begin{array}{l}1 \\
2 \\
3 \\
4\end{array}$ & $\begin{array}{l}1 \\
0 \\
0 \\
0\end{array}$ & $\begin{array}{l}3 \\
4 \\
6 \\
6\end{array}$ & $\begin{array}{l}6 \\
19 \\
13 \\
13\end{array}$ & $\begin{array}{r}10 \\
7 \\
7 \\
10\end{array}$ & $\begin{array}{r}10 \\
6 \\
4 \\
1\end{array}$ & $\begin{array}{l}3 \\
2 \\
0\end{array}$ & $\begin{array}{r}8 \\
10 \\
14\end{array}$ & $\begin{array}{l}14 \\
13 \\
12\end{array}$ & $\begin{array}{l}2 \\
3 \\
2\end{array}$ & $\begin{array}{l}3 \\
2 \\
2\end{array}$ & $\begin{array}{l}4.10 \\
0.96 \\
0.84 \\
0.79\end{array}$ & $\begin{array}{l}3.9 .3 \\
3.57 \\
3.30 \\
3.20\end{array}$ & $\begin{array}{l}2.30 \\
2.77 \\
2.73\end{array}$ & $\begin{array}{l}3.00 \\
3.00 \\
3.00\end{array}$ & $\begin{array}{l}-0.27 \\
-0.53 \\
-0.63\end{array}$ & $\begin{array}{l}-1.03 \\
-1.07 \\
-1.10\end{array}$ & $\begin{array}{l}-0.83 \\
-0.83 \\
-0.83\end{array}$ & $\begin{array}{l}32.0 \\
64.0 \\
76.0\end{array}$ \\
\hline 6 & $\begin{array}{l}1 \\
2 \\
3 \\
4\end{array}$ & $\begin{array}{l}0 \\
0 \\
0 \\
0\end{array}$ & $\begin{array}{l}0 \\
0 \\
0 \\
0\end{array}$ & $\begin{array}{l}4 \\
2 \\
1 \\
1\end{array}$ & $\begin{array}{l}15 \\
15 \\
21 \\
22\end{array}$ & $\begin{array}{l}11 \\
4 \\
8 \\
7\end{array}$ & & & & & & $\begin{array}{l}0.67 \\
0.56 \\
0.50 \\
0.41\end{array}$ & $\begin{array}{l}4.23 \\
4.23 \\
4.23 \\
4.20\end{array}$ & & & $\begin{array}{r}0.00 \\
0.00 \\
-0.03\end{array}$ & & & . \\
\hline 7 & $\begin{array}{l}1 \\
2 \\
3 \\
4\end{array}$ & $\begin{array}{l}5 \\
\vdots \\
4 \\
4\end{array}$ & $\begin{array}{l}10 \\
14 \\
15 \\
15\end{array}$ & $\begin{array}{r}4 \\
6 \\
9 \\
11\end{array}$ & $\begin{array}{l}3 \\
4 \\
2 \\
0\end{array}$ & $\begin{array}{l}3 \\
1 \\
0 \\
0\end{array}$ & & & & & & $\begin{array}{l}1.17 \\
1.02 \\
0.79 \\
0.67\end{array}$ & $\begin{array}{l}2.63 \\
2.40 \\
2.30 \\
2.23\end{array}$ & & & $\begin{array}{l}-0.23 \\
-0.33 \\
-0.40\end{array}$ & & & \\
\hline 8 & $\begin{array}{l}1 \\
2 \\
3 \\
4\end{array}$ & $\begin{array}{l}0 \\
0 \\
0 \\
0\end{array}$ & $\begin{array}{l}1 \\
3 \\
3 \\
3\end{array}$ & $\begin{array}{l}9 \\
12 \\
16 \\
16\end{array}$ & $\begin{array}{l}13 \\
15 \\
11 \\
11\end{array}$ & $\begin{array}{l}7 \\
0 \\
0 \\
0\end{array}$ & $\begin{array}{l}3 \\
2 \\
0\end{array}$ & $\begin{array}{r}9 \\
10 \\
10\end{array}$ & $\begin{array}{l}15 \\
15 \\
18\end{array}$ & $\begin{array}{l}2 \\
3 \\
2\end{array}$ & $\begin{array}{l}1 \\
0 \\
0\end{array}$ & $\begin{array}{l}0.131 \\
0.66 \\
0.63 \\
0.63\end{array}$ & $\begin{array}{l}3.87 \\
3.40 \\
3.27 \\
3.27\end{array}$ & $\begin{array}{l}2.63 \\
2.63 \\
2.73\end{array}$ & $\begin{array}{l}3.20 \\
3.20 \\
3.20\end{array}$ & $\begin{array}{l}-0.47 \\
-0.60 \\
-0.60\end{array}$ & $\begin{array}{l}-1.23 \\
-1.23 \\
-1.13\end{array}$ & $\begin{array}{l}-0.67 \\
-0.67 \\
-0.67\end{array}$ & $\begin{array}{l}70.0 \\
90.0 \\
90.0\end{array}$ \\
\hline$\%$ & $\begin{array}{l}1 \\
2 \\
3 \\
4\end{array}$ & $\begin{array}{l}1 \\
0 \\
0 \\
0\end{array}$ & $\begin{array}{l}6 \\
6 \\
5 \\
3\end{array}$ & $\begin{array}{l}4 \\
7 \\
6 \\
8\end{array}$ & $\begin{array}{l}16 \\
45 \\
47 \\
18\end{array}$ & $\begin{array}{l}3 \\
2 \\
2 \\
1\end{array}$ & & & & & & $\begin{array}{l}1.02 \\
0.88 \\
0.85 \\
0.72\end{array}$ & $\begin{array}{l}3.47 \\
3.43 \\
3.53 \\
3.57\end{array}$ & & & $\begin{array}{r}-0.03 \\
0.07 \\
0.10\end{array}$ & & & \\
\hline 10 & $\begin{array}{l}1 \\
2 \\
3 \\
4\end{array}$ & $\begin{array}{l}1 \\
0 \\
1 \\
0\end{array}$ & $\begin{array}{ll}0 & 1 \\
9 & 1 \\
8 & 1 \\
6 & 2\end{array}$ & $\begin{array}{l}14 \\
16 \\
16 \\
20\end{array}$ & $\begin{array}{l}6 \\
5 \\
5 \\
4\end{array}$ & $\begin{array}{l}1 \\
0 \\
0 \\
0\end{array}$ & & & & & & $\begin{array}{l}0.85 \\
0.67 \\
0.73 \\
0.57\end{array}$ & $\begin{array}{l}2.93 \\
2.87 \\
2.83 \\
2.93\end{array}$ & & & $\begin{array}{r}-0.07 \\
-0.40 \\
0.00\end{array}$ & & & \\
\hline 11 & $\begin{array}{l}1 \\
2 \\
3 \\
4\end{array}$ & $\begin{array}{l}2 \\
2 \\
2 \\
2\end{array}$ & $\begin{array}{l}2 \\
3 \\
2 \\
2\end{array}$ & $\begin{array}{r}15 \\
10 \\
6 \\
5\end{array}$ & $\begin{array}{l}6 \\
11 \\
16 \\
17\end{array}$ & $\begin{array}{l}5 \\
4 \\
4 \\
4\end{array}$ & $\begin{array}{l}1 \\
1 \\
1\end{array}$ & $\begin{array}{l}1 \\
2 \\
2\end{array}$ & $\begin{array}{l}5 \\
4 \\
3\end{array}$ & $\begin{array}{l}12 \\
10 \\
11\end{array}$ & $\begin{array}{l}11 \\
13 \\
13\end{array}$ & $\begin{array}{l}1.04 \\
1.05 \\
1.02 \\
1.02\end{array}$ & $\begin{array}{l}3.33 \\
3.40 \\
3.60 \\
3.63\end{array}$ & $\begin{array}{l}4.03 \\
4.07 \\
4.10\end{array}$ & $\begin{array}{l}3.70 \\
3.70 \\
3.70\end{array}$ & $\begin{array}{l}0.07 \\
0.27 \\
0.30\end{array}$ & $\begin{array}{l}0.70 \\
0.73 \\
0.77\end{array}$ & $\begin{array}{l}0.37 \\
0.37 \\
0.37\end{array}$ & $\begin{array}{l}18.2 \\
72.7 \\
81.8\end{array}$ \\
\hline
\end{tabular}


APPENDIX E

COMPUTER PROGRAMS TO ANALYZF FINAL RESULTS 


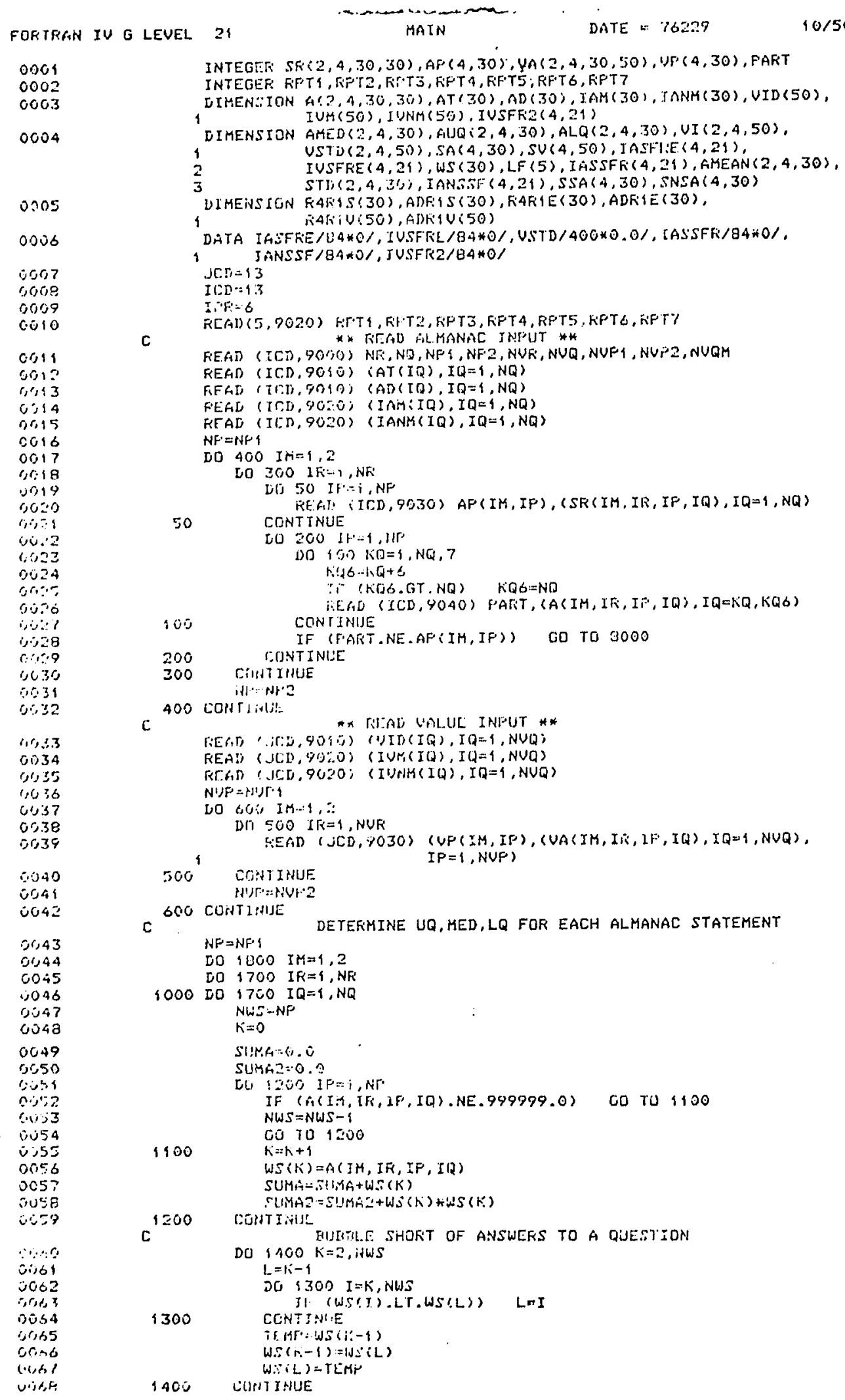


$c$

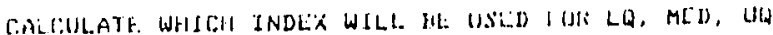

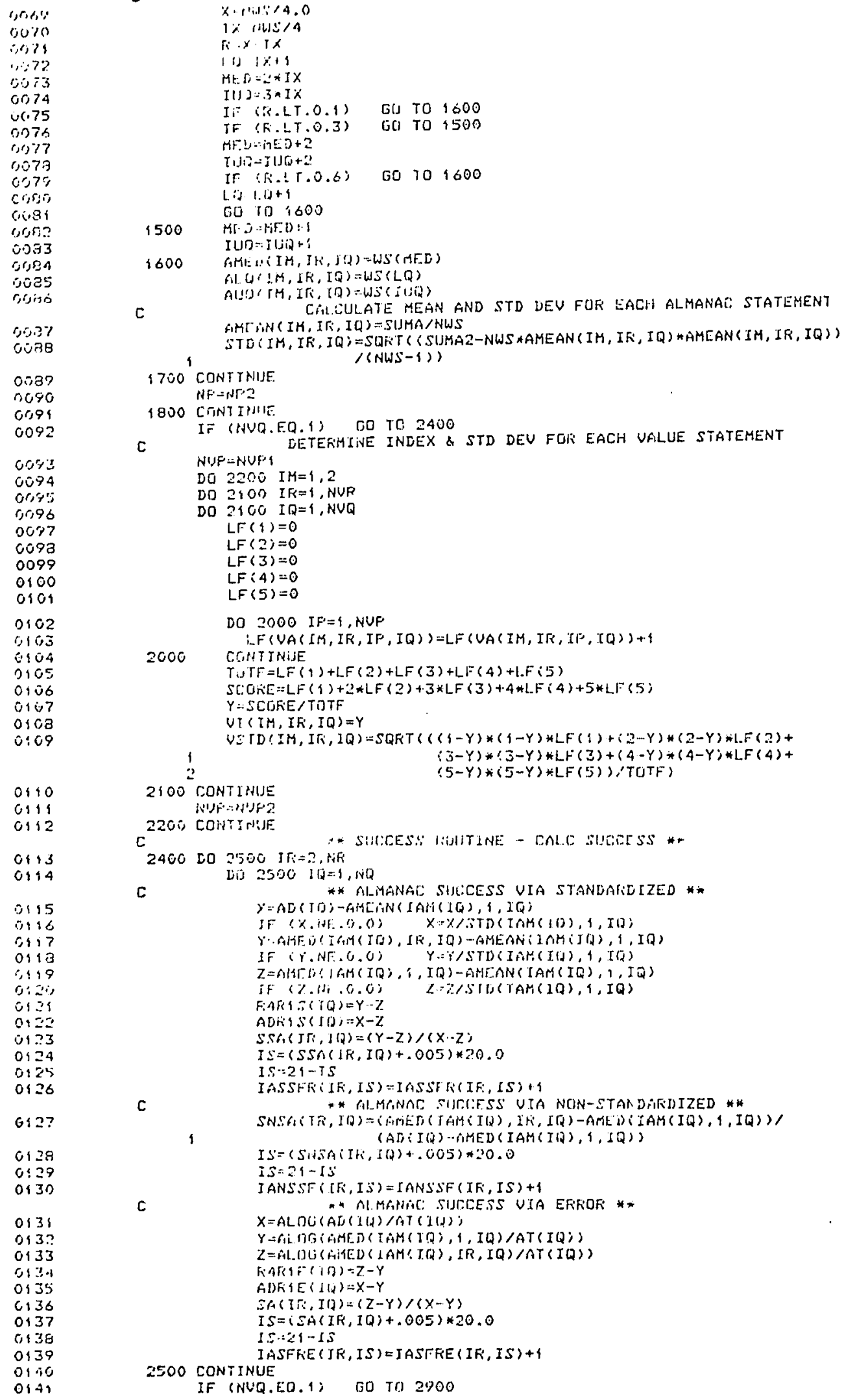




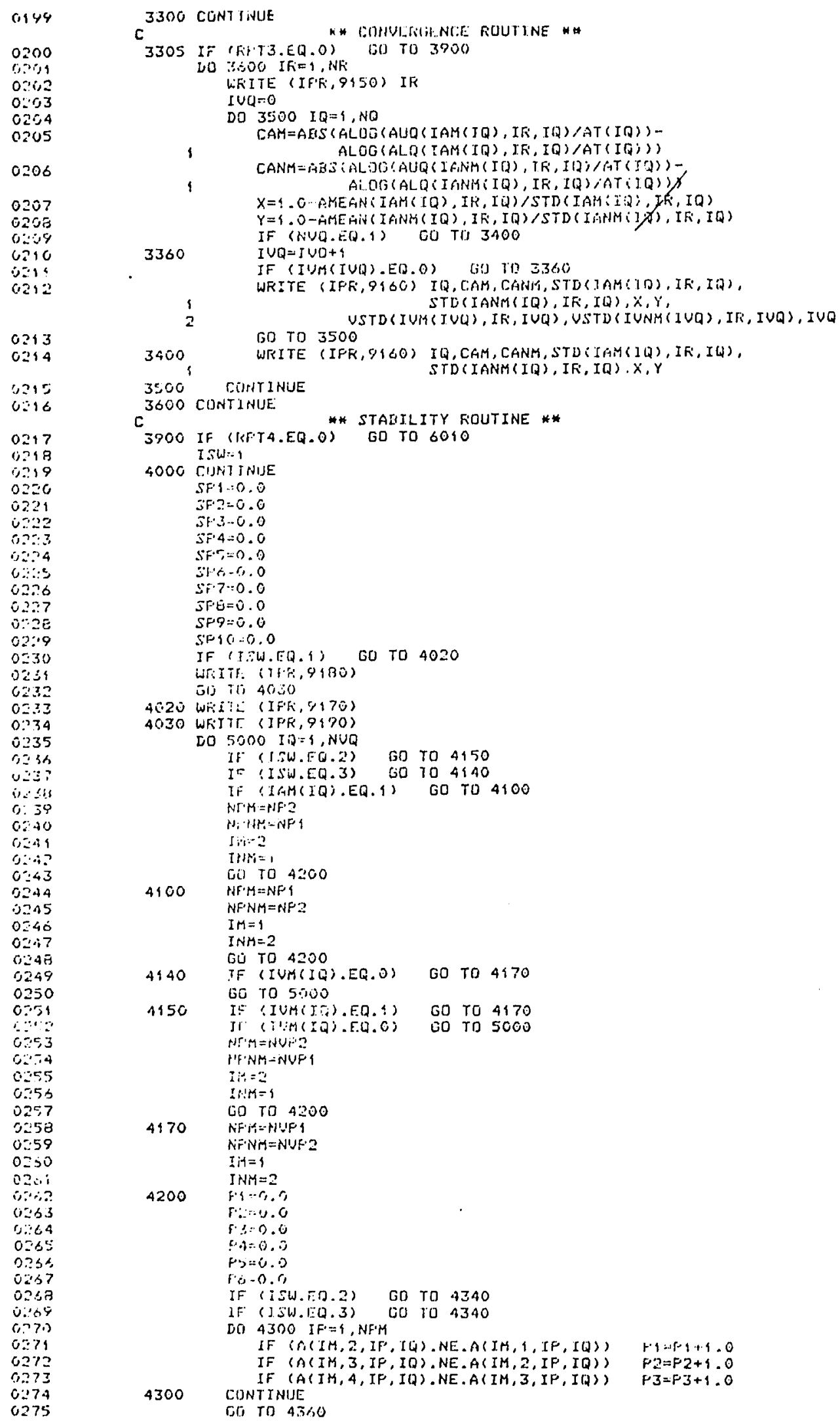




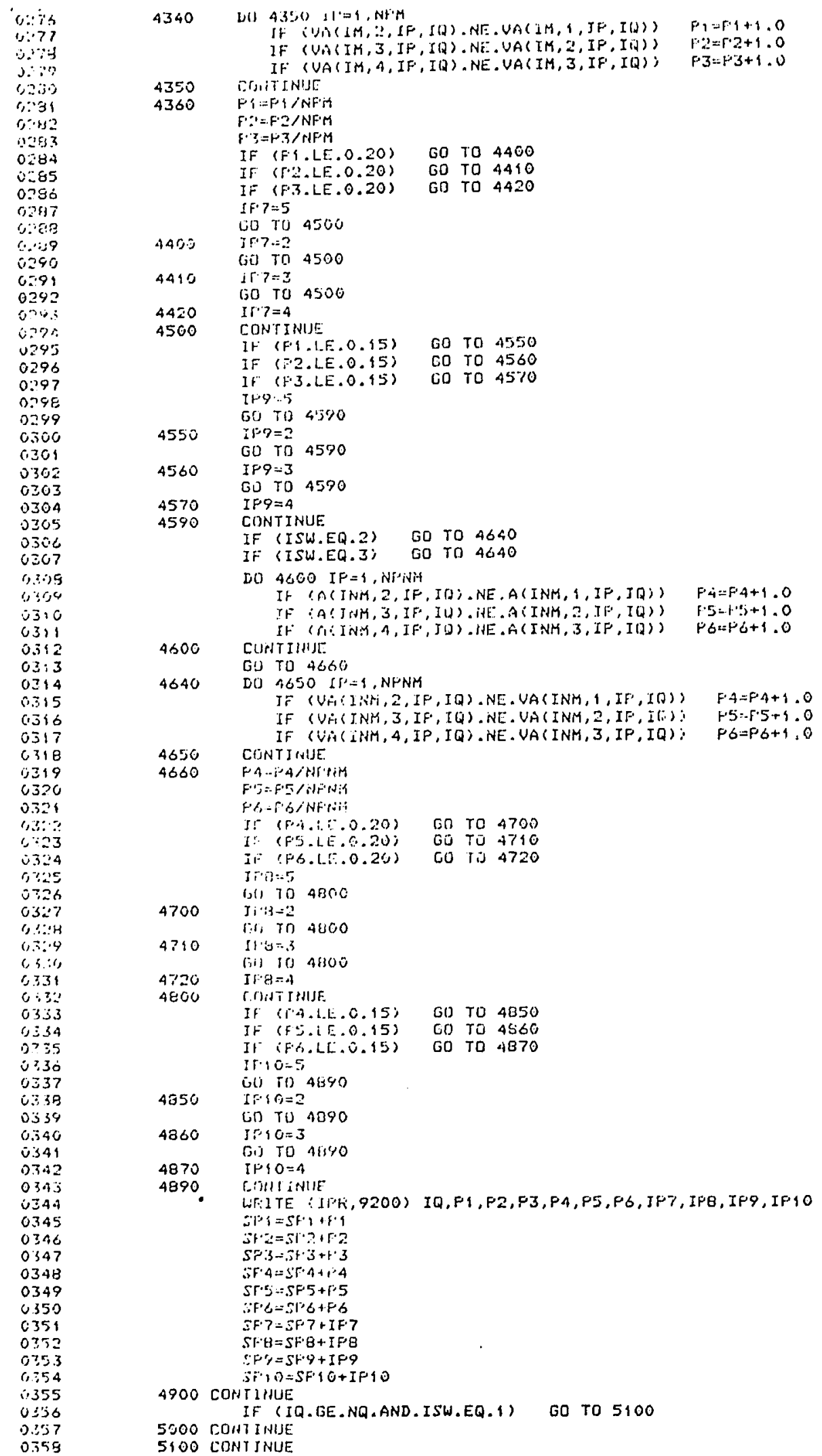

6:36

1:77

$3 \% 3$

$5 \therefore$

c.230

. 31

c, $\because$. 45

1.253

0284

0.85

075

0.247

C:C

$\because \cdot 9$

0290

0.91

0

o.

ט29'

0296

0.797

การ

0249

0.300

(.) 301

0302

030

0304

0305

030

050

\%.3.

0.04

ن310

(3)

0.342

$03: 3$

$0 ? 14$

0.315

पढ⿱

031

C318

औ319

0320

0.32

1,

c 23

ن.34

5) ?:25

0726

$03:-7$

1) $\therefore: 4$

(.).

C 5.10

C.3.

$0: 3$

033.3

6) 34

D)

0 338

0339

0.540

ज. 34

0.342

0343

טखA4

0345

0746

0348

0349

075

0.54

i. 355

0 's

0.37

0.559

4340 Dil $435011:=9, \mathrm{NF} \cdot \mathrm{M}$

If (WN $(1 M, Z, I F, I O) . N F . V A(I M, 1, J F, I(1))$

IF (VN(IM,3,IF,IQ).NE..VA(IK, $, I F, I N))$

IF (VA (IM, A, IF, IQ).NE. VASIM, 3,IF,IQ);

4350 BrMTENUE

$4360 \quad F Y: F i$ iNFin

$F: \because=F-2 / N F M$

$R_{1} \cdot z=F \cdot 3 / \mathrm{HFM}$

IF (F. $1 . L E .0 .20)$ GO TO 4460

IF $([2,2=0.20)$ GD TO 4410

IF $(F, 3 . L E .0 .20)$ GO TO 4420

$f F \cdot 7=5$

60 T0 4500

A40.5 3\%7:=?

4410 (iu) TO 4500

i $\Gamma=3$

GO TO 4500

$44: 0 \quad$ Ir $7=4$

4500 CONTIRUEE

It (F. L F. O. (5) GO TO 4550

IF (F. 2 . O.45) CO TO 4560

if" (F.J.LE.0.4S) CO TO 4570

I\%Q

60 TO 4500

$4550 \quad T 1 \% 7=2$

GO TO 4590

$4560 \quad$ IF $=3$

IF
GO TO

$\begin{array}{ll}4570 & \text { IF }=4 \\ 4590 & \text { CONTINUE }\end{array}$

IF (ISW.EQ 3) GO TO 4640

IF (ISW.EQ.3; GO TO 4640

DO 4600 IF $=9$, NiPiNit

If $(A(I N M, 2, I F, I B ;, N E, A(I N M, 1, I F, J Q)$

IF $\therefore A(J U M, 3, I F, I U)$, INE A A INM, $, I F, I(D))$

4600

IF $\left(S_{1} \leq I N M, A, I F, J D\right)$.INE.A $\left.A(I N M, 3, I F, I D)\right)$

$F \cdot \because=F \cdot 4+1.0$

$P \cdot 5=1 \cdot+;+1.0$

$+6=8 \delta+1.0$

CUNTIHIS:

$4640 \quad$ DO $4650 \quad\left[\Gamma^{2}=1\right.$, NPNM

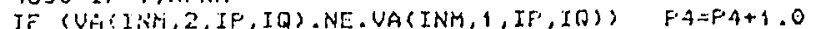

IF (VPICINM, 3, IF, IQ).NE. UA (INM, 2, IF, I(i) : F'5:-F.5+9.0

4650 CENTIOUIJE

$4660 \quad$ FA..PAIHTPM

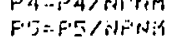

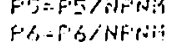

It (F.i.i. :0.20) कO TO 4700

IY (F.LE.C.ZU) GO TÚ 4790

ii $(P 6 .() 0.20$.

Co Ti) 4720

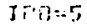

(j) 70 OB 4800

$4700 \quad J_{i} \cdot 3=2$

lis in 4800

$4710 \quad 11 \cdot 3=3$

(ii) 104800

$I F \cdot a=4$

4800 C.RitT IHIJE.

If (IA.L.E.0.15; GU TO 4850

If $(F . .15 .0 .95)$ 00 TO 4560

If (FG.LL.0.15) GO TO $4 B 70$

If.10=5

G(i) 10$) 4840$

4050 IF $10=?$

LD TO 4890

4360 Jif

(i) $T 0$ A6r4o

IP $10=4$

4890 CIMII INIIE

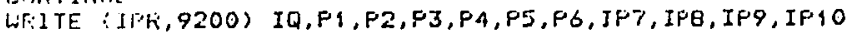

$S P 1=S F \cdot+1+1 \cdot 1$

$3+2=51 \cdot 2+5 \cdot 3$

$S F \cdot 3-3+3+1 \cdot 3$

iF. $4=S \cdot F \cdot 4+1 \cdot 4$

$s \Gamma \cdot 5=5 F 5+P 5$

$\because F \cdot G=51 \cdot 6+F G$

$S F \cdot 7=S F 7+I F \cdot 7$

$S F^{\prime} H=S F^{\prime} B+I F^{\prime} B$

$\therefore P_{Y}^{\prime}=S H^{\circ} \cdot Y+I P Q$

4900 CONTIHUE

SF $10=S F 10+I F 10$

5000 CONTI INUE

5100 CONTINUE

$1=1+1+1.0$

$2=r \cdot 2+1.0$

$F \cdot S=F \cdot 5+9.0$
$F O=F \cdot 6+1,0$ 


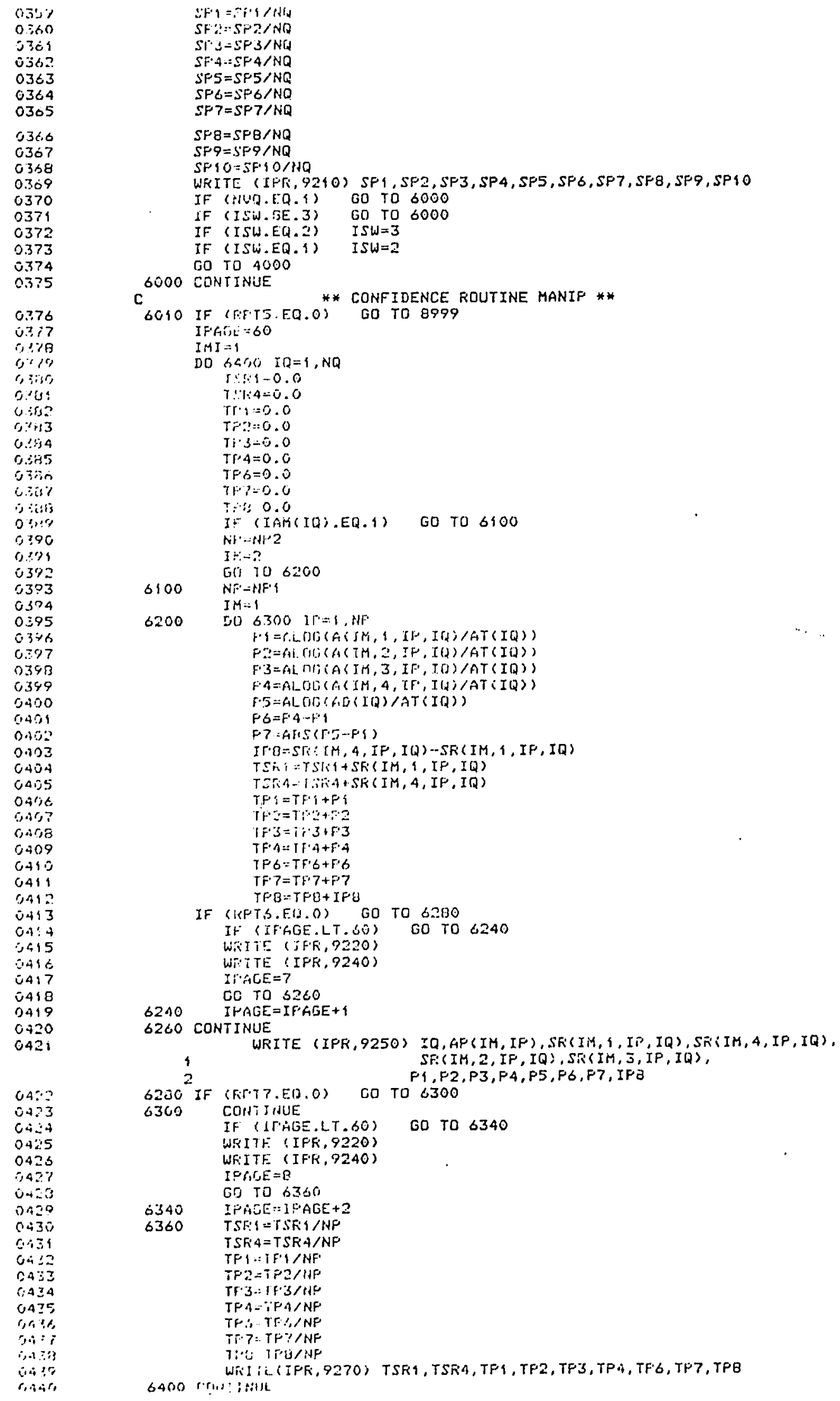




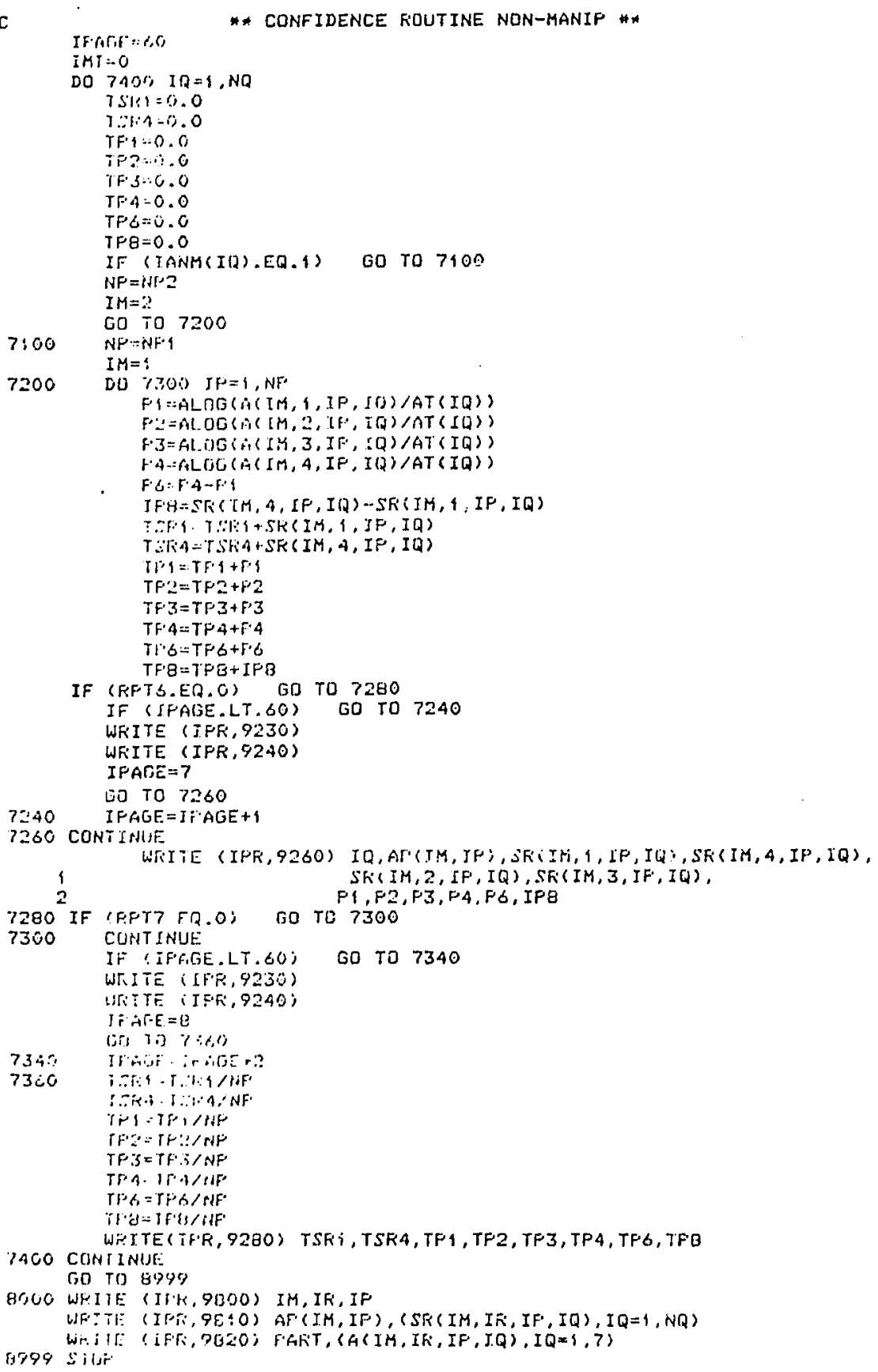


0511

6513

0544

0515

S0000 Fritimit $(913)$

9010 FUFIMAT (BF 10.0 )

9020 POFIMATC8011)

YC30 FOLFAT (IA.6X.50I1)

9040 FORMAT (I $4,6 X, 7 F 90.0)$

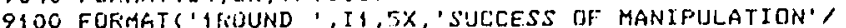

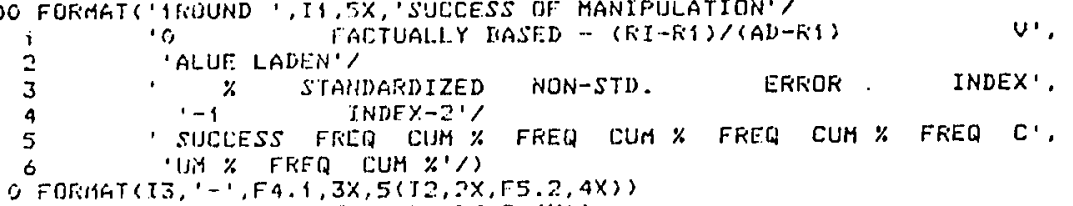

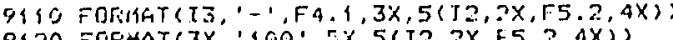

9120 FOFHAT $(3 X, 1100 \cdot, 5 X, 5(12,2 X, 15.2,4 X))$

9130 FORMAT $1 \%, 27 \%$ 'SULCESS OF MHRIFIJLATION - DETAIL.'

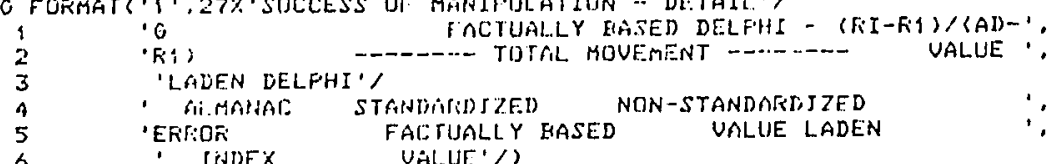

6 "ERTOR JUDEX UALUF'/

9435 FORHAT6" STATEMENT SUCCESS FOF ROUND SUCCESS FOR ROUND SUCCESS.

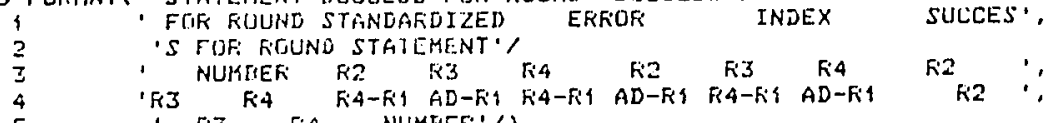

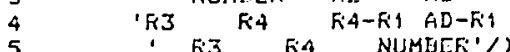

9140 FOFMAT( $5 X, I 2,2 X, 3(3 F 6,2,1 X),\{X, 6 F 6,2,2 X, 3 F 6,2,5 X, I 2)$

9145 FORMAT $(5 X, I 2,2 X, 3(3 F 6,2,\{X), 1 X, 4 F 6.2)$

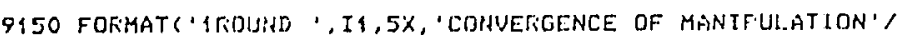

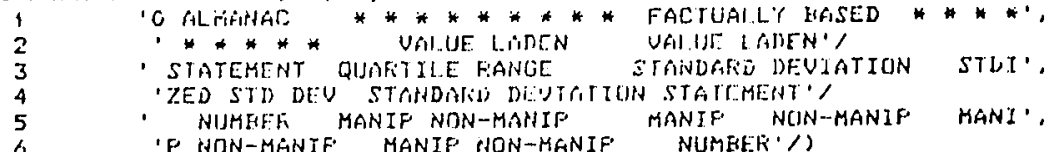

9960 FGEMAT ( $5 X, 72,5 X, F 5,2,3 X, F 5,2,\{X, 2 F 12,2,2 X, F 6,2,2 X, F 6,2$,

$14 \times, 15.2,3 X, 55,2,7 x, 12)$

9470 FEFITHTS'ASTAEIETTY OF MANIPULATIUN - FACTUALLY HASED DELFHI')

9180 FOKIAAT ' $\$$ TTAEILITY OF MANIFULATION - WALUE LADEIY DELFHI')

9490 FORMAT 'O

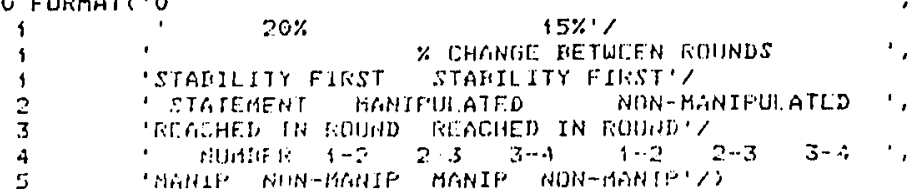

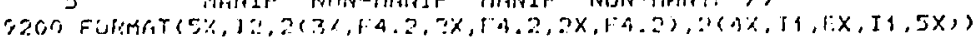

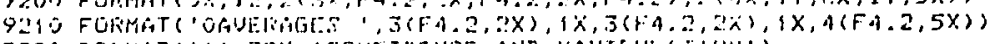

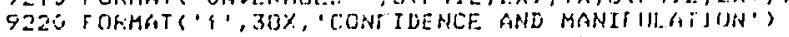

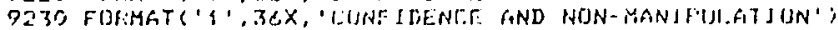

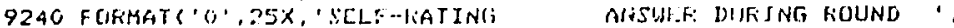

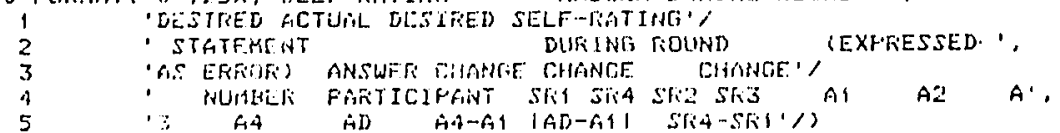

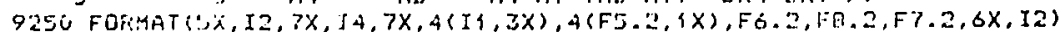

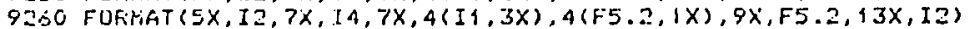

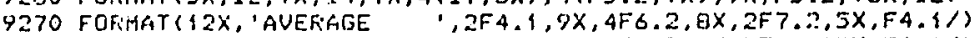

2280 FUFMAT (12X. AUERAGE $\because 2 F 4.4,9 X, 4 F 6.2, B X, F 7.2,12 X, F 4.1 /)$

9800 FOFHAT ('OF'AETICIFANTS OUT OF SEQUENCE',3I3)

9810 FDFIHAT (IS, $6 X, 30 I\{)$

9820 FOKIMAT (I5, 6X, 7F 90.0$)$

$$
\text { END }
$$


ROUND 3 SUCCESS OF MANIFULATION

\begin{tabular}{|c|c|c|c|c|c|c|c|c|c|c|}
\hline \multirow{3}{*}{ auci:ess } & \multicolumn{3}{|c|}{ FACTUALLY BASED } & \multicolumn{3}{|c|}{$\left(F I-R_{1} 1\right) /(A D-F 1)$} & \multicolumn{4}{|c|}{ UALUE LADEN } \\
\hline & STrirtDa & RDI I ZED & NON- & STD. & & ROF & IND & $E X-\{$ & & NDEX- \\
\hline & & & & $\operatorname{CoN}:$ & FREQ & CUM $\%$ & FFiEQ & CUM \% & FIEQ & CUM $\%$ \\
\hline 100 & 0 & 0.0 & 0 & 0.0 & 0 & 0.0 & 2 & 0.07 & 7 & 0.23 \\
\hline $95-94.9$ & 4 & 0.13 & 4 & 0.13 & 5 & 0.17 & 4 & 0.20 & 3 & 0.3 .3 \\
\hline 90.74 .9 & 2 & 0.20 & 2 & 0.20 & 4 & 0.30 & 3 & 0.30 & 2 & 0.40 \\
\hline $85-89.9$ & 8 & 0.47 & 8 & 0.47 & 5 & 0.47 & 5 & 0.47 & 3 & 0.10 \\
\hline $60-34.9$ & 3 & 0.57 & 3 & 0.57 & 2 & 0.53 & 2 & 0.53 & 2 & 0.57 \\
\hline $75-74.9$ & 0 & 0.57 & 0 & 0.57 & 3 & 0.63 & 0 & 0.53 & 0 & 0.57 \\
\hline $70-74.9$ & 3 & 0.67 & 3 & 0.67 & 5 & 0.80 & 1 & 0.57 & 1 & 0.60 \\
\hline $65-69.9$ & 4 & 0.80 & 4 & 0.60 & 1 & 0.83 & 4 & 0.70 & 4 & 0.73 \\
\hline$\therefore-6.4 .9$ & 2 & 0.87 & 2 & 0.87 & 0 & 0.83 & 2 & 0.77 & 2 & 0.100 \\
\hline $5=-5.9$ & 0 & 0.87 & 0 & 0.87 & 1 & 0.87 & 3 & 0.87 & 3 & 0.70 \\
\hline $5 i-5+.9$ & 0 & 0.87 & 0 & 0.87 & 0 & 0.87 & 0 & 0.87 & 0 & 0.90 \\
\hline 45.49 .9 & 0 & 0.87 & 0 & 0.87 & 0 & 0.87 & 0 & 0.87 & 0 & 0.70 \\
\hline $40-44.9$ & 0 & 0.87 & 0 & 0.87 & \{ & 0.90 & 2 & 0.93 & 1 & 0.93 \\
\hline $38-39.9$ & 1 & 0.70 & 1 & 0.70 & 2 & 0.97 & 0 & 0.93 & 0 & 0.93 \\
\hline $30-34.9$ & 2 & 0.97 & 2 & 0.97 & 0 & 0.97 & 1 & 0.97 & 1 & 0.97 \\
\hline $2 \%-2 \% .4$ & 0 & 0.97 & 0 & 0.97 & 0 & 0.77 & 1 & 1.00 & 1 & 1.00 \\
\hline $20-24.9$ & 0 & 0.97 & 0 & 0.77 & 0 & 0.97 & 0 & 1.00 & (1) & 1.00 \\
\hline $15-19.9$ & 0 & 0.97 & 0 & 0.97 & \{ & 1.00 & 0 & 9.00 & $\theta$ & 1.00 \\
\hline $10-44.5$ & 1 & 1.00 & 1 & 1.00 & 0 & 1.00 & 0 & 1.00 & 0 & 1.00 \\
\hline $5-9.9$ & 0 & 1.00 & 0 & 1.00 & 0 & 1.00 & 0 & 1.60 & 0 & 1.00 \\
\hline $0-4.9$ & 0 & 1.00 & 0 & 1.00 & 0 & 4.00 & 0 & 1.00 & () & 1.00 \\
\hline
\end{tabular}

RTUID 4 SUCCESS OF MANIFULATION

\begin{tabular}{|c|c|c|c|c|c|c|c|c|c|c|}
\hline \multirow{3}{*}{$\stackrel{\ddot{n}}{\text { SUCEESS }}$} & \multicolumn{6}{|c|}{ FGCTUALL.Y FASED - (KII-FI $) /(A D-F i)$} & \multicolumn{4}{|c|}{ YAL UE LADEN } \\
\hline & STGHEN & FLIZED & NOH & STD. & & FoFi & IND & {$[x-1$} & & BDEEX- - \\
\hline & FFE & $\cos x$ & FRED & CUM $\%$ & FFEQ & CIJM $x$ & FFEQ & cuis \% & FFED & CUM \% \\
\hline 100 & 4 & 0.13 & 4 & 0.13 & 4 & 0.13 & 3 & 0.10 & 13 & 0.43 \\
\hline $75-97.7$ & 4 & 0.27 & 4 & 0.27 & 6 & 0.33 & 5 & 0.27 & 2 & 0.50 \\
\hline $9 i-74.7$ & 5 & 0.43 & 5 & 0.43 & 5 & 0.50 & 5 & 0.13 & 3 & 0.80 \\
\hline $85-89.9$ & 5 & 0.60 & 5 & 0.60 & 5 & 0.67 & 0 & 0.43 & 0 & 0.60 \\
\hline $5 \therefore-8 \div .9$ & 4 & 0.73 & 4 & 0.73 & 0 & 0.67 & 3 & 0.53 & 3 & 0.70 \\
\hline $75-74.9$ & 0 & 0.7 .3 & 0 & 0.73 & 2 & 0.73 & 6 & 0.73 & 3 & 0.80 \\
\hline $70-7+.9$ & 1 & 0.77 & 1 & 0.77 & 3 & 0.83 & 2 & 0.80 & 2 & 0.197 \\
\hline $65-69.9$ & 2 & 0.83 & 2 & 0.83 & 1 & 0.87 & 2 & 0.87 & 2 & 0.173 \\
\hline $60-6+.9$ & 2 & 0.90 & 2 & 0.90 & 0 & 0.87 & 3 & 0.77 & $i$ & 0.97 \\
\hline $5.5 \% .8$ & 0 & 0.90 & 0 & 0.90 & $\mathfrak{1}$ & 0.90 & 0 & 0.97 & 0 & 0.97 \\
\hline $50-5 \div .9$ & 0 & 0.40 & 0 & 0.90 & 0 & 0.40 & 0 & 0.47 & 0 & 0.97 \\
\hline$\therefore 5-47.7$ & 0 & 0.70 & 0 & 0.90 & 9 & 0.90 & 0 & 0.47 & 0 & 0.97 \\
\hline$\therefore-14.9$ & 1 & 0.43 & 1 & 0.93 & 2 & 0.97 & 0 & 0.47 & 0 & 0.87 \\
\hline $35-32.9$ & 1 & 0.77 & 1 & 0.97 & 0 & 0.97 & 0 & 0.97 & 0 & 0.97 \\
\hline $30-34.9$ & 0 & 0.97 & 0 & 0.97 & 0 & 0.97 & 1 & 1.00 & 1 & 1.00 \\
\hline $25-29.9$ & 0 & 0.97 & 0 & 0.97 & 0 & 0.97 & 0 & 1.00 & 0 & 1.00 \\
\hline $20 \cdots: \because 4.9$ & 0 & 0.87 & 0 & 0.97 & 1 & 1.00 & 0 & 1.00 & 0 & 1.00 \\
\hline $15-17.9$ & 1 & 1.00 & 1 & 1.00 & 0 & 1.00 & 0 & 1.00 & 0 & 1.00 \\
\hline $10-14.9$ & 0 & 1.00 & 0 & 1.00 & $\theta$ & 1.00 & 0 & 1.00 & 0 & 1.00 \\
\hline $5-9.9$ & 0 & 1.00 & 0 & 1.00 & 0 & 1.00 & 0 & 1.00 & 0 & 1.00 \\
\hline $0-4.7$ & 0 & 1.00 & 0 & 1.00 & 0 & 1.00 & 0 & 1.00 & 0 & 1.00 \\
\hline
\end{tabular}


SUCCESS OF MANIFULATION - DETAIL

\begin{tabular}{|c|c|c|c|c|c|c|c|c|c|c|c|c|c|c|c|}
\hline \multirow{3}{*}{$\begin{array}{l}\text { ALHARHAC } \\
\text { STATEHFNT } \\
\text { NUMEER }\end{array}$} & \multicolumn{9}{|c|}{$-\angle F I-$} & \multicolumn{6}{|c|}{ - TOTAL MOUEMENT --} \\
\hline & \multicolumn{3}{|c|}{ STANDARDIZED } & \multicolumn{3}{|c|}{ 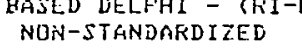 } & \multicolumn{3}{|c|}{ EFFiOK } & & \multicolumn{2}{|c|}{ VALUE LADEN } \\
\hline & $\begin{array}{l}\text { SiJCC. } \\
\text { R:2 }\end{array}$ & 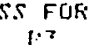 & $\begin{array}{l}\text { hOUtin } \\
\text { Ris }\end{array}$ & $\begin{array}{cl}\operatorname{susc} \\
\mathrm{R}^{2}\end{array}$ & $S S$ & KDIIND & & & & & D & & & & \\
\hline & & & & & & & & & & & & & & & \\
\hline 3 & 0.71 & 0.86 & 1.00 & 0.71 & 0.136 & 1.00 & 0.79 & 0.90 & 1.00 & 0.19 & 0.49 & 0.00 & $0.8 B$ & -0.67 & -0.5 .3 \\
\hline 2 & 0.3 & 0.31 & & & 0.31 & & 0 & 0.38 & $\ddot{0}$. & 0.34 & 0.50 & 0.41 & & -0.63 & \\
\hline 3 & 0.42 & 0.67 & 0.5 & .42 & 0.57 & 0.07 & & 0.72 & 0.72 & $0.3 \%$ & 0.56 & 0.34 & 0.47 & -0.70 & \\
\hline 4 & 0.45 & c. 72 & 0.72 & 0.45 & 0.72 & 0.72 & .50 & 0.76 & 0.76 & 0.32 & 0.44 & 0.30 & 0.40 & -0.63 & -0 \\
\hline 5 & 0.33 & 0.85 & 0.92 & 0.83 & 0.85 & 0.92 & 10 & 0.8 & 0.91 & -0.65 & -0.71 & -0.11 & -0.45 & 0.60 & $0.5 \%$ \\
\hline 6 & 0.08 & 0.13 & 0. & 0.08 & 0.13 & 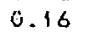 & 0.10 & 0. & 0. & 0.14 & 0.33 & 0.00 & 0.43 & -0.60 & -0.67 \\
\hline 7 & 0.78 & 0.67 & 0.91 & 0.78 & 0.87 & 0.41 & 0.86 & 0.92 & 0.95 & 1.09 & 1.19 & 1.13 & 1.19 & -0.90 & -0.90 \\
\hline 8 & 50 & 0.07 & & 0.50 & 0.69 & 0.83 & 0.5 & 0.77 & & 0.97 & & & & & 0.37 \\
\hline 9 & 0.3 & 0.5 . & 0. & 0. & 0. & 0 & & 0.05 & is & 0.41 & -0.43 & -0.51 & -0.55 & 0.83 & 0.07 \\
\hline 10 & 0.33 & 0.67 & $\hat{0}$ & 0.33 & 0.67 & 0.07 & & $0 .:$ & & -1.04 & $-\mathfrak{- 1 . 5 5}$ & -0.41 & -0.59 & -0.67 & -0.63 \\
\hline & 0.48 & $0.80^{\circ}$ & 0. & \%.78 & 0.5 & & & 0. & 0. & $1.0,2$ & 1.07 & 0.69 & 0.72 & -0.87 & -0.70 \\
\hline$i$ & 0.51 & 0.74 & i. & 0.91 & 0.4 & & & 0. & 1. & -0.39 & -0.37 & -2.68 & -2.00 & -0.63 & $-0 . \because 1$ \\
\hline & & 0.72 & & & & & & & & & & & & & \\
\hline $\mathfrak{f}$ & C. 1 & 0.3 & 0. & 0. & 0. & & & 0. & 0. & 0. & & 09 & & 0.50 & 0.50 \\
\hline 1 & 0.71 & 0.83 & 0. & 0.71 & 0.133 & $\theta$. & 8 & 0.106 & 0. & 0.33 & 0.97 & 0.47 & 0.53 & -0.53 & -0.73 \\
\hline 1 & 0.63 & 0.6 & 0 & 0.63 & 0.8 & 0. & & 0. & 0. & 4.8 & 1.10 & & & 0.50 & 0.03 \\
\hline$i$ & 0.36 & 0.86 & 0 & & 0. & & & 0. & & & & & & -0.57 & $-0.7 ?$ \\
\hline is & 072 & 0.64 & & & i. & & & & & & & & & -0.40 & -0.60 \\
\hline 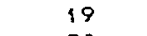 & & 0.2 & & & & & & 0. & & -0 & -0 & -0 & & & \\
\hline 2 & 0.43 & 0.65 & $\theta$. & 0 & 0. & 0 & 0.5 & 0. & 0. & 0.60 & 0.69 & 0 & 77 & -0.50 & -0.80 \\
\hline & 0 & 0. & & & & & & & & & & & & & -0.67 \\
\hline & 0 & 0.7 & & & & & & & & 0.55 & 0.57 & 0.59 & 0.72 & & 0.83 \\
\hline 23 & 0.63 & 0.87 & & 0 & 0.88 & 0. & & $\ddot{0}$ & 0. & 1. & 1.32 & 0.88 & $0.9 \dot{0}$ & -0.77 & -0.73 \\
\hline & - & 0.3 & 0 & & 0. & & & 0. & & & & & 0.12 & -0.20 & \\
\hline & 0.58 & 0. & & & 0. & & & & & $\ddot{0}$. & 0. & 1.35 & 1 & -0.57 & -0.73 \\
\hline & & 0. & & & & & & & & -0.47 & -0.52 & -0.48 & -0.54 & 0.43 & \\
\hline 27 & & 0.93 & 0. & & 0.93 & & & 0. & & 0.37 & 0.93 & $0.6 ?$ & 0.73 & -0.50 & -0.53 \\
\hline & & & & & & & & & & & 0.80 & 45 & & & -0.70 \\
\hline-4 & 0.20 & 0.83 & $\theta$. & 0. & 0. & 0. & 0 & 0. & 0. & -0.83 & -0.99 & -0.44 & -0.56 & -0.60 & -0.6 \\
\hline 30 & .53 & 0.95 & 1.00 & 0.53 & 0.95 & 1.00 & 0.40 & 0.91 & 1.00 & -0.30 & -0.30 & -1.00 & -1.00 & -0.70 & -0.67 \\
\hline
\end{tabular}

VALUE LADEN DELFHI

INDEX

vallie

$\underset{\text { SUCESS FOR ROLIND STAMEAENT }}{\text { Ri }}$

$0.01 \quad 1.00 \quad 1.25$

0.89 1.00 1.00

$0.320 .00 \quad 0.75$

$0.35 \quad 0.85 \quad 1.00$

$\begin{array}{lll}0.70 & 0.90 & 0.90\end{array}$

$0.93 \quad 1.15 \quad 1.00$

$\begin{array}{lll}0.18 & 0.73 & 0.52\end{array}$

$0.050 .75 \quad 1.25$

$0.320 .84 \quad 1.05$

$\begin{array}{lll}0.81 & 1.00 & 1.24 \\ 0.52 & 0.57 & 0.83\end{array}$

$\begin{array}{lll}0.92 & 0.57 & 0.83 \\ 0.53 & 1.14 & 1.00\end{array}$

$\begin{array}{lll}0.5 .3 & 1.11 & 1.00 \\ 0.80 & 0.93 & 1.00\end{array}$

$\begin{array}{lll}0.27 & 0.32 & 0.73\end{array}$

$0.32 \quad 0.42 \quad 0.79$

0.350 .650 .74

$0.470 .44 \quad 0.37$

$0.01 \quad 0.560 .83$

$\begin{array}{lll}0.42 & 0.67 & 0.02\end{array}$

$0.50 \quad 0.5150 .95$

0.440 .08 1. 03

$0.80 \quad 0.9511 .05$

$\begin{array}{lll}0.21 & 0.26 & 0.32 \\ 0.50 & 0.08 & 0.78\end{array}$

$\begin{array}{lll}0.51 & 0.96 & 0.32 \\ 0.32 & 0.58 & 0.77 \\ 0.32 & 0.58 & 0.08\end{array}$

$\begin{array}{lll}0.32 & 0.58 & 0.89 \\ 0.81 & 0.31 & 0.94\end{array}$

$0.81 \quad 1.05 \quad 1.38$

$0.63 \quad 0.8 ? \quad 0.95$

$0.00 \quad 0.95 \quad 4.05$

1
2
4
5
6
8
9
11
12
13
15
18
15
22
23
24
37
31
32
35
34
58
34
34
41
42
44
40
48
49
50




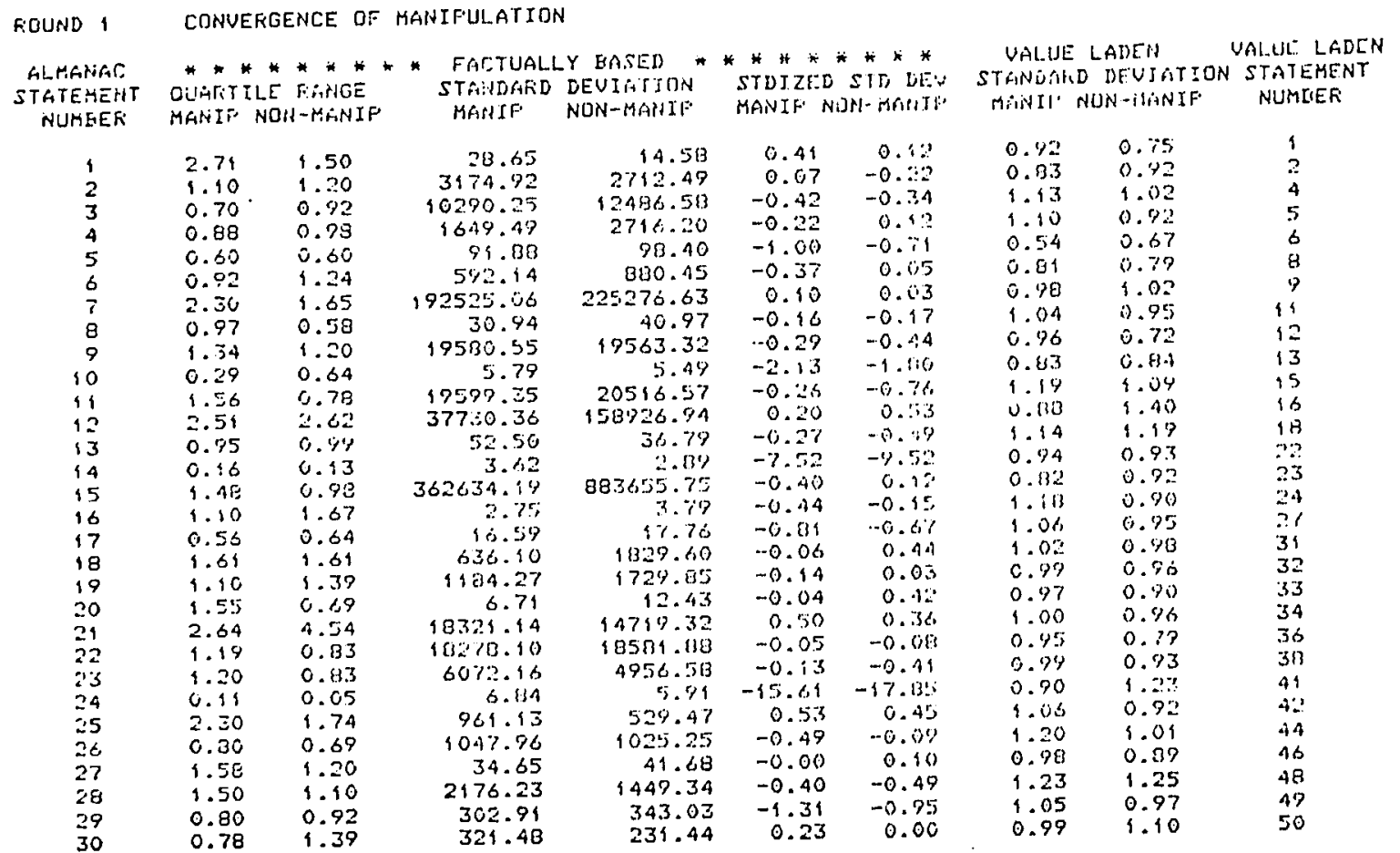

\begin{tabular}{|c|c|c|c|c|c|c|c|c|c|}
\hline 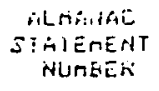 & 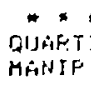 & $\begin{array}{l}\text { * * * * * } \\
\text { ILE FANGË } \\
\text { NON-MANIF }\end{array}$ & $\begin{array}{c}\text { * FACTUALL } \\
\text { STANDAIED } \\
\text { malliF }\end{array}$ & $\begin{array}{l}\text { LY IAASED } \\
\text { LEVIAIIUN } \\
\text { NUN-MANIF }\end{array}$ & $\begin{array}{l}\text { *** } \\
\text { STDIZEL } \\
\text { MANIF }\end{array}$ & $\begin{array}{l}* \text { * * * } \\
\text { SID LEV } \\
\text { DN-MANIF. }\end{array}$ & $\begin{array}{l}\text { UNLIJE } \\
\text { STAINOMY } \\
\text { MIANIF }\end{array}$ & $\begin{array}{l}\text { LADEN } \\
\text { DD DEUEAIION } \\
\text { NON-MANIF }\end{array}$ & $\begin{array}{l}\text { UALLEE } \\
\text { STAATE } \\
\text { NUMI }\end{array}$ \\
\hline 1 & 0.51 & 0.92 & 9.26 & 6.01 & -1.15 & $-0.7 \theta$ & 0.90 & 0.55 & 1 \\
\hline 2 & 0.41 & 9.98 & 884.19 & 1442.61 & -1.72 & -0.90 & 0.79 & $0.5 A$ & $\therefore$ \\
\hline 3 & 0.47 & $0.5 \%$ & 3610.13 & 7373.10 & -2.69 & -0.77 & 0.75 & 0.36 & 4 \\
\hline 4 & 0.34 & 0.53 & 949.72 & 693.24 & -1.08 & $-1 . \ddot{0} \theta$ & 0.96 & 0.834 & 5 \\
\hline 5 & 0.27 & 0.33 & 46.09 & 32.80 & -2.07 & -3.79 & 0.16 & 0.50 & 6 \\
\hline 6 & 0.49 & 0.42 & $43: .03$ & $2 \pi 4.62$ & -1.26 & -1.84 & 0.50 & 0.54 & 0 \\
\hline 7 & 8.47 & 0.47 & 404314.50 & 173972.50 & -1.61 & -0.34 & 0.126 & 0.88 & \\
\hline 8 & 0.62 & 0.41 & 18.19 & 13.29 & -1.53 & -1.67 & 1.05 & 0.16 & 11 \\
\hline 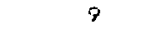 & 0.65 & c. 73 & 7242.27 & 13635.71 & -1.16 & -1.03 & 0.188 & 0.67 & 12 \\
\hline 10 & 0.49 & 0.53 & 4.30 & 5.07 & -2.41 & -1.33 & 0.111 & 0.85 & 13 \\
\hline 11 & 0.41 & 0.29 & 42845.38 & 7350.75 & -1.32 & -3.76 & 0.39 & 1.01 & 15 \\
\hline 15 & 1.43 & 1. $\%$ & 12004.40 & $16505.1 \%$ & 0.48 & 0.011 & 0.75 & 1.31 & 16 \\
\hline 13 & 0.37 & 0.37 & 44.12 & $22.7 \%$ & -1.56 & $-1.4 \%$ & 5.93 & 1.17 & 90 \\
\hline 14 & ن. 42 & 0.13 & 3.42 & 2.47 & -8.43 & $-11.4 ?$ & 0.80 & 0.2 .2 & 23 \\
\hline 15 & 0.21 & 0.49 & 190367.14 & 229076.315 & -2.73 & -1.611 & 0.80 & $0.7 c$ & $\Rightarrow$ \\
\hline 16 & 0.41 & 0.72 & 1.77 & 2.52 & -1.70 & -0.53 & 1.11 & 0.70 & 24 \\
\hline 17 & 0.27 & 0.64 & 10.66 & 10.00 & -2.35 & -4.78 & 0.134 & 0.46 & $\because$ \\
\hline 18 & $0.5 \%$ & 0.69 & 327.45 & 302.82 & -1.12 & -0.55 & 0.94 & 0.913 & 31 \\
\hline $1 \%$ & 0.89 & ง.a2 & 630.23 & $83: 2.21$ & -0.44 & -0.58 & 1.19 & 0.76 & 32 \\
\hline 20 & 0.69 & 0.69 & 3.036 & 2.25 & -0.81 & $-1 \cdot 1 B$ & 0.87 & 0.810 & 33 \\
\hline 21 & $0.5 ?$ & 2.93 & 15806.513 & $1,385,3.00$ & -0.05 & 0.31 & 0.138 & 0.7 .5 & 34 \\
\hline 22 & 0.29 & 0.69 & 7243.61 & 6900.84 & $-1.6 Z$ & -1.33 & 0.7 .3 & $0.0 \%$ & $3 c$ \\
\hline 23 & 0.14 & 0.47 & 3532.73 & 3426.32 & -1.59 & -0.97 & 9.12 & 0.75 & $3 B$ \\
\hline 24 & 0.04 & 0.04 & 7.08 & 5.194 & -15.47 & -18.09 & 0.8 .9 & $0.7 \%$ & 41 \\
\hline 25 & 9.32 & 0.96 & 555.33 & 387.84 & 0.36 & 0.45 & 0.176 & 0.75 & 42 \\
\hline 20 & 0.58 & 0.55 & 500.87 & 794.72 & -1.03 & -0.41 & 1.1 .5 & 0.736 & 44 \\
\hline 27 & 0.48 & 0.69 & 31.15 & 12.53 & -0.78 & -0.94 & 0.75 & 0.83 & 36 \\
\hline $2 a$ & 0.32 & 0.86 & 1331.10 & 1223.44 & $-1.7 i$ & -0.89 & 1.16 & 0.92 & 48 \\
\hline 29 & 0.51 & 0.58 & 344.26 & 226.85 & -0.86 & -2.08 & 0.82 & 0.67 & 49 \\
\hline 30 & 0.69 & 0.92 & 261.12 & 117.39 & 0.49 & -0.67 & 1.03 & 0.95 & 50 \\
\hline
\end{tabular}




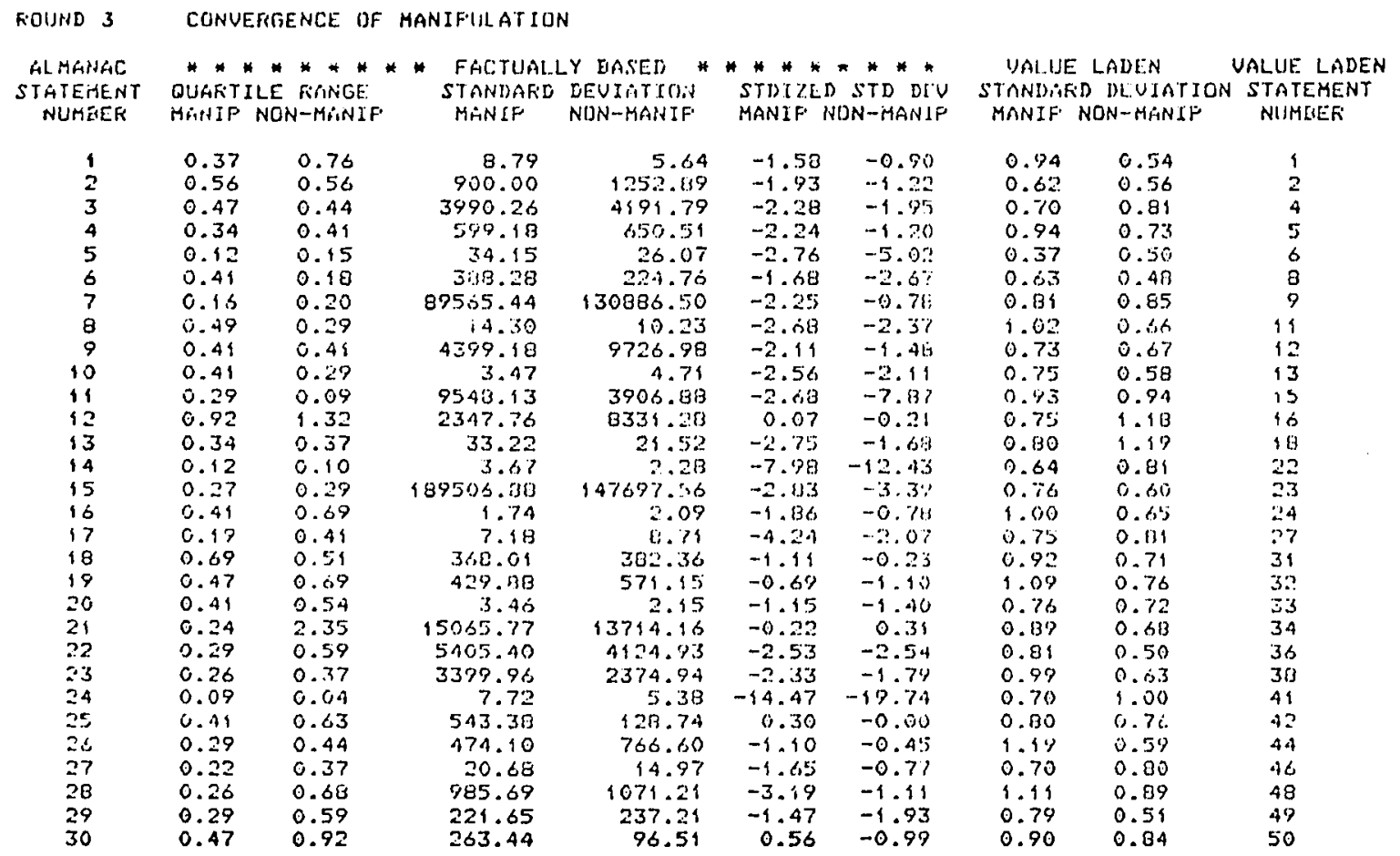

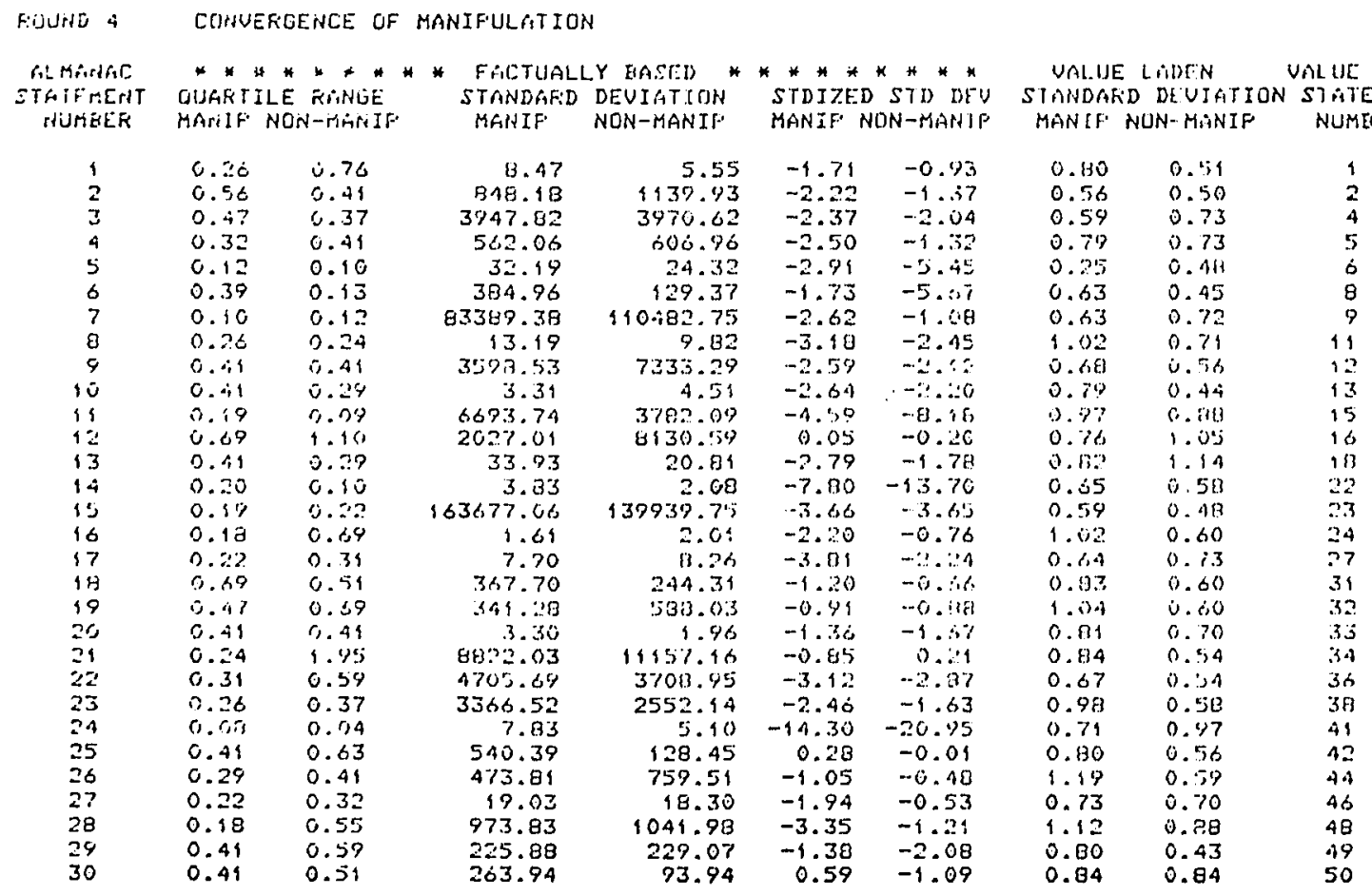


STAEILTTY OF MANIFULATION - FACTUALLY EASED DELPHI

$20 \%$

$15 \%$

\% CHANGE IETWEEN ROUNDS STAEILITY FIRST STAEILITY FIFST

\begin{tabular}{|c|c|c|c|c|c|c|c|c|c|c|}
\hline \multirow{2}{*}{$\begin{array}{l}\text { STAIEMENT } \\
\text { NUMAER }\end{array}$} & & NIFULA & $\begin{array}{l}\text { ANGE } \\
\text { TED }\end{array}$ & NON & AANIF & ATED & \multicolumn{2}{|c|}{ KEACHED IN ROUUND } & \multirow{2}{*}{\multicolumn{2}{|c|}{$\begin{array}{l}\text { Fi.ALHED IN FUUND } \\
\text { MANIF NON-MANIP }\end{array}$}} \\
\hline & $1-2$ & $2-3$ & $3-4$ & $1-2$ & $2-3$ & $3-4$ & MANIF & NON-HANIP & & \\
\hline 1 & 0.70 & 0.40 & 0.47 & 0.47 & 0.17 & 0.07 & 4 & 3 & 5 & 4 \\
\hline 2 & 0.57 & 0.20 & 0.70 & 0.47 & 0.30 & 0.17 & 3 & 4 & 5 & 5 \\
\hline 3 & 0.60 & 0.27 & $0 . \approx 0$ & 0.47 & 0.37 & 6.20 & 4 & 4 & 5 & 5 \\
\hline 4 & 0.67 & 0.33 & 0.23 & $0.4 \pi$ & 0.20 & 0.13 & 5 & 3 & 5 & 4 \\
\hline 5 & 0.53 & 0.27 & 0.23 & 0.43 & 0.33 & 0.17 & 5 & 4 & 5 & 5 \\
\hline 6 & 0.40 & 0.2 .3 & 0.10 & 0.53 & 0.23 & 0.23 & 4 & 5 & 4 & 5 \\
\hline$?$ & 0.67 & 0.33 & 0.20 & 0.60 & 0.20 & 0.17 & 4 & 3 & 5 & 5 \\
\hline 8 & 0.67 & 0.90 & 0.33 & 0.33 & 0.23 & 0.13 & 5 & 4 & 5 & 4 \\
\hline 9 & Q) $4 r$ & 6.70 & 0.13 & 0.50 & 0.37 & $0 . \therefore 3$ & 4 & 5 & 4 & 5 \\
\hline$\leqslant 0$ & 0.27 & 0.50 & 0.20 & 0.23 & 0.13 & 0.20 & 4 & $\ddot{3}$ & s & 3 \\
\hline 14 & 0.0 & 0.5 & 0.27 & 0.5 .3 & 0.10 & 0.10 & 5 & 4 & 5 & 4 \\
\hline 12 & 0.70 & 0.47 & 0.33 & 0.43 & 0.20 & $0.0 \%$ & 5 & 4 & 5 & 4 \\
\hline 1.3 & 0.73 & (j. 43 & 0.20 & 0.37 & 0.13 & 0.17 & 4 & 3 & 5 & 3 \\
\hline 14 & $0.3 x$ & 0.70 & 0.70 & $0 . \therefore 0$ & 0.10 & 0.13 & 3 & 2 & 5 & 3 \\
\hline 15 & 0.50 & 0.20 & 0.23 & 0.60 & 0.30 & 0.23 & 3 & 5 & 5 & 5 \\
\hline 10 & 0.57 & 0.23 & 0.20 & 0.47 & 0.30 & 0.17 & 4 & 4 & 5 & 5 \\
\hline 17 & 0.57 & 0.37 & 0.27 & 0.30 & 0.27 & 0.20 & 5 & 4 & 5 & 5 \\
\hline$i t$ & 0.50 & 0.37 & 0.20 & 0.47 & 0.23 & 0.30 & 4 & 5 & 5 & 5 \\
\hline is & 0.60 & (1. .:77 & 0.17 & 0.50 & $0.3 x$ & 0.20 & 4 & 4 & 5 & 5 \\
\hline$=0$ & 0.53 & 0.37 & 0.33 & 0.27 & 6.17 & 0.20 & 5 & 3 & 5 & 5 \\
\hline 21 & 0.67 & 0.27 & 0.30 & 0.47 & 0.30 & 0.37 & 5 & 5 & 5 & 5 \\
\hline$\therefore ?$ & 0.67 & 0.23 & 4.30 & 0.37 & 0.23 & 0.13 & 5 & 4 & 5 & 4 \\
\hline 23 & 0.6 .7 & 0.30 & 0.30 & 0.4 .3 & 0.20 & 0.16 & 5 & 3 & 5 & 4 \\
\hline 24 & 0.33 & 0.33 & 0.07 & 0.03 & 0.17 & 0.07 & 4 & 2 & 4 & 2 \\
\hline 25 & 0.77 & 0.50 & 0.20 & 0.50 & 0.43 & 0.10 & 4 & 4 & 5 & 4 \\
\hline 26 & 0.43 & 0.47 & 0.23 & 0.33 & 0.23 & 0.17 & 5 & 4 & 5 & 5 \\
\hline 37 & 0.57 & 0.43 & 0.23 & 0.57 & 0.37 & 0.27 & 5 & 5 & 5 & 5 \\
\hline 28 & $0 .=0$ & 0.37 & 0.17 & 0.40 & 0.23 & 0.20 & 4 & 4 & 5 & 5 \\
\hline 29 & 0.47 & 0.30 & 0.10 & 0.43 & 0.20 & 0.13 & 4 & 3 & 4 & 4 \\
\hline 30 & 0.67 & 0.47 & 0.23 & 0.43 & 0.17 & 0.03 & 5 & 3 & 5 & 4 \\
\hline JERAGES & 0.57 & 0.34 & 0.22 & 0.42 & 0.25 & 0.17 & 4.33 & 3.77 & 4.87 & 4.37 \\
\hline
\end{tabular}




\begin{tabular}{|c|c|c|c|c|c|c|c|c|c|c|}
\hline \multirow{2}{*}{$\begin{array}{l}\text { STATEMFNT } \\
\text { HUMHER }\end{array}$} & \multicolumn{3}{|c|}{ * CHAHSGE } & IUE TWEEN & \multicolumn{2}{|c|}{ FOUNDS } & \multicolumn{2}{|c|}{$20 \%$} & $\begin{array}{l}\text { STAKILL } \\
\text { REACHE }\end{array}$ & $\begin{array}{l}15 \% \\
\text { ITY FILST } \\
\text { D IN KOUNDD }\end{array}$ \\
\hline & $1-2$ & $2 \cdots 3$ & $3-4$ & $1-2$ & $2-3$ & $3-4$ & MANIF & NDN-MANIF & MANIF' & NON-MANIF \\
\hline 1 & 0.37 & 0.17 & 0.20 & 0.17 & 0.10 & 0.07 & 3 & 2 & 5 & 3 \\
\hline 2 & 0.47 & 0.36 & 0.13 & 0.30 & 0.03 & 0.10 & 4 & 3 & 4 & 3 \\
\hline 4 & 0.67 & 0.27 & 0.10 & 0.37 & 0.10 & 0.20 & 4 & 3 & 4 & 3 \\
\hline 5 & 0.30 & 0.30 & 0.23 & 0.40 & 0.20 & 0.10 & 5 & 3 & 5 & 4 \\
\hline 6 & $\therefore .37$ & 0.13 & 0.10 & 0.33 & $0.0 ?$ & 0.10 & 3 & 3 & 3 & 3 \\
\hline 8 & 0.41 & 0.20 & 0.07 & 0.23 & 0.07 & 0.10 & 3 & 3 & 4 & 3 \\
\hline 9 & 0.57 & 0.33 & 0.20 & 0.27 & 0.10 & 0.10 & 4 & 3 & 5 & 3 \\
\hline 11 & 0.20 & 0.17 & 0.17 & 0.30 & 0.10 & 0.03 & 2 & 3 & 5 & 3 \\
\hline 12 & 0.53 & 0.53 & 0.30 & 0.27 & 0.20 & 0.13 & 5 & 3 & 5 & 4 \\
\hline 13 & 0.27 & 0.27 & 0.23 & 0.38 & 0.27 & 0.20 & 5 & 4 & 5 & 5 \\
\hline 15 & 0.47 & 0.33 & 0.27 & $0 . ? ?$ & 0.30 & 0.23 & 5 & 5 & 5 & 5 \\
\hline ic & 0.37 & 0.23 & 0.27 & $0 . \therefore 3$ & 0.23 & 0.17 & 5 & 4 & 5 & 5 \\
\hline $1 B$ & 0.3 .3 & 0.77 & 0.43 & $0.1 \%$ & 0.20 & 0.10 & 4 & 2 & 4 & 4 \\
\hline$\because ?$ & 0.38 & 0.5 .3 & 0.17 & 0.33 & 0.13 & 0.13 & 3 & 3 & 3 & $\ddot{j}$ \\
\hline 23 & 0.13 & 0.30 & 0.27 & 0.27 & 0.23 & 0.17 & 2 & 4 & 2 & 5 \\
\hline 24 & 0.40 & 0.37 & 0.23 & 0.33 & 0.20 & 0.10 & 5 & 3 & 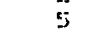 & 4 \\
\hline 27 & 0.43 & 0.43 & 0.13 & 0.20 & 0.20 & 0.13 & 4 & 2 & 4 & 4 \\
\hline $3 i$ & $0 . \approx 3$ & 0.23 & 0.07 & 0.30 & 0.17 & 0.20 & 4 & 3 & 4 & 5 \\
\hline 32 & 0.43 & 0.03 & 0.13 & 0.30 & 0.13 & 0.23 & 3 & 3 & 3 & 3 \\
\hline 33 & 0.40 & 0.20 & 0.17 & 0.40 & 0.07 & 0.07 & 3 & 3 & 5 & 3 \\
\hline 34 & 0.53 & 6.33 & 8.17 & 0.30 & 0.13 & 0.17 & 4 & 3 & 5 & 3 \\
\hline 36 & 0.37 & $0 \therefore 7$ & 0.47 & 0.20 & 0.17 & 0.10 & 4 & 2 & 5 & 9 \\
\hline 38 & $0=0$ & $\because 20$ & 0.13 & 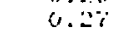 & 0.23 & 0.07 & 3 & 4 & 4 & $\therefore$ \\
\hline .19 & 0.3 .3 & 0.20 & 0.0 .3 & 0.17 & 0.27 & 0.17 & 3 & 2 & .7 & s \\
\hline $4:$ & 0.53 & 0.00 & 0.10 & 0.43 & 0.20 & 0.10 & 3 & 3 & 4 & 4 \\
\hline 41 & 0.37 & 0.17 & 0.10 & 0.33 & 0.23 & 0.13 & 3 & 4 & 4 & 4 \\
\hline 46 & 0.40 & $0.0 \%$ & $\therefore .13$ & 0.27 & 0.17 & 0.17 & 3 & 3 & 3 & 5 \\
\hline 45 & 0.37 & 0.23 & 0.17 & 0.33 & 0.03 & 0.03 & 4 & 3 & 5 & 3 \\
\hline 49 & 0.40 & 0.23 & 0.20 & 0.43 & 0.23 & 0.13 & 4 & 4 & 5 & 4 \\
\hline 50 & 0.50 & 0.27 & 0.07 & 0.30 & 0.13 & 0.23 & 4 & 3 & 4 & 3 \\
\hline G. JEFIATES & 0.40 & 0.24 & 0.16 & 0.30 & 0.16 & 0.13 & 3.70 & 3.10 & 4.27 & 3.80 \\
\hline
\end{tabular}

\begin{tabular}{|c|c|c|c|c|c|c|c|c|c|c|}
\hline \multirow{2}{*}{$\begin{array}{l}\text { STATEMENT } \\
\text { NUMGEF }\end{array}$} & \multicolumn{4}{|c|}{ \% CHGAGE LETWEEN } & \multicolumn{2}{|l|}{ COUNDS } & \multicolumn{2}{|c|}{$\begin{array}{l}20 \% \\
\text { STAEILITY FIFST }\end{array}$} & \multicolumn{2}{|c|}{$\begin{array}{l}15 \% \\
\text { STAHILITY FIREST }\end{array}$} \\
\hline & & $2-3$ & 34 & $1-2$ & $2-3$ & $3-4$ & MANLT & NDN-MANIP & & \\
\hline 3 & 0.23 & 0.13 & 0.17 & 0.23 & 0.23 & 0.13 & 3 & 4 & 3 & 4 \\
\hline 7 & 0.20 & 0.47 & 0.20 & 0.27 & 0.27 & 0.10. & 2 & 4 & 5 & 4 \\
\hline 10 & 0.27 & 0.20 & $0.1 ?$ & 0.17 & 0.13 & $0.63^{\circ}$ & 3 & 2 & 5 & 3 \\
\hline$\{4$ & 0.20 & 0.17 & 0.23 & 0.17 & 0.17 & 0.13 & 2 & 2 & 5 & 4 \\
\hline 97 & 0.13 & 0.37 & 0.10 & 0.27 & 0.23 & 0.10 & 2 & 4 & 2 & 4 \\
\hline 19 & 0.27 & 0.47 & 0.17 & 0.33 & 0.27 & 0.03 & 3 & 4 & 5 & 4 \\
\hline 20 & 0.30 & 0.27 & 0.13 & 0.20 & 0.30 & 0.13 & 4 & 2 & 4 & 4 \\
\hline 21 & 0.27 & 0.17 & 0.10 & 0.27 & 0.23 & 0.13 & 3 & 4 & 4 & 4 \\
\hline 25 & 0.27 & 0.13 & 0.03 & 0.17 & 0.17 & 0.20 & 3 & 2 & 3 & 5 \\
\hline 26 & 0.23 & 0.20 & 0.10 & 0.23 & 0.20 & 0.13 & 3 & 3 & 4 & 4 \\
\hline 20 & 0.23 & 0.13 & 0.07 & 0.37 & 0.13 & 0.13 & 3 & 3 & 3 & 3 \\
\hline 24 & c. 30 & 0.07 & 0.10 & 0.27 & 0.17 & 0.0 & 3 & 3 & 3 & 4 \\
\hline 30 & 0.23 & 0.67 & 0.23 & 0.10 & 0.33 & 0.13 & 3 & 4 & $z$ & 4 \\
\hline 35 & 0.30 & 0.03 & 0.17 & 0.30 & 0.10 & 0.0 & 3 & 3 & 3 & 3 \\
\hline 37 & 0.27 & 0.30 & 0.17 & 0.20 & 0.10 & 0.03 & 4 & 2 & 5 & 3 \\
\hline $3 \%$ & & 0.67 & $0 . \therefore 0$ & 0.10 & 0.13 & 0.07 & 2 & 2 & 3 & 2 \\
\hline 40 & 0.30 & 0.20 & 0.23 & 0.27 & 0.20 & 0.20 & 3 & 3 & 5 & 5 \\
\hline 43 & 0.30 & 0.27 & 0.30 & 0.23 & 0.23 & 0.10 & 4 & 4 & 5 & 4 \\
\hline 45 & 0.37 & 0.13 & 0.23 & 0.13 & 0.17 & 0.13 & 3 & 2 & 3 & 2 \\
\hline 47 & $0.1,3$ & 0.03 & 0.10 & 0.33 & 0.27 & 0.07 & 2 & 4 & 2 & 4 \\
\hline FAGES & $+7=$ & 0.14 & 0.10 & 0.16 & 0.43 & $\begin{array}{l}0.07 \\
0.12\end{array}$ & $1.93 \cdot-$ & 2.03 & 2.50 & $\cdots \quad 2.47$ \\
\hline & $\therefore . .$. & $=12$ & & $\therefore \therefore$ & 0.76 & 3.10 & 2.10 & 3.05 & $\therefore 75$ & 3.23 \\
\hline
\end{tabular}


CONFIDENCE AND MANIFIJLATION

\begin{tabular}{|c|c|c|c|c|c|c|c|c|c|c|c|c|c|}
\hline $\begin{array}{c}\text { STATE HENT } \\
\text { NUMLER }\end{array}$ & FARTICIPGNT & $\begin{array}{c}S \\
\text { DI.I } \\
\text { SFit }\end{array}$ & $\begin{array}{l}\text { ELF-F } \\
\text { RING } \\
S F 4\end{array}$ & $\begin{array}{l}\text { FATIH } \\
\text { ROUH } \\
\text { SFE }\end{array}$ & $\begin{array}{l}4 G \\
+D \\
S R 3\end{array}$ & $\begin{array}{l}\text { ANS } \\
\text { (EXF } \\
\text { AI }\end{array}$ & $\begin{array}{c}\text { SWEFI DL } \\
\text { PRESSED } \\
\text { A2 }\end{array}$ & $\begin{array}{c}\text { UKING } \\
D \text { AS E } \\
\text { AZ }\end{array}$ & $\begin{array}{r}\text { FOUND } \\
\text { R'ROFi) } \\
\text { A4 }\end{array}$ & $\begin{array}{c}\text { DESIKED } \\
\text { ANSWER } \\
A D\end{array}$ & \multicolumn{2}{|c|}{$\begin{array}{l}\text { D ACTUAL DESITIED } \\
\text { CHANGE CHANGE: }\end{array}$} & $\begin{array}{l}\text { SELF-FAT } \\
\text { CHANGE. } \\
\text { SFA-SF' }\end{array}$ \\
\hline 1 & 684 & 3 & 3 & 1 & 6 & 0.92 & -0.18 & -0.18 & -0.18 & 0.29 & -1.10 & 0.63 & 0 \\
\hline$i$ & 706 & 3 & 2 & 4 & 4 & -0.57 & 0.11 & 0.33 & 0.33 & i). .24 & 0.92 & 0.88 & -1 \\
\hline\{ & 1489 & 2 & 2 & 1 & 4 & -2.89 & -0.59 & -0.18 & -0.18 & 0.27 & 2.71 & $3 .\{B$ & 0 \\
\hline 1 & 1720 & 2 & 2 & 5 & 8 & -0.59 & 0.11 & 0.11 & 0.11 & 0.29 & 0.69 & 0.818 & 0 \\
\hline i & $i \varepsilon 54$ & 1 & 2 & 8 & 8 & 0.51 & 0.51 & 0.54 & 0.51 & 0.29 & 0.0 & $0.2: 3$ & 1 \\
\hline 1 & 2008 & 4 & 5 & 6 & 2 & $-0.5 \%$ & -0.59 & -0.25 & -0.25 & i. .24 & 0.34 & 0.00 & 1 \\
\hline 1 & 2.225 & 4 & 4 & 3 & 6 & -0.18 & 0.14 & 0.14 & 0.11 & 0.29 & 0.20 & 0.47 & 0 \\
\hline ; & 2376 & 2 & 3 & 1 & 8 & -2.39 & 0.33 & 0.33 & 0.33 & 0.39 & 3.22 & 3.18 & 1 \\
\hline 1 & $24: 1$ & 3 & 3 & 1 & 4 & -2.89 & -0.41 & 0.20 & 0.20 & 0.20 & 3.09 & 3.18 & 0 \\
\hline\{ & 2039 & 3 & 2 & $B$ & 2 & 0.51 & 0.51 & 0.0 & 0.29 & $0.2 \%$ & -0.22 & 0.22 & -1 \\
\hline 1 & 2065 & 4 & 4 & 1 & 6 & -0.89 & -0.25 & -0.25 & -0.25 & 0.29 & 0.50 & 1.10 & 0 \\
\hline 1 & $2 \%+17$ & $\mathfrak{1}$ & 1 & $\mathfrak{1}$ & 7 & $-? . A \%$ & 0.11 & 0.11 & 0.31 & $0.2 \%$ & 3.00 & 3.16 & 0 \\
\hline 1 & 3.17 & 3 & 2 & 6 & 1 & -1.28 & $-1.2 \mathrm{~F}$ & 0.30 & 0.80 & $0 . \therefore$ & 2.06 & 1.21 & i) \\
\hline 1 & $.54 \div 7$ & i & 1 & 1 & 3 & 2.12 & $0.1 \mathrm{i}$ & 0.44 & 0.44 & 0.27 & - & 1.03 & 0 \\
\hline 1 & $4: 5 i 5$ & $i$ & 2 & 6 & 6 & -0.10 & .0 .16 & -9.18 & -0.10 & 0.29 & 0.0 & 0.47 & 1 \\
\hline 1 & $4: 180$ & 1 & 2 & 1 & 6 & $-0.5 \%$ & 0.0 & 0.0 & 0.0 & 0.24 & $0.1 \%$ & 0.883 & 1 \\
\hline 1 & 5371 & $\because$ & 1 & 4 & 5 & -0.54 & 0.19 & 0.33 & 0.33 & 0.27 & 0.92 & 0.413 & -1 \\
\hline $\mathrm{i}$ & 55713 & 2 & 1 & 4 & 4 & -2.189 & -0.59 & -0.18 & 0.33 & 0.21 & 3.22 & 3.13 & -1 \\
\hline 1 & $54: 3$ & 2 & 1 & 4 & 6 & -0.59 & 0.37 & 0.37 & 0.37 & 0.21 & 0.96 & 0.815 & -9 \\
\hline 1 & SABS & 3 & 3 & 1 & 6 & $-2.0 \%$ & 0.11 & 0.11 & 0.41 & 0.27 & 3.00 & 3.10 & 0 \\
\hline 1 & 6.193 & 4 & 3 & 3 & 5 & -0.59 & 0.11 & 0.37 & 0.37 & 0.21 & 0.96 & 0.613 & $-\mathfrak{i}$ \\
\hline 1 & $65 \div 0$ & 1 & 2 & $?$ & a & 0.33 & 0.33 & 0.33 & $0 . .5 .3$ & 0.29 & 0.0 & 0.0 .1 & 1 \\
\hline 1 & 6955 & $\therefore$ & $i$ & 5 & $\Phi$ & -0.16 & 0.37 & $0.3 ?$ & 0.29 & 0.29 & i). 48 & 0.41 & -1 \\
\hline 1 & $72+4$ & 4 & 3 & 4 & 4 & $-2.0 \%$ & -0.12 & 0.33 & 0.33 & 0.28 & $\because .22$ & 3.13 & -1 \\
\hline\{ & 7366 & 3 & 4 & 6 & 6 & -2.89 & -2.89 & -2.89 & -2.69 & 0.24 & 0.0 & 3.14 & 1 \\
\hline 1 & 7536 & 2 & 3 & 6 & 6 & 1.02 & 1.02 & 1.02 & 1.02 & 0.29 & 0.0 & 0.73 & 1 \\
\hline 1 & 8150 & 2 & 2 & 4 & 9 & -1.10 & 0.44 & 0.44 & 0.44 & 0.29 & 1.51 & 1.34 & i) \\
\hline\{ & A224 & 2 & 2 & 6 & 6 & 0.11 & 0.11 & 0.11 & 0.11 & 0.20 & 0.0 & 0.10 & 0 \\
\hline 1 & 8206 & 4 & 2 & 2 & 5 & -2.89 & 0.11 & 0.20 & 0.25 & 0.29 & 3.1 .1 & 3.16 & -2 \\
\hline 1 & 9071 & 1 & 1 & 5 & 6 & 10.73 & 0.50 & 0.50 & 0.37 & 0.29 & -10.56 & 10.64 & 0 \\
\hline & AUERAISE & 2.4 & 2.3 & & & -0.58 & -0.05 & 0.11 & 0.13 & & 0.71 & $1.8: 2$ & -0.9 \\
\hline 2 & 034 & 3 & 4 & 6 & 6 & 0.21 & 0.24 & 0.24 & 0.24 & 0.27 & 0.0 & 0.03 & 1 \\
\hline 2 & $70 \%$ & 3 & 3 & 6 & 6 & -0.10 & -0.10 & -0.10 & -0.10 & 0.27 & 0.0 & $0.3 i$ & 0 \\
\hline 2 & 1489 & 1 & 3 & 7 & $B$ & -0.32 & -0.32 & -0.32 & -0.32 & 0.27 & 0.0 & $0 . \therefore 1$ & 2 \\
\hline 2 & 1720 & 2 & 2 & 2 & 6 & 1.19 & 0.32 & 0.32 & 0.32 & 0.27 & -0.015 & 0.92 & 0 \\
\hline$\overline{2}$ & 1854 & $\overline{1}$ & 3 & $i$ & $B$ & 5.70 & 0.09 & 0.09 & $0.0 \%$ & 0.27 & -5.101 & 5.63 & 2 \\
\hline$\overline{2}$ & $\therefore 008$ & 3 & 3 & 6 & $B$ & $0.0 \%$ & 0.09 & 0.24 & 0.2 .1 & 0.27 & 0.15 & 0.117 & 0 \\
\hline 2 & 2.25 & 3 & 4 & 2 & 6 & -3.31 & -1.01 & -1.01 & -1.01 & 0.21 & 2.30 & 3.213 & 1 \\
\hline 2 & 2376 & 1 & \{ & 6 & 日 & 0.60 & 0.37 & 0.37 & 0.27 & 0.27 & -0.33 & 0.3 .3 & 0 \\
\hline 2 & 2451 & 2 & 2 & 6 & 6 & -0.32 & -0.32 & -0.32 & -0.32 & 0.27 & 0.0 & 0.59 & 0 \\
\hline 2 & 20.39 & 2 & 3 & 7 & 6 & -0.90 & -0.10 & -0.10 & -0.10 & 0.27 & 0.0 & 0.36 & 1 \\
\hline 2 & 2605 & 2 & 2 & 7 & 6 & -0.10 & -0.10 & -0.10 & -0.10 & 0.27 & 0.0 & 0.36 & 0 \\
\hline 2 & 2947 & 1 & $\mathfrak{1}$ & 4 & 8 & -1.70 & -0.10 & -0.10 & -0.10 & 0.27 & 1.61 & 1.97 & i) \\
\hline 2 & $3: 17$ & 2 & 2 & 2 & 6 & 0.60 & -0.61 & -0.61 & -0.61 & 0.27 & -1.20 & 0.33 & $\theta$ \\
\hline 2 & 3497 & 2 & 2 & 5 & 4 & -0.64 & -0.20 & 0.24 & 0.21 & 0.27 & 0.835 & 0.88 & 0 \\
\hline 2 & 4015 & 1 & 2 & 6 & 5 & -1.70 & -1.70 & -0.32 & -0.32 & 0.27 & 1.39 & 1.97 & $\mathfrak{i}$ \\
\hline 2 & 4080 & \{ & 2 & 6 & 6 & -0.32 & -0.32 & -0.32 & -0.32 & 0.27 & 0.0 & 0.59 & 1 \\
\hline 2 & 5374 & 3 & 3 & 4 & 4 & -0.32 & -0.10 & 0.24 & 0.27 & $0.2 \%$ & 0.59 & 0.59 & 0 \\
\hline 2 & 5578 & 1 & 3 & 2 & 6 & -1.30 & -0.42 & -0.42 & -0.42 & 0.27 & 0.88 & 1.57 & 2 \\
\hline 2 & 5823 & 2 & 2 & 6 & 6 & -0.61 & 0.27 & 0.27 & 0.27 & 0.27 & 0.39 & 0.08 & 0 \\
\hline 2 & $6430^{\circ}$ & 2 & 2 & 6 & 6 & -0.32 & -0.32 & -0.32 & 0.02 & 0.27 & 0.34 & 0.59 & 0 \\
\hline 2 & 6493 & 3 & 3 & 6 & 6 & -0.32 & -0.32 & -0.32 & 0.04 & 0.27 & 0.41 & 0.59 & 0 \\
\hline 2 & 6520 & 1 & 1 & 6 & 6 & 0.0 .9 & 0.09 & 0.09 & 0.09 & 0.27 & 0.0 & 0.18 & 0 \\
\hline 2 & 6966 & 3 & 2 & 3 & 4 & -0.61 & -0.10 & 0.27 & 0.27 & 0.27 & $0.8 \mathrm{n}$ & $0.8 G$ & -1 \\
\hline 2 & 7244 & 2 & 2 & 2 & 6 & -2.06 & -0.61 & -0.61 & -0.10 & 0.27 & 1.97 & 2.33 & 0 \\
\hline 2 & 7366 & 3 & 3 & 6 & 6 & -1.37 & -1.37 & -1.37 & -1.37 & 0.27 & 0.0 & 1.64 & 0 \\
\hline 2 & 7536 & 3 & 2 & 2 & $B$ & 1.70 & -0.32 & -0.32 & -0.32 & 6.27 & -2.01 & 9.4 .3 & -1 \\
\hline$a$ & 8150 & 1 & 2 & 5 & 8 & 1.13 & 0.24 & 0.24 & 0.2 .1 & $0.2 ?$ & $-0 . \pi ?$ & 0.86 & 1 \\
\hline 2 & $6: 24$ & 3 & 3 & 2 & 6 & -1.01 & 0.09 & 0.07 & 0.13 & C.2.7 & $1 .: 9$ & $\{.203$ & 0 \\
\hline 2 & 950. & 4 & 3 & 4 & 6 & 0.60 & 0.29 & 0.24 & 0.21 & 6.27 & -0.36 & 0.33 & 2 \\
\hline 2 & 9001 & 1 & 2 & 4 & 4 & -1.04 & -0.32 & 0.27 & 0.27 & 0.27 & 1.28 & 9.28 & 1 \\
\hline & GIDE KG,GE & 2.0 & 2.4 & & & -0.18 & -0.22 & -0.11 & -0.07 & & 0.11 & 1.10 & 0.4 \\
\hline
\end{tabular}


CONFIDENCE AND NON-MANTFIJLATION

\begin{tabular}{|c|c|c|c|c|c|c|c|c|c|}
\hline \multirow{3}{*}{$\begin{array}{l}\text { STHTEMENT } \\
\text { NUMEER }\end{array}$} & \multirow[b]{3}{*}{ FARTICIFANT } & \multicolumn{4}{|c|}{ SELF-RATING } & \multicolumn{4}{|c|}{ ANSWEF DUFING KOUND } \\
\hline & & & \multicolumn{4}{|c|}{ (EXFFESSED AS ERROR) } \\
\hline & & SFi & $5 \times 4$ & SR2 & SFi3 & A 1 & $A: ?$ & 43 & 64 \\
\hline 1 & 438 & 2 & 2 & 9 & 9 & -0.59 & -0.59 & -0.59 & -0.59 \\
\hline 1 & 302 & 3 & 3 & 6 & 6 & -0.98 & -0.18 & -0.10 & $-0 .\{\}$ \\
\hline$i$ & 354 & 4 & 2 & 5 & 8 & -1.10 & -0.89 & -0.81 & $-0.8 i$ \\
\hline$i$ & 900 & 2 & 3 & 4 & 6 & -1.28 & -0.81 & -0.01 & -0.01 \\
\hline$i$ & 1914 & 4 & 3 & $i$ & 6 & -2.89 & -1.10 & -1.90 & -1.10 \\
\hline 1 & 9446 & 4 & 4 & 6 & 6 & 0.33 & 0.33 & 0.33 & 0.33 \\
\hline 9 & 1500 & f & 2 & 1 & 6 & 0.33 & 0.11 & 0.14 & 0.11 \\
\hline$i$ & Zu० 7 & 2 & 3 & 3 & 6 & -1.79 & -1.50 & -1.50 & -1.50 \\
\hline$i$ & 2076 & 4 & 5 & 7 & 7 & -0.41 & -0.41 & -0.41 & -0.41 \\
\hline$j$ & 2304 & 3 & 4 & 6 & 6 & -2.07 & -2.134 & -2.69 & $-2.13 \%$ \\
\hline 9 & 3424 & 4 & 3 & 5 & 6 & -0.94 & -0.69 & $-0.0 \%$ & $-0.6 \%$ \\
\hline 1 & 3439 & 1 & 3 & 6 & 6 & -0.41 & -0.41 & -0.41 & -0.41 \\
\hline 1 & 3.541 & 2 & 3 & 7 & 6 & -2.89 & -2.89 & -2.89 & -2.99 \\
\hline$i$ & 3013 & 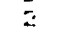 & 3 & 4 & 4 & 0.61 & $\ddot{0} .0$ & -0.18 & -6.33 \\
\hline$i$ & 4132 & 4 & 3 & 1 & 4 & -2.89 & -0.25 & -0.41 & -0.41 \\
\hline 1 & 4344 & 3 & 3 & ¿ & 6 & 0.11 & 0.19 & 0.11 & 0.11 \\
\hline$i$ & $A, 139$ & 2 & 2 & 6 & 6 & -0.18 & -0.18 & -0.18 & -0.18 \\
\hline 9 & 4705 & 4 & 2 & $d$ & 4 & -1.50 & -9.50 & -0.59 & -0.59 \\
\hline 1 & 5535 & i & 1 & 5 & 6 & 1.43 & -0.18 & -0.18 & -0.18 \\
\hline$i$ & Scista & 2 & 2 & 6 & 6 & -0.41 & -0.91 & -0.41 & -0.41 \\
\hline$i$ & 6817 & 1 & 3 & 9 & 6 & -0.59 & $-0.5 \%$ & -0.59 & -0.59 \\
\hline 1 & 6.973 & 3 & 2 & 8 & 8 & -1.10 & -1.10 & -1.10 & $-0.13^{4}$ \\
\hline$i$ & 695,6 & 3 & $i$ & 4 & 4 & 0.33 & -0.12 & -0.25 & -0.25 \\
\hline$i$ & 76,45 & 3 & 3 & 6 & 4 & -1.28 & -1.28 & -0.94 & -0.74 \\
\hline$i$ & 3136 & 2 & 3 & 4 & 6 & -1.79 & -0.69 & -0.69 & -0.69 \\
\hline$i$ & 8728 & 3 & 4 & 3 & 6 & 0.0 & -0.18 & -0.16 & -0.18 \\
\hline 1 & 8811 & 3 & 3 & 8 & 6 & -0.94 & -0.94 & -0.94 & -0.94 \\
\hline$i$ & $5 \div 94$ & f & 3 & 5 & 5 & 0.11 & $-0.1 日$ & -0.10 & -0.18 \\
\hline 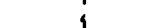 & 9702 & 2 & 2 & 4 & 6 & -1.28 & -0.94 & -0.94 & -0.94 \\
\hline$i$ & 9765 & 3 & 3 & 8 & 6 & -2.20 & -2.20 & -2.20 & -2.20 \\
\hline & AUEKAGE & 2.4 & 2.8 & & & -0.88 & -0.75 & -0.72 & -0.72 \\
\hline 2 & $\{33$ & i & 3 & 8 & e & -0.32 & -0.32 & -0.32 & -0.32 \\
\hline 2 & 302 & $i$ & 2 & 4 & 4 & -0.79 & -0.61 & -0.32 & -0.20 \\
\hline 2 & 351 & i & 4 & 6 & 6 & -0.61 & -0.61 & -0.61 & -0.69 \\
\hline 3 & 900 & 3 & 4 & 6 & 6 & -0.64 & -0.61 & -0.61 & -0.61 \\
\hline 2 & 1914 & $\tilde{4}$ & $\mathfrak{i}$ & 1 & 2 & -4.92 & -1.01 & -0.61 & -0.10 \\
\hline 2 & 1446 & 2 & 2 & 8 & 3 & -0.6 .1 & -0.61 & -0.32 & -0.32 \\
\hline 2 & 1500 & $\mathfrak{i}$ & \{ & 4 & 7 & -1.81 & 0.00 & 0.09 & 0.09 \\
\hline 2 & 2087 & 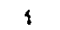 & 4 & 6 & 2 & $0.6,0$ & 0.60 & $0.0 \%$ & 0.09 \\
\hline 2 & 3096 & 2 & 2 & 4 & 4 & 0.78 & 0.37 & 0.21 & 0.09 \\
\hline 2 & 23134 & 2 & 3 & 3 & 6 & 0.60 & 0.37 & 0.37 & 0.07 \\
\hline 2 & 3421 & 3 & 2 & 6 & 4 & 0.37 & 0.37 & 0.24 & $0.0 \%$ \\
\hline 2 & 3431 & 1 & 3 & 6 & 6 & -0.10 & -0.10 & -0.10 & -0.10 \\
\hline 2 & $36+14$ & $\mathfrak{i}$ & 3 & 3 & 4 & 1.13 & -1.01 & -0.10 & -0.10 \\
\hline 3 & 3913 & 2 & 4 & $c$ & 6 & -0.10 & -0.10 & -0.10 & -0.10 \\
\hline 2 & 4132 & 2 & 3 & 9 & 6 & -0.32 & -0.32 & -0.32 & -0.32 \\
\hline 2 & 4344 & 3 & 3 & 6 & 6 & 0.93 & 0.03 & 0.93 & 0.73 \\
\hline 3 & 4688 & 2 & 3 & 6 & 6 & 0.60 & 0.60 & 0.60 & -0.10 \\
\hline$i$ & 4705 & 3 & 3 & $\dot{i}$ & 6 & -0.61 & -0.61 & -0.61 & -0.69 \\
\hline$\overline{2}$ & 5585 & 1 & 2 & 5 & 7 & 1.47 & 0.09 & 0.07 & 0.09 \\
\hline 2 & 5328 & 3 & 2 & 4 & 5 & 0.75 & 0.24 & -0.10 & -0.10 \\
\hline 2 & 6a1? & 3 & 2 & 7 & 6 & 0.34 & 0.31 & 0.31 & 0.31 \\
\hline 2 & 6873 & 2 & 2 & 2 & 8 & -0.61 & -0.32 & -0.32 & -0.32 \\
\hline 2 & 6956 & f & 4 & g & 4 & -0.32 & 0.37 & 0.24 & 0.24 \\
\hline 2 & 7645 & 2 & 3 & 6 & 6 & -0.01 & -0.61 & -0.61 & -0.61 \\
\hline 2 & E130 & 2 & 2 & 1 & 6 & -4.01 & 0.09 & 0.69 & 0.09 \\
\hline 2 & 8728 & 2 & 4 & 3 & $\epsilon$ & -0.32 & -4.22 & -0.22 & -0.22 \\
\hline 2 & EBi1 & 2 & 3 & 5 & 8 & -1.30 & -0.61 & -0.61 & -0.01 \\
\hline 2 & 9214 & 4 & 2 & 7 & 7 & 0.60 & 0.60 & 0.60 & 0.60 \\
\hline$\overline{2}$ & 9902 & $i$ & 2 & 5 & 9 & 0.60 & -0.10 & -0.10 & -0.10 \\
\hline 2 & 9005 & 3 & 3 & 8 & 6 & -0.10 & -0.10 & -0.10 & -0.10 \\
\hline & JERAGE & 1.7 & 2.6 & & & -0.31 & -0.09 & -0.07 & -0.08 \\
\hline
\end{tabular}

DESIFED ACTUAL DESIFED SELF-FATING . ANSWER CHANGE CHANGE CHANGE $A D$ A4 $A \mid$ IAD-AII SRI-SRI

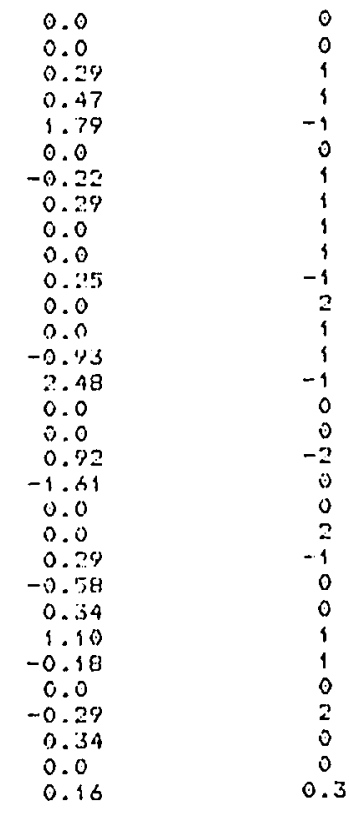

$\begin{array}{cc}0.0 & 2 \\ 0.59 & 1 \\ 0.0 & 3 \\ 0.0 & 2 \\ 4.03 & 0 \\ 0.29 & 0 \\ 1.90 & 0 \\ -0.51 & 3 \\ -0.09 & 0 \\ -0.22 & 1 \\ -0.29 & -1 \\ 0.0 & 2 \\ -1.22 & 2 \\ 0.0 & 2 \\ 0.0 & 1 \\ 0.0 & 0 \\ -0.69 & 1 \\ 0.0 & 0 \\ -1.39 & 1 \\ -0.04 & -1 \\ 0.0 & -1 \\ 0.29 & 0 \\ 0.596 & 0 \\ 0.0 & 1 \\ 4.09 & 0 \\ 0.10 & 2 \\ 0.69 & 1 \\ 0.0 & 1 \\ -0.69 & 1 \\ 0.0 & 2 \\ 0.23 & 0.9\end{array}$ 